\section{OAK RIDGE \\ NATIONAL \\ LABORATORY}

LOCKHEED MATTIN/7

\section{Bioremediation of PCBs: CRADA Final Report (CRADA ORNL 90-0039)}

K. T. Klasson

D. A. Abramowicz
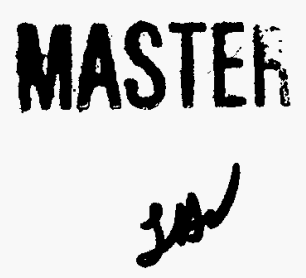
This report has been reproduced directly from the best available copy.

Available to DOE and DOE contractors from the Office of Scientific and Technical Information, P.O. Box 62, Oak Ridge, TN 37831; prices available from (615) 576-8401, FTS 626-8401.

Available to the public from the National Technical Information Service, U.S. Department of Commerce, 5285 Port Royal Rd., Springfield, VA 22161.

This report was prepared as an account of work sponsored by an agency of the United States Government. Neither the United States Government nor any agency thereof, nor any of their employees, makes any warranty, express or Implied, or assumes any legal liability or responsibility for the accuracy, completeness, or usefulness of any informati9on, apparatus, product, or process disclosed, or represents that its use would not infringe privately owned rights. Reference herein to any specfic commercial product, process, or service by trade name, trademark, manufacturer, or otherwise, does not necessarily constitute or imply its endorsement, recommendation, or favoring by the United States Government or any agency thereof. The views and opinions of authors expressed herein do not necessarily state or reflect those of the United States Government or any agency thereof. 
ORNL/TM-13242

\title{
BIOREMEDIATION OF PCBs:
}

CRADA FINAL REPORT

(CRADA ORNL 90-0039)

K. T. Klasson

Chemical Technology Division

\author{
D. A. Abramowicz \\ General Electric Company Corporate Research and Development \\ Niskayuna, New York
}

Date Published: June 1996

\author{
Prepared by \\ OAK RIDGE NATIONAL LABORATORY \\ Oak Ridge, Tennessee 37831-6044 \\ managed by \\ LOCKHEED MARTIN ENERGY RESEARCH CORP. \\ for the \\ U.S. DEPARTMENT OF ENERGY \\ under contract DE-AC05-960R22464
}




\section{CONTENTS}

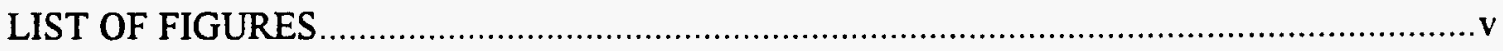

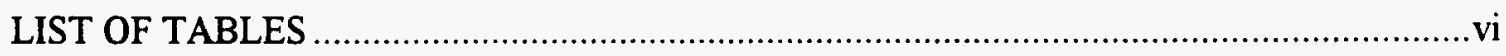

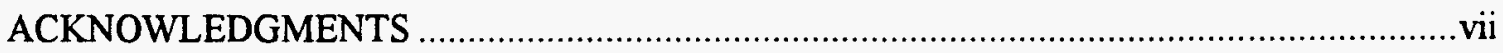

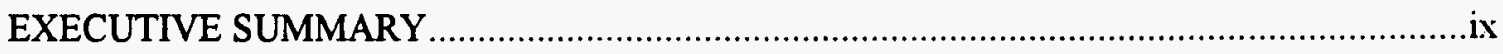

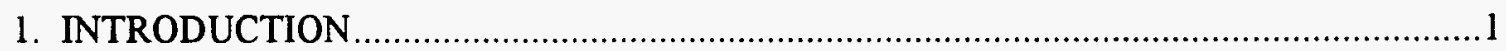

2. CRADA

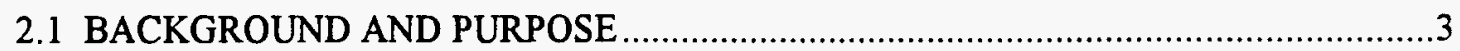

2.2 TASK BREAKDOWN IN CRADA AND RESULT SUMMARY .............................

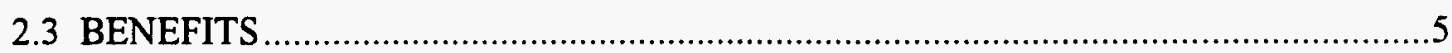

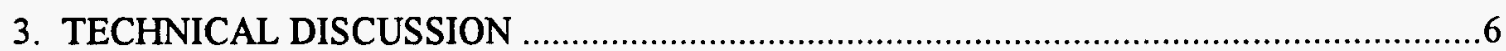

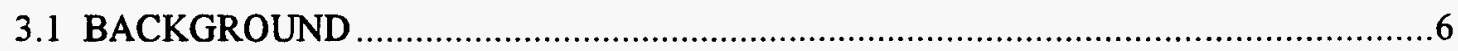

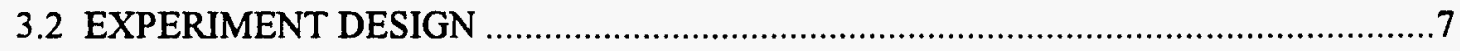

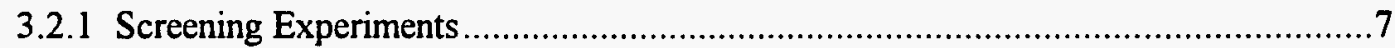

3.2.2 Verification and Enhancement Experiments .................................................

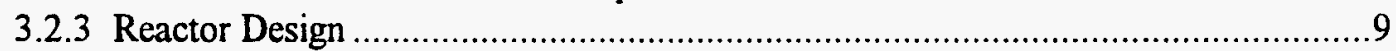

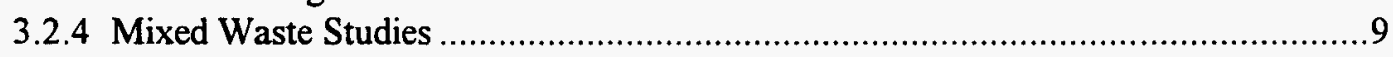

3.2.5 Sequential Anaerobic-Aerobic Studies ...................................................... 10

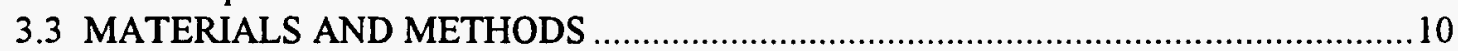

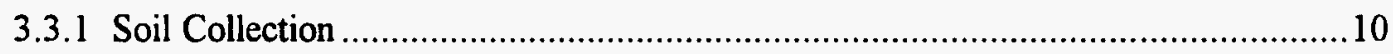

3.3.2 Soil Slurry Reactor Study ..................................................................... 11

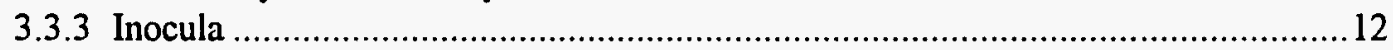

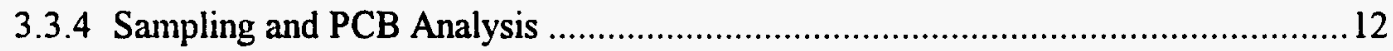

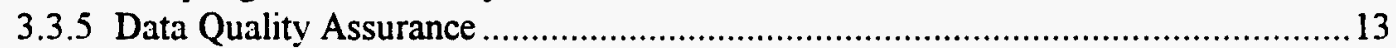

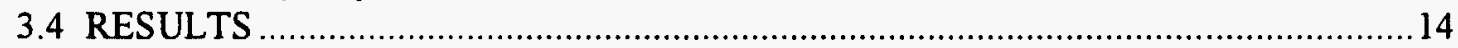

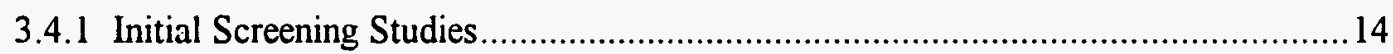

3.4.2 Verification and Enhancement Studies ..........................................................22

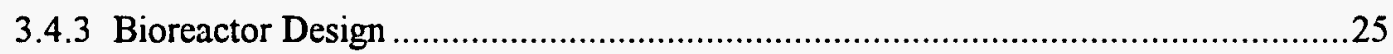

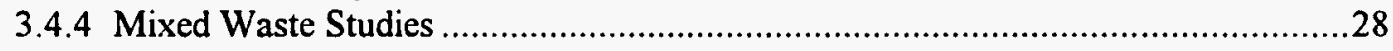

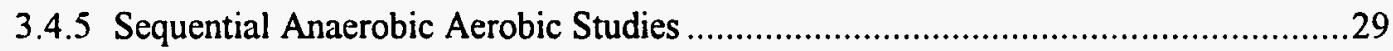

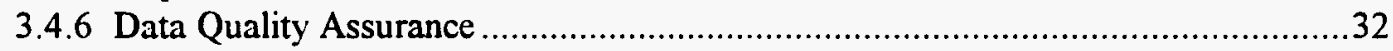

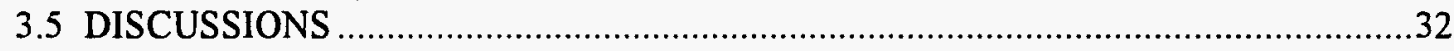

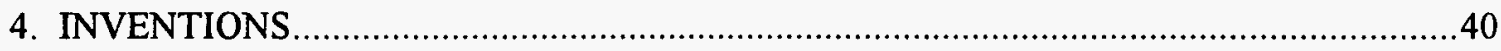

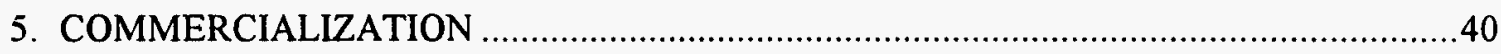

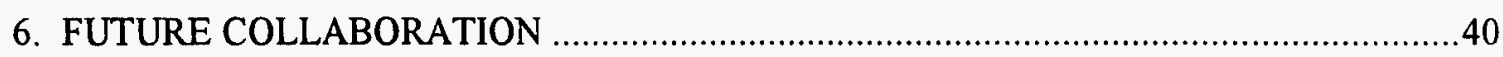

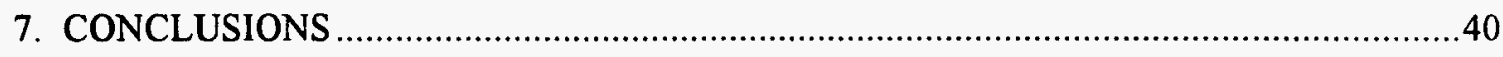

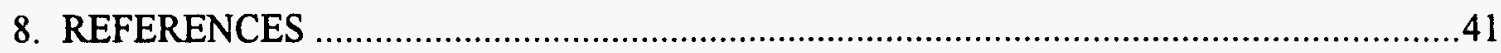




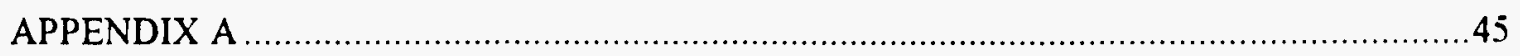

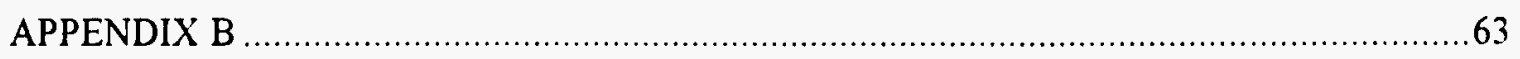

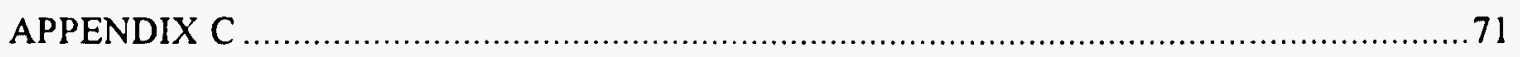

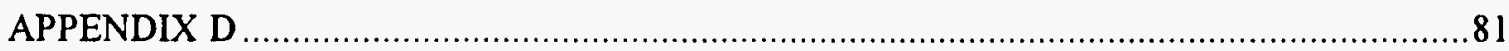




\section{LIST OF FIGURES}

Figure

1. Typical GC peak profile of sample taken at start-up. ............................................ 16

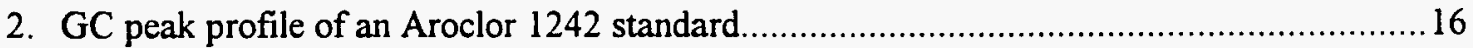

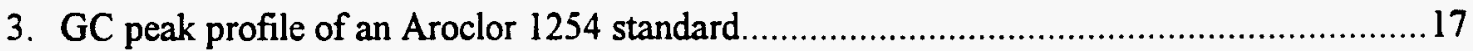

4. GC peak profile in sample taken after 15 weeks of anaerobic incubation of a reactor inoculated with bacteria from Hudson River.

5. Average PCB chlorine content in eight (A through $\mathrm{H})$ uninoculated reactors amended with acetone as carbon source.

6. Average PCB chlorine content in eight (A through $\mathrm{H}$ ) uninoculated reactors amended with maleate and acetone as carbon sources.

7. Average $\mathrm{PCB}$ chlorine content in eight ( $\mathrm{A}$ through $\mathrm{H}$ ) uninoculated reactors amended with pyruvate and acetone as carbon sources.

8. Average $\mathrm{PCB}$ chlorine content in eight $(\mathrm{A}$ through $\mathrm{H})$ uninoculated reactors amended with a complex nutrient mixture and acetone as carbon sources.

9. Average $\mathrm{PCB}$ chlorine content in eight $(\mathrm{A}$ through $\mathrm{H})$ inoculated reactors amended with acetone as carbon source.

10. Average $\mathrm{PCB}$ chlorine content in eight $(\mathrm{A}$ through $\mathrm{H})$ inoculated reactors amended with maleate and acetone as carbon sources.

11. Average $\mathrm{PCB}$ chlorine content in eight ( $\mathrm{A}$ through $\mathrm{H})$ inoculated reactors amended with pyruvate and acetone as carbon sources.

12. Average $\mathrm{PCB}$ chlorine content in eight $(\mathrm{A}$ through $\mathrm{H})$ inoculated reactors amended with a complex nutrient mixture and acetone as carbon sources.

13. Average PCB chlorine content in reactors with various soils collected from the same general area.

14. Average PCB chlorine content in reactors inoculated with organisms from Hudson River (HR) or Woods Pond (WP) sediments and amended with malate or maleate.

15. Average PCB chlorine content during incubation of soils inoculated with Hudson River organisms and amended with chemical reducing agents.

16. Average $\mathrm{PCB}$ chlorine content in reactors amended with a vitamin solution at two different concentrations. 
17. Average PCB chlorine content in HR-inoculated reactors amended with a surfactant (Witconol) and a complex nutrient mixture and acetone as carbon sources

18. GC peak profile of sample taken at start-up of reactors with WAG 11 soil.....................29

19. GC profile in sample taken after 61 weeks of incubation of WAG 11 soil...........................

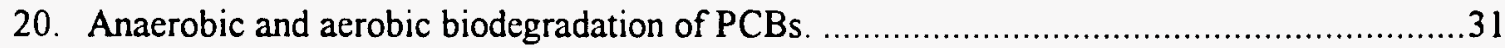

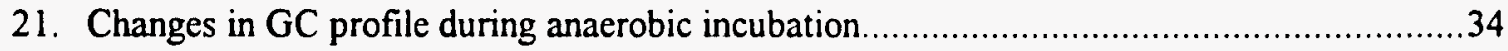

22. PCB concentration profiles taken from a reactor inoculated with Hudson River

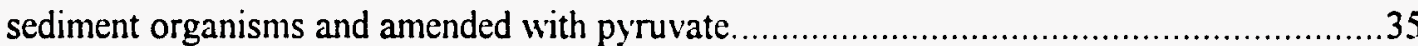

23. Change over time in number of PCB chlorines for reactors with different inducers..............36

24. Mole percent change in reactors inoculated with organisms from different sources.............38

25. PCB homolog concentrations in sequential anaerobic-aerobic incubation of contaminated soils

26. Estimated PCB concentration with various half-lives in humans and the effect of sequential anaerobic-aerobic treatment

\section{LIST OF TABLES}

Table

Page

1. Ranking of various experimental conditions 


\section{ACKNOWLEDGMENTS}

This study was made possible by funding provided by the U.S. Department of Energy Office

of Technology Development. I gratefully acknowledge the support from the previous Principal Investigators Terry Donaldson and Mark Reeves. Laboratory experiments and analyses were carried out by Betty Evans, Connie Dudley, and John Barton. Technical assistance in preparation of presentations and publications was provided by John Barton and Mark Reeves. Technical support, consulting, and soil and sediment samples were provided by Dan Abramowicz, Mike Brennan, Jan Principe, and Lynn Smullen at General Electric Company Research and Development Center, Niskayuna, New York, and Mary Jim Beck and Marlene Hinton at the Tennessee Valley Authority Research Center in Muscle Shoals, Alabama. 


\section{EXECUTIVE SUMMARY}

The Cooperative Research and Development Agreement was signed between Oak Ridge National Laboratory (ORNL) and General Electric Company (GE) on August 12, 1991. The objective was a collaborative venture between researchers at GE and ORNL to develop bioremediation of polychlorinated biphenyls (PCBs). The work was conducted over three years, and this report summarizes ORNL's effort. All planned tasks in the Cooperative Research and Development Agreement (CRADA) were not completed due to technical issues and funding limitations. A major accomplishment by ORNL, not previously demonstrated, was the utilization of existing bacterial consortia (obtained from GE) for PCB dechlorination in soils. The work conducted at ORNL has generated 15 publications and presentations. A significant achievement was reached by GE when demonstrating the anaerobic PCB dechlorination in a field study. During this study, it was found that the field study results compared well with results obtained in the laboratory on a much smaller scale

ORNL research presented in this report focused on laboratory studies in controlled environments on scales between 100 and $1000 \mathrm{~mL}$. PCB-dechlorinating organisms were successfully transferred from Hudson River and Woods Pond sediments to a sandy soil contaminated with PCBs and was the first documented case of this type of transfer. The most extensive dechlorination (from the meta position) of indigenous PCBs was observed in reactors amended with pyruvate, maleate, or a complex carbon source. Higher-chlorinated biphenyls anaerobically dechlorinated to less-chlorinated products were susceptible to aerobic biodegradation using commercially available bacterial strains. The total concentration of PCBs decreased by $70 \%$ for sequential anaerobic-aerobic treatment compared with a $67 \%$ decrease for aerobic treatment alone. The sequential treatment resulted in PCB products with fewer chlorines and shorter halflives in humans compared with either anaerobic or aerobic treatment alone. 


\section{INTRODUCTION}

Polychlorinated biphenyls (PCBs) are a family of compounds used extensively in many industrial applications until the mid-1970s. They were produced as complex mixtures by direct chlorination of biphenyl and were marketed for use in transformers, capacitors, printing ink, paints, dedusting agents, pesticides, etc. The mixtures were available under various trade names (Aroclor, Clophen, Kanechlor, Phenoclor, and Pyralene), with associated numbers denoting the average chlorine content; for example, Aroclor 1242 manufactured by Monsanto contains $42 \mathrm{wt} \%$ chlorine. The discovery of widespread environmental occurrence of these very stable compounds and their suspected carcinogenic effect in humans led to a ban of the use of PCBs in many countries. Public concern in the United States resulted in the regulation of PCBs through the Toxic Substances Control Act (TSCA) in 1976. Even though a ban is in place, PCBs have persisted in the environment due to their low water solubility, strong adsorption characteristics, negligible volatilization, and low chemical reactivity. It is estimated that several million pounds have been released into the environment.'

Although PCBs are often described as inert, aerobic microbial degradation of PCBs is well known and has been studied extensively. More recently, anaerobic reductive dechlorination of PCBs by microorganisms has also been studied. A review by Abramowicz summarizes the research results of both the aerobic and anaerobic bioprocesses. ${ }^{2}$ A complete biodegradation of PCBs to form nonhazardous end products is complex, and an engineered approach may consist of three stages: (1) partial dechlorination of the chlorinated biphenyl under anaerobic conditions, (2) aerobic attack on the biphenyl ring to cause ring cleavage, and (3) mineralization of the resulting chlorinated benzoic acids to form $\mathrm{H}_{2} \mathrm{O}, \mathrm{CO}_{2}, \mathrm{Cl}^{-}$, and cell mass. It is believed that the first stage is rate limiting, and the bulk of current research is directed toward this first stage. Extensive efforts have been aimed at isolation of a pure culture capable of dechlorinating PCBs. 
Anaerobic dechlorination has been observed in many river and pond sediments and has been proven and repeated in several laboratory settings. ${ }^{2}$ Isolation of dechlorinating organisms is difficult, and mixed cultures capable of PCB dechlorination found at a specific site tend to lose their activities when transferred to another matrix void of humic acids. ${ }^{3}$ The treatment period (or incubation period) is on the order of several months, but methods have been developed to enhance or induce dechlorination of halogenated aromatics and thus shorten the incubation period. The most commonly used methods involve nutrient amendments ${ }^{4,5,6,7,8}$ and addition of specific polyhalogenated biphenyls. ${ }^{8.9 .10}$ The result of sequential anaerobic-aerobic treatment of PCBcontaminated soils has been published by Shannon et al.," but few details about the procedure were presented. Anaerobic studies with PCB-contaminated soil were performed by Tiedje et al. by combining non-contaminated sediments (as a source of bacteria and humic acids) and contaminated soil to form sediment-soil slurries. ${ }^{12}$ In rare cases, anaerobic degradation of the biphenyl ring has also been reported..$^{13,14,15}$ 


\section{CRADA}

\subsection{BACKGROUND AND PURPOSE}

The Cooperative Research and Development Agreement (CRADA) was signed between Oak Ridge National Laboratory (ORNL) and General Electric Company (GE) on August 12, 1991. The objective was a three-year collaborative venture between researchers at GE and ORNL to develop a workable bioremediation strategy for removing PCBs from the environment. The desired result was to demonstrate successful bioremediation of PCB-contaminated material in the laboratory and in the field (PCB sediments, GE; PCB soil, ORNL).

\subsection{TASK BREAKDOWN IN CRADA AND RESULT SUMMARY}

The CRADA task breakdown is listed below in an abbreviated form, together with the result achieved in each task.

Phase I, Task I. Comparison of PCB-degrading cultures developed at ORNL with bacteria present in Hudson River sediments, as investigated by GE. This task was a GE effort.

Results. The consortium developed by ORNL, named ORNL ES-3, was determined by GE not to be a PCB-dechlorinating culture.

Phase I, Task 2. Isolation and characterization of PCB-degrading microorganisms studied by ORNL and GE. This task was a GE and ORNL effort.

Results. Isolation of dechlorinating organisms could not be accomplished by GE or ORNL. Effects of various nutrient amendments on enhancing the microorganisms' dechlorinating activity in soils and sediment slurries were investigated by both research groups, with results comparing well. Efforts outside of the CRADA, focused on the isolation of PCB-dechlorinating microorganisms, have also been unsuccessful. 
Phase I, Task 3. Application of existing bacterial consortia for remediation of PCBcontaminated solid matrices (other than aquatic sediments). This task was a ORNL effort.

Results. ORNL was able to utilize existing bacterial consortia (obtained from GE) for PCB dechlorination in soils. This was a major accomplishment that had not been previously demonstrated.

Phase II, Task 1. Extension of bioremediation to various GE and DOE sites. Investigation of the effect of radioactivity (ORNL effort) and organic content/PCB concentration (GE effort) on the dechlorination.

Results. ORNL could not complete the studies within the time frame of the CRADA. GE published an article on the effect of PCB concentration and other factors on dechlorination. ${ }^{16}$ GE's work investigated a broad range of conditions to accelerate PCB dechlorination in Hudson River sediments. Although some additives (e.g., specific metals or complex nutrients) offered minor rate enhancements (about two times), the greatest effect on PCB dechlorination rate was observed from variable PCB concentration. A linear through-zero response with PCB concentration was observed up to a maximal constant rate (Appendix C).

Phase II, Task 2. Optimization of anaerobic bioreactor design for remediation. This was an ORNL effort.

Results. Anaerobic dechlorination was enhanced in anaerobic soil slurry reactors by the addition of a carbon source. Advanced bioreactor design (stirred tanks) did not support anaerobic dechlorination; stationary reactors produced reproducible results.

Phase II, Task 3. Development of molecular biology techniques for tracking microbial genotypes. This task was an ORNL effort.

Results. Since organisms could not be isolated or identified by either research group, no progress could be made on this task. 
Phase III, Task 1. Implementation of in situ field demonstration of PCB dechlorination at a DOE (soil) and GE (sediment) site.

Results. GE has performed a demonstration of PCB bioremediation in the Hudson River, N.Y., and in Woods Pond, Mass. The results of the GE field test have been published (Appendix D). Preliminary laboratory studies demonstrated that the addition of 2,6dibromobiphenyl (26-BB) to Woods Pond sediments stimulated the extensive meta dechlorination of the background Aroclor 1260 contamination and complete otho debromination of the added 26-BB within approximately six months. In the spring of 1992, GE added 26-BB directly to Woods Pond sediments contained within a caisson in situ. Identical results (meta dechlorination and ortho debromination) were observed within approximately one year. The decreased reaction rate was the result of lower environmental temperatures, as predicted by isothermal laboratory experiments. ORNL was not able to complete a demonstration within the time frame of the CRADA. A demonstration at ORNL was planned in 1995 and 1996 but was canceled due to lack of funding.

\subsection{BENEFITS}

The work conducted under the CRADA between GE and ORNL generated new information and expanded knowledge about bioremediation of PCBs. ORNL's efforts resulted in the first documented case where Hudson River organisms were transferred from their native sediment to a soil matrix without the addition of river sediments. ${ }^{8.17}$ ORNL's research efforts have gènerated 15 publications and presentations related to PCBs since initiation of the CRADA. ${ }^{8,15,17,18,19,20,21,22,23,24,25,26,27,28,29}$ GE's efforts yielded multiple publications and presentations detailing the correlation between laboratory and field data. 


\section{TECHNICAL DISCUSSION}

\subsection{BACKGROUND}

ORNL's efforts in the experimental portion of the project were divided into three phases. In the first phase, the focus was a screening study to evaluate various culture conditions using existing bacterial consortia for remediation of PCB-contaminated solid matrices (other than aquatic sediments). The second phase concentrated on scale-up and improvements of the best conditions found during Phase I. If the results from Phases I and II so warranted, a field experiment was to be conducted in Phase III on a DOE site. The three phases are described in more detail below, including experimental procedures and design.

Phase I-Bench-scale tests to identify favorable conditions for dechlorination in soils. Observation of many sediment sites contaminated with PCBs has shown dechlorination to be a natural and widespread process. ${ }^{2}$ Laboratory and field studies have been directed toward the enhancement and induction of dechlorination in PCB-contaminated sediments. However, activities may be heterogeneous and every site is (apparently) different. Conditions that may work for one site are not guaranteed to work for another site, but certain conditions generally do exist under which dechlorination of PCB-contaminated soils is likely to occur. A range of such conditions was the starting point for ORNL's bench-scale tests.

Phase II-Scale-up for a field experiment at ORNL. In preparation for a field experiment, a series of experiments were conducted on a smaller scale in the laboratory under conditions that mimicked conditions anticipated in the field experiment. These experiments were included to allow for simple bioreactor design and verification of, improvements on, or further studies of the operating conditions. The bioreactor design studies were conducted in larger (1-L) stirred-tank reactors with appropriate sterile controls, and improvement studies were conducted on a smaller 
$(100-\mathrm{mL})$ scale. One objective for these smaller-scale studies was to establish additional nutrient requirements for optimal microbial dechlorination in PCB-contaminated soil from ORNL.

Phase III-Field experiment. The previously described efforts (Phases I and II) were expected to lead to a technology applicable to a field experiment that would be performed on a DOE site.

\subsection{EXPERIMENT DESIGN}

\subsubsection{Screening Experiments}

Initial screening explored a number of factors that had been found to be important to microbial dechlorination by investigators at GE and elsewhere. These factors are listed in Table I with an "Importance Ranking." Ranking was based on importance of a factor to induce, enhance, or inhibit dechlorination and were partially subjective.

Table 1. Ranking of various experimental conditions

\begin{tabular}{|c|c|c|}
\hline Importance ranking & Factor type & Specific factor \\
\hline 1 & Inoculum & $\begin{array}{l}\text { Woods Pond sediment } \\
\text { Hudson River sediment }\end{array}$ \\
\hline 4 & Heat treatment & $80^{\circ} \mathrm{C}, 30 \mathrm{~min}$ \\
\hline 2 & $\begin{array}{l}\text { Single congener } \\
\text { as "inducer" }\end{array}$ & $\begin{array}{l}\text { 2,6-dibromobiphenyl (26-BB) } \\
\text { 2,3,6-trichlorobiphenyl (236-CB) } \\
\text { 2,4,6-trichlorobiphenyl (246-CB) }\end{array}$ \\
\hline 5 & Reductant & Cysteine- $\mathrm{HCl}, \mathrm{Na}_{2} \mathrm{~S}$ \\
\hline 3 & Carbon source & $\begin{array}{l}\text { Organic acids or a complex carbon } \\
\text { source (e.g., Tryptone, Peptone, etc.) }\end{array}$ \\
\hline 6 & Macro nutrients & Mineral solution \\
\hline 7 & Micro nutrients & Trace metals \\
\hline Not ranked & Temperature (constant) & Room temperature, $25^{\circ} \mathrm{C}$ \\
\hline Not ranked & $\mathrm{pH}$ (initially adjusted) & $\mathrm{pH} 6.0-7.0$ \\
\hline
\end{tabular}


To limit the number of experiments, it was decided that only factors with a ranking of four or above would be studied. All other factor groups with a low ranking were lumped together as one. Thus, there were ten variables to study. Rather than using a complete 210 factorial experiment (1024 separate experiments), the following reduction was made.

1. Only one sediment was tested as an inoculum, chosen based on the type of Aroclor contamination in the soil. Hudson River sediment would be used for soil contaminated with Aroclor 1242. Woods Pond sediment would to be used for all other types of contamination. This subdivision is rationale based on published studies by Quensen and coworkers demonstrating that Hudson River microorganisms displayed the fastest dechlorination activities with Aroclor 1242 contaminated material, and that sediment organisms (obtained from sediments contaminated with Aroclor 1260) displayed the most rapid dechlorination of highly chlorinated PCBs. ${ }^{30}$

2. No experiments with mixtures of single congeners were conducted.

3. No experiments with a combination of carbon sources were conducted.

4. Macro and micro nutrients were added in all initial screening experiments, and the $\mathrm{pH}$ and temperature were held constant for all reactors.

This reduced the number of initial experiments to 64 . These experiments were started over a period of two weeks, with eight experiments per day, four days per week. After the two-week start-up period, each bottle was sampled periodically.

\subsubsection{Verification and Enhancement Experiments}

The effects of several variables were studied in the screening study (Sect. 3.2.1). The best dechlorination activity was obtained under anaerobic conditions using a well-defined inorganic minerals-and-metals medium amended with acetone and either maleic acid, pyruvic acid, or a 
complex nutrient source. For the verification studies, several conditions were studied on a small scale to duplicate previous studies and to further optimize conditions for dechlorination. Some of these conditions included the use of soil with lower PCB contamination levels, the use of surfactant to enhance bioavailability, the use of alternate inoculum source (from Woods Pond), the use of chemical reducing agents, and the use of alternate carbon sources.

\subsubsection{Reactor Design}

The focus of the large-scale study was sequential anaerobic and aerobic degradation of PCBs in contaminated soil. Five continuously stirred fermenters were used in the study, and each fermenter contained approximately $200 \mathrm{~g}$ of contaminated soil and $800 \mathrm{~mL}$ of medium, with acetone and maleic acid as carbon sources (Sect. 3.2.2). All reactors were inoculated with microorganisms eluted from Hudson River sediments. One of the fermenters served as a sterile control, which was steam sterilized at $121^{\circ} \mathrm{C}$ twice for $1 \mathrm{~h}, 24 \mathrm{~h}$ apart. The remaining four fermenters were identical. After the end of the anaerobic treatment period, microorganisms capable of aerobically degrading PCBs were to be added together with biphenyl (as a carbon source), and the fermenters were to be sparged with sterile air for the remaining aerobic treatment period. (This aerobic treatment were not performed in the final study for the large reactors.)

\subsubsection{Mixed Waste Studies}

The most promising environmental conditions were studied in eight $100-\mathrm{mL}$ and three $1-\mathrm{L}$ slurry reactors. In the smaller reactors, maleic acid $(1.1 \mathrm{~g} / \mathrm{L})$ was used as a carbon source; 26-BB, 236-CB, or 246-CB congeners were used as dechlorination inducers; and both inocula from the Hudson River and Woods Pond were tested. The larger reactors contained maleic acid as a carbon source and were inoculated with organisms from Hudson River, Woods Pond, or were left 
uninoculated. The contaminated soil used in these studies came from a contaminated site at the White Wing Scrap Yard on the Oak Ridge Reservation. ${ }^{31}$

\subsubsection{Sequential Anaerobic-Aerobic Studies}

Aerobic studies were not directly in the scope of the CRADA; however, aerobic studies were conducted as a second stage for some previously anaerobic reactors to investigate the benefit of engineered systems. The aerobic culture used was obtained from GE with cultivation instructions, and the two reactors that had shown the most dechlorination activity during the initial screening study were selected for the test. Two other reactors that had the same media composition but had not shown dechlorination activity while anaerobic were used as controls. The four reactors were inoculated with the aerobic culture; the difference during the aerobic phase then provided direct evaluation of the contrast between sequential anaerobic-aerobic and aerobic alone.

\subsection{MATERIALS AND METHODS}

\subsubsection{Soil Collection}

PCB-contaminated soil and interface material (sandy layer between gravel and soil) were collected from a capacitor bank at a power substation located in Chattanooga, Tenn. Over time, PCBs were released through spills in and around these capacitors. A mixture of soil and interface was collected in January 1993. The soil was analyzed and found to have the following characteristics: $26.1 \%$ clay, $24.7 \%$ sand, $49.2 \%$ silt, $0.86 \%$ organic carbon, $0.08 \%$ total nitrogen, and a $\mathrm{pH}$ of 8.1 . The interface was found to have $0.4 \%$ organic carbon, $0.018 \%$ total nitrogen, and a $\mathrm{pH}$ of 8.55 . Collected soil/interface was combined with sterile water (equal volumes), and the slurry was ball milled antiseptically and anaerobically for $4 \mathrm{~h}$ to ensure homogeneity. The PCB 
concentration was approximately $100 \mathrm{mg} / \mathrm{kg}$ in dry soil, and historic documentation indicated that the PCB mixtures spilled at the site were Aroclor $1242 .^{32}$

Soil with PCB and radioactive contamination was collected from Waste Area Grouping 11 at ORNL. The soil was a red clay, typical of the area, and was contaminated with Aroclor 1254 at concentrations greater than $6000 \mathrm{mg} / \mathrm{kg}$ dry soil; since this was considered high, the contaminated soil was combined (1:10) with an uncontaminated soil from a adjacent location. Radioactive components identified in the soil were cesium $\left({ }^{137} \mathrm{Ce}\right)$, potassium $\left({ }^{40} \mathrm{~K}\right)$, uranium $\left({ }^{234} \mathrm{U},{ }^{235} \mathrm{U}\right.$, and ${ }^{238} \mathrm{U}$ ), and thorium $\left({ }^{228} \mathrm{Th},{ }^{236} \mathrm{Th}\right.$, and $\left.{ }^{232} \mathrm{Th}\right)$ at gross alpha and beta contamination levels of 1800 $\mathrm{Bq} / \mathrm{kg}$ and $2000 \mathrm{~Bq} / \mathrm{kg}$, respectively, after combination with the uncontaminated soil, and the soil was used without milling.

\subsubsection{Soil Slurry Reactor Study}

Anaerobic batch incubations were prepared under a nitrogen environment in $150-\mathrm{mL}$ nominalvolume serum bottles (Wheaton Scientific, Millville, N.J.), and the bottles were capped with Teflon-lined caps (The West Co., Phoenixville, Pa.) and aluminum crimp-seals (Wheaton).

The final concentrations of nutrients in the anaerobic bioreactors were (per liter): $200 \mathrm{~g}$ soil, various amounts of carbon source $[1.14 \mathrm{~g}$ maleic acid, $1.09 \mathrm{~g}$ pyruvic acid (sodium salt), or $0.33 \mathrm{~g}$ yeast extract and $0.66 \mathrm{~g}$ nutrient broth], $2.3 \mathrm{~g}$ acetone, $1.2 \mathrm{~g} \mathrm{NaHCO}_{3}, 525 \mathrm{mg} \mathrm{NH}_{4} \mathrm{Cl}, 100 \mathrm{mg}$ $\mathrm{MgCl}_{2} \cdot 6 \mathrm{H}_{2} \mathrm{O}, 75 \mathrm{mg} \mathrm{CaCl}, 35 \mathrm{mg} \mathrm{K} \mathrm{K}_{2} \mathrm{HPO}_{4}, 27 \mathrm{mg} \mathrm{KH}_{2} \mathrm{PO}_{4}, 21.5 \mathrm{mg} \mathrm{FeCl} \cdot 4 \mathrm{H}_{2} \mathrm{O}, 300 \mu \mathrm{g}$ $\mathrm{H}_{3} \mathrm{BO}_{3}, 200 \mu \mathrm{g} \mathrm{CoCl} \mathrm{Cl}_{2} \cdot 6 \mathrm{H}_{2} \mathrm{O}, 100 \mu \mathrm{ZnSO}_{4} \cdot 7 \mathrm{H}_{2} \mathrm{O}, 30 \mu \mathrm{g} \mathrm{MnCl}_{2} \cdot 4 \mathrm{H}_{2} \mathrm{O}, 30 \mu \mathrm{g} \mathrm{Na} \mathrm{MoO}_{4} \cdot 2 \mathrm{H}_{2} \mathrm{O}$ $20 \mu \mathrm{g} \mathrm{NiCl} \cdot 6 \mathrm{H}_{2} \mathrm{O}, 10 \mu \mathrm{g} \mathrm{CuCl} \cdot \mathrm{H}_{2} \mathrm{O}, 10 \mu \mathrm{ga}_{2} \mathrm{SeO}_{3}$, and $1 \mathrm{mg}$ resazurin. The final $\mathrm{pH}$ of the slurry was 6.5 to 7.5 , and the reactors were incubated at room temperature.

During the aerobic phase, previously anaerobic reactors were exposed to air and supplemented with additional nutrients (1.5 g biphenyl, $2.1 \mathrm{~g} \mathrm{NH}_{4} \mathrm{Cl}, 4.4 \mathrm{~g} \mathrm{~K}_{2} \mathrm{HPO}_{4}$, and $1.7 \mathrm{~g}$ 
$\mathrm{KH}_{2} \mathrm{PO}_{4}$ per liter slurn). The reactors were placed on an orbital shaker (200 rpm) at room temperature and exposed to air as needed (indicated by resazurin color change).

\subsubsection{Inocula}

Naturally occurring organisms present in Hudson River sediments have been shown to be responsible for extensive dechlorination of $\mathrm{PCBs}$ in that environment. ${ }^{33}$ The anaerobic inoculum was prepared from equal volumes of dewatered sediments and mineral medium. The slurry was mixed for $1 \mathrm{~h}$ followed by a 15 -min settling time. The supernatant was removed and filtered through cotton fiber before use. One reactor was inoculated with a medium containing organisms present in Hudson River sediments, and the other reactor was left uninoculated but otherwise identical. The aerobic culture [Pseudomonas sp. LB400 (NRRL-18064)] was supplied by GE and maintained on the medium used in the aerobic studies (Sect. 3.3.2). The seed culture was grown for two weeks prior to use.

\subsubsection{Sampling and PCB Analysis}

One milliliter of slurry was removed at each sampling time and was combined with $1 \mathrm{~mL}$ of acetone and $4 \mathrm{~mL}$ of hexane, shaken for $4 \mathrm{~h}$, and centrifuged at $1000 \mathrm{rpm}$ for $5 \mathrm{~min}$. One milliliter of the organic phase was combined with $0.1 \mathrm{~mL}$ internal standard (octachloronaphthalene in hexane), and $1 \mu \mathrm{L}$ of the mixture was injected into a gas chromatograph (GC) [Hewlett-Packard, Avondale, Pa.] equipped with an electron capture detector and a $30-\mathrm{m} \times 0.247-\mathrm{mm} \mathrm{DB}-1(0.25-\mu \mathrm{m}$ film thickness) capillary column (J\&W Scientific, Folsom, Calif.). The splitless/split injector temperature was $270^{\circ} \mathrm{C}$, and the detector temperature was $300^{\circ} \mathrm{C}$. Initial oven temperature was kept at $40^{\circ} \mathrm{C}$ for $2 \mathrm{~min}$, after which two temperature ramps $\left(20^{\circ} \mathrm{C} / \mathrm{min}\right.$ to $160^{\circ} \mathrm{C}$ and $5^{\circ} \mathrm{C} / \mathrm{min}$ thereafter) were used to increase oven temperature to $270^{\circ} \mathrm{C}$. Calibration was performed using an 
Aroclor (Ultra Scientific, North Kingstown, R.I.) mixture of $70 \mathrm{wt} \%$ Aroclor 1242, $20 \mathrm{wt} \%$ Aroclor 1254, and $10 \mathrm{wt} \%$ Aroclor 1260 in hexane. The PCB congener composition of the Aroclors needed for calibration was supplied by Dr. Abramowicz (General Electric, Schenectady, N.Y.), and similar data have been published elsewhere. ${ }^{34}$ Data analysis using Hewlett-Packard Chemstation software was conducted on 68 congener-containing peaks. Peak identification has previously been published by Brown et al ${ }^{33,35}$ Extracted soil was dried at $80^{\circ} \mathrm{C}$ for $20 \mathrm{~h}$ to determine the dry soil weight of each sample.

The number of mono-, di-, tri-, etc., chlorobiphenyls was calculated based on the known PCB congener composition in the standards and peak identification mentioned above. In addition to homolog calculations, the expected half-life in humans of the PCB congeners was calculated based on data compiled by Brown et al. ${ }^{35}$ Whenever the average chlorine content per biphenyl was estimated in samples with an inducer (26-BB, 236-CB, or 246-CB), the "inducer peak" and peaks resulting from products of inducer dehalogenation were eliminated from calculations. The GC method is listed in Appendix A, and the resources used for peak identification and calculations have been compiled in Appendix B. Appendix B also lists toxicity data for PCB congeners as described by Safe. ${ }^{36}$

\subsubsection{Data Quality Assurance}

Duplicate samples were taken at each sampling period from 5 to $10 \%$ of the reactors. In addition, duplicate samples were injected into the GC at a frequency of 5 to $10 \%$ of all samples injected. 


\subsection{RESULTS}

\subsubsection{Initial Screening Studies}

Sixty-four slurry reactor experiments (each under different conditions) were conducted, and the following variables were studied:

Inoculum. Half the bioreactors were inoculated with a consortium of organisms eluted from Hudson River sediments to investigate the possibility of using exogenous organisms.

Carbon Source Addition. All reactors had acetone in the medium; two-thirds of the reactors also received pyruvic acid, maleic acid, or a complex nutrient mixture.

Heat Treatment. Half the bioreactors were heat treated by placing them in an oven maintained at a temperature of $80^{\circ} \mathrm{C}$ for $45 \mathrm{~min}$.

Single Congener Addition. Three halogenated biphenyls were used as inducers in this study: 2,3,6- trichlorobiphenyl (236-CB), 2,4,6-trichlorobiphenyl (246-CB), and 2,6-dibromobiphenyl (26-BB), which were added to levels of approximately $150 \mathrm{mg} / \mathrm{kg}$ dry soil.

Sampling was conducted at start-up and then after $3,7,11,15,23$, and 45 weeks of incubation. A typical GC chromatogram of a sample taken at start-up is shown in Fig. 1. For reference, GC chromatograms of standard Aroclor 1242 and 1254 are shown in Figs. 2 and 3. The initial material had a peak pattern intermediate between Aroclor 1242 and Aroclor 1254; although the material does not appear to be a mixture of these Aroclors. Rather, the material appeared similar to Aroclor 1242 that has been weathered due to partial evaporation. A representative GC chromatogram of a sample taken after 15 weeks of anaerobic incubation of a reactor in which dechlorination was evident is shown in Fig. 4. When comparing chromatograms in Fig. 1 with Fig. 4 , it is clear that a shift in peak profiles has occurred. For rapid quantitative comparisons between a large number of reactors, the average number of chlorines per biphenyl was used as a marker of dechlorination. Overall results of analyses are summarized as the chlorine content per biphenyl of 
the PCBs in each reactor in Figs. 5 to 12. Each figure contains results from eight bioreactor experiments. All eight bioreactor experiments listed in the same graph were conducted with the same carbon source and the same inoculum (or lack thereof). The different bioreactors listed in each graph received various halogenated biphenyls (as single congeners) and different heat treatment (see title of Fig. 5).

Several conclusions may be drawn based on the results presented in Figs. 5 to 12 regarding the extent of dechlorination and the effect of various amendments on the microbial dechlorination activity. Overall, dechlorination activity was observed in about $30 \%$ of the bioreactors. (No activity was observed in any of the uninoculated systems.) The best results were obtained in inoculated reactors amended with maleate, pyruvate, or a rich nutrient mixture (data A in Figs. 10, 11 , and 12) where the average chlorine contents decreased from about 4.3 to around 3.5 , after 15 to 23 weeks of incubation. No inducers were required to obtain the most extensive dechlorination. Attempts to add additional nutrients or microorganisms after the 23-week period did not induce further dechlorination, and the average chlorine content remained the same until reactors were shut down after 45 weeks. 


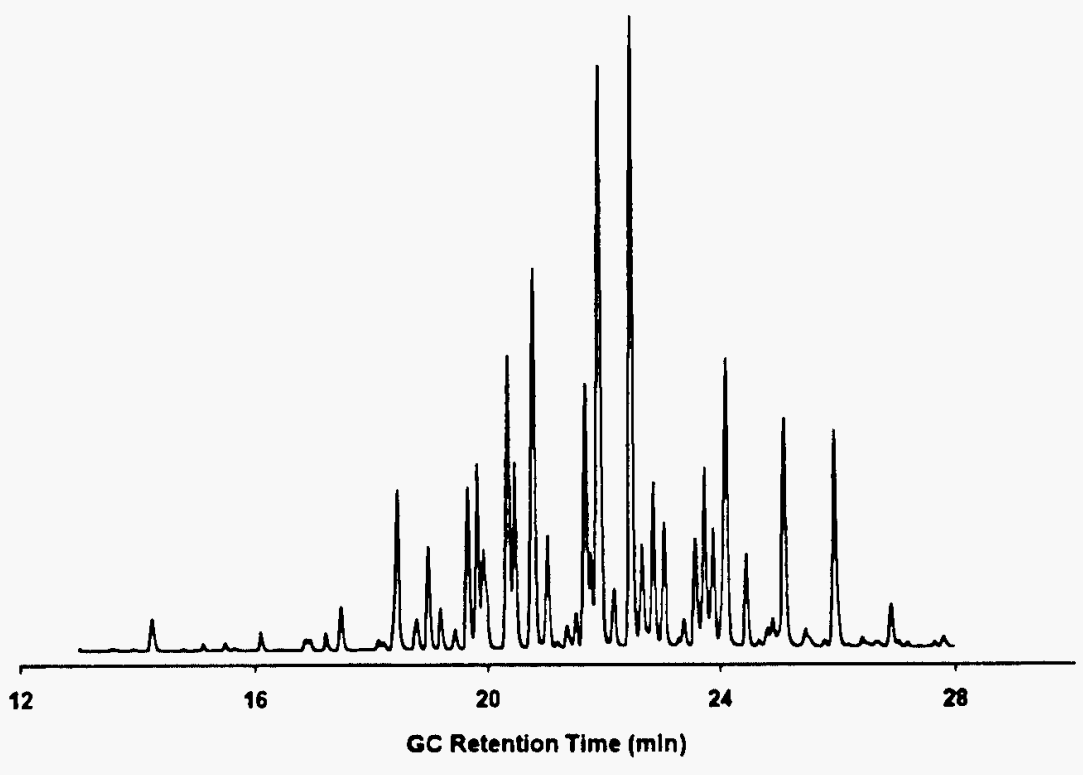

Fig. 1. Typical GC peak profile of sample taken at start-up.

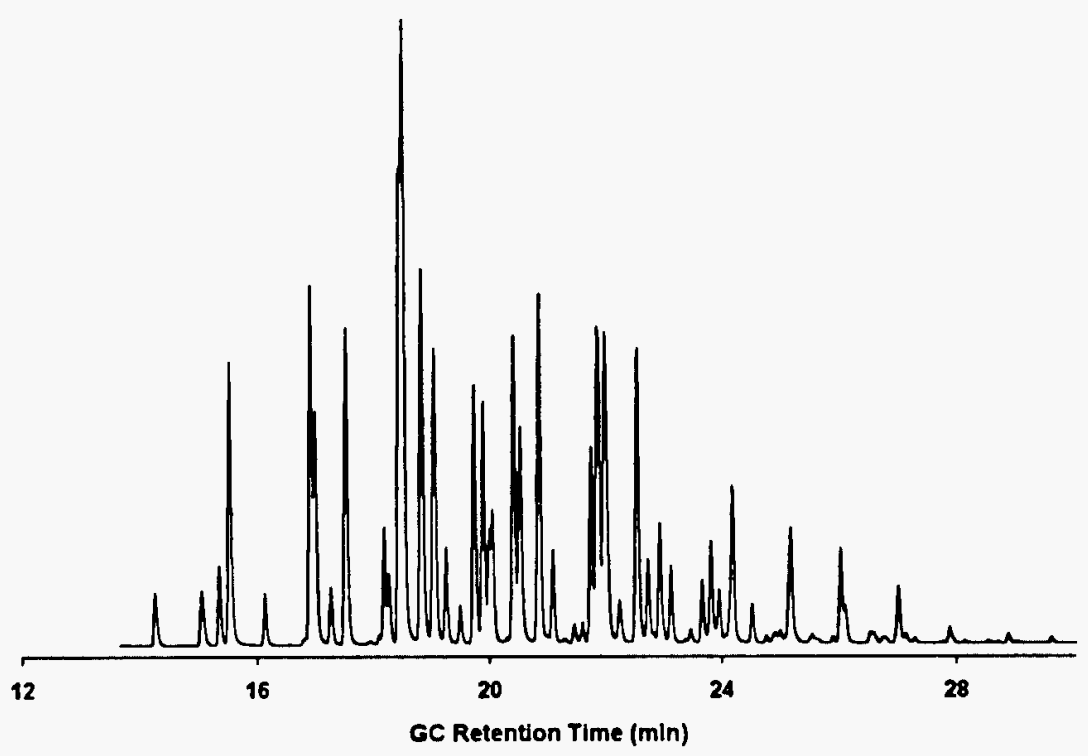

Fig. 2. GC peak profile of an Aroclor 1242 standard. 


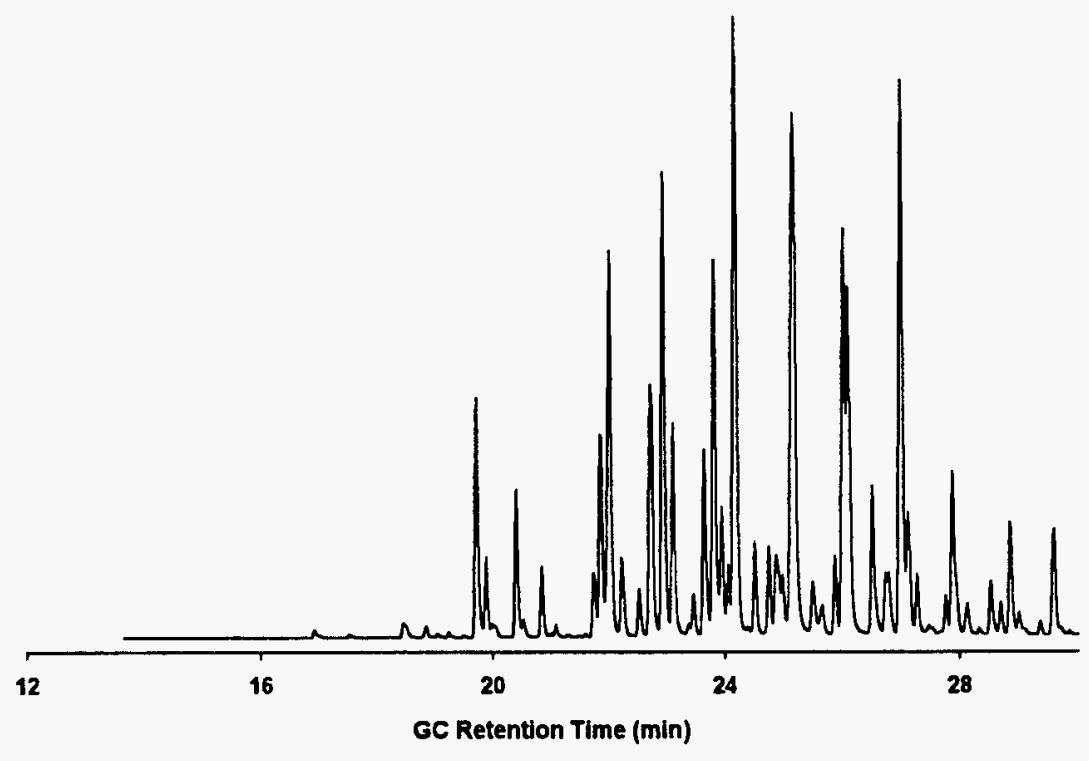

Fig. 3. GC peak profile of an Aroclor 1254 standard.

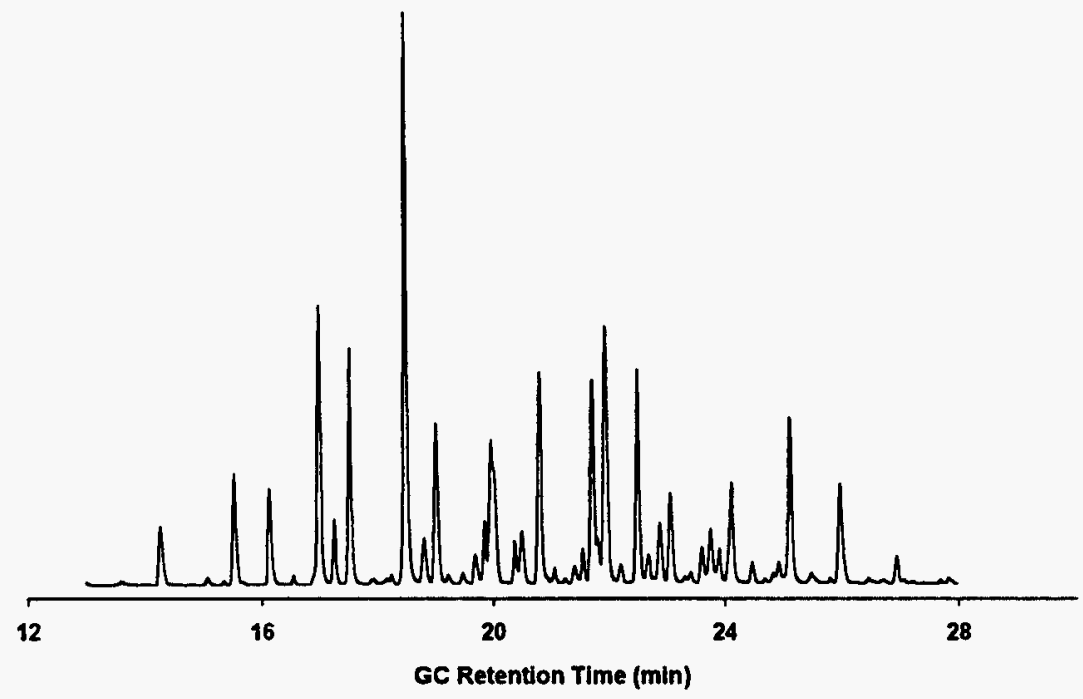

Fig. 4. GC peak profile in sample taken after 15 weeks of anaerobic incubation of a reactor inoculated with bacteria from Hudson River. 


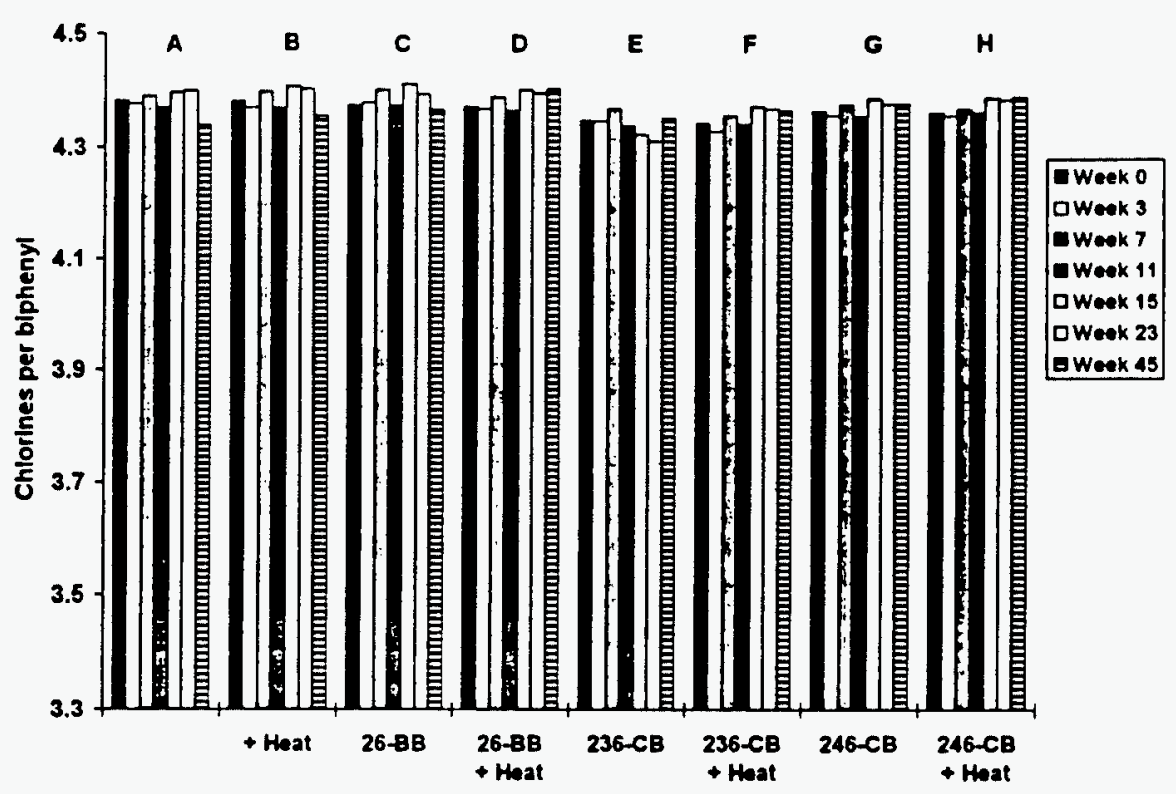

Fig. 5. Average PCB chlorine content in eight (A through $\mathrm{H}$ ) uninoculated reactors amended with acetone as carbon source. Different heat treatment and single-congener amendments are shown on the ordinate.

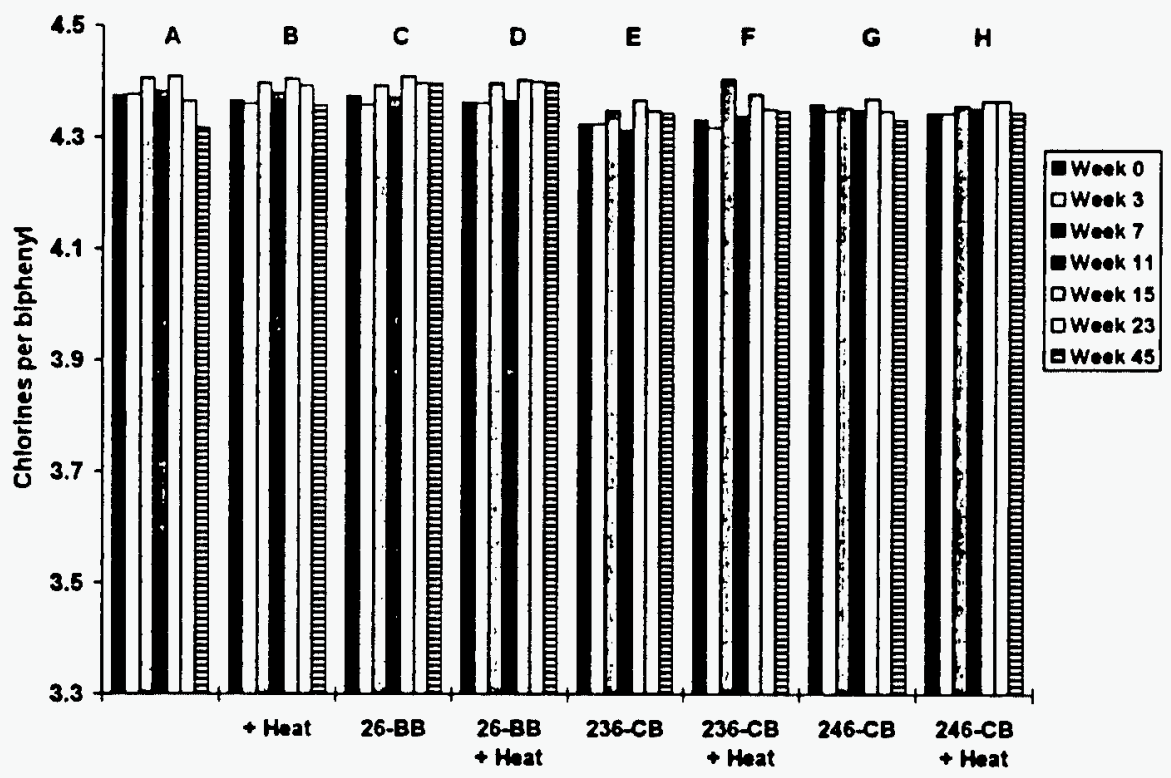

Fig. 6. Average PCB chlorine content in eight (A through H) uninoculated reactors amended with maleate and acetone as carbon sources. 


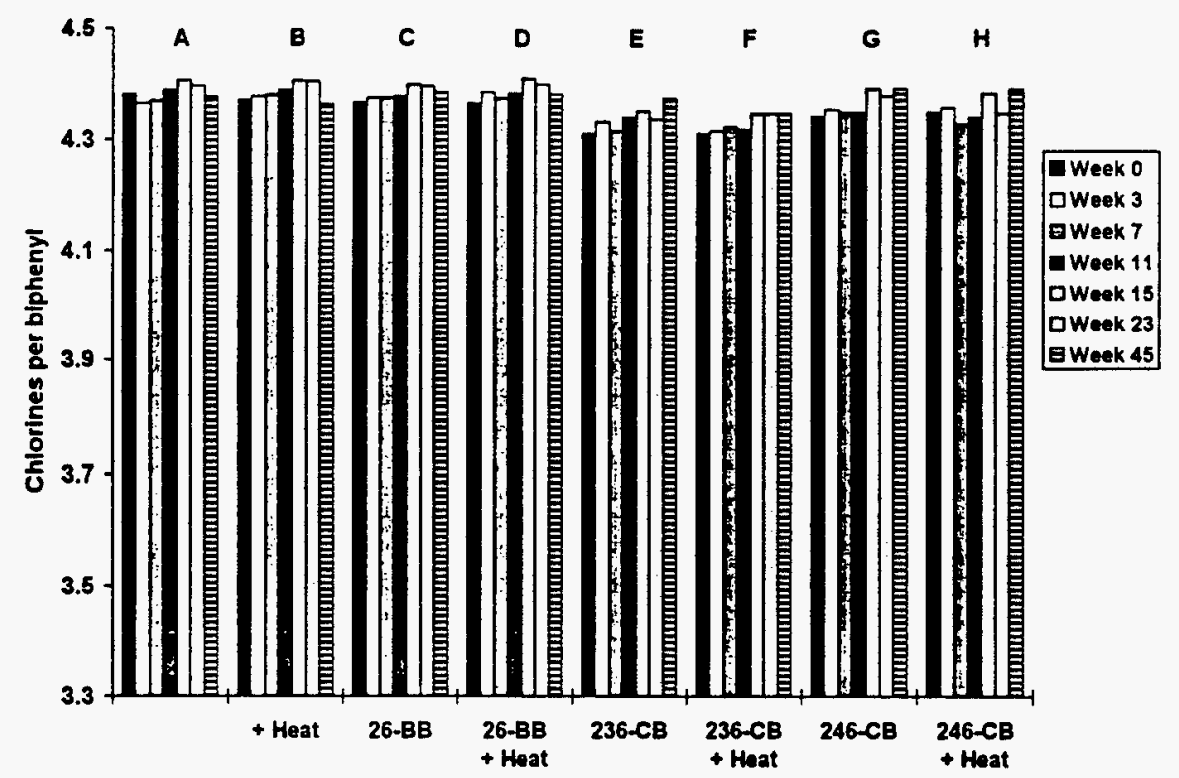

Fig. 7. Average PCB chlorine content in eight (A through H) uninoculated reactors amended with pyruvate and acetone as carbon sources.

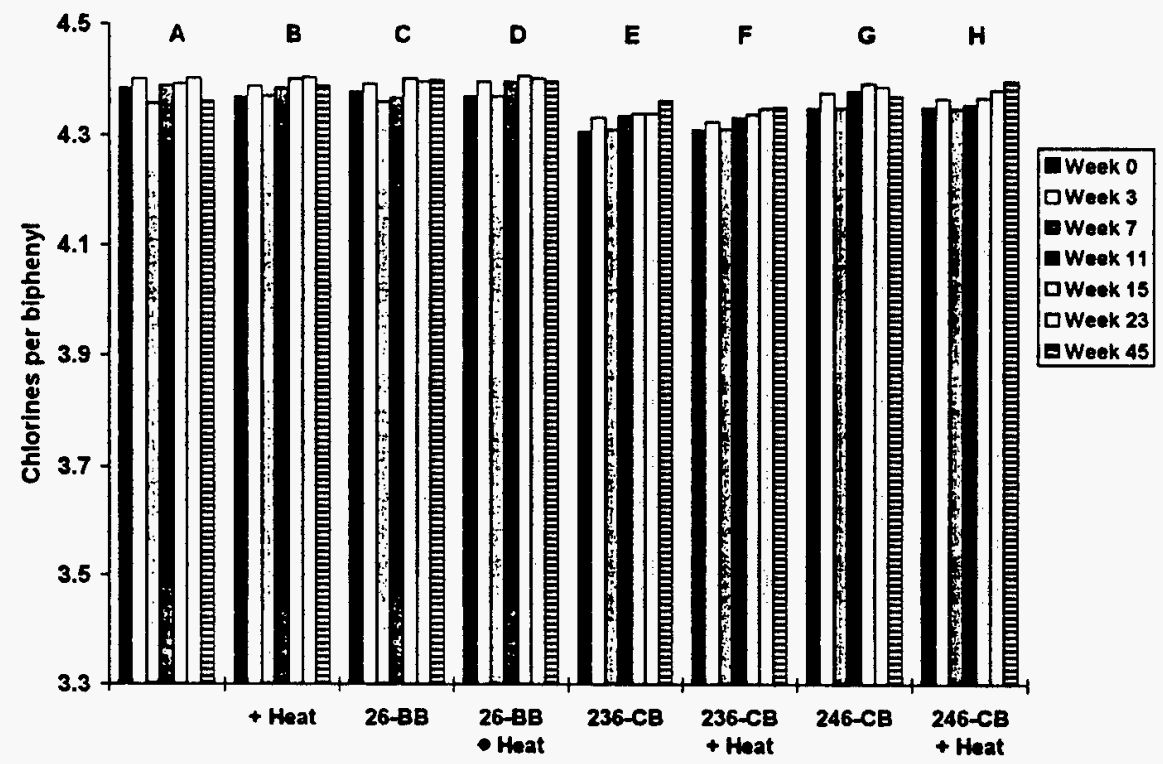

Fig. 8. Average PCB chlorine content in eight (A through H) uninoculated reactors amended with a complex nutrient mixture and acetone as carbon sources. 


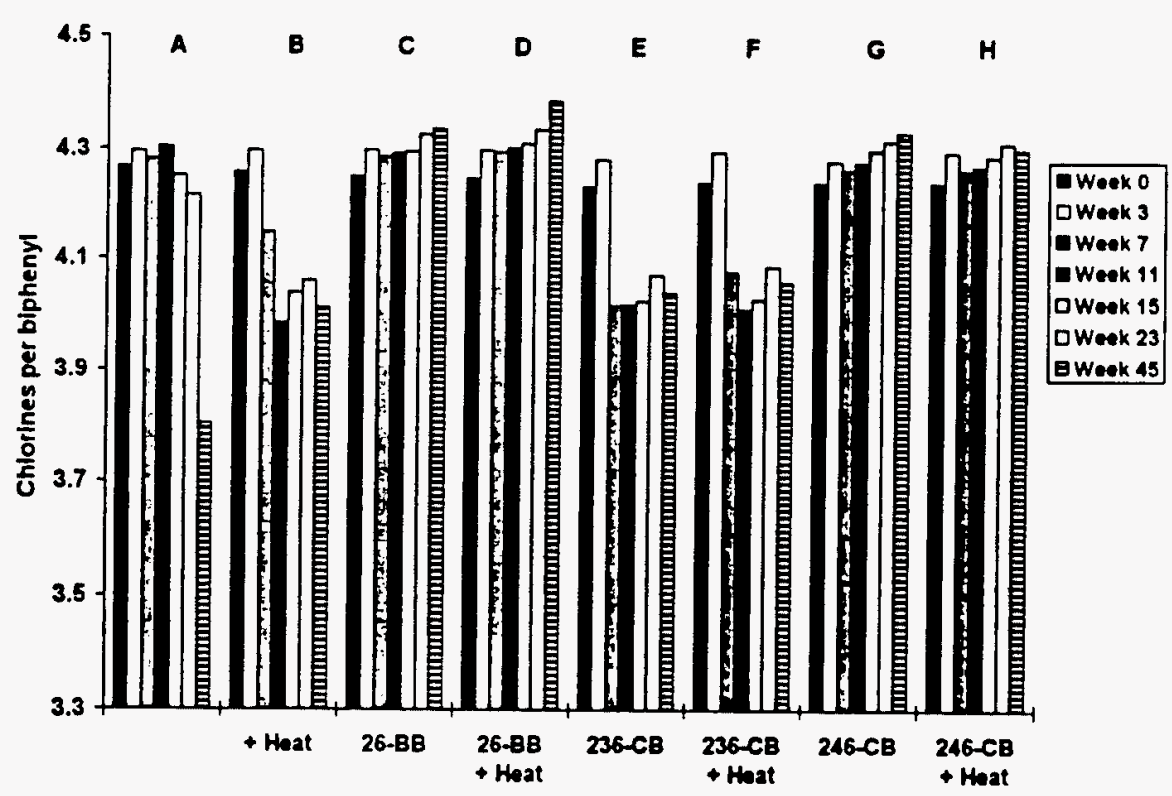

Fig. 9. Average $\mathrm{PCB}$ chlorine content in eight (A through $\mathbf{H}$ ) inoculated reactors amended with acetone as carbon source.

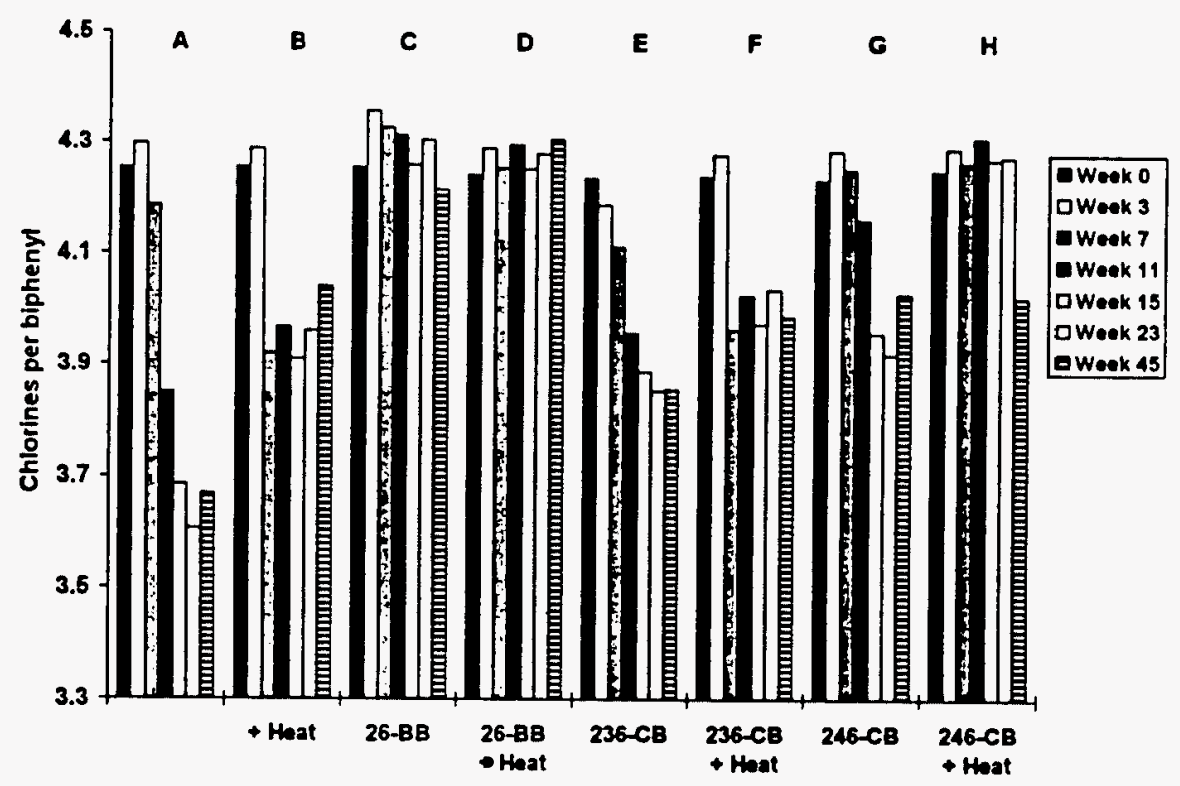

Fig. 10. Average PCB chlorine content in eight (A through $\mathbf{H}$ ) inoculated reactors amended with maleate and acetone as carbon sources. 


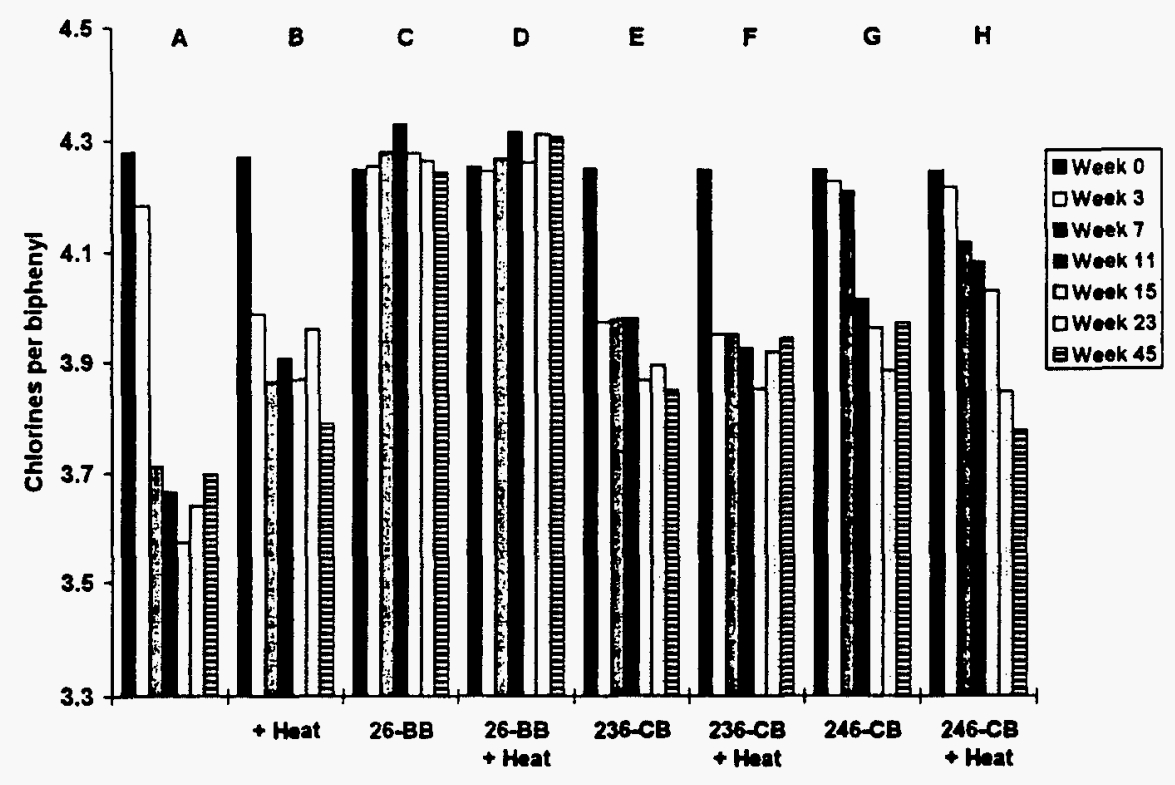

Fig. 11. Average PCB chlorine content in eight (A through $\mathrm{H}$ ) inoculated reactors amended with pyruvate and acetone as carbon sources.

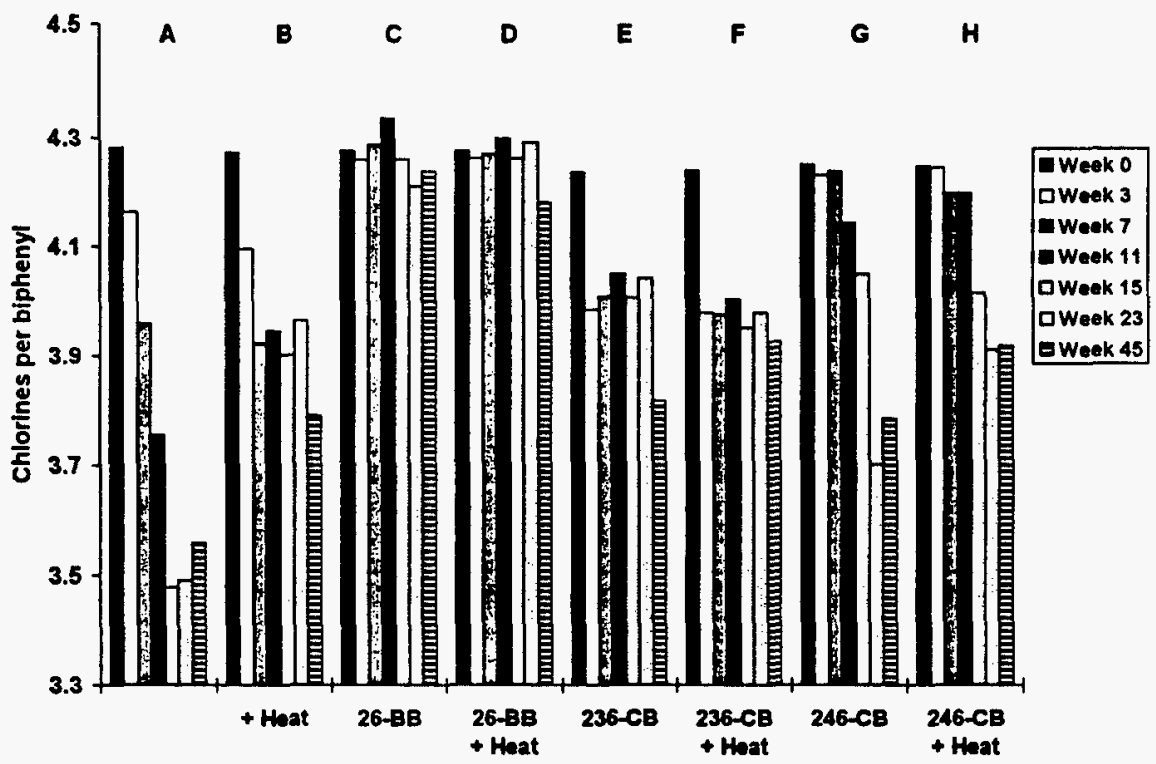

Fig. 12. Average PCB chlorine content in eight (A through $\mathbf{H})$ inoculated reactors amended with a complex nutrient mixture and acetone as carbon sources. 
Effect of Inoculum. Indigenous microorganisms (uninoculated reactors) did not show any dechlorinating activity over the 45-week study (Figs. 5-8). The addition of organisms from Hudson River sediments caused PCB dechlorination in 20 of the 32 inoculated bioreactors.

Effect of Carbon Source. The addition of a carbon source beyond acetone resulted in improved dechlorination. Improvements were noted using maleic acid, pynuvic acid, or the complex nutrient mixture as the second carbon source (acetone being the first).

Effect of Heat Treatment. For the most part, heat treatment appeared to inhibit dechlorination (compare data in Figs. 10B, 10F, 11B, 11F, and 12B with 10A, 10E, 11A, 11E, and $12 \mathrm{~A}$, respectively). In one case, clear improvement in rate was observed in the heat-treated reactor (compare Fig. 9B with 9A), although the untreated reactor displayed more extensive dechlorination. This was not expected since the use of mild heat treatment has previously been used to selectively enrich for PCB-dechlorinating microorganisms in river sediments. ${ }^{37}$

Effect of Single Congener Addition. The addition of 26-BB inhibited dechlorination and debromination. Dechlorination activity was generally induced faster in reactors amended with 236-CB, and activity was seen in as little as 3 weeks (see data for experiments $\mathrm{G}$ and $\mathrm{H}$ in Figs. 11 and 12). However the extent of dechlorination was greater in reactors not receiving a single congener (see data for experiment $A$ in Figs. 10, 11, and 12). It should be noted that direct comparisons between results from reactors amended with single congeners and results from nonamended reactors cannot be made since the addition of a single congener will cause the chlorine content to be overestimated in the calculations.

\subsubsection{Verification and Enhancement Studies}

The best dechlorination activity in the screening study (see Sect. 3.4.1) was obtained under anaerobic conditions using a simple inorganic minerals-and-metals medium amended with an 
inoculum, acetone, and either maleic acid, pyruvic acid, or a complex nutrient mixture. For the verification studies, several conditions were studied on a small scale to duplicate previous studies and to further optimize the conditions for dechlorination. Some of these conditions included the following.

Various Soil Samples. Several soil samples with the same soil characteristics but varying PCB levels were collected from the same general area. During PCB analyses of the samples, it was found that PCB level and congener (GC peak) pattern varied from sample to sample. The different soil samples were inoculated under the best conditions found in the screening studies, and uninoculated blanks were used to determine the presence of existing dechlorinating organisms. The PCB concentration in these samples varied from 21 to $42 \mathrm{mg} / \mathrm{kg}$, and the average chlorine per biphenyl content was 4.0 to 4.4 .

Inoculum Source. Historic records had indicated that Aroclor 1242 spills around capacitors were responsible for soil contamination. However, comparisons between analyses of soil samples and Aroclor standards indicated that the PCB profile in the contaminated soil was quite different from the typical Aroclor 1242 profile (compare Figs. 1 and 2); the average chlorine content was higher than expected (similar to weathered Aroclor 1242 or Aroclor 1248). Thus, it was decided to conduct experiments with a bacterial consortium from Woods Pond, a shallow lake exposed to Aroclor 1260 (which has a higher chlorine content than Aroclor 1242).

Alternate Carbon Source. In the ORNL studies, maleic acid $(\mathrm{HOCOCH}=\mathrm{CHCOOH})$ was used successfully to induce dechlorination. Similarly, malic acid $\left(\mathrm{HOCOCH}{ }_{2} \mathrm{CHOHCOOH}\right)$ has been used by GE and others to achieve the same induction. In a limited study, the two organic acids were compared. 
Chemical Reducing Agents. Since the anaerobic dechlorination is a reductive process, the chemical reducing agents $\mathrm{Na}_{2} \mathrm{~S}$ and cysteine- $\mathrm{HCl}$ were added to investigate the possibility of enhancing the reductive process.

Surfactant Addition. A biodegradable surfactant (Witconol SN70 from Witco Chemical Corp., Houston, Tx.) was tested. This surfactant has successfully been used in soil washing studies. ${ }^{38,39}$

Vitamins. A vitamin solution was added at two different levels to promote growth and add potential enzymatic cofactors. The vitamin solution consisted of (per liter) ${ }^{40} 20 \mathrm{mg}$ biotin, $20 \mathrm{mg}$ folic acid, $10 \mathrm{mg}$ pyridoxal- $\mathrm{HCl}, 60 \mathrm{mg}$ lipoic acid, $50 \mathrm{mg}$ riboflavin, $50 \mathrm{mg}$ thiamine- $\mathrm{HCl}, 50 \mathrm{mg}$ Ca-d-pantothenate, $50 \mathrm{mg}$ cyanocobalamin, $50 \mathrm{mg}$-aminobenzoic acid, and $50 \mathrm{mg}$ nicotinic acid, and the solution was added at levels of 5 to $10 \mathrm{~mL}$ per liter of prepared medium. Vitamin $B_{12}$ has been found to catalyze the reduction of pentachlorobiphenyl in a chemical system. ${ }^{41}$

Samples from these reactors were collected on a routine basis and the results are shown in Figs. 13 to 16 in which the average number of chlorines per biphenyl has been plotted as a function of incubation time for the various condition studied. The initial PCB contamination levels in the different soils collected varied between 21 and $42 \mathrm{mg} / \mathrm{kg}$, with an average number of chlorines per biphenyls of 4.0 to 4.4 . It is possible that the difference in the average number of chlorines per biphenyl was due to differences in rates of evaporation over time. As noted in Fig. 13, dechlorination was only observed in the reactors inoculated with organisms eluted from Hudson River sediments, indicating that indigenous dechlorinating organisms were not present in any of the soils. A long lag preceded dechlorination, but eventually the extent to which dechlorination occurred was similar to that observed as in the previous screening studies (compare results in Figs. $13 \mathrm{~B}, 13 \mathrm{D}, 13 \mathrm{~F}$, and 12A). 
It was found that neither the alternate carbon source (malic acid) or the alternate inoculum (Woods Pond) changed the dechlorination pattern substantially; the best combination for this specific soil was the use of Hudson River sediment organisms in maleic acid-amended medium (Fig. 14). As seen in Fig. 15, low or high levels $(160 \mathrm{mg} / \mathrm{L}$ or $500 \mathrm{mg} / \mathrm{L})$ of the reducing agent cysteine- $\mathrm{HCl}$ or low levels of $\mathrm{Na}_{2} \mathrm{~S}$ did not influence the dechlorination, but the higher levels of $\mathrm{Na}_{2} \mathrm{~S}$ inhibited the dechlorination slightly. The addition of a vitamin solution to the medium showed a similar result, as the highest vitamin concentration inhibited the dechlorination slightly (Fig. 16). The results of studies with surfactant-amended medium are shown in Fig. 17. The addition of a surfactant did not increase the apparent rate or extent of dechlorination. In fact, the highest surfactant concentration used $(0.1 \mathrm{~g} / \mathrm{L})$ inhibited dechlorination over the 40 -week study. The surfactant concentration in solution was well below the critical micelle concentration for the surfactant.

\subsubsection{Bioreactor Design}

Samples were taken of the five 1-L stirred-tank bioreactors over a total of 52 weeks. No evidence of bacterial dechlorination was noted at any time. The $\mathrm{pH}$ was monitored and also remained the same at 6.5 to 7.0 . Several small bioreactors were conducted for enhancement studies (Sect. 3.4.2) before and after the 1-L bioreactors were started. Essentially all the small bioreactors (that were not continuously agitated) became anaerobic and showed sign of dechlorination (data not shown). Thus, it can only be concluded that the stirring, with possible entrapment of oxygen, had an inhibitory effect on anaerobic dechlorination activity. This effect has also been observed by other investigators. ${ }^{42}$ 


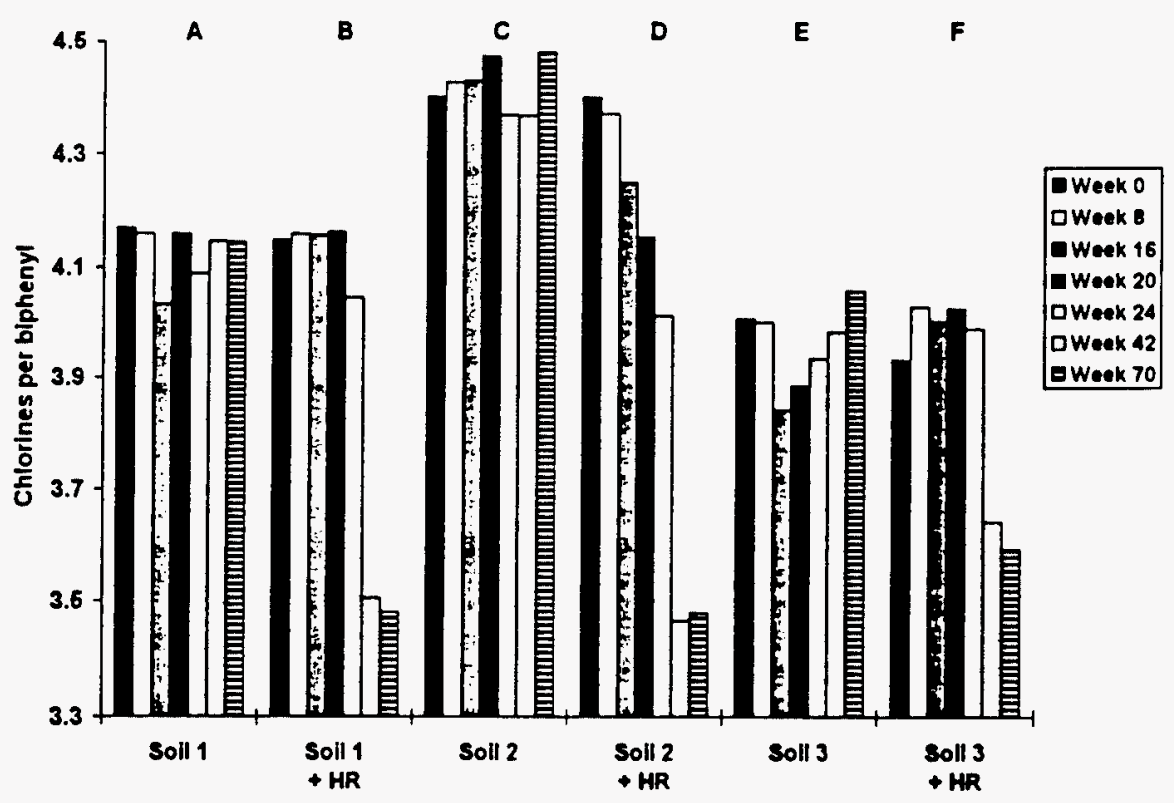

Fig. 13. Average PCB chlorine content in reactors with various soils collected from the same general area. Some reactors were inoculated with organisms from Hudson River (HR) sediments, and all reactors were amended with a complex nutrient mixture and acetone as carbon sources.

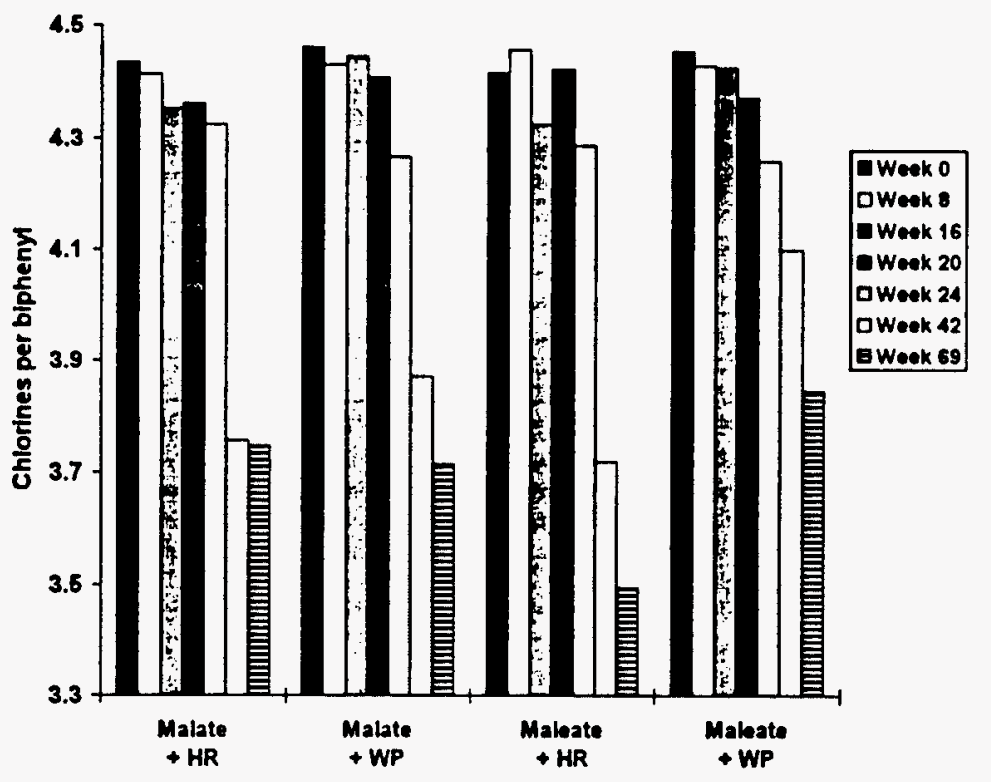

Fig. 14. Average PCB chlorine content in reactors inoculated with organisms from Hudson River (HR) or Woods Pond (WP) sediments and amended with malate or maleate. 


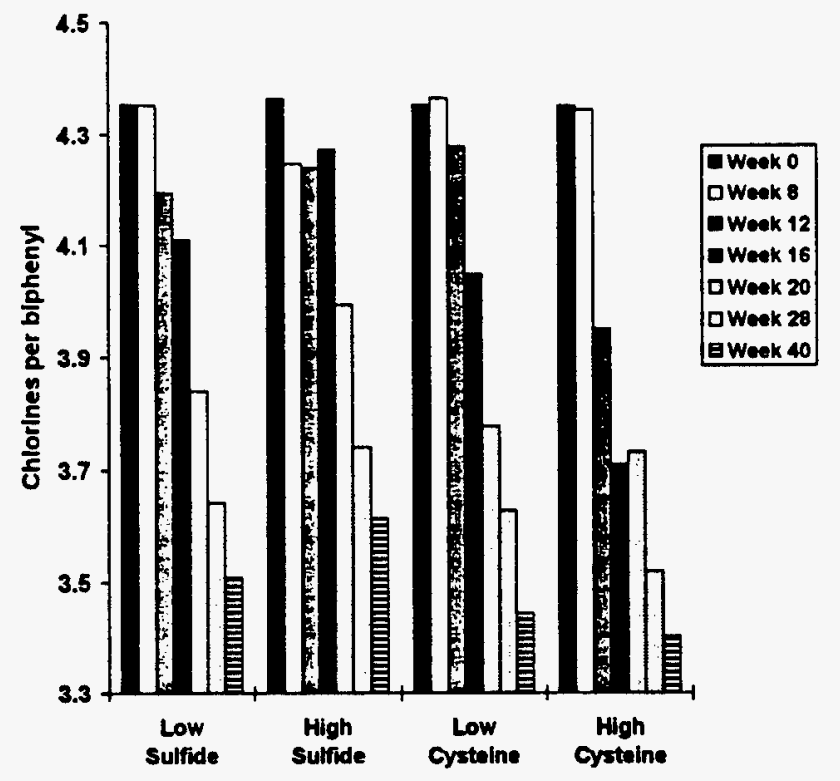

Fig. 15. Average PCB chlorine content during incubation of soils inoculated with Hudson River organisms and amended with chemical reducing agents. The low and high levels were 160 and $500 \mathrm{mg} / \mathrm{L}$, respectively, and the medium was amended with complex nutrient mixture and acetone as carbon sources.

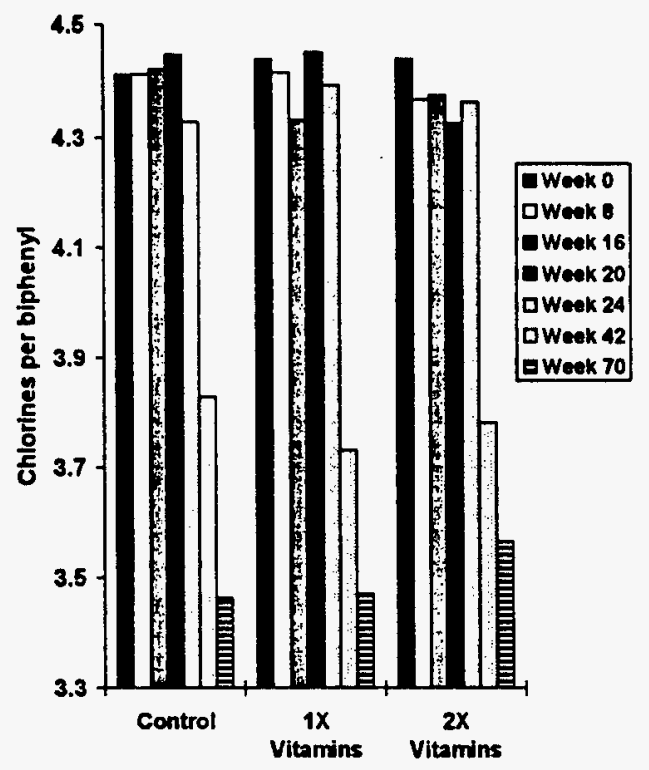

Fig. 16. Average PCB chlorine content in reactors amended with a vitamin solution at two different concentrations. The medium was amended with maleate and acetone as carbon sources. 


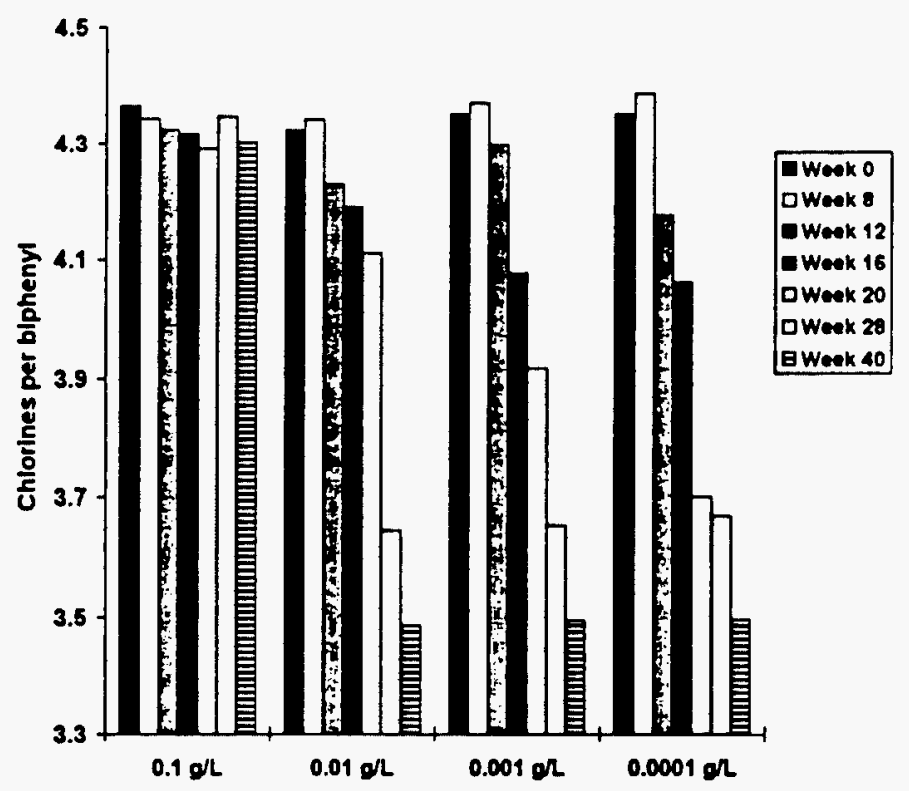

Fig. 17. Average PCB chlorine content in HR-inoculated reactors amended with a surfactant (Witconol) and a complex nutrient mixture and acetone as carbon sources.

\subsubsection{Mixed Waste Studies}

Laboratory studies with PCB-contaminated soil from Waste Area Group 11 at the Oak Ridge site was performed in three 1-L continuously stirred batch reactors and in eight 100-mL stationary reactors. As previously mentioned (Sect. 3.2.4), maleic acid $(1.1 \mathrm{~g} / \mathrm{L}$ ) was used as a carbon source in the smaller reactors; 26-BB, 236-CB, or 246-CB congeners were used as dechlorination inducers; and both inocula from the Hudson River and Woods Pond were tested. The larger reactors contained maleic acid as a carbon source and were inoculated with organisms from Hudson River, Woods Pond, or were left uninoculated.

A typical GC chromatogram taken at start-up is shown in Fig. 18. The PCB Aroclor present in the sample was essentially Aroclor 1254 (compare Fig. 18 with Fig. 3) at approximately 1000 $\mathrm{mg} / \mathrm{kg}$. The three $1-\mathrm{L}$ reactors were sampled monthly and allowed to incubate under anaerobic 
conditions for up 61 weeks. No dechlorination was observed in any of the reactors. This conclusion was drawn by comparing GC chromatograms from samples taken after 61 weeks of incubation with original sample results (compare Figs. 18 and 19). The smaller reactors were incubated for 50 weeks without noticeable dechlorination (data not shown).

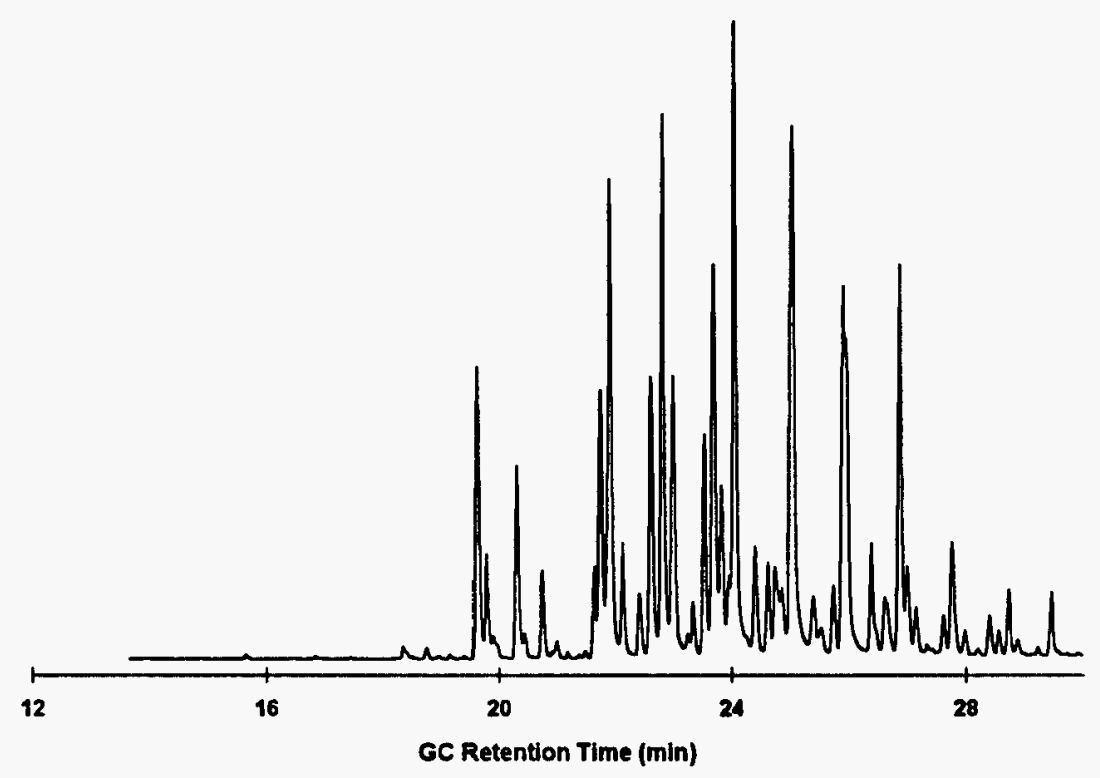

Fig. 18. GC peak profile of sample taken at start-up of reactors with WAG 11 soil. (Aroclor 1254 at $1000 \mathrm{mg} / \mathrm{kg}$ )

\subsubsection{Sequential Anaerobic Aerobic Studies}

The anaerobic incubation period (45 weeks total) of inoculated and uninoculated microcosms was followed by inoculation with Pseudomonas sp. LB400 and aerobic incubation for an additional 19 weeks. The reactors studied contained either pyruvate or the complex carbon source (described in Sect. 3.3.2). In Fig. 20, the GC peak profile is displayed for the sequential treatment and for aerobic treatment alone. Figure 20B shows the peak profile after 19 weeks of anaerobic incubation of an inoculated reactor. Even though the anaerobic reactors were maintained for 45 
weeks, all anaerobic activity was observed during the first 15 to 19 weeks. Results from analyscs during the aerobic incubation indicate a substantial decrease in peak sizes below a 24-min GC retention time and the sizes of peaks occurring after $24 \mathrm{~min}$ remaining the same (sce chromatograms in Figs. 20C and 20D). No evaporation was noted in sterile microcosms conducted in parallel and vented to the atmosphere in a similar fashion (data not shown). The decrease of individual peak sizes during this aerobic phase (Fig. 20C) is similar to that reported by Shannon et al. by a proprietary organism." The decrease in peak sizes in Fig. 20D is similar to that reported by Bedard et al. for Alcaligenes eutrophus H850 (NRRL 15940). ${ }^{43}$ The superior ability of Pseudomonas sp. LB400 to aerobically degrade PCBs in mixtures in the presence of biphenyl has been documented by Bedard et al. ${ }^{44}$

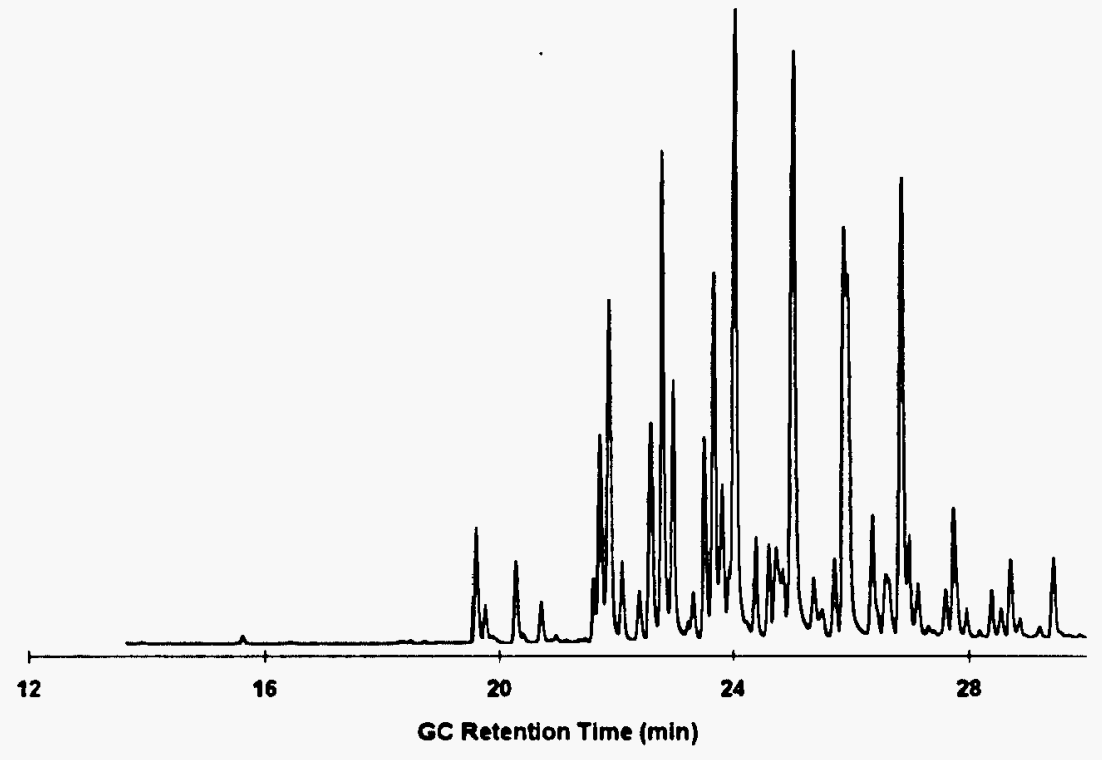

Fig. 19. GC profile in sample taken after 61 weeks of incubation of WAG 11 soil. 


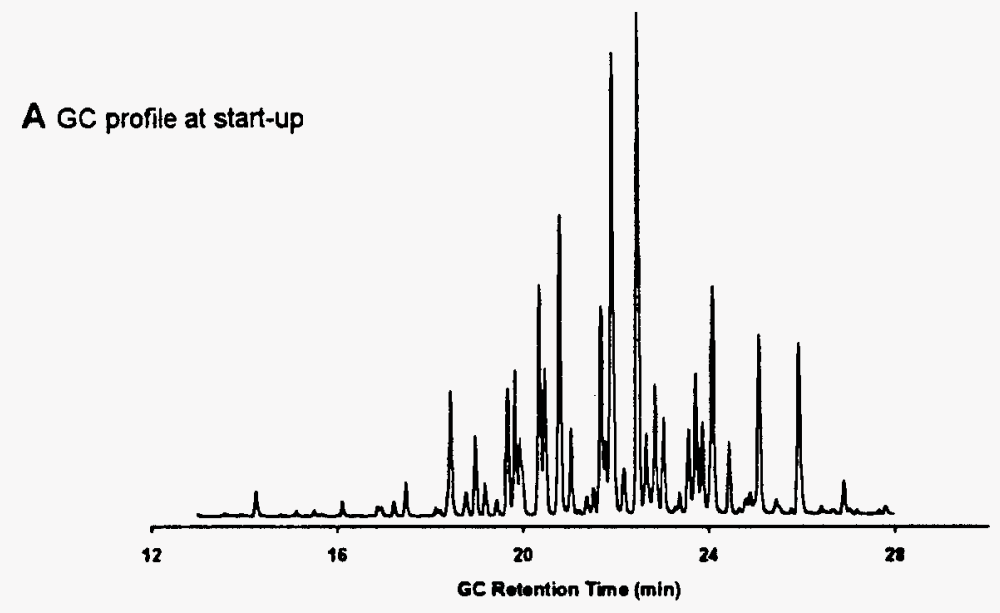

B GC profile after anaerobic incubation period

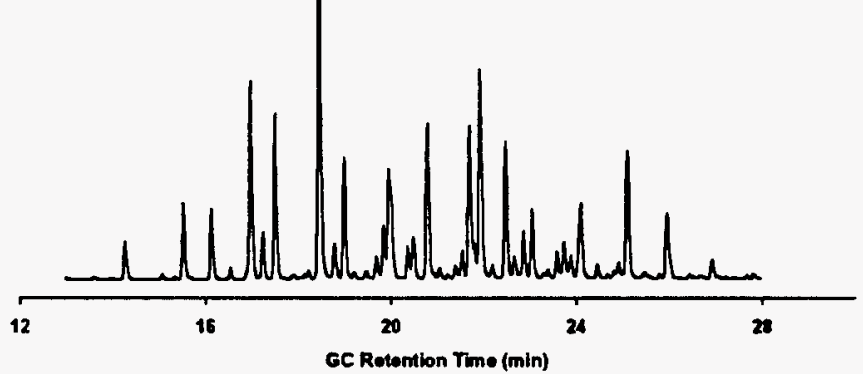

C GC profile after anaerobic and aerobic incubation periods
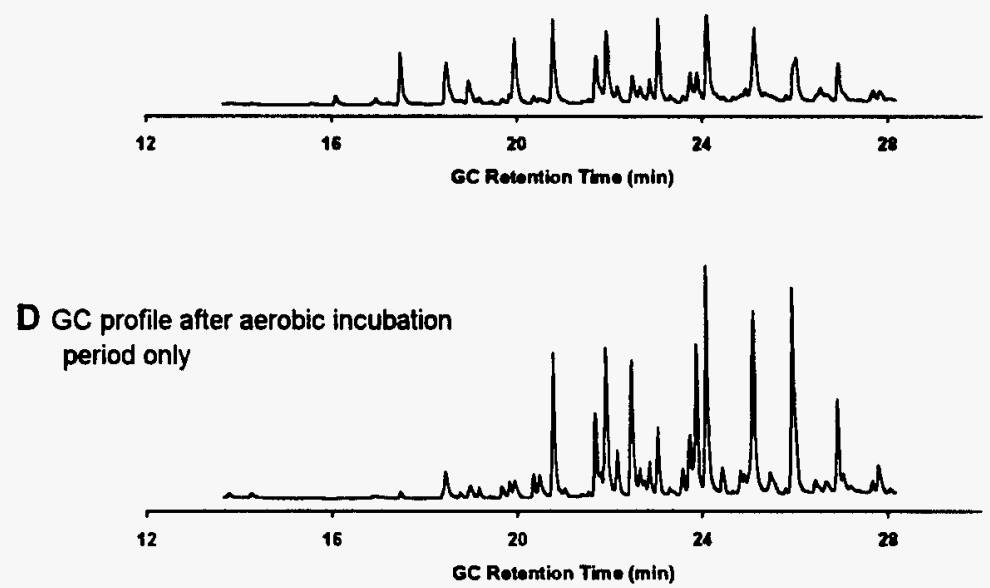

Fig. 20. Anaerobic and aerobic biodegradation of PCBs. 


\subsubsection{Data Quality Assurance}

A total of 110 duplicate samples was collected from various reactors during the study. These samples were subjected to the same sample preparation and analytical procedures as the original samples. The pooled standard deviation ${ }^{45}$ of $\mathrm{PCB}$ concentration and average number chlorines per biphenyl were $11 \mathrm{mg} / \mathrm{kg}$ and 0.02 , respectively. This indicated that sample reproducibility was extremely good.

In addition, an instrument reproducibility test was also performed by duplicate injection of the same sample into the GC of 110 samples. The pooled standard deviation in this case was $4 \mathrm{mg} / \mathrm{kg}$ and 0.02 for the PCB concentration and the average number of chlorines per biphenyl, respectively.

The PCB concentration in the samples subjected to data quality assurance ranged from 14 to $1300 \mathrm{mg} / \mathrm{kg}$, and the average number of chlorines per biphenyl ranged from 3 to 4.6 .

\subsection{DISCUSSIONS}

The collected soil did not contain indigenous bacteria capable of dechlorinating weathered or freshly added PCBs under the conditions of these experiments. Activity was only observed when organisms from a known "active" site (Hudson River or Woods Pond) were added to the reactors. Only a few variables were consistently found to inhibit dechlorination in the systems studied. These were addition of 26-BB and Witconol SN70 (a surfactant) at $0.1 \mathrm{~g} / \mathrm{L}$. To some extent, sodium sulfide at $500 \mathrm{mg} / \mathrm{L}$, elevated levels of vitamins, and mild heat treatment at $80^{\circ} \mathrm{C}$ for 45 min were inhibitory to dechlorination. In $1-\mathrm{L}$ bioreactor studies or in studies with Oak Ridge soil, dechlorination was never observed; it is speculated that the continuous agitation caused oxygen to dissolve into the broth and inhibit the anaerobic bacteria. The slight inhibition of dechlorination of PCBs has also been documented in sediment slurry reactors by Abramowicz et al. ${ }^{16}$ 
Dechlorination in all of the active reactors followed a traditional meta dechlorination, which commenced after a lag of as few as 3 weeks to as many as 20 weeks. In all cases, the lowest average chlorine content was 3.5 to 3.6 chlorines per biphenyl. Attempts to prolong or "restart" dechlorination (by addition of extra nutrients or consortium) failed, indicating that the bacterial consortium was limited to dechlorinate only a few very selective chlorine substitution patterns. To illustrate the typical dechlorination pattern, the chromatograms presented in Figs. 1 and 4 have been combined into Fig. 21 . The numbers above the peaks are the assigned ORNL peak numbers. Based on these chromatographic results, Fig. 22 was created. In this figure, the mole percent of the congeners in GC peaks has been plotted in a histogram for the initial sample (Fig. 22A) and the 15-week sample (Fig. 22B). The mole percent change is shown in Fig. 22C where bars have been labeled with the major congener names. The major products of the dechlorination were congeners $24-24,24-26,24-4,26-4,24-2,2-4$, and 2-2. This chlorination pattern is consistent with pattern M described by Brown and observed by Quensen et al., ${ }^{30}$ which is generally associated with meta dechlorination of Aroclor 1242, yielding mostly para- and ortho-substituted congeners. The dechlorination by pattern $M$ of the weathered Aroclor 1248 in our study was not seen in the Quensen study where dechlorination of virgin Aroclor 1248 by Hudson River organisms in river sediment spiked with the Aroclor followed a pattern C (para and meta removal).

In the initial screening studies, single congeners (236-CB and 246-CB) were added as an attempt to induce a particular dechlorination. For example, 236-CB should induce meta dechlorination and 246-CB should induce para dechlorination. It was found that the addition of either of these congeners resulted in meta dechlorination, while the ortho and para chlorine numbers remained essentially the same (see Fig. 23). The addition of 26-BB, which was added as a general dechlorination inducer (as determined by GE), inhibited dechlorination as previously described. 

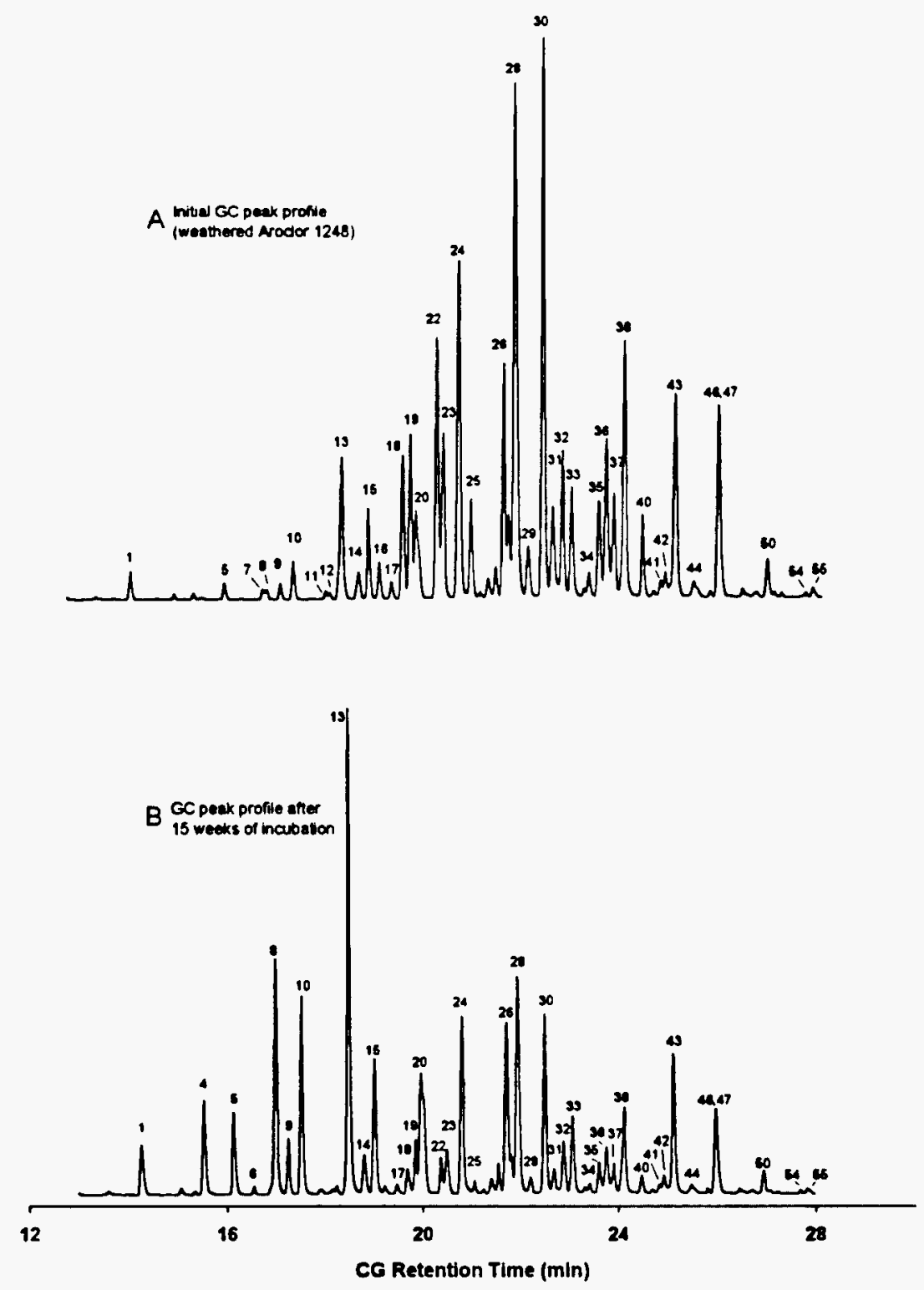

Fig. 21. Changes in GC profile during anaerobic incubation. (Data shown for incubation with pyruvic acid and Hudson River sediment organisms.) 

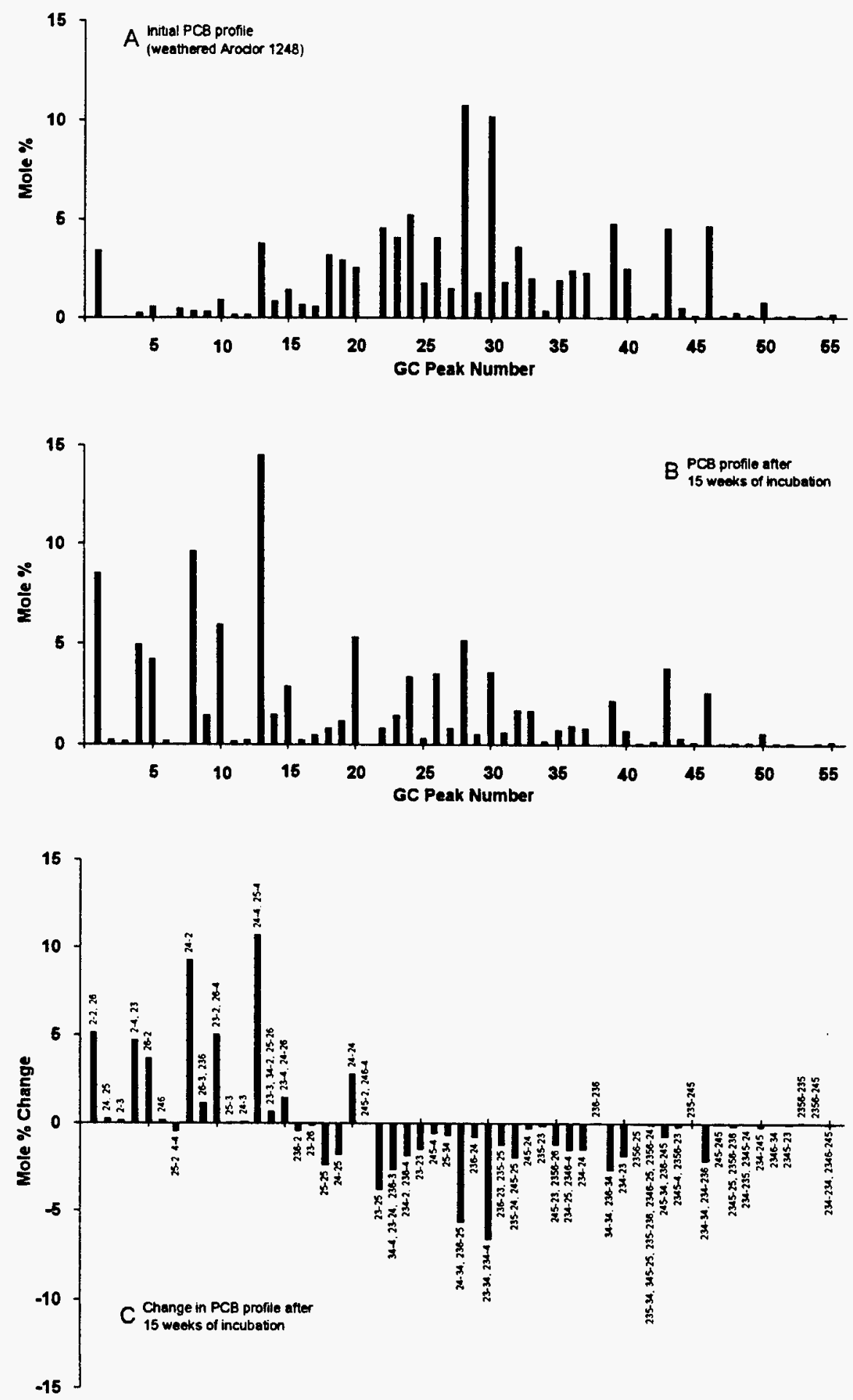

Fig. 22. PCB concentration profiles taken from a reactor inoculated with Hudson River sediment organisms and amended with pyruvate. (Peak labels in $22 \mathrm{C}$ indicate the congeners present in the peak.) 


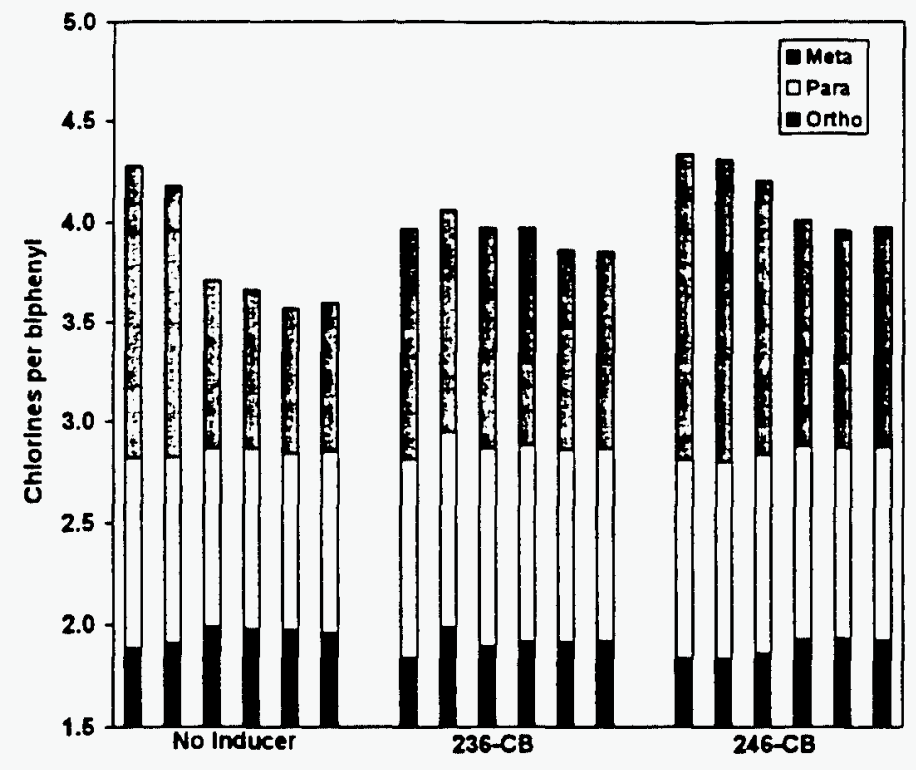

Fig. 23. Change over time in number of PCB chlorines for reactors with different inducers. (Data presented over a 19-week period.)

The dechlorination pattern $M$ was not significantly affected by the type of inoculum. This may be noted in Fig. 24, where results from two reactors under identical environmental conditions but for the inoculum source are presented. As is noted, the two graphs are very similar, indicating that a comparable dechlorination mechanism was present in both reactors.

The change in homolog composition during representative anaerobic and aerobic fermentations is shown in Fig. 25. A decrease in tetra-, penta-, and hexachlorobiphenyls was accompanied by an increase in di- and trichlorobiphenyls during anaerobic incubation of the microcosm inoculated with organisms eluted from Hudson River sediments. During subsequent aerobic incubation, all dichlorobiphenyls and a large fraction of the tri-, tetra-, and pentachlorobiphenyls were degraded. Overall, a 70\% decrease in total concentration of PCBs was observed for the sequential anaerobic-aerobic fermentation. The aerobic treatment alone proved quite effective in reducing the total PCB concentration by $67 \%$, leaving mainly tetra- and 
pentachlorobiphenyls (Fig. 25). The achieved overall reduction of PCBs in the sequential anaerobic-aerobic treatment compares well with Shannon et al., who noted an $81 \%$ reduction of PCBs in a contaminated soil $(1240 \mathrm{mg} / \mathrm{kg}$ Aroclor 1248$){ }^{11}$ The greater degradation noted by Shannon et al. may be attributed to the lack of easily degraded trichlorobiphenyls ${ }^{43,44}$ not originally present in weathered soil used in our studies. The results in the current study represent an improvement over the sequential treatment results presented by Anid et al., who observed an approximately $40 \%$ reduction of $300 \mathrm{mg} / \mathrm{kg}$ (spiked) Aroclor 1242 in Hudson River sediments. ${ }^{46}$ The improvement noted in the current study is attributed to limited capability of the aerobic isolate (S3) used in the Anid study to degrade trichlorobiphenyls.

The near congener-specific analysis also allowed for calculation of PCB half-life in humans during the incubations based on published data. ${ }^{35}$ Initially, over $50 \%$ of the PCB congeners had a half-life between 0.1 and 1 year in humans (Fig. 26). After anaerobic incubation, redistribution of congeners resulted in an increase in PCB congeners with a half-life shorter than 0.1 year. This was accompanied by a decrease in PCB congeners with a slightly longer half-life. Interestingly, the fraction of PCB congeners with a half-life longer than 1 year increased, indicating that some of the generated congeners during anaerobic conditions have a longer half-life than their predecessors.

As is noted in Fig. 26, the aerobic fermentation proved very effective both in conjunction with anaerobic fermentation and by itself. Overall, sequential anaerobic-aerobic fermentation represented a substantial improvement over anaerobic fermentation alone and offered a slight improvement over aerobic fermentation alone when evaluating results based on expected half-life in humans. 

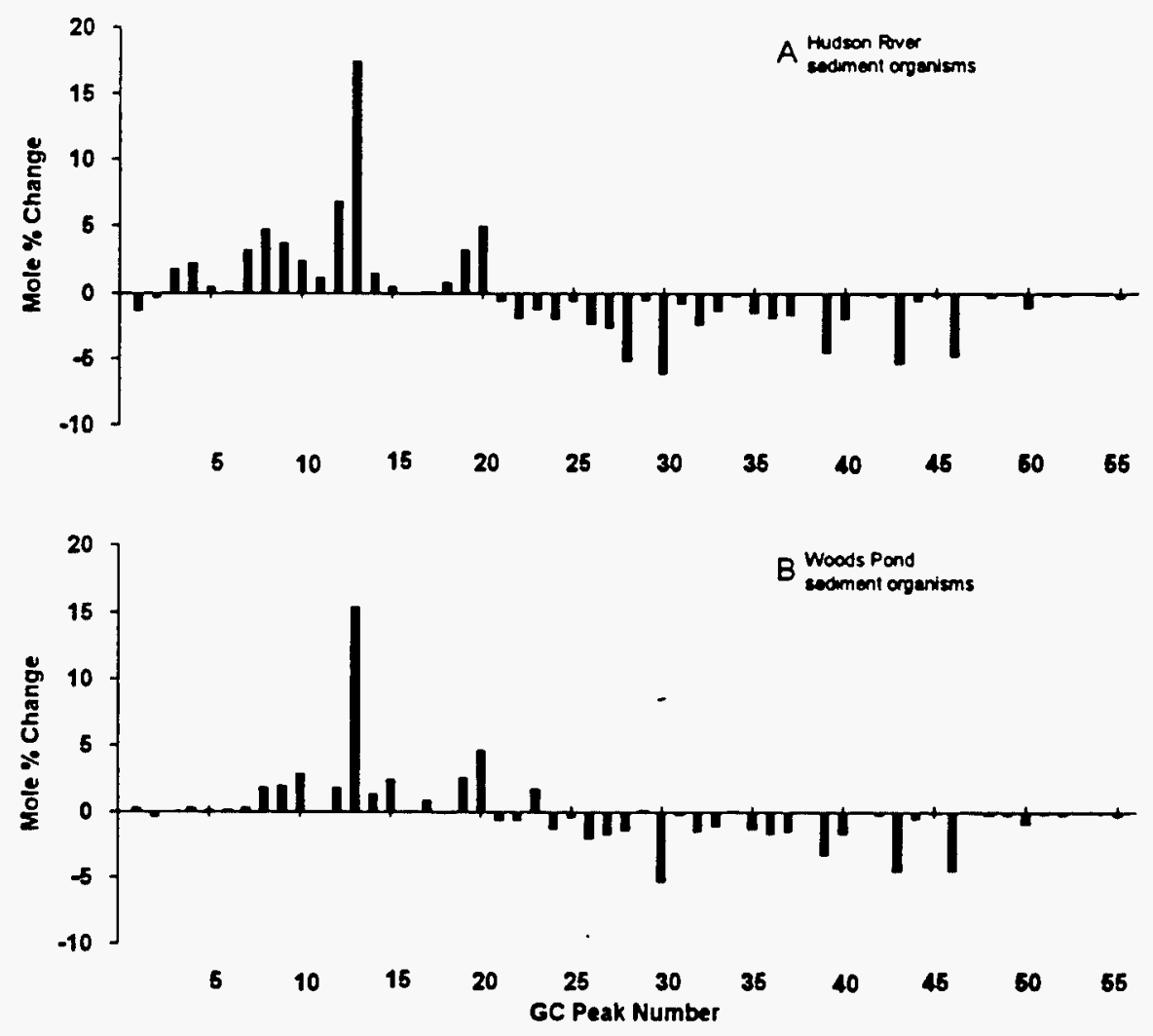

Fig. 24. Mole percent change in reactors inoculated with organisms from different sources. These reactors were amended with a complex nutrient mixture and acetone as carbon sources. 


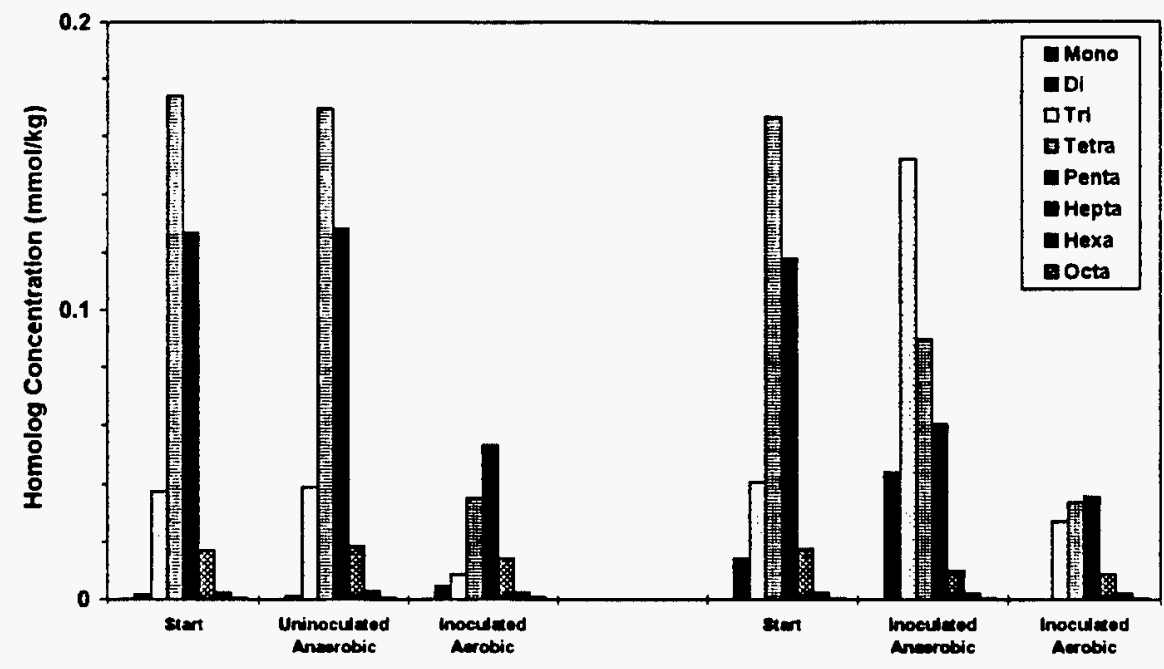

Fig. 25. PCB homolog concentrations in sequential anaerobic-aerobic incubation of contaminated soils. Left set of bars represents an uninoculated anaerobic incubation followed by aerobic incubation with Pseudomonas sp. The right set of bars corresponds to anaerobic incubation with Hudson River sediment organisms followed by aerobic incubation with Pseudomonas sp.

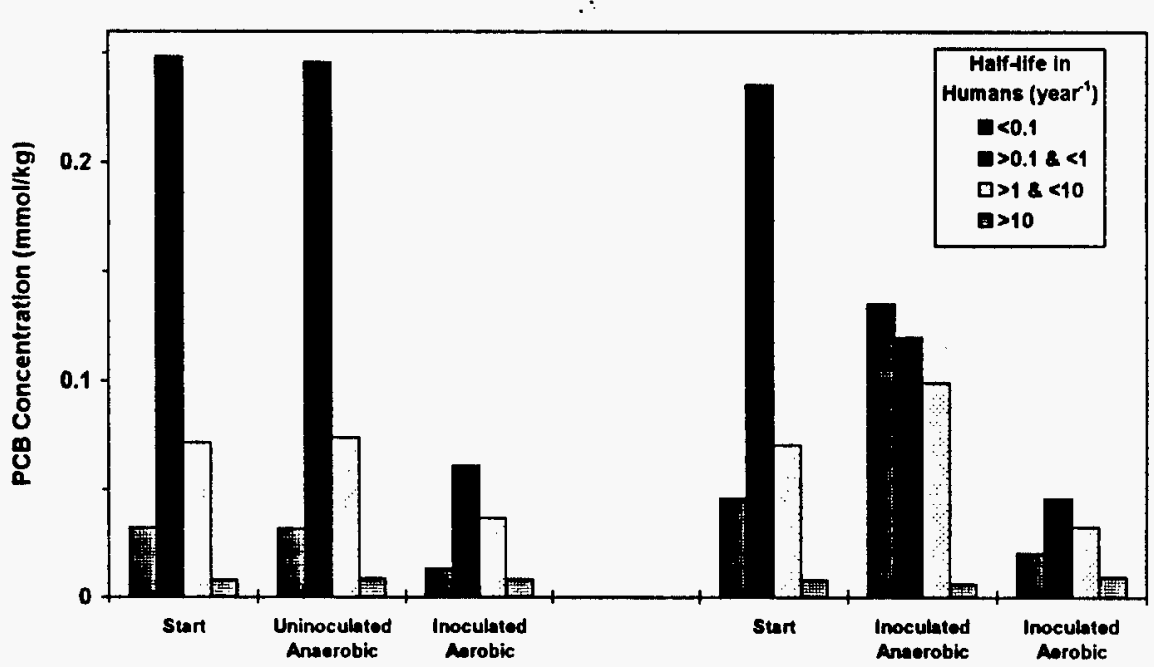

Fig. 26. Estimated PCB concentration with various half-lives in humans and the effect of sequential anaerobic-aerobic treatment. 


\section{INVENTIONS}

No inventions were generated during the work of the CRADA. The generated information has been (or will be) published in the open literature

\section{COMMERCIALIZATION}

The private environmental company Envirogen was co-founded by GE researcher Dr. Ron Unterman, and the company is conducting PCB remediation demonstrations.

\section{FUTURE COLLABORATION}

No future collaborations between GE and ORNL researchers are planned.

\section{CONCLUSIONS}

PCB-dechlorinating organisms were successfully transferred from Hudson River and Woods Pond sediments to a sandy soil contaminated with PCBs. The organisms expressed only meta dechlorinating abilities in the studies. The addition of 236-CB decreased the lag prior to onset of meta dechlorination, but $246-\mathrm{CB}$ did not affect para dechlorination. The most extensive dechlorination of indigenous PCBs was observed in reactors without single congener amendments. The addition of pyruvate, maleate, or a complex carbon source (as supplement to acetone) improved dechlorinating activity. It is not surprising that anaerobic dechlorination occurs naturally in the sediments of lakes and rivers, most of which present a carbon-rich environment to support bacterial growth and metabolism. The data presented herein provide an example of anaerobic dechlorination of PCBs in a sandy soil of very low organic carbon content, without the addition of actual sediment matrix. 
Higher chlorinated biphenyls anaerobically dechlorinated to less chlorinated products were susceptible to aerobic degradation. The total concentration of PCBs decreased by $70 \%$ for sequential anaerobic-aerobic treatment, compared with a $67 \%$ decrease for aerobic treatment alone.

The sequential treatment resulted in PCB products with fewer chlorines and shorter half-lives in humans compared with either anaerobic or aerobic treatment alone.

\section{REFERENCES}

1. M. D. Erickson, Analytical Chemistry of PCBs, Butterworth Publishers, Stoneham, Mass., 1986, p. 34.

2. D. A. Abramowicz, Crit. Rev. Biotechnol. 3 (10), 241-251 (1990).

3. A. W. Boyle, N. White, and H. D. May, "Anaerobic Dechlorination of 2,3,6Trichlorobiphenyl: An Analysis of the Requirement for Humic Acids and a Determination of Suitable Sources of Carbon and Energy," presented at the ASM Conference on Anaerobic Dehalogenation and Its Environmental Implications, Athens (August 1992).

4. L. Niels and T. M. Vogel, Appl. Environ. Microbiol. 56, 2612-2617, (1990).

5. T. G. Linkfield and J. M. Tiedje, J. Ind. Microbiol. 5, 9-16 (1990).

6. W. W. Mohn and J. M. Tiedje, Microbiol. Rev. 5, 482-507 (1992).

7. H. V. Hendriksen, S. Larsen, and B. K. Ahring, Appl. Environ. Microbiol. 58, 365-370 (1992).

8. K. T. Klasson and B. S. Evans, "PCB Dechlorination in Anaerobic Soil Slurry Reactors," pp. 135-145 in Gas, Oil, and Environmental Biotechnology V1, eds. V. Srivastava and J. Smith, Institute of Gas Technology, Des Plaines, III., 1995.

9. A. W. Boyle et al., "Characterization, Growth, and Stimulation of PCB-Dechlorinating Anaerobes," pp. 227-250 in 11th Progress Report on the Research and Development Program for the Destruction of PCB's, General Electric Company Corporate R\&D Center, Schenectady, N.Y., 1992.

10. D. L. Bedard et al., "Bromobiphenyls Stimulate Anaerobic Dechlorination of Aroclor 1260 Contaminant in Sediment Slurries," presented at the 2nd International Symposium for In Situ and On-Site Bioreclamation, San Diego (April 1993).

11. M. J. R. Shannon et al., "Evaluating Polychlorinated Biphenyl Bioremediation Processes: From Laboratory Feasibility Testing to Pilot Demonstration," pp. 354-358 in Bioremediation 
of Chlorinated and Polycyclic Aromatic Hydrocarbons, eds. R. E. Hinchee et al., Lewis Publishers, Boca Raton, Fla., 1994.

12. J. M. Tiedje et al., Biodegradation 4, 231-240 (1993).

13. M Chen et al., Ecotoxicol. Environ. Safety 16, 95-105 (1988).

14. G.-Y. Rhee et al., Wat. Res. 23, 957-964 (1989).

15. J. W. Barton, K. T. Klasson, and M. E. Reeves, "Investigation of Anaerobic Microbial PCB Dechlorination for Field Demonstration," presented at the 17th Symposium on Biotechnology for Fuels and Chemicals, Vail, Colo. (May 1995).

16. D. A. Abramowicz et al., Environ. Sci. Technol. 27, 1125-1131 (1993).

17. K. T. Klasson and B. S. Evans, "PCB Dechlorination in Anaerobic Soil Slurry Reactors," presented at IGT's Sixth International Symposium on Gas Oil, and Environmental Biotechnology, Colorado Springs, Colo. (November 1993).

18. K. T. Klasson et al., "Sequential Anaerobic-Aerobic Degradation of Indigenous PCBs in a Contaminated Soil Matrix," in Gas, Oil, and Environmental Biotechnology VII, eds. V. Srivastava and J. Smith, Institute of Gas Technology, Des Plaines, Ill. (in press, 1996).

19. K. T. Klasson et al., "Reductive Dechlorination of Indigenous PCBs in Soil Using a Sediment-free Inoculum," Biotechnol. Prog. (in press, 1996).

20. B. S. Evans, C. A. Dudley, and K. T. Klasson, "Sequential Anaerobic-Aerobic Biodegradation of PCBs in Soil Slurry Microcosms," Appl. Biochem. Biotechnol. (in press, 1996).

21. K. T. Klasson et al., "Biological Dechlorination of PCBs," presented at the AIChE 1992 Summer National Meeting, Minneapolis (August 1992).

22. K. T. Klasson et al., "Bioremediation of PCB-Contaminated Soils," presented at the Fourth Technology Information Exchange (TIE) Workshop, Knoxville, Tenn. (May 1993).

23. K. T. Klasson, "Biological Dechlorination of PCBs," presented at the Center for Environmental Technology, University of Tennessee, Knoxville, Tenn. (September 1993).

24. K. T. Klasson et al., "Sequential Anaerobic-Aerobic Degradation of Indigenous PCBs in a Contaminated Soil Matrix," presented at IGT's Seventh International Symposium on Gas, Oil, and Environmental Biotechnology, Colorado Springs, Colo. (December 1994).

25. K. T. Klasson et al., "Factors Affecting Reductive Dechlorination of Indigenous PCBs in a Contaminated Soil Matrix," presented at the Third International In Situ and On-Site Bioreclamation Symposium, San Diego (April 1995). 
26. K. T. Klasson, "Sequential Anaerobic-Aerobic Biodegradation of Indigenous PCBs in a Contaminated Soil Matrix," presented at the Department of Chemical Engineering at University of Cincinnati, Cincinnati (March 1995).

27. K. T. Klasson, B. S. Evans, and C. A. Dudley, "Sequential Anaerobic-Aerobic Biodegradation of PCB's in Soil Slurry Reactors," presented at the 17th Symposium on Biotechnology for Fuels and Chemicals, Vail, Colo. (May 1995).

28. K. T. Klasson, "Development of a Prediction Tool for PCB Bioremediation," presented at ACS's Meeting on Emerging Technologies in Hazardous Waste Management VII, Atlanta (September 1995).

29. J. W. Barton, M. E. Reeves, and K. T. Klasson, "Anaerobic and Aerobic Biodegradation of PCBs in Contaminated Soil," presented at ACS's Meeting on Emerging Technologies in Hazardous Waste Management VII, Atlanta (September 1995).

30. J. F. Quensen III, S. A. Boyd, and J. M. Tiedje, Appl. Environ. Microbiol. 56, 1360 (1990).

31. J. K. Williams et al., Surface Radiological Investigations at White Wing Scrap Yard, Oak Ridge Reservation, Oak Ridge Tennessee, ORNL/ER-52, Oak Ridge National Laboratory, Oak Ridge, Tenn., September 1991.

32. M. J. Beck, "Biotransformation of PCBs in Substation Soils," presented at TVA/EPRI PCB Biotransformation Project EPA Review, Washington, D.C. (December 1993).

33. J. F. Brown, Jr., et al., Environ. Toxicol. Chem. 6, 579-593 (1987).

34. D. E. Shultz, G. Petrick, and J. C. Duinker, Environ. Sci. Technol. 23, 852-859 (1989).

35. J. F. Brown, Jr., Environ. Sci. Technol. 28, 2295-2305 (1994).

36 S. H. Safe, Crit. Rev. Toxicol. 24, 87-149 (1994).

37. D. Yee et al., Appl. Environ. Microbiol. 48, 1110-1114 (1992).

38. A. S. Abdul and T. L. Gibson, Environ. Sci. Technol. 25, 665-671 (1991).

39. A. S. Abdul et al., Ground Water 30, 219-231 (1992).

40. B. R. S. Genthner, M. P. Davis, and M. P. Bryant, Appl. Environ. Microbiol. 42, 12-19 (1981).

41. N. Assaf-Anid, L. Nies, and T. M. Vogel, Appl. Environ. Microbiol. 58, 1057-1060 (1992).

42 M. K. Brennan, General Electric Company Corporate Research and Development, Niskayuna, N.Y., personal communication to D. A. Abramowicz, General Electric Company Corporate Research and Development, Niskayuna, N.Y., April 1996. 
43. D. L. Bedard et al., Appl. Environ. Microbiol. 53, 1094-1102 (1987).

44. D. L. Bedard et al., Appl. Environ. Microbiol. 51, 761-768 (1986).

45. J. K. Taylor, Statistical Techniques for Data Analysis, Lewis Publishers, Chelsea, Mich., 1990 , p. 46.

46. P. J. Anid, L. Niels, and T. M. Vogel, "Sequential Anaerobic-Aerobic Biodegradation of PCBs in the River Model," pp. 428-436 in On-Site Bioreclamation: Processes for Xenobiotic and Hydrocarbon Treatment, eds. R. E. Hinchee and R. F. Olfenbuttel, Butterworth-Heinemann, Boston, 1991. 


\section{APPENDIX A}

\section{GAS CHROMATOGRAPHY METHOD FOR PCB ANALYSIS}

AND CALCULATION OF ANALYTICAL RESULTS 
The listing below is the method used for data acquisition and data analysis on a Hewlett-Packard GC. Typically, the method was used in data acquisition mode for analysis overnight and then in a data reprocessing mode the following day.

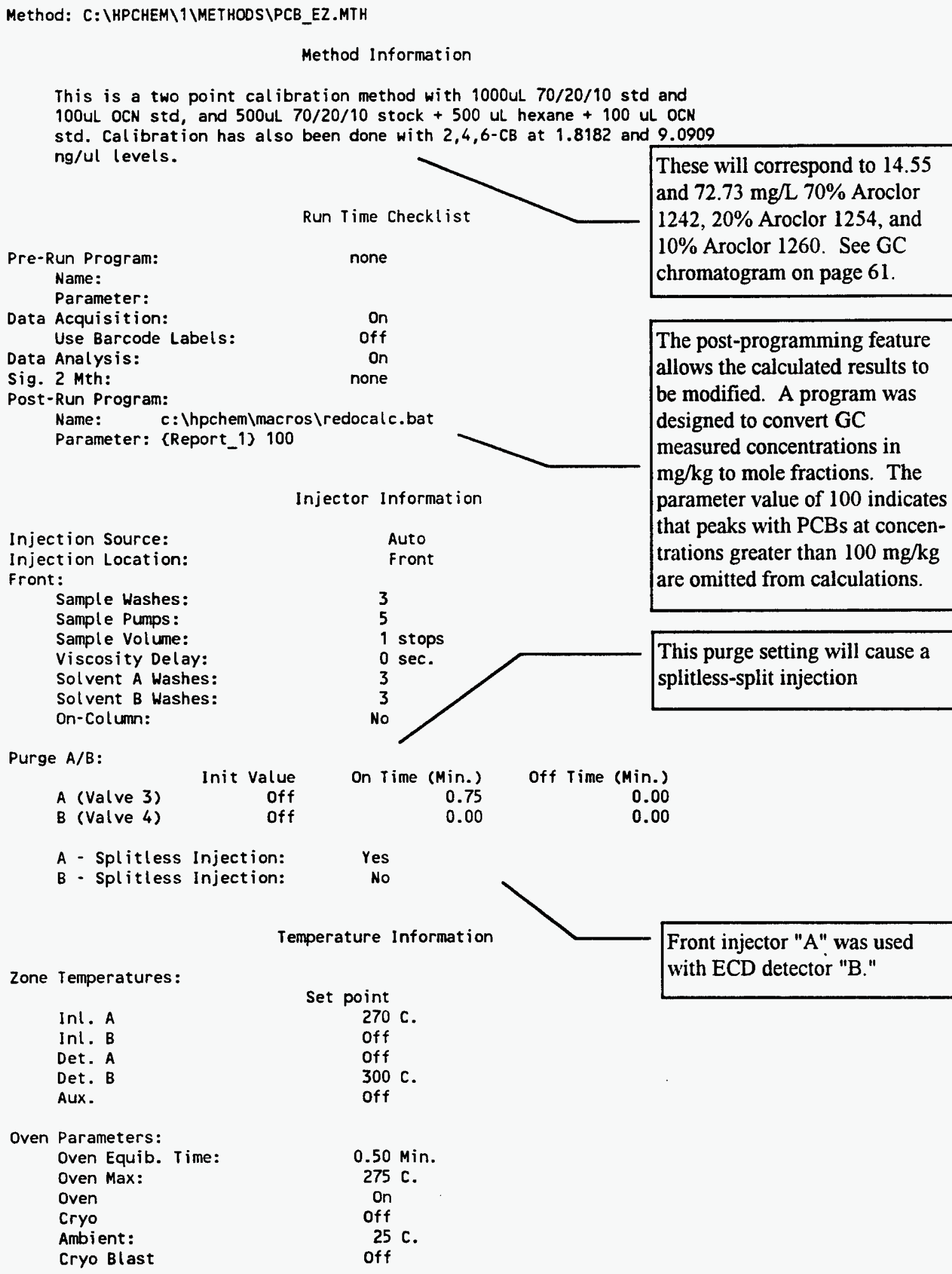

Run Time Checklist

Purge A/B:

Zone Temperatures:

Int. A

Inl. B

Det. A

Det. B

Aux.

$$
\begin{aligned}
& \text { Set point } \\
& 270 \mathrm{C} . \\
& \text { Off } \\
& \text { Off } \\
& 300 \mathrm{C} . \\
& \text { off }
\end{aligned}
$$

Oven Parameters:

Oven Equib. Time: $\quad 0.50 \mathrm{Min}$.

Oven Max:

Oven

Cryo

Ambient:

Cryo Blast

These will correspond to 14.55 and $72.73 \mathrm{mg} / \mathrm{L} 70 \%$ Aroclor 1242, 20\% Aroclor 1254, and $10 \%$ Aroclor 1260 . See GC chromatogram on page 61 .

The post-programming feature allows the calculated results to be modified. A program was designed to convert $\mathrm{GC}$ measured concentrations in $\mathrm{mg} / \mathrm{kg}$ to mole fractions. The parameter value of 100 indicates that peaks with PCBs at concentrations greater than $100 \mathrm{mg} / \mathrm{kg}$ are omitted from calculations.

This purge setting will cause a splitless-split injection

Front injector " $A$ " was used with ECD detector "B." 
Oven Program:

Initial Temp:

Initial Time:

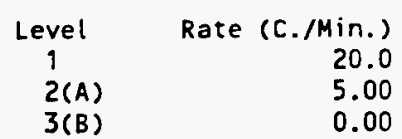

Next Run Time:

5.00

signal Information

Save Data:

Signal 2

Source:

Peak Width:

Data Rate:

Data Storage:

Signal 2

Det. $B$

$0.053 \mathrm{Min}$.

$5.000 \mathrm{~Hz}$.

Al

Detector Information

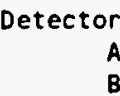

State

off

on

Inlet A Pressure Program Information

Constant Flow:

Pressure:

Temperature:
On

$11.6 \mathrm{psi}$

$40 \mathrm{C}$

GC Pressure Units: psi

Fixed Values:

Column Length $(\mathrm{m}): \quad 30.00$

Column Diameter $(\mathrm{mm}): 0.250$

Gas:

$\mathrm{He}$

Vacuum Comp:

off

\section{Auxiliary Channel E}

Comment :

Pressure Program:

Initial Pres.:

Initial Time:
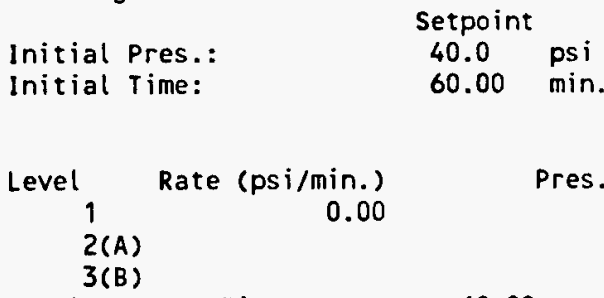

(psi)

Final

Time (min)

60.00

Cal ibration Parameters:

$\begin{array}{rrr} & \text { Pres. } & \text { Flow } \\ & \text { (psi) } & (\mathrm{ml} / \mathrm{min}) \\ 1 & 25.0 & 1.0\end{array}$

Last Aux. pressure calibration: 07 Oct $94 \quad$ 10:48 AM 


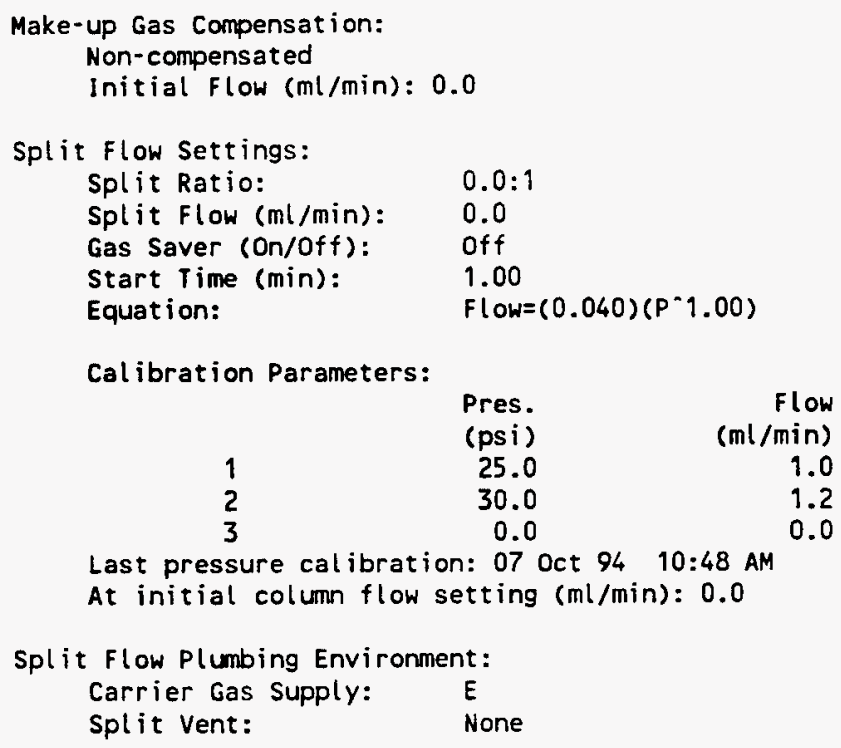

Signal Plot Information

Signal Attn. (2*) offset (\%) Time (Min.)

$\begin{array}{llll}1 & 1 & 10 & 5\end{array}$

$\begin{array}{llll}2 & 4 & 10 & 50\end{array}$

Integration Events

Events:

Initial Area Reject

Initial Peak Width

Shoulder Detection

Initial Threshold

Area Reject

Peak Width

Peak Width

Peak Width

Peak Width

Peak Width

Peak Width
Value: Time:

999999999 INITIAL

0.030 INITIAL

OFF INITIAL

-1 INITIAL

$500 \quad 10.000$

$0.100 \quad 17.000$

$0.050 \quad 17.400$

$0.150 \quad 23.000$

$0.050 \quad 23.200$

$0.150 \quad 24.500$

$0.050 \quad 25.137$
These events are updated with calibration to ensure detection of all calibrated peaks

Report Specification

Destination:

Based on:

Calculations:

Printer Output: Chromatogram: Full Report Header: None Area
Report/Chromatogram to Printer Report to File: Auto naming selected

Graphics Options

Title:

Include:

Axes Units:

Peak Names:

Retention Times:

Basel ines:

Tick Marks:

Peak Labels Font:

Vertical

on

On

On

On

Off 
Calibration Table

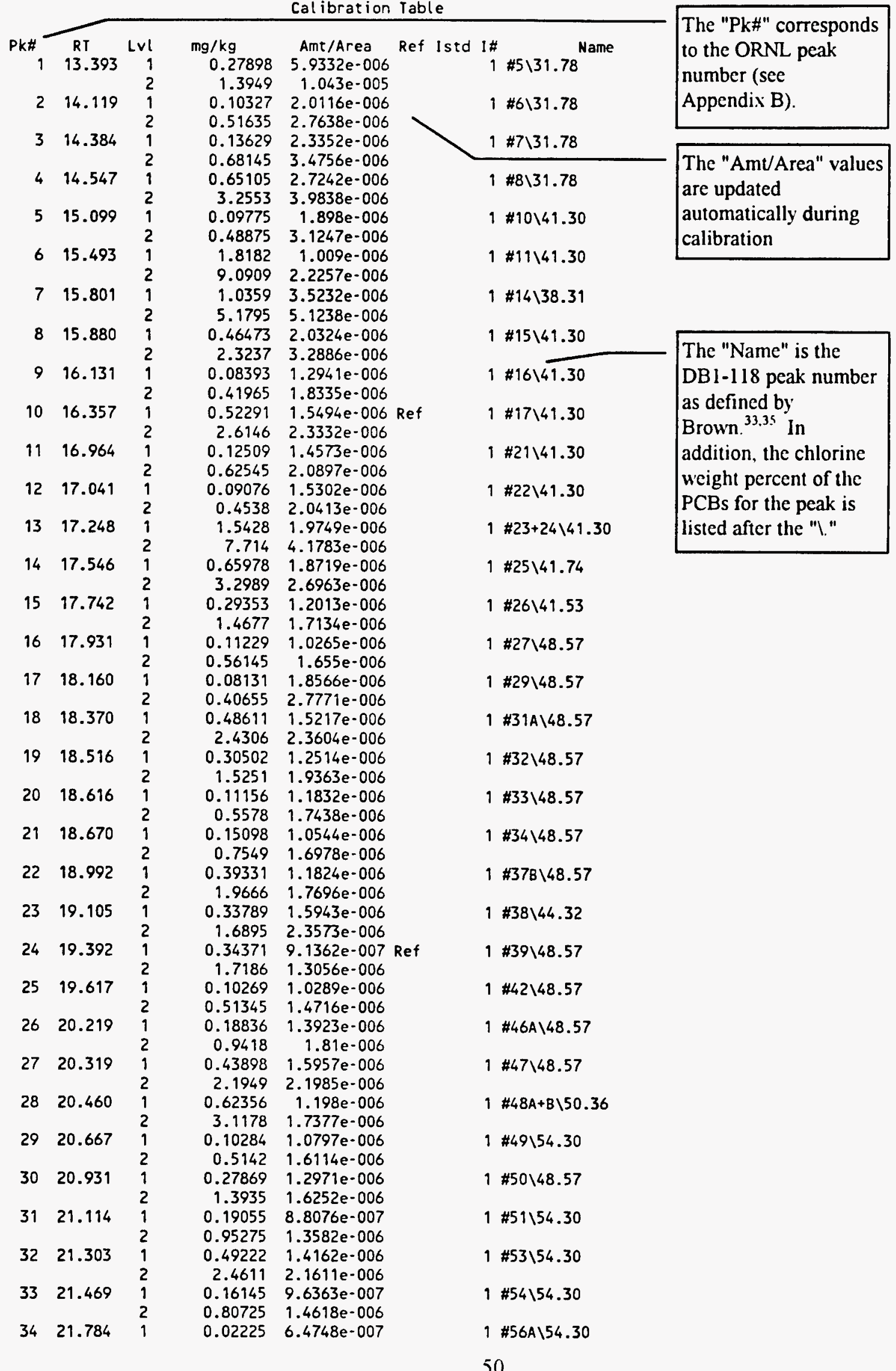




\begin{tabular}{|c|c|c|c|c|c|}
\hline & & 2 & 0.11125 & $8.2224 \mathrm{e}-007$ & \\
\hline 35 & 21.957 & $\begin{array}{l}1 \\
2\end{array}$ & $\begin{array}{r}0.13644 \\
0.6822\end{array}$ & $\begin{array}{l}1.0177 \mathrm{e}-006 \\
1.4642 \mathrm{e}-006\end{array}$ & $1 \# 57 A \backslash 54.30$ \\
\hline 36 & 22.099 & $\begin{array}{l}1 \\
2\end{array}$ & $\begin{array}{r}0.20495 \\
1.0248\end{array}$ & $\begin{array}{l}7.8308 e-007 \\
1.0871 e-006\end{array}$ & $1 \# 58 A+B \backslash 54.30$ \\
\hline 37 & 22.231 & $\begin{array}{l}1 \\
2\end{array}$ & $\begin{array}{r}0.11098 \\
0.5549\end{array}$ & $\begin{array}{l}1.0942 e-006 \\
1.3712 e-006\end{array}$ & $1 \# 59 \backslash 54.30$ \\
\hline 38 & 22.332 & $\begin{array}{l}1 \\
2\end{array}$ & $\begin{array}{l}0.02225 \\
0.11125\end{array}$ & $\begin{array}{l}3.0725 e-007 \\
4.9001 e-007\end{array}$ & $1 \# 60 \backslash 58.95$ \\
\hline 39 & 22.430 & $\begin{array}{l}1 \\
2\end{array}$ & $\begin{array}{r}0.38458 \\
1.9229\end{array}$ & $\begin{array}{r}9.5867 e-007 \\
1.329 e-006\end{array}$ & $1 \# 61 \backslash 53.96$ \\
\hline 40 & 22.748 & $\begin{array}{l}1 \\
2\end{array}$ & $\begin{array}{r}0.0992 \\
0.496\end{array}$ & $\begin{array}{l}1.3182 \mathrm{e}-006 \\
1.6809 \mathrm{e}-006\end{array}$ & $1 \# 63 \backslash 54.30$ \\
\hline 41 & 22.962 & $\begin{array}{l}1 \\
2\end{array}$ & $\begin{array}{l}0.07113 \\
0.35565\end{array}$ & $\begin{array}{l}5.6977 e-007 \\
8.3891 e-007\end{array}$ & $1 \# 64 \backslash 58.95$ \\
\hline 42 & 23.078 & $\begin{array}{l}1 \\
2\end{array}$ & $\begin{array}{l}0.09193 \\
0.45965\end{array}$ & $\begin{array}{r}6.3094 e-007 \\
8.242 e-007\end{array}$ & $1 \# 65+66+67+68 \backslash 57.34$ \\
\hline 43 & 23.331 & $\begin{array}{l}1 \\
2\end{array}$ & $\begin{array}{r}0.53484 \\
2.6742\end{array}$ & $\begin{array}{l}1.1289 e-006 \\
1.6199 e-006\end{array}$ & $1 \# 69 \backslash 56.52$ \\
\hline 44 & 23.655 & $\begin{array}{l}1 \\
2\end{array}$ & $\begin{array}{r}0.032 \\
0.16\end{array}$ & $\begin{array}{r}6.9251 e-007 \\
8.348 e-007\end{array}$ & $1 \# 71 \backslash 57.69$ \\
\hline 45 & 23.999 & $\begin{array}{l}1 \\
2\end{array}$ & $\begin{array}{l}0.04029 \\
0.20145\end{array}$ & $\begin{array}{l}6.8007 e-007 \\
8.8317 e-007\end{array}$ & $1 \# 73 \backslash 58.95$ \\
\hline 46 & 24.129 & $\begin{array}{l}1 \\
2\end{array}$ & $\begin{array}{r}0.23142 \\
1.1571\end{array}$ & $\begin{array}{l}1.2006 e-006 \\
1.4334 e-006\end{array}$ & $1 \# 74 \backslash 56.94$ \\
\hline 47 & 24.204 & $\begin{array}{l}1 \\
2\end{array}$ & $\begin{array}{r}0.34138 \\
1.7069\end{array}$ & $\begin{array}{l}9.6343 e-007 \\
1.4841 e-006\end{array}$ & $1 \# 75 \backslash 58.95$ \\
\hline 48 & 24.586 & $\begin{array}{l}1 \\
2\end{array}$ & $\begin{array}{l}0.0957 \\
0.4785\end{array}$ & $\begin{array}{l}4.8974 e-007 \\
6.5511 e-007\end{array}$ & $1 \# 77+78 \backslash 60.16$ \\
\hline 49 & 24.835 & $\begin{array}{l}1 \\
2\end{array}$ & $\begin{array}{l}0.04305 \\
0.21525\end{array}$ & $\begin{array}{r}5.414 e-007 \\
6.1859 e-007\end{array}$ & $1 \# 79+80 \backslash 58.95$ \\
\hline 50 & 25.023 & $\begin{array}{l}1 \\
2\end{array}$ & $\begin{array}{r}0.33484 \\
1.6742\end{array}$ & $\begin{array}{l}8.5748 \mathrm{e}-007 \\
1.1385 e-006\end{array}$ & $1 \# 82 \backslash 58.95$ \\
\hline 51 & 25.143 & $\begin{array}{l}1 \\
2\end{array}$ & $\begin{array}{l}0.03025 \\
0.15125\end{array}$ & $\begin{array}{r}4.2664 \mathrm{e}-007 \\
5.051 \mathrm{e}-007\end{array}$ & $1 \# 83 \backslash 58.95$ \\
\hline 52 & 25.278 & $\begin{array}{l}1 \\
2\end{array}$ & $\begin{array}{l}0.02065 \\
0.10325\end{array}$ & $\begin{array}{l}5.7817 e-007 \\
6.8128 e-007\end{array}$ & $1 \# 84 \backslash 58.95$ \\
\hline 53 & 25.458 & $\begin{array}{l}1 \\
2\end{array}$ & $\begin{array}{l}0.01309 \\
0.06545\end{array}$ & $\begin{array}{l}3.5515 e-007 \\
4.4307 e-007\end{array}$ & $1 \# 85 \backslash 62.78$ \\
\hline 54 & 25.717 & $\begin{array}{l}1 \\
2\end{array}$ & $\begin{array}{l}0.09367 \\
0.46835\end{array}$ & $\begin{array}{r}6.392 \mathrm{e}-007 \\
9.0488 \mathrm{e}-007\end{array}$ & $1 \# 88 \backslash 62.78$ \\
\hline 55 & 25.824 & $\begin{array}{l}1 \\
2\end{array}$ & $\begin{array}{l}0.04029 \\
0.20145\end{array}$ & $\begin{array}{l}8.0056 e-007 \\
7.0317 e-007\end{array}$ & $1 \# 89 \backslash 58.95$ \\
\hline 56 & 25.890 & $\begin{array}{l}1 \\
2\end{array}$ & $\begin{array}{r}0.04505 \\
0.2255\end{array}$ & $\begin{array}{l}4.0954 e-007 \\
5.9611 e-007\end{array}$ & $1 \# 90 \backslash 62.78$ \\
\hline 57 & 26.052 & $\begin{array}{l}1 \\
2\end{array}$ & $\begin{array}{r}0.01876 \\
0.0938\end{array}$ & $\begin{array}{l}1.4104 e-006 \\
1.3984 e-006\end{array}$ & $1 \# 91158.95$ \\
\hline 58 & 26.235 & $\begin{array}{l}1 \\
2\end{array}$ & $\begin{array}{l}0.01047 \\
0.05235\end{array}$ & $\begin{array}{l}4.2294 \mathrm{e}-007 \\
4.4668 \mathrm{e}-007\end{array}$ & $1 \# 92 \backslash 62.78$ \\
\hline 59 & 26.420 & $\begin{array}{l}1 \\
2\end{array}$ & $\begin{array}{l}0.08553 \\
0.42765\end{array}$ & $\begin{array}{l}5.8903 e-007 \\
7.8781 e-007\end{array}$ & $1 \# 93 \backslash 62.78$ \\
\hline 60 & 26.564 & $\begin{array}{l}1 \\
2\end{array}$ & $\begin{array}{l}0.05367 \\
0.26835\end{array}$ & $\begin{array}{l}6.8299 e-007 \\
8.8498 e-007\end{array}$ & $1 \# 94 \backslash 62.78$ \\
\hline 61 & 26.719 & $\begin{array}{l}1 \\
2\end{array}$ & $\begin{array}{r}0.05222 \\
0.2611\end{array}$ & $\begin{array}{r}9.542 e-007 \\
9.06 e-007\end{array}$ & $1 \# 95 \backslash 60.15$ \\
\hline 62 & 26.824 & $\begin{array}{l}1 \\
2\end{array}$ & $\begin{array}{l}0.02415 \\
0.12075\end{array}$ & $\begin{array}{l}1.2133 \mathrm{e}-006 \\
1.4564 \mathrm{e}-006\end{array}$ & $1 \# 99 \backslash 66.00$ \\
\hline 63 & 27.178 & $\begin{array}{l}1 \\
2\end{array}$ & $\begin{array}{l}0.03055 \\
0.15275\end{array}$ & $\begin{array}{l}1.4956 e-006 \\
1.4675 e-006\end{array}$ & $1 \# 100 \backslash 62.78$ \\
\hline 64 & 27.388 & $\begin{array}{l}1 \\
2\end{array}$ & $\begin{array}{l}0.18313 \\
0.91565\end{array}$ & $\begin{array}{l}7.3569 \mathrm{e}-007 \\
9.5298 \mathrm{e}-007\end{array}$ & $1 \# 102 \backslash 62.78$ \\
\hline 65 & 28.236 & $\begin{array}{l}1 \\
2\end{array}$ & $\begin{array}{r}0.0736 \\
0.368\end{array}$ & $\begin{array}{l}9.3304 e-007 \\
9.2156 e-007\end{array}$ & $1 \# 106 \backslash 62.78$ \\
\hline 66 & 28.346 & $\begin{array}{l}1 \\
2\end{array}$ & $\begin{array}{l}0.01367 \\
0.06835\end{array}$ & $\begin{array}{l}5.2734 e-007 \\
5.3137 e-007\end{array}$ & $1 \# 107 \backslash 62.78$ \\
\hline 67 & 28.618 & $\begin{array}{l}1 \\
2\end{array}$ & $\begin{array}{l}0.0 \\
0.0\end{array}$ & $\begin{array}{l}0.0 \\
0.0\end{array}$ & 1 REF $\backslash 00.00$ \\
\hline 68 & 28.689 & $\begin{array}{l}1 \\
2\end{array}$ & $\begin{array}{r}0.0 \\
0.0\end{array}$ & $\begin{array}{r}0.0 \\
0.0\end{array}$ & $1 \# 109 \backslash 00.00$ \\
\hline 69 & 28.875 & $\begin{array}{l}1 \\
2\end{array}$ & $\begin{array}{r}0.0304 \\
0.152\end{array}$ & $\begin{array}{l}4.1567 e-007 \\
4.7481 e-007\end{array}$ & 1 \#110\66.00 \\
\hline
\end{tabular}




$\begin{array}{rrrrrr}70 & 29.733 & 1 & 0.01222 & 6.6122 \mathrm{e}-007 & 1 \# 112166.00 \\ 71 & 30.455 & 2 & 0.0611 & 6.4533 \mathrm{e}-007 & \\ & & 0.024 & 7.1347 \mathrm{e}-007 & 1 \# 115 \backslash 66.00 \\ 72 & 31.898 & 2 & 1 & 0.72727 & 6.5813 \mathrm{e}-007 \\ & & 2 & 0.72727 & 4.697 \mathrm{e}-006 \text { Ref ISTD } & 1 \text { OCN } 100.00\end{array}$

Calibration Settings

Title:

CALIBRATION FOR 70/20/10 STD WITH OCN AS I.S.

Reference window:

Non-reference window:

Units of amount:

Multiplier:

RF uncal peaks:

ISTD\# to adjust uncal peaks:

Sample Amount:

$$
\begin{aligned}
& 1.000 \% \\
& 0.600 \% \\
& \mathrm{mg} / \mathrm{kg} \\
& 1.0 \\
& 0.0 \\
& 0 \\
& 0.0
\end{aligned}
$$

Sample ISTD Information

Multilevel Information

Fit: Piecewise

Origin: Force

The above method generated the following typical report when printed, which represented the analytical results of the sample injected. The calculated concentrations listed are the concentrations in the hexanc mixture. For recalculation to concentrations in the extracted soil, see below.

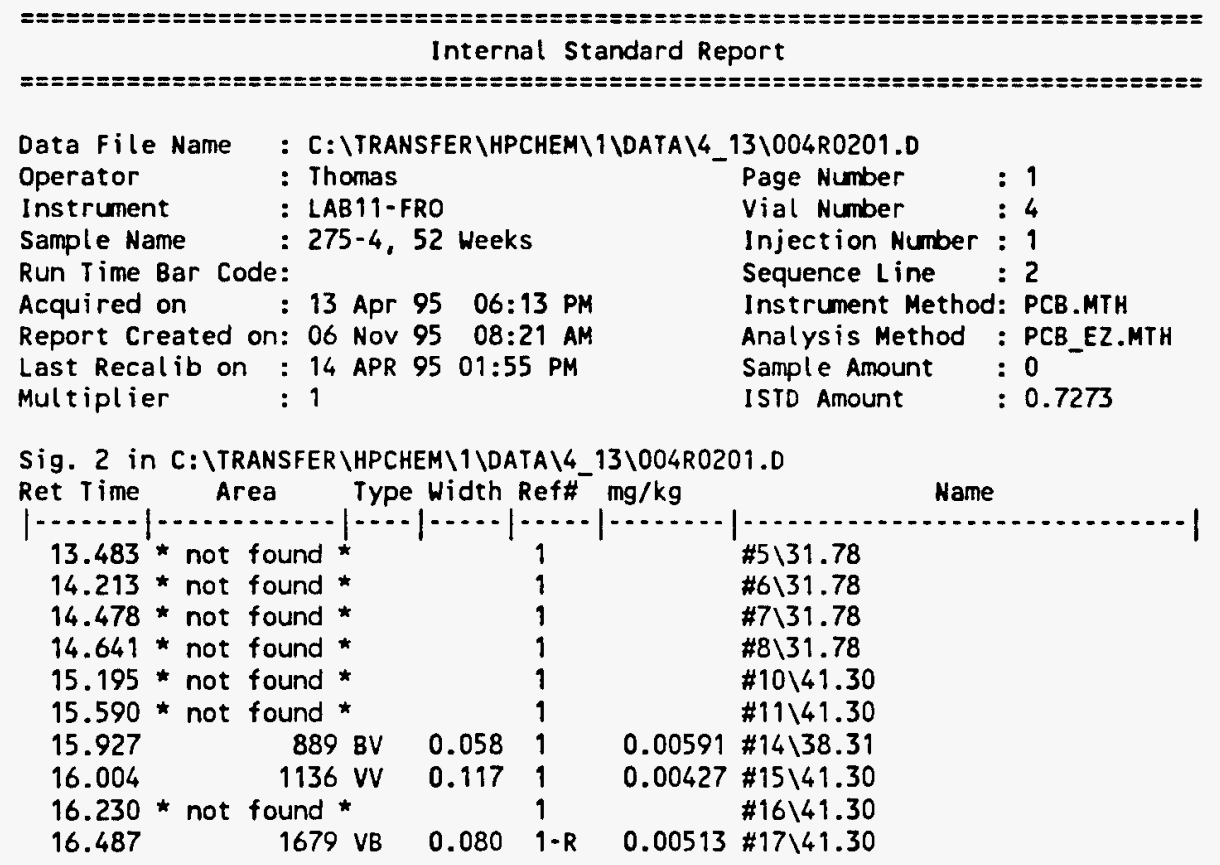




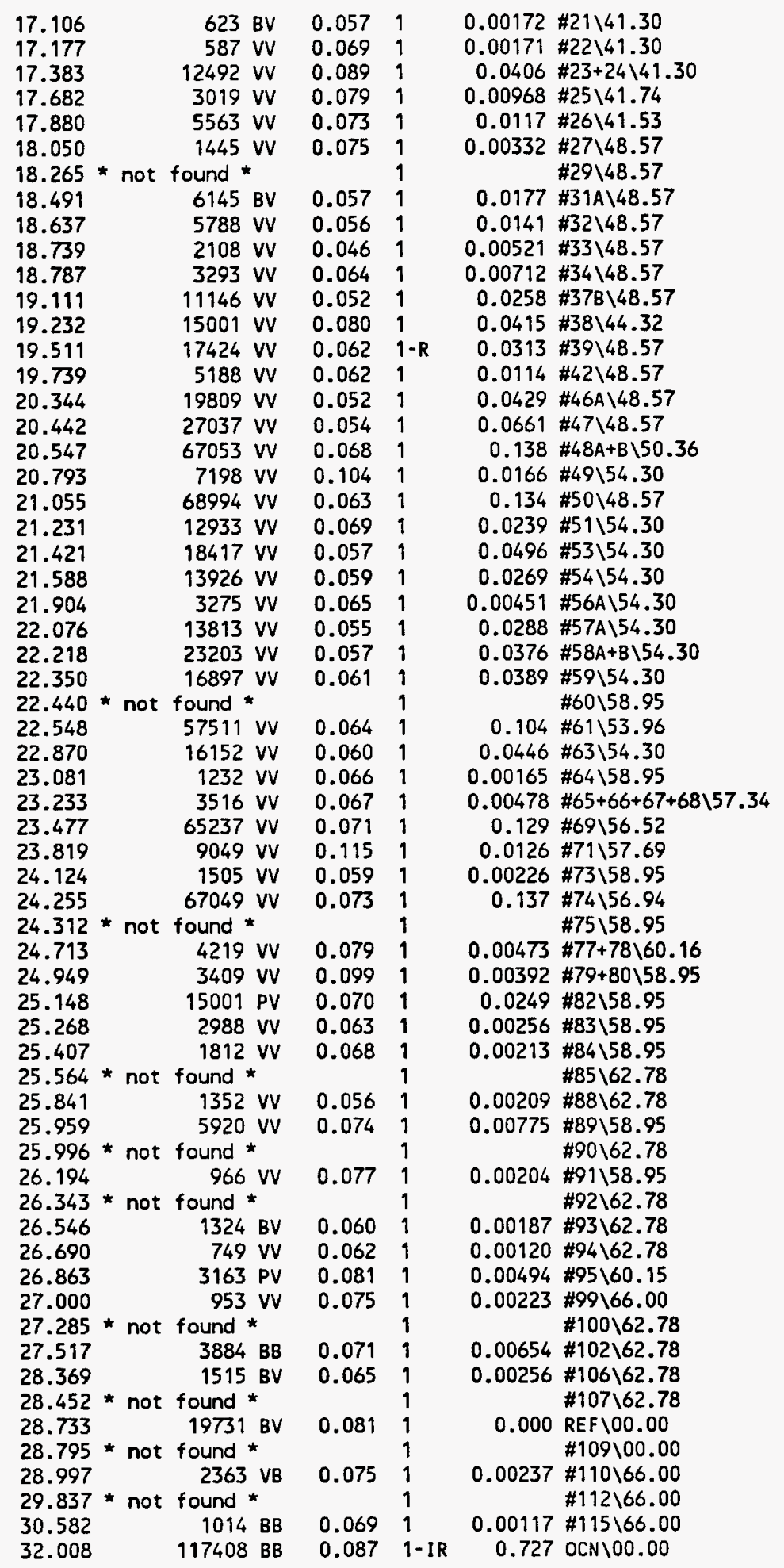

$\begin{array}{ccrr}\text { Time Reference Peak } & \text { Expected RT } & \text { Actual RT } & \text { Difference } \\ 10 & 16.457 & 16.487 & 0.2 \% \\ 24 & 19.497 & 19.511 & 0.1 \% \\ 72 & 32.006 & 32.008 & 0.0 \%\end{array}$

Calibration table contains at least one peak with amt $=0$ 
The above report is actually never printed. Instead, the post-programming feature in the GC method above intercepts the report before printing and invokes the following short batch file. The batch file (REDOCALC.BAT) accepts two inputs (\%l and \%2); "\%1" is the file name of the report file printed, and "\%2" is a maximum PCB concentration accepted for calculation (typically $100 \mathrm{mg} / \mathrm{kg}$ ).

ECHO ON

CD 1

C: \HPCHEM \MACROSIRECALC $\% 9 \% 2$

ECHO OFF

This short batch file in return uses the following program written in BASIC and compiled to reformat the typical report (see above) to a friendlier report. The program (RECALC.EXE) uses the chlorine weight percent (part of peak names) to recalculate the PCB concentrations to mole percent and also summarizes the results by calculating total PCB concentration and average chlorine content.

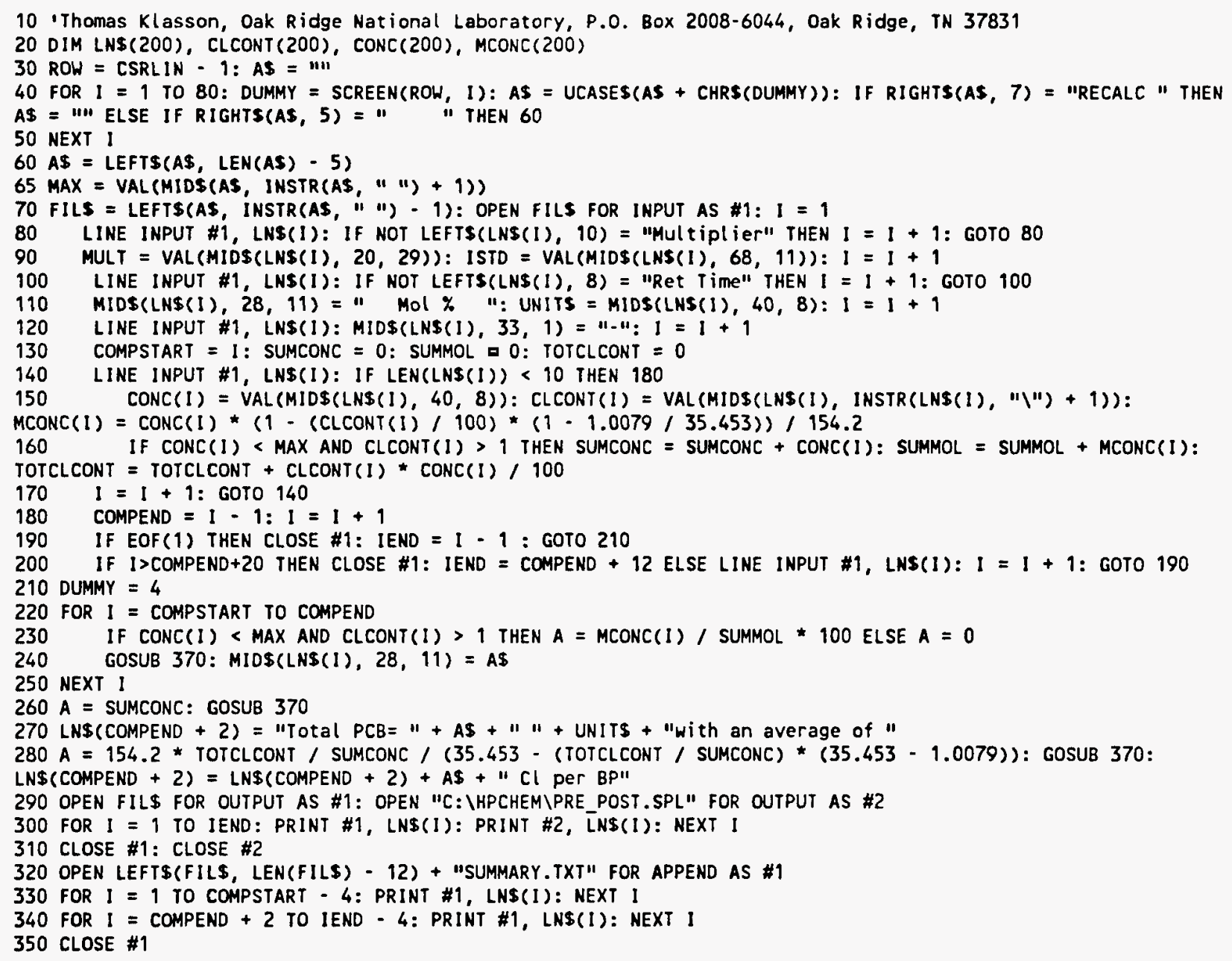


360 END

370 REM $\ldots \ldots . .$. CONVERT VALUE A TO STRING A\$, FORMAT $="+\$$ +DUMMY $\cdots . . . . . . .$.

380 IF $A=0$ THEN AS = "O." + STRINGS(DUMMY, "0") + "E+00": GOTO 430

390 IF $A<0$ THEN AS = "-": $A=$ ABS(A) ELSE AS = " "

400 IF $A<1$ THEN $B \$=$ "E-" ELSE $B \$=" E+"$

$410 \mathrm{~K} \&=$ INT $\left(A * 10^{\circ}\right.$ (DUMMY - INT(LOG(A) / LOG(10) + VAL("1.9E-" + RIGHTS(STRS(DUMMY + 2), 1)))) + .5)

$420 \mathrm{AS}=A \$+\operatorname{MIDS}(S T R \$(K \&), 2,1)+" . "+$ RIGHT\$(STR\$(K\&), DUMMY) + B\$ + RIGHTS("O" + MIDS(STRS(INT(LOG(A)

( LOG(10) + VAL("1.9E-" + RIGHT\$(STRS(DUMMY + 2), 1)))), 2), 2)

430 RETURN

Below is the reprinted report. Incorporated into the calculation is also the multiplier that converts sample concentrations to concentration in extracted soil. This multiplier is entered during reprocessing in a sequence table (a table created for automatically injecting multiple samples).

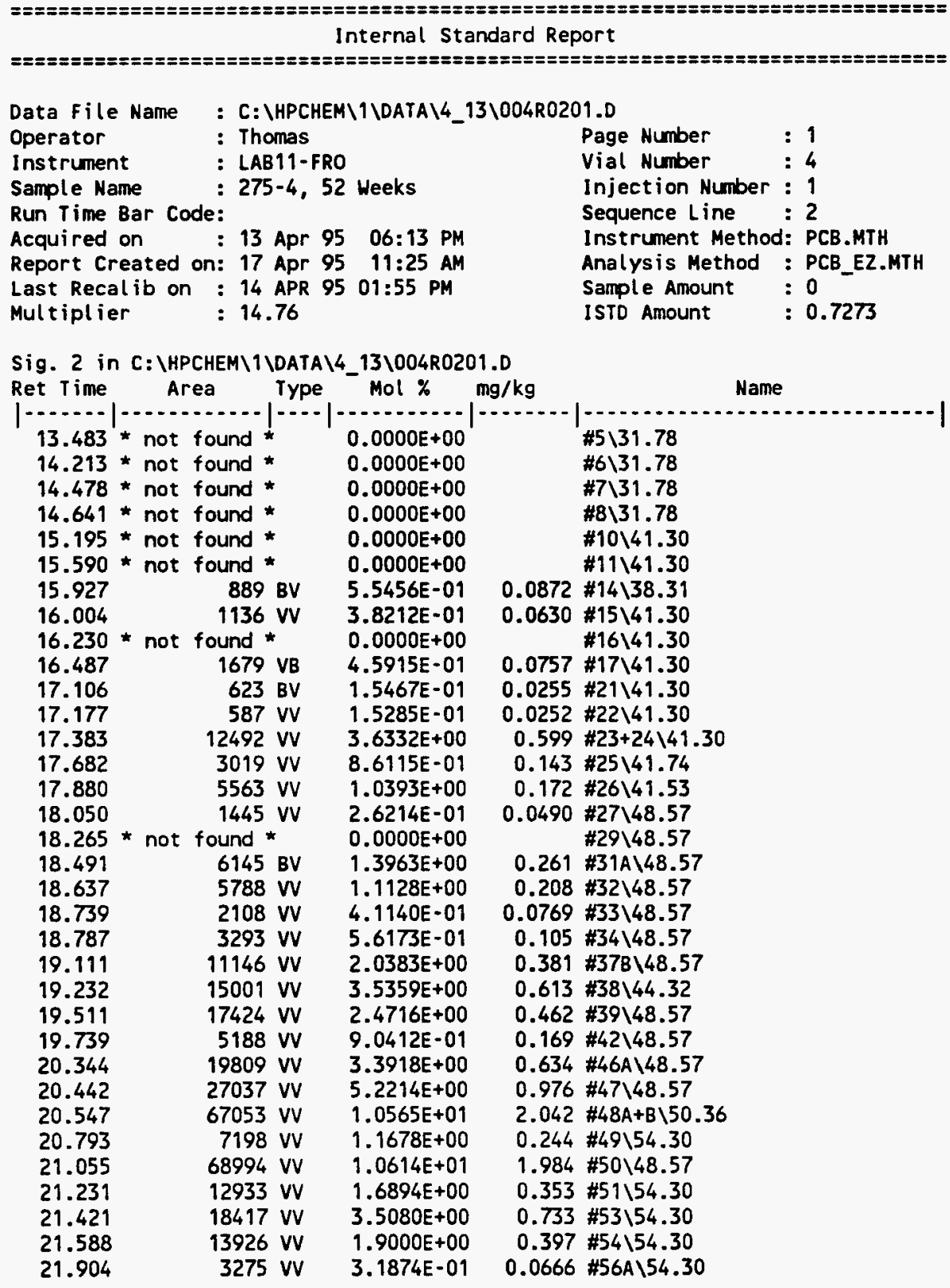




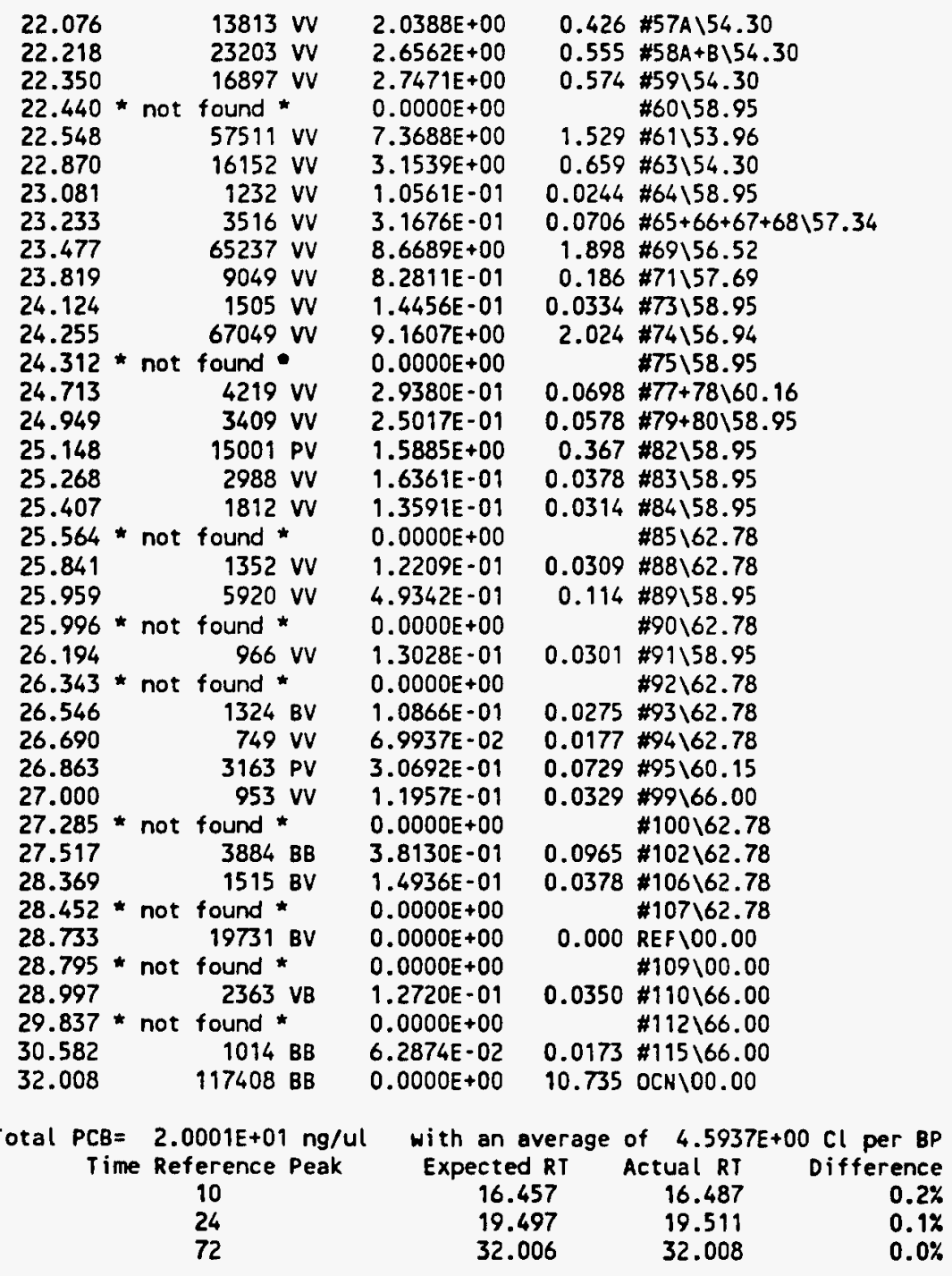

Calibration table contains at least one peak with amt $=0$

Not all calibrated peaks were found 
In addition to the standard recalculations performed on all samples (resulting in the above-mentioned format), additional details were found using the below program written in BASIC and compiled. The program (DETAILS2.EXE) accepts one argument, the filename of the file to be inspected, from the DOS prompt. The program listing may be found below.

10 'Thomas Klasson, Oak Ridge National Laboratory, P.0. 80x 2008-6044, Oak Ridge, TN 37831

20 CLEAR : DIM A\$(200), LN\$(200), LBLS(200), PEAK\$(200), CONC(200), CLCONT(200), MCONC(200), ORTHO(200), PARA(200), META(200), KBI (200)

30 READ N: FOR I = 1 TO $N: \operatorname{READ} \operatorname{PEAK} \$(I), \operatorname{ORTHO}(1), \operatorname{META}(1), \operatorname{PARA}(1), \operatorname{KBI}(1)$ : NEXT I

40 EMPTYS = STRINGS(80, " "): FOR I = 1 TO 10: KEY 1 , "": NEXT 1

50 ROW = CSRLIN - 1: AS = "1"

60 FOR I = 1 TO 80: DUMMY = SCREEN(ROW, 1): AS = UCASE\$(AS + CHR\$(DUMMY)): IF RIGHTS(AS, 12) = "DETAIL2.EXE

"THEN AS = "" ELSE IF RIGHT\$(AS, 5) =" "THEN 80

70 NEXT 1

80 FILS = LEFT\$(AS, LEN(A\$) - 5): GOSUB 440

90 DUMMY $=4:$ EDITS $=0$

$100 \mathrm{~N}=$ COMPEND - COMPSTART + $1:$ SUMMARY\$ = LN\$(COMPEND + 2): SUMMOL = SUMM: SUMCONC = SUMC: TOTCLCONT = SUMCL

110 SUMORTHO $=0:$ SUMPARA $=0:$ SUMMETA $=0:$ MONO $=0:$ DI $=0:$ TRI $=0:$ TETRA $=0:$ PENTA $=0:$ HEXA $=0:$ HEPTA $=0:$ OCTA $=0:$ LTOT $=0: L T 1=0: L T 10=0:$ MT10 $=0$

120 FOR $I=$ COMPSTART TO COMPEND

130 SUMORTHO $=$ SUMORTHO + MCONC $(1)$ * ORTHO $(I+1-\operatorname{COMPSTART}):$ SUMPARA $=$ SUMPARA + MCONC $(1)$ * PARA $(1+1-$ COMPSTART $):$ SUMMETA $=$ SUMMETA + MCONC $(I) *$ META $(1+1-$ COMPSTART $)$

140 IF MCONC(I) $>0$ AND $C L C O N T(1)>1$ THEN THALF $=.6931 /($ KBI $(I+1$ - COMPSTART $)+8.000001 E-03)$ ELSE 270

150 IF THALF $<=.1$ THEN LTO1 $=$ LTO1 + MCONC(I): GOTO 180

160 IF THALF $<1$ THEN LTI $=$ LT1 + MCONC $(1):$ GOTO 180

170 IF THALF $s=10$ THEN LT10 = LT10 + MCONC(1) ELSE MT10 = MT10 + MCONC(1)

$180 \mathrm{NCL}=$ ORTHO $(I+1$ - COMPSTART $)+$ META $(I+1$ - COMPSTART $)+$ PARA $(I+1$ - COMPSTART $):$ ON INT (NCL) GOTO

$200,210,220,230,240,250,260,260$

190 MONO $=$ MONO $+\operatorname{MCONC}(1):$ GOTO 270

200 MONO $=$ MONO $+\operatorname{MCONC}(1) *(2-\mathrm{NCL}): D I=D I+M C O N C(1) *(N C L-1):$ GOTO 270

$210 \mathrm{DI}=\mathrm{DI}+\mathrm{MCONC}(1) \star(3-\mathrm{NCL}): T R I=T R I+M C O N C(I) *(N C L-2):$ GOTO 270

220 TRI = TRI + MCONC(I) * $(4$ - NCL): TETRA = TETRA + MCONC(I) * (NCL - 3): GOTO 270

230 TETRA $=$ TETRA + MCONC(1) * $(5-N C L):$ PENTA = PENTA + MCONC(I) * $(N C L$ - 4): GOTO 270

240 PENTA $=$ PENTA + MCONC(I) * $(6-N C L):$ HEXA $=$ HEXA + MCONC(1) * $(N C L$ - 5): GOTO 270

$250 \mathrm{HEXA}=$ HEXA + MCONC(1) * $(7-\mathrm{NCL}):$ HEPTA = HEPTA + MCONC(I) * (NCL - 6): GOTO 270

260 HEPTA $=$ HEPTA $+\operatorname{MCONC}(1) \star(8-$ NCL $):$ OCTA $=$ OCTA + MCONCC(I) * $(N C L-7)$

270 NEXT I

280 CLS : FOR I = 5 TO 14: PRINT LN\$(I): NEXT I

290 PRINT SUMMARY\$: PRINT : A = SUMORTHO + SUMMETA + SUMPARA

300 PRINT "

310 PRINT "Ortho = "; : PRINT USING "\#\#.\#"; SUMORTHO * $\overline{100 / A_{i}}$ : PRINT " or "; : PRINT USING "\#.\#"; SUMORTHO * VAL(MIDS(SUMMARY\$, 50, 12)) / A; : PRINT " $\mathrm{Cl} / \mathrm{BP}$ | MONo = ";

320 PRINT USING "\#\#.\#\#"; MONO * SUMM / SUMMOL; : PRINT " Penta= "; : PRINT USING "\#\#.\#\#"; PENTA *

SUMM / SUMMOL

330 PRINT "Para = "; : PRINT USING "\#.\#\#"; SUMPARA * 100 / A; : PRINT " or "; : PRINT USING "\#.\#"; SUMPARA * VAL(MID\$(SUMMARY\$, 50, 12)) / $A_{;}:$PRINT " Cl/BP $\mid \mathrm{Di}="$;

340 PRINT USING "\#\#.\#\#"; DI * SUMM / SUMMOL; : PRINT " HeXa = "; : PRINT USING "\#\#.\#\%"; HEXA * SUMM / SUMMOL

350 PRINT "Meta = "; : PRINT USING "\#.\#"; SUMMETA * 100 / A; : PRINT " or "; : PRINT USING "\#.\#"; SUMMETA * VAL(MID\$(SUMMARY\$, 50, 12)) / A; : PRINT " Cl/BP | Tri = ";

360 PRINT USING "\#\#.\#\#"; TRI * SUMM / SUMMOL; : PRINT " Hepta= "; : PRINT USING "\#\#.\#\%"; HEPTA * SUMM SUMMOL

370 PRINT "[M+P] $/ 0=" ;:$ PRINT USING " \#.\#"; (SUMMETA + SUMPARA) / SUMORTHO; : PRINT "

| Tetra="; : PRINT USING "\#\#.\#\#\%"; TETRA * SUMM / SUMMOL; : PRINT " Octa = "; : PRINT USING "\#\#.\#\#"; OCTA * SUMM / SUMMOL

380 PRINT : PRINT " Half-Life in Humans

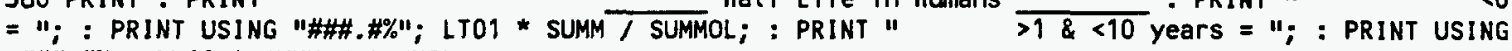

"\#\#.\#\%"; LT10 * SUMM / SUMMOL

390 PRINT " $>0.1 \&<1$ year = "; : PRINT USING "\#\#.\#"; LTI * SUMM / SUMMOL; : PRINT "
years = "; : PRINT USING "\#\#.\#\%"; MT10 * SUMM / SUMMOL

"1. PRINT "

$<0.1$ year

400 PRINT : PRINT "Press E to edit peaks. Press any other key to quit";

410 A\$ = INKEY\$: IF A\$ = "I" THEN 410

420 IF A\$ = "E" OR A\$ = "e" THEN IF EDITS = 0 THEN FOR I = 1 TO $\mathrm{N}:$ AS(I) = LN\$(I + COMPSTART - 1): NEXT I:

EDITS = EDITS + 1: GOTO 640 ELSE 640

430 END

440 OPEN FIL\$ FOR INPUT AS \#1: $1=1:$ SUMMOL $=0:$ TOTCLCONT $=0:$ SUMCONC $=0$

450 LINE INPUT \#1, LNS(1): IF NOT LEFT\$(LN\$(1), 8) = "Ret Time" THEN I = I + 1: GOTO 450 


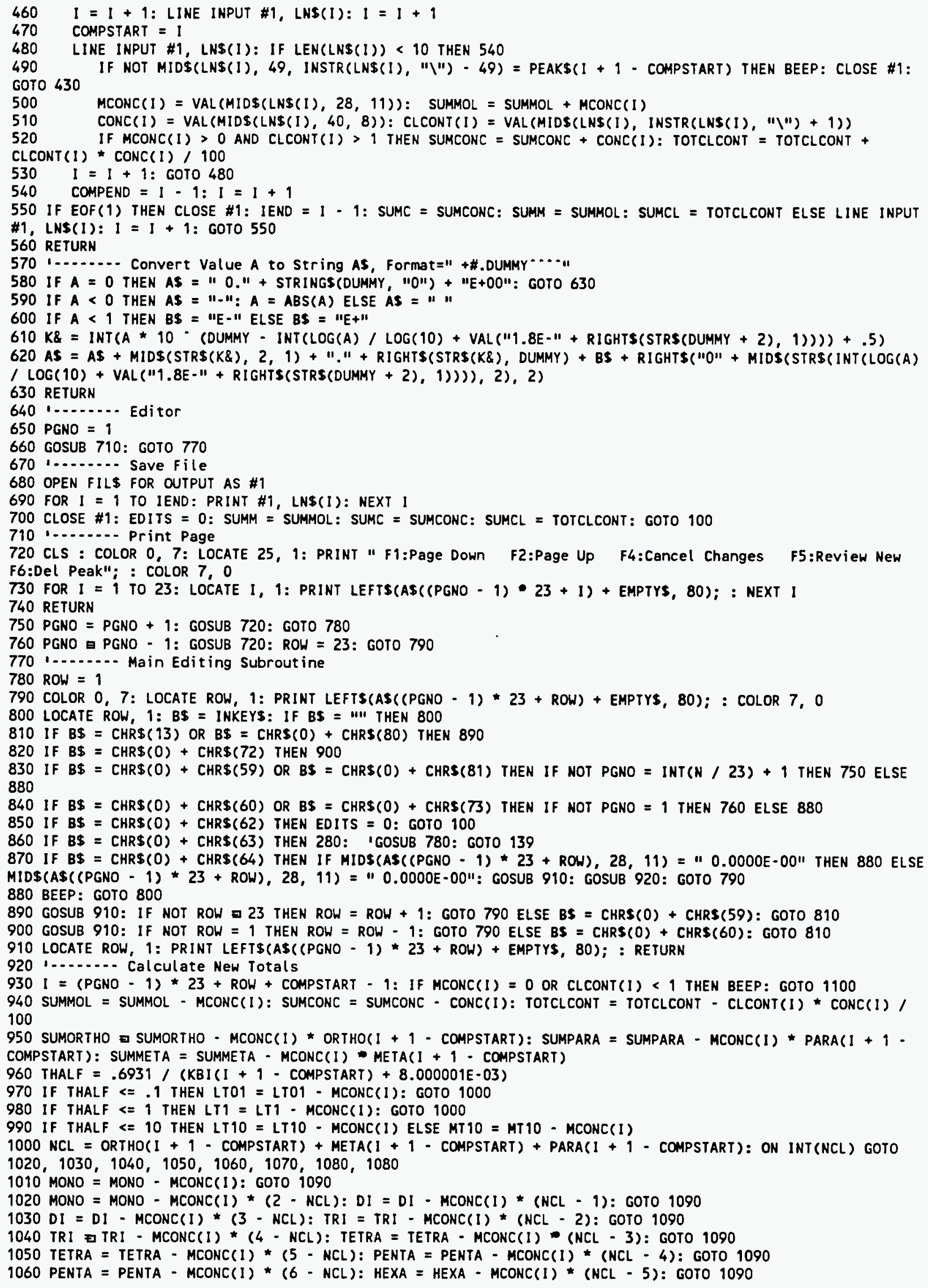


1070 HEXA $=$ HEXA - MCONC $(1) *(7-$ NCL $):$ HEPTA $=$ HEPTA - MCONC(1) * (NCL - 6): GOTO 1090

1080 HEPTA $=$ HEPTA - MCONC $(1) \star(8-N C L):$ OCTA $=$ OCTA $-\operatorname{MCONC}(1) *(N C L-7)$

$1090 \mathrm{~A}$ a SUMCONC: GOSUB 570: MIDS(SUMMARYS, 12,11$)=$ AS: $A=154.2$ *TOTCLCONT $/$ SUMCONC / (35.453 (TOTCLCONT / SUMCONC) * $(35.453-1.0079)):$ GOSUB 570: MID\$(SUMMARY\$, 51, 11) = AS 1100 RETURN

1110 DATA $72:+0, m, p, K b i$

1120 DATA "\#5", $2,0,0,200$

1130 DATA "\#6", $1,0.53,0.47,60$

1140 DATA "\#7", $1,1,0,60$

1150 DATA "\#8", $1,0,1,80$

1160 DATA "\#10", $3,0,0,100$

1170 DATA "\#11", $2,0,1,80$

1180 DATA "\#14", $1.31,0.65,0.69,20$

1190 DATA "\#15", $2,0,1,40$

1200 DATA "\#16", $2,1,0,34$

1210 DATA "\#17", $2,0.70,0.30,12$

1220 DATA "\#21", $1,2,0,3.6$

1230 DATA "\#22" $, 1,1,1,2.4$

1240 DATA $" \# 23+24 ", 1,0.46,1.54,0.48$

1250 DATA "\#25", $1.11,1.05,0.89,5.2$

1260 DATA "\#26", $1,1,1,1.8$

1270 DATA "\#27", $3,1,0,36$

1280 DATA "\#29", $3,1,0,20$

1290 DATA "\#31A", $2,2,0,6.5$

1300 DATA "\#32", $2,1,1,5.8$

1310 DATA "\#33", $2,0,2,2$

1320 DATA "\#34", $2,0.88,1.12,2$

1330 DATA " $\$ 37 B ", 2,2,0,6.4$

1340 DATA "\#38", $0.77,1.11,1.5,0.8$

1350 DATA "\#39" $2,1,1,7$

1360 DATA "\#42", $2,2,0,6.6$

1370 DATA "\#46A" $1,1,1,2,0.21$

1380 DATA "\#47", $1,2,1,1.2$

1390 DATA "\#48A+B" $1.65,1.33,1.35,0.8$

1400 DATA "\#49" , 3, $1,1,6$

1410 DATA "\#50" $1,1.54,1.46,1$

1420 DATA "\#51", $2.65,2.35,0,1.5$

1430 DATA "\$53" $2,2,1,2$

1440 DATA "\#54", $2,1,2,0.2$

1450 DATA "\#56A", $2,3,0,1$

1460 DATA "\#57A" $2,2,1,1$

1470 DATA "\#58A+B" $, 2,2, ;, 3.6$

1480 DATA "\#59" , $2,1,2,0.8$

1490 DATA "\#60" $4,2,0,7$

1500 DATA "\#61", $1.89,2,1.06,4.2$

1510 DATA "\#63", $2,2,1,3.4$

1520 DATA "\#64", $3,3,0,1.8$

1530 DATA " $\$ 65+66+67+68 ", 2.29,1.52,0.58,0.14$

1540 DATA "\#69" $1,2,2,0.11$

1550 DATA "\#71", $2.44,2.72,0.56,0.04$

1560 DATA "\#73" $2,3,1,0.026$

1570 DATA "\#74", $2.15,2,1.43,0.17$

1580 DATA "\#75" $2,2,2,0.046$

1590 DATA "\#77+78", $2.62,3,0.69,1$

1600 DATA "\#79+80" $2,2.5,1.5,0.024$

1610 DATA "\#82", $2,2,2,0.03$

1620 DATA "\#83", $2,2.05,1.95,0.14$

1630 DATA "\#84", $2,3,1,1$

1640 DATA "\#85", $3,4,0,0$

1650 DATA "\#88", $3,3,1,0.03$

1660 DATA "\#89",2,2,2,0.17

1670 DATA "\#90" $3,2,2,0.11$

1680 DATA "\#91", $1,3,2,0.041$

1690 DATA "\#92" $3,3,1,1.8$

1700 DATA "\#93" $3,3,1,2.4$

1710 DATA "\#94" $3,3,1,0.08$

1720 DATA "\#95" $, 1.63,2.69,2,0.01$

1730 DATA "\#99" $4,3,1,0.08$

1740 DATA "\#100", 2,4, 1, 0.009

1750 DATA "\#102",2,3,2,0.003

1760 DATA "\#106" , $2,3,2,0.016$ 
1770 DATA "\#107", $2,3,2,0.044$

1780 DATA "REF" $0,0,0,0$

1790 DATA "\#109", 3,4,1,0.003

1800 DATA "\#110", $3,3,2,0.06$

1810 DATA "\#112", $3,3,2,0.044$

1820 DATA "\#115", $2,4,2,0$

1830 DATA "OCN" , $0,0,0,0$

The output from the program is shown below.

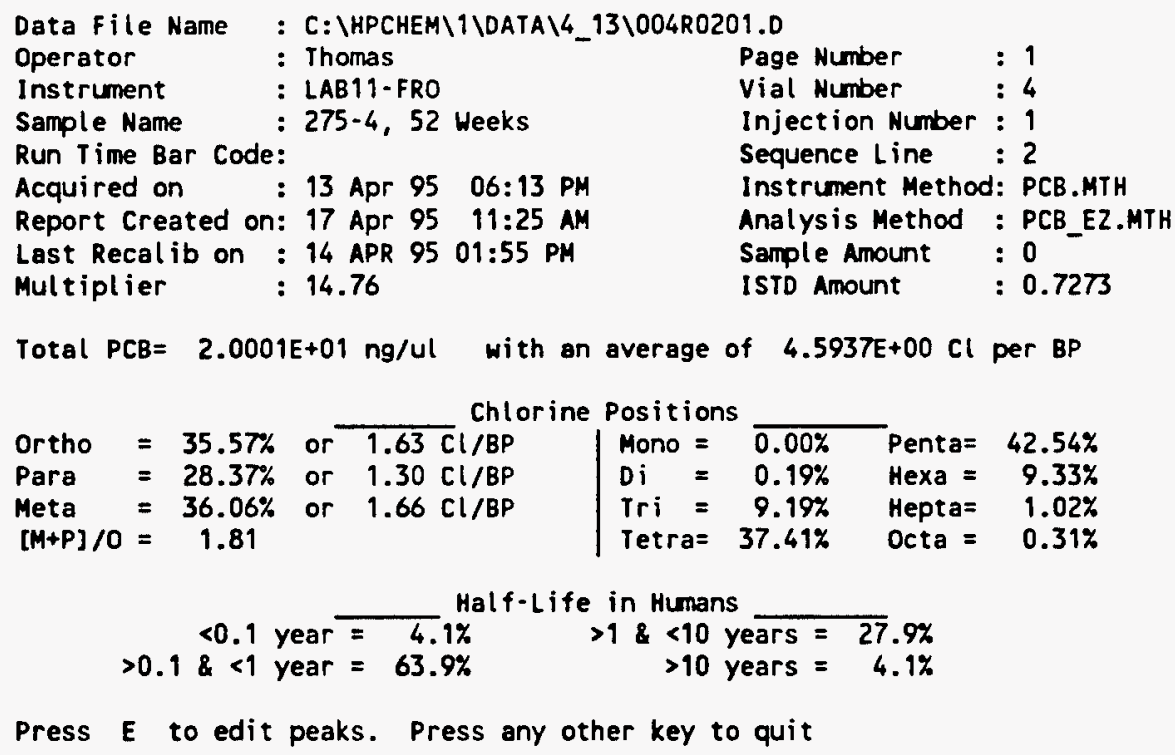

As is noted, the program provides information about chlorine positions and mol percent of PCBs with different retention times in humans. 
Sig. 2 in C:LHPCHEM $\ldots$.. 1099R0201.D

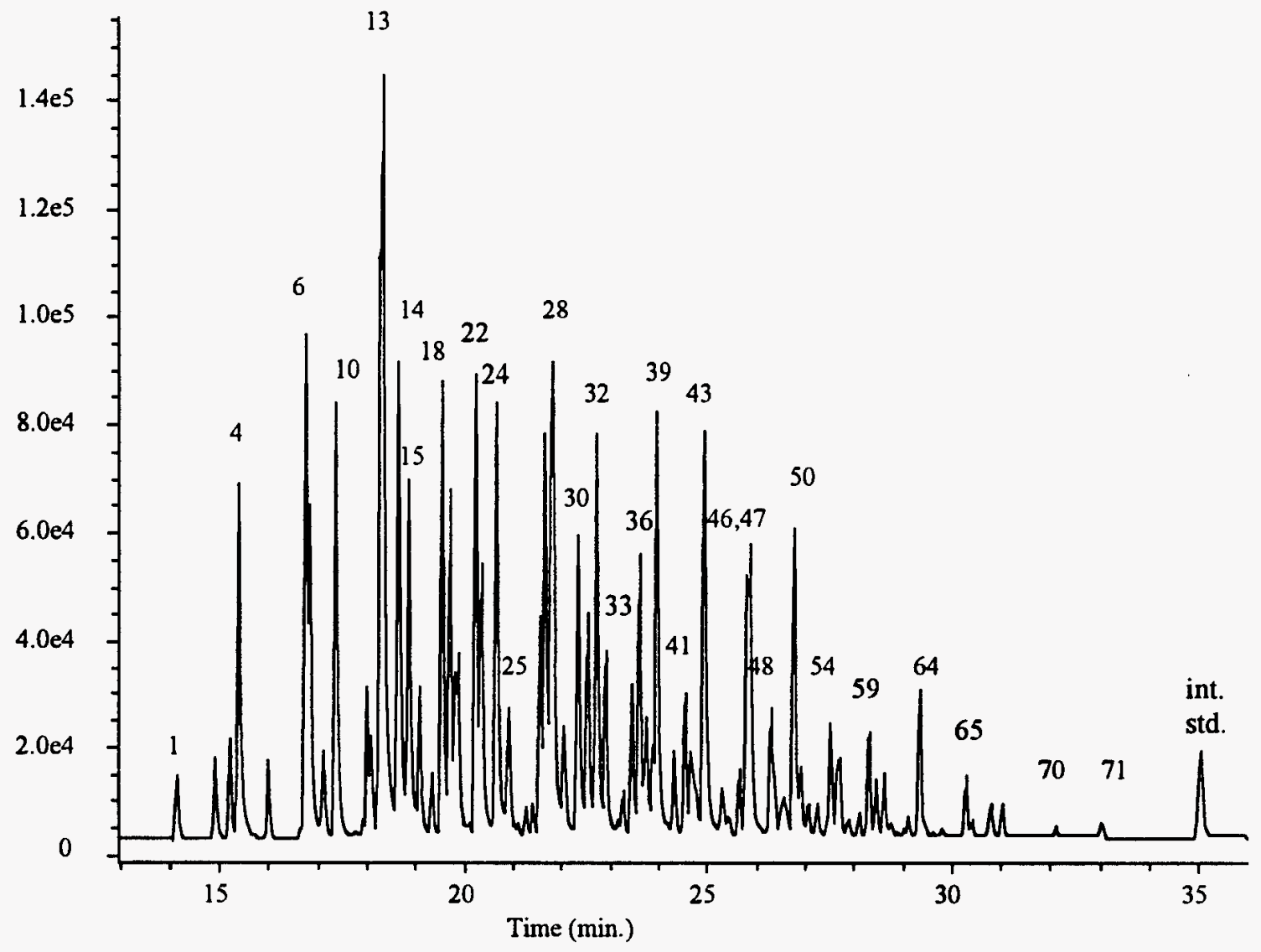

The above figure depicts a gas chromatogram of the PCB standard used (70\% Aroclor 1242, 20\% Aroclor 1254 , and $10 \%$ Aroclor 1260 ). 


\section{APPENDIX B}

RESOURCE AND DATA FOR PCB CONGENERS 


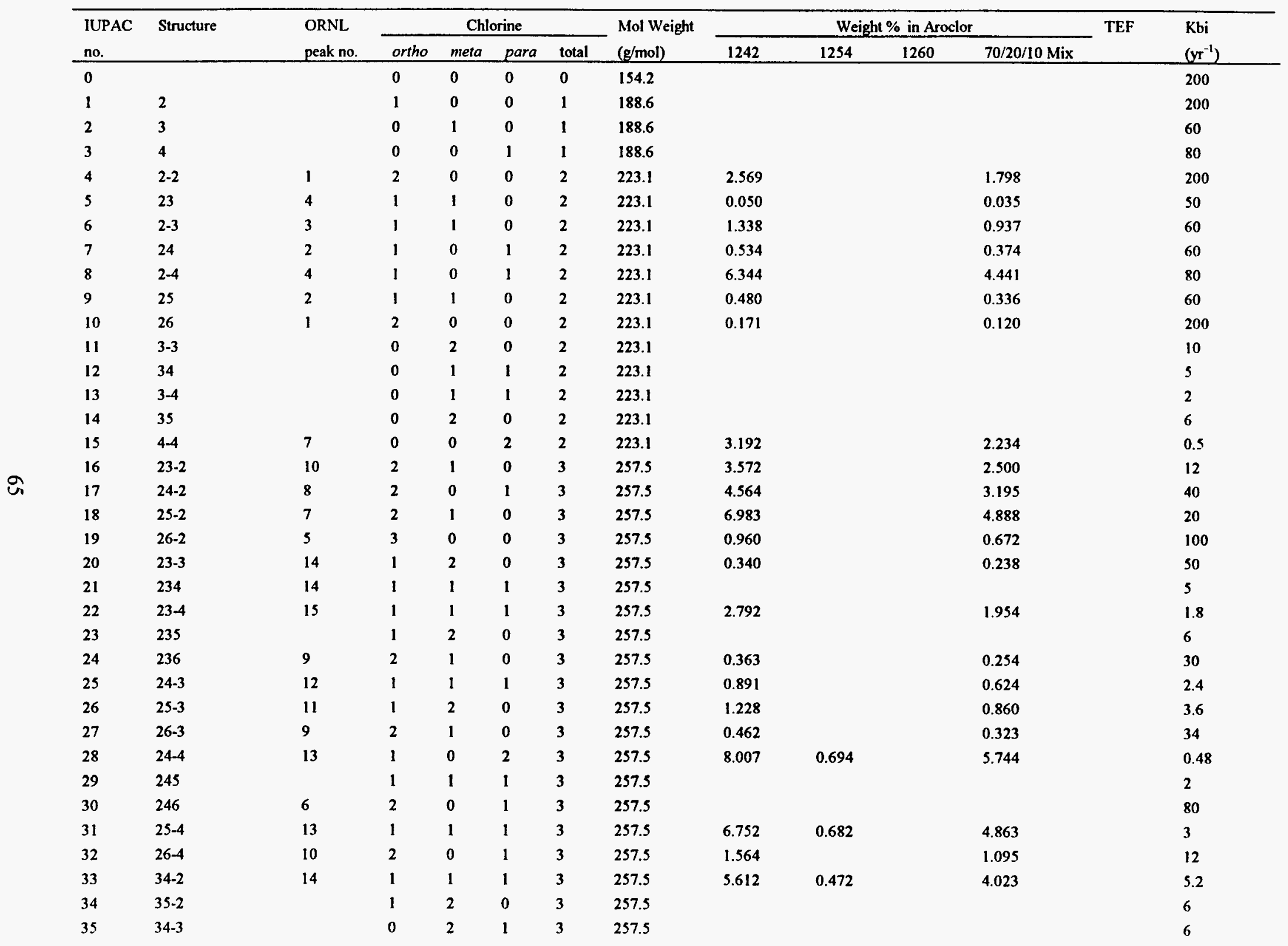




\begin{tabular}{|c|c|c|c|c|c|c|c|c|c|c|c|c|c|}
\hline \multirow{2}{*}{$\begin{array}{l}\text { IUPAC } \\
\text { no. }\end{array}$} & \multirow[t]{2}{*}{ Structure } & \multirow{2}{*}{$\begin{array}{l}\text { ORNL } \\
\text { peak no. }\end{array}$} & \multicolumn{4}{|c|}{ Chlorine } & \multirow{2}{*}{$\begin{array}{l}\text { Mol Weight } \\
(\mathrm{g} / \mathrm{mol})\end{array}$} & \multicolumn{4}{|c|}{ Weight $\%$ in Aroclor } & \multirow[t]{2}{*}{ TEF } & \multirow{2}{*}{$\begin{array}{l}\text { Khi } \\
\left(V T^{-1}\right)\end{array}$} \\
\hline & & & ortho & meta & para & total & & 1242 & 1254 & 1260 & 70/20/10 Mix & & \\
\hline 36 & $35-3$ & & 0 & 3 & 0 & 3 & 257.5 & & & & & & 2 \\
\hline 37 & $34-4$ & 23 & 0 & 1 & 2 & 3 & 257.5 & 1.938 & & & 1.357 & & 0.8 \\
\hline 38 & 345 & & 0 & 2 & 1 & 3 & 257.5 & & & & & & 5 \\
\hline 39 & $35-4$ & & 0 & 2 & 1 & 3 & 257.5 & & & & & & 0.8 \\
\hline 40 & $23-23$ & 25 & 2 & 2 & 0 & 4 & 292.0 & 1.008 & & & 0.706 & & 6.6 \\
\hline 41 & $234-2$ & 24 & 2 & 1 & 1 & 4 & 292.0 & 1.652 & 0.547 & & 1.266 & & 5 \\
\hline 42 & $23-24$ & 23 & 2 & 1 & 1 & 4 & 292.0 & 0.978 & & & 0.685 & & 3.4 \\
\hline 43 & $235-2$ & 19 & 2 & 2 & 0 & 4 & 292.0 & & & & & & 5 \\
\hline 44 & $23-25$ & 22 & 2 & 2 & 0 & 4 & 292.0 & 3.257 & 2.118 & & 2.704 & & 6.4 \\
\hline 45 & $236-2$ & 16 & 3 & 1 & 0 & 4 & 292.0 & 1.103 & & & 0.772 & & 36 \\
\hline 46 & $23-26$ & 17 & 3 & 1 & 0 & 4 & 292.0 & 0.799 & & & 0.559 & & 20 \\
\hline 47 & $24-24$ & 20 & 2 & 0 & 2 & 4 & 292.0 & 1.095 & & & 0.767 & & 2 \\
\hline 48 & 245.2 & 21 & 2 & 1 & 1 & 4 & 292.0 & 1.308 & & & 0.915 & & 5 \\
\hline 49 & $24-25$ & 19 & 2 & 1 & 1 & 4 & 292.0 & 2.630 & 1.282 & & 2.097 & & 5.8 \\
\hline 50 & $246-2$ & 13 & 3 & 0 & 1 & 4 & 292.0 & & & & & & 40 \\
\hline 51 & $24-26$ & 15 & 3 & 0 & 1 & 4 & 292.0 & 0.092 & & & 0.064 & & 40 \\
\hline 52 & $25-25$ & 18 & 2 & 2 & 0 & 4 & 292.0 & 3.315 & 5.106 & & 3.342 & & 6.5 \\
\hline 53 & $25-26$ & 14 & 3 & 1 & 0 & 4 & 292.0 & 0.329 & 0.221 & & 0.275 & & 20 \\
\hline$\$ 4$ & $26-26$ & & 4 & 0 & 0 & 4 & 292.0 & & & & & & 60 \\
\hline 55 & $234-3$ & 29 & 1 & 2 & 1 & 4 & 292.0 & & & & & & 6 \\
\hline 56 & $23-34$ & 30 & 1 & 2 & 1 & 4 & 292.0 & 1.368 & 0.422 & & 1.042 & & 2 \\
\hline 57 & $235-3$ & & 1 & 3 & 0 & 4 & 292.0 & & & & & & 2 \\
\hline 58 & $23-35$ & & 1 & 3 & 0 & 4 & 292.0 & & & & & & 1.5 \\
\hline 59 & $236-3$ & 23 & 2 & 2 & 0 & 4 & 292.0 & 0.401 & & & 0.281 & & 5 \\
\hline 60 & $234-4$ & 30 & 1 & 1 & 2 & 4 & 292.0 & 1.137 & 0.392 & & 0.874 & & 1 \\
\hline 61 & 2345 & & 1 & 2 & 1 & 4 & 292.0 & & & & & & 5 \\
\hline 62 & 2346 & & 2 & 1 & 1 & 4 & 292.0 & & & & & & 5 \\
\hline 63 & $235-4$ & & 1 & 2 & 1 & 4 & 292.0 & & & & & & 0.6 \\
\hline 64 & $236-4$ & 24 & 2 & 1 & 1 & 4 & 292.0 & 1.457 & 0.385 & & 1.097 & & 7 \\
\hline 65 & 2356 & & 2 & 2 & 0 & 4 & 292.0 & & & & & & 6 \\
\hline 66 & $24-34$ & 28 & 1 & 1 & 2 & 4 & 292.0 & 3.469 & 2.611 & & 2.951 & & 0.8 \\
\hline 67 & $245-3$ & & 1 & 2 & 1 & 4 & 292.0 & & & & & & 2 \\
\hline 68 & $24-35$ & & 1 & 2 & 1 & 4 & 292.0 & & & & & & 1 \\
\hline 69 & $246-3$ & & 2 & 1 & 1 & 4 & 292.0 & & & & & & 5 \\
\hline 70 & $25-34$ & 27 & 1 & 2 & 1 & 4 & 292.0 & 3.405 & 3.173 & & 3.018 & & 1.2 \\
\hline 71 & $26-34$ & 24 & 2 & 1 & 1 & 4 & 292.0 & & & & & & 7 \\
\hline
\end{tabular}




\begin{tabular}{|c|c|c|c|c|c|c|c|c|c|c|c|c|c|}
\hline IUPAC & \multirow[t]{2}{*}{ Structure } & \multirow{2}{*}{$\begin{array}{l}\text { ORNL } \\
\text { peak no. }\end{array}$} & \multicolumn{4}{|c|}{ Chlorine } & \multirow{2}{*}{$\begin{array}{l}\text { Mol Weight } \\
(\mathrm{g} / \mathrm{mol})\end{array}$} & \multicolumn{4}{|c|}{ Weight $\%$ in Aroclor } & \multirow[t]{2}{*}{ TEF } & \multirow{2}{*}{$\begin{array}{l}\mathrm{Kbi} \\
\left(\mathbf{M r}^{-1}\right)\end{array}$} \\
\hline no. & & & ortho & meta & para & total & & 1242 & 1254 & 1260 & 70/20/10 Mix & & \\
\hline 72 & $25-35$ & 24 & 1 & 3 & 0 & 4 & 292.0 & & & & & & 1.5 \\
\hline 73 & $26-35$ & & 2 & 2 & 0 & 4 & 292.0 & & & & & & 5 \\
\hline 74 & $245-4$ & 26 & 1 & 1 & 2 & 4 & 292.0 & 1.601 & 0.873 & & 1.295 & & 0.21 \\
\hline 75 & $246-4$ & 21 & 2 & 0 & 2 & 4 & 292.0 & 0.175 & & & 0.123 & & 2 \\
\hline 76 & $345-2$ & 28 & 1 & 2 & 1 & 4 & 292.0 & & & & & & 5 \\
\hline 77 & $34-34$ & 39 & 0 & 2 & 2 & 4 & 292.0 & 0.226 & & & 0.158 & 0.02 & 0.2 \\
\hline 78 & $345-3$ & & $\mathbf{0}$ & 3 & 1 & 4 & 292.0 & & & & & & 1 \\
\hline 79 & $34-35$ & & $\mathbf{0}$ & 3 & 1 & 4 & 292.0 & & & & & & 0.1 \\
\hline 80 & $35-35$ & & 0 & 4 & 0 & 4 & 292.0 & & & & & & 0.02 \\
\hline 81 & $345-4$ & & 0 & 2 & 2 & 4 & 292.0 & & & & & NA & 0.02 \\
\hline 82 & $234-23$ & 40 & 2 & 2 & 1 & 5 & 326.4 & 0.687 & 1.006 & & 0.682 & & 3.4 \\
\hline 83 & $235-23$ & 33 & 2 & 3 & 0 & 5 & 326.4 & & 0.766 & & 0.153 & & 1 \\
\hline 84 & $236-23$ & 31 & 3 & 2 & 0 & 5 & 326.4 & 0.562 & 2.263 & 0.187 & 0.865 & & 1.5 \\
\hline 85 & $234-24$ & 36 & 2 & 1 & 2 & 5 & 326.4 & 0.710 & 1.329 & & 0.763 & & 0.8 \\
\hline 86 & $2345-2$ & & 2 & 2 & 1 & 5 & 326.4 & & & & & & 5 \\
\hline 87 & $234-25$ & 36 & 2 & 2 & 1 & 3 & 326.4 & 0.776 & 3.703 & 0.624 & 1.346 & & 3.6 \\
\hline 88 & $2346-2$ & & 3 & 1 & 1 & 5 & 326.4 & & & & & & 5 \\
\hline 89 & $234-26$ & & 3 & 1 & 1 & 5 & 326.4 & & & & & & 6 \\
\hline 90 & $235-24$ & 32 & 2 & 2 & 1 & 5 & 326.4 & 0.171 & 0.878 & 0.310 & 0.326 & & 0.3 \\
\hline 91 & $236-24$ & 29 & 3 & 1 & 1 & 5 & 326.4 & 0.701 & 1.083 & & 0.707 & & 6 \\
\hline 92 & $235-25$ & 31 & 2 & 3 & 0 & 5 & 326.4 & 0.195 & 1.320 & 0.440 & 0.445 & & 1.5 \\
\hline 93 & $2356-2$ & 28 & 3 & 2 & 0 & 5 & 326.4 & & & & & & 5 \\
\hline 94 & $235-26$ & 26 & 3 & 2 & 0 & 5 & 326.4 & & & & & & 6 \\
\hline 95 & $236-25$ & 28 & 3 & 2 & 0 & 5 & 326.4 & 0.149 & 4.983 & 2.350 & 1.336 & & 6 \\
\hline 96 & $236-26$ & & 4 & 1 & 0 & 5 & 326.4 & & & & & & 40 \\
\hline 97 & $245-23$ & 35 & 2 & 2 & 1 & 5 & 326.4 & 0.715 & 2.186 & & 0.938 & & 1 \\
\hline 98 & $246-23$ & 28 & 3 & 1 & 1 & 5 & 326.4 & & & & & & 5 \\
\hline 99 & $245-24$ & 33 & 2 & 1 & 2 & 5 & 326.4 & 0.741 & 2.955 & & 1.110 & & 0.2 \\
\hline 100 & 246-24 & & 3 & 0 & 2 & 5 & 326.4 & & & & & & 1 \\
\hline 101 & $245-25$ & 32 & 2 & 2 & 1 & 5 & 326.4 & 0.709 & 7.498 & 2.780 & 2.274 & & 2 \\
\hline 102 & $245-26$ & 28 & 3 & 1 & 1 & 5 & 326.4 & & & & & & 5 \\
\hline 103 & $246-25$ & & 3 & 1 & 1 & 5 & 326.4 & & & & & & 2 \\
\hline 104 & $246-26$ & & 4 & 0 & 1 & 5 & 326.4 & & & & & & 40 \\
\hline 105 & $234-34$ & 46 & 1 & 2 & 2 & 5 & 326.4 & 0.551 & 1.505 & & 0.687 & 0.001 & 0.17 \\
\hline 106 & $2345-3$ & 43 & 1 & 3 & 1 & 5 & 326.4 & & & & & & 1.5 \\
\hline 107 & $235-34$ & 42 & 1 & 3 & 1 & 5 & 326.4 & & 0.717 & & 0.143 & & 0.14 \\
\hline
\end{tabular}




\begin{tabular}{|c|c|c|c|c|c|c|c|c|c|c|c|c|c|}
\hline \multirow{2}{*}{$\begin{array}{l}\text { IUPAC } \\
\text { no. }\end{array}$} & \multirow[t]{2}{*}{ Structure } & \multirow{2}{*}{$\begin{array}{l}\text { ORNL } \\
\text { peak no. }\end{array}$} & \multicolumn{4}{|c|}{ Chlorine } & \multirow{2}{*}{$\begin{array}{l}\text { Mol Weight } \\
(\mathrm{g} / \mathrm{mol})\end{array}$} & \multicolumn{4}{|c|}{ Weight $\%$ in Aroclor } & \multirow[t]{2}{*}{ TEF } & \multirow{2}{*}{$\begin{array}{l}\text { Kbi } \\
\left(3 T^{-1}\right)\end{array}$} \\
\hline & & & ortho & meta & para & total & & 1242 & 1254 & 1260 & 70/20/10 Mix & & \\
\hline 108 & $234-35$ & 42 & 1 & 3 & 1 & 5 & 326.4 & & & & & & 0.07 \\
\hline 109 & $2346-3$ & & 2 & 2 & 1 & 5 & 326.4 & & & & & & 1.5 \\
\hline 110 & $236-34$ & 39 & 2 & 2 & 1 & 5 & 326.4 & 0.770 & 9.000 & 1.470 & 2.486 & & 4.2 \\
\hline 111 & $235-35$ & 36 & 1 & 4 & 0 & 5 & 326.4 & & & & & & 0 \\
\hline 112 & $2356-3$ & 34 & 2 & 3 & 0 & 5 & 326.4 & & & & & & 1.5 \\
\hline 113 & 236-35 & & 2 & 3 & 0 & 5 & 326.4 & & & & & & 1.5 \\
\hline 114 & $2345-4$ & 44 & 1 & 2 & 2 & 5 & 326.4 & & 0.298 & & 0.060 & 0.002 & 0.04 \\
\hline 115 & $2346-4$ & 36 & 2 & 1 & 2 & 5 & 326.4 & & 0.294 & 0.039 & 0.063 & & 0.3 \\
\hline 116 & 23456 & 37 & 2 & 2 & 1 & 5 & 326.4 & & & & & & 5 \\
\hline 117 & $2356-4$ & & 2 & 2 & 1 & 5 & 326.4 & & & & & & 1.5 \\
\hline 118 & $245-34$ & 43 & 1 & 2 & 2 & 3 & 326.4 & 0.572 & 7.122 & 0.947 & 1.920 & 0.0001 & 0.11 \\
\hline 119 & $246-34$ & & 2 & 1 & 2 & $s$ & 326.4 & & & & & & 6 \\
\hline 120 & $245-35$ & & 1 & 3 & 1 & 5 & 326.4 & & & & & & 0.035 \\
\hline 121 & $246-35$ & & 2 & 2 & 1 & 5 & 326.4 & & & & & & 0.04 \\
\hline 122 & $345-23$ & & 1 & 3 & 1 & 5 & 326.4 & & & & & & 2 \\
\hline 123 & $345-24$ & 42 & 1 & 2 & 2 & $s$ & 326.4 & & & & & 0.00005 & 0.07 \\
\hline 124 & $345-25$ & 42 & 1 & 3 & 1 & 5 & 326.4 & & 0.376 & & 0.075 & & 2 \\
\hline 125 & $345-26$ & & 2 & 2 & 1 & 5 & 326.4 & & & & & & 5 \\
\hline 126 & $345-34$ & & 0 & 3 & 2 & 5 & 326.4 & & & & & 0.1 & 0.1 \\
\hline 127 & $345-35$ & & 0 & 4 & 1 & $s$ & 326.4 & & & & & & 0 \\
\hline 128 & 234-234 & 55 & 2 & 2 & 2 & 6 & 360.9 & & 1.386 & & 0.277 & & 0.17 \\
\hline 129 & 2345.23 & 52 & 2 & 3 & 1 & 6 & 360.9 & & 0.712 & & 0.142 & & 1 \\
\hline 130 & $234-235$ & 49 & 2 & 3 & 1 & 6 & 360.9 & & 0.739 & & 0.148 & & 0.1 \\
\hline 131 & $2346-23$ & & 3 & 2 & 1 & 6 & 360.9 & & & & & & 2 \\
\hline 132 & $234-236$ & 46 & 3 & 2 & 1 & 6 & 360.9 & 0.192 & 2.465 & 2.760 & 0.904 & & 2 \\
\hline 133 & $235-235$ & & 2 & 4 & 0 & 6 & 360.9 & & & & & & 0 \\
\hline 134 & $2356-23$ & 44 & 3 & 3 & 0 & 6 & 360.9 & & 0.479 & 0.644 & 0.160 & & 2 \\
\hline 135 & $235-236$ & 42 & 3 & 3 & 0 & 6 & 360.9 & & 0.753 & 1.180 & 0.269 & & 3 \\
\hline 136 & $236-236$ & 38 & 4 & 2 & 0 & 6 & 360.9 & & & 1.530 & 0.153 & & 7 \\
\hline 137 & $2345-24$ & 49 & 2 & 2 & 2 & 6 & 360.9 & & 0.739 & & 0.148 & & 0.024 \\
\hline 138 & $234-245$ & 50 & 2 & 2 & 2 & 6 & 360.9 & & 6.204 & 10.61 & 2.302 & & 0.08 \\
\hline 139 & $2346-24$ & 43 & 3 & 1 & 2 & 6 & 360.9 & & & & & & 0.3 \\
\hline 140 & $234-246$ & & 3 & 1 & 2 & 6 & 360.9 & & & & & & 0.8 \\
\hline 141 & $2345-25$ & 48 & 2 & 3 & 1 & 6 & 360.9 & & 1.005 & 2.490 & 0.450 & & 1 \\
\hline 142 & $23456-2$ & & 3 & 2 & 1 & 6 & 360.9 & & & & & & 5 \\
\hline 143 & $2345-26$ & 44 & 3 & 2 & 1 & 6 & 360.9 & & & & & & 5 \\
\hline
\end{tabular}




\begin{tabular}{|c|c|c|c|c|c|c|c|c|c|c|c|c|c|}
\hline \multirow{2}{*}{$\begin{array}{l}\text { IUPAC } \\
\text { no. }\end{array}$} & \multirow[t]{2}{*}{ Structure } & \multirow{2}{*}{$\begin{array}{l}\text { ORNL } \\
\text { peak no. }\end{array}$} & \multicolumn{4}{|c|}{ Chlorine } & \multirow{2}{*}{$\begin{array}{l}\text { Mol Weight } \\
(\mathrm{g} / \mathrm{mol})\end{array}$} & \multicolumn{4}{|c|}{ Weight $\%$ in Aroclor } & \multirow[t]{2}{*}{ TEF } & \multirow{2}{*}{$\begin{array}{l}\text { Kbi } \\
\left(\mathrm{vr}^{-1}\right)\end{array}$} \\
\hline & & & ortho & meta & para & total & & 1242 & 1254 & 1260 & $70 / 20 / 10 \mathrm{Mix}$ & & \\
\hline 144 & $2346-25$ & 42 & 3 & 2 & 1 & 6 & 360.9 & & & 1.180 & 0.118 & & 2 \\
\hline 145 & $2346-26$ & & 4 & 1 & 1 & 6 & 360.9 & & & & & & 5 \\
\hline 146 & $235-245$ & 45 & 2 & 3 & 1 & 6 & 360.9 & & 0.804 & 1.160 & 0.277 & & 0.026 \\
\hline 147 & $2356-24$ & 42 & 3 & 2 & 1 & 6 & 360.9 & & 0.134 & & 0.027 & & 0.8 \\
\hline 148 & $235-246$ & & 3 & 2 & 1 & 6 & 360.9 & & & & & & 0.3 \\
\hline 149 & $236-245$ & 43 & 3 & 2 & 1 & 6 & 360.9 & 0.223 & 3.329 & 9.350 & 1.757 & & 1.4 \\
\hline 151 & $2356-25$ & 41 & 3 & 3 & 0 & 6 & 360.9 & & 0.893 & 3.100 & 0.489 & & 1.8 \\
\hline 152 & $2356-26$ & 35 & 4 & 2 & 0 & 6 & 360.9 & & & & & & 2 \\
\hline 153 & $245-245$ & 47 & 2 & 2 & 2 & 6 & 360.9 & & 5.636 & 12.20 & 2.347 & & 0.046 \\
\hline 154 & $245-246$ & & 3 & 1 & 2 & 6 & 360.9 & & & & & & 0.2 \\
\hline 155 & $246-246$ & 31 & 4 & 0 & 2 & 6 & 360.9 & & & & & & 0.2 \\
\hline 156 & $2345-34$ & 61 & 1 & 3 & 2 & 6 & 360.9 & & 0.888 & 0.684 & 0.246 & 0.0004 & 0.01 \\
\hline 157 & $234-345$ & & 1 & 3 & 2 & 6 & 360.9 & & & & & 0.0003 & 0.05 \\
\hline 158 & $2346-34$ & 51 & 2 & 2 & 2 & 6 & 360.9 & & 0.995 & & 0.199 & & 0.14 \\
\hline 160 & $23456-3$ & 51 & 2 & 3 & 1 & 6 & 360.9 & & & 0.087 & 0.009 & & 1.5 \\
\hline 161 & $2346-35$ & 46 & 2 & 3 & 1 & 6 & 360.9 & & & & & & 0 \\
\hline 162 & $235-345$ & & 1 & 4 & 1 & 6 & 360.9 & & & & & & 0.015 \\
\hline 163 & $2356-34$ & 50 & 2 & 3 & 1 & 6 & 360.9 & & & & & & 0.03 \\
\hline 164 & $236-345$ & 50 & 2 & 3 & 1 & 6 & 360.9 & & & & & & 1.5 \\
\hline 165 & $2356-35$ & & 2 & 4 & $\mathbf{0}$ & 6 & 360.9 & & & & & & 0 \\
\hline 166 & $23456-4$ & & 2 & 2 & 2 & 6 & 360.9 & & & & & & 0.07 \\
\hline 167 & $245-345$ & 57 & 1 & 3 & 2 & 6 & 360.9 & & 0.646 & & 0.129 & NA & 0.041 \\
\hline 168 & $246-345$ & & 2 & 2 & 2 & 6 & 360.9 & & & & & & 0.07 \\
\hline 169 & $345-345$ & & 0 & 4 & 2 & 6 & 360.9 & & & & & 0.05 & 0 \\
\hline 170 & $2345-234$ & 65 & 2 & 3 & 2 & 7 & 395.3 & & 0.652 & 3.760 & 0.506 & & 0.016 \\
\hline 171 & $2346-234$ & 61 & 3 & 2 & 2 & 7 & 395.3 & & 0.047 & 1.040 & 0.113 & & 0.075 \\
\hline 172 & $2345-235$ & 63 & 2 & 4 & 1 & 7 & 395.3 & & 0.585 & 0.928 & 0.210 & & 0.009 \\
\hline 173 & $23456-23$ & & 3 & 3 & 1 & 7 & 395.3 & & & & & & 2 \\
\hline 174 & $2345-236$ & 59 & 3 & 3 & 1 & 7 & 395.3 & & 0.626 & 4.630 & 0.588 & & 2.4 \\
\hline 175 & $2346-235$ & & 3 & 3 & 1 & 7 & 395.3 & & & & & & 0.14 \\
\hline 178 & $2356-235$ & 53 & 3 & 4 & 0 & 7 & 395.3 & & & 0.900 & 0.090 & & 0 \\
\hline 179 & $2356-236$ & 48 & 4 & 3 & 0 & 7 & 395.3 & & & 2.080 & 0.208 & & 2 \\
\hline
\end{tabular}




\begin{tabular}{|c|c|c|c|c|c|c|c|c|c|c|c|c|c|}
\hline \multirow{2}{*}{$\begin{array}{l}\text { IUPAC } \\
\text { no. }\end{array}$} & \multirow[t]{2}{*}{ Structure } & \multirow{2}{*}{$\begin{array}{l}\text { ORNL } \\
\text { peak no. }\end{array}$} & \multicolumn{4}{|c|}{ Chlorine } & \multirow{2}{*}{$\begin{array}{l}\text { Mol Weight } \\
(\mathrm{g} / \mathrm{mol})\end{array}$} & \multicolumn{4}{|c|}{ Weight \% in Aroclor } & \multirow[t]{2}{*}{ TEF } & \multirow{2}{*}{$\begin{array}{l}\text { Kbi } \\
\left(\mathrm{yr}^{-1}\right)\end{array}$} \\
\hline & & & ortho & meta & para & total & & 1242 & 1254 & 1260 & 70/20/10 Mix & & \\
\hline 180 & $2345-245$ & 64 & 2 & 3 & 2 & 7 & 395.3 & & 0.744 & 11.10 & 1.259 & & 0.003 \\
\hline 181 & $23456-24$ & 59 & 3 & 2 & 2 & 7 & 395.3 & & & & & & 1.5 \\
\hline 182 & $2345-246$ & 54 & 3 & 2 & 2 & 7 & 395.3 & & & & & & 0.05 \\
\hline 183 & $2346-245$ & 56 & 3 & 2 & 2 & 7 & 395.3 & & & 3.100 & 0.310 & & 0.11 \\
\hline 184 & $2346-246$ & & 4 & 1 & 2 & 7 & 395.3 & & & & & & 0.3 \\
\hline 185 & $23456-25$ & 58 & 3 & 3 & 1 & 7 & 395.3 & & & 0.718 & 0.072 & & 1.8 \\
\hline 186 & $23456-26$ & & 4 & 2 & 1 & 7 & 395.3 & & & & & & 2 \\
\hline 187 & $2356-245$ & 54 & 3 & 3 & 1 & 7 & 395.3 & & 0.608 & 5.220 & 0.644 & & 0.03 \\
\hline 188 & 2356.246 & & 4 & 2 & 1 & 7 & 395.3 & & & & & & 0.1 \\
\hline 189 & $2345-345$ & & 1 & 4 & 2 & 7 & 395.3 & & & & & $\mathrm{NA}$ & 0.006 \\
\hline 190 & $23456-34$ & 66 & 2 & 3 & 2 & 7 & 395.3 & & & 0.937 & 0.094 & & 0.044 \\
\hline 191 & 2346-345 & & 2 & 3 & 2 & 7 & 395.3 & & & & & & 0.04 \\
\hline 192 & $23456-35$ & & 2 & 4 & 1 & 7 & 395.3 & & & & & & 0.015 \\
\hline 193 & $2356-345$ & & 2 & 4 & 1 & 7 & 395.3 & & & & & & 0 \\
\hline 194 & $2345-2345$ & 71 & 2 & 4 & 2 & 8 & 429.8 & & & 1.650 & 0.165 & & 0 \\
\hline 195 & $23456 \cdot 234$ & 70 & 3 & 3 & 2 & 8 & 429.8 & & & 0.844 & 0.084 & & 0.044 \\
\hline 196 & $2345-2346$ & & 3 & 3 & 2 & 8 & 429.8 & & & 0.858 & 0.086 & & 0.06 \\
\hline 197 & $2346-2346$ & & 4 & 2 & 2 & 8 & 429.8 & & & & & & 0.1 \\
\hline 198 & $23436-235$ & & 3 & 4 & 1 & 8 & 429.8 & & & & & & 0.05 \\
\hline 199 & $2345-2356$ & 68 & 3 & 4 & 1 & 8 & 429.8 & & & & & & 1.6 \\
\hline 200 & $23456-236$ & & 4 & 3 & 1 & 8 & 429.8 & & & & & & 0.08 \\
\hline 201 & $2346-2356$ & 62 & 4 & 3 & 1 & 8 & 429.8 & & & 1.660 & 0.166 & & 0.003 \\
\hline 202 & $2356-2356$ & & 4 & 4 & 0 & 8 & 429.8 & & & & & & o \\
\hline 203 & $23456-245$ & 69 & 3 & 3 & 2 & 8 & 429.8 & & & 1.232 & 0.123 & & 0.02 \\
\hline 204 & $23456-246$ & 63 & 4 & 2 & 2 & 8 & 429.8 & & & & & & 0.08 \\
\hline 205 & $23456-345$ & & 2 & 4 & 2 & 8 & 429.8 & & & & & & 0 \\
\hline 206 & 23456-2345 & & 3 & 4 & 2 & 9 & 464.2 & & & 0.712 & 0.071 & & 0 \\
\hline 207 & $23456-2346$ & & 4 & 3 & 2 & 9 & 464.2 & & & & & & 0.05 \\
\hline 208 & $23456-2356$ & & 4 & 4 & 1 & 9 & 464.2 & & & & & & 0 \\
\hline 209 & $23456-23456$ & & 4 & 4 & 2 & 10 & 498.7 & & & & & & $\mathbf{0}$ \\
\hline
\end{tabular}

Aroclor composition (weight percent) was provided by GE and was used for $G C$ calibration

TEF (Toxic Equiralence Factor) is the factor the congener concentration should be multiplied by to get the (toxic) equivalent concentration of 2,3,7,8-tetrachlorodibenzo-p-dioxin. NA indicates the congener is a coplanar or monoortho coplanar $\mathrm{PCB}$ without an assigned $\mathrm{TEF}^{36}$

$\mathrm{Kbi}$ is the congener-dependent first-order rate constant for expected PCB disappearance from humans." The congener-dependent reaction rate is combined with the fecal execretion rate ( 0.008 s.' $\left.{ }^{13}\right)$ to give an overall reaction rate. The half-life of a PCB congener " $i$ " may be calculated as $\mathrm{t}_{1 / 2}=(\ln 2)(\mathrm{Kbi}+0.008)$ 


\section{APPENDIX D}

D. A. Abramowicz et al., Environ. Sci. Technol. 27, 1125-1131 (1993).

Reprinted with permission by the copyright owner. 


\title{
Factors Influencing the Rate of Polychlorinated Biphenyl Dechlorination in Hudson River Sediments
}

\author{
Daniel A. Abramowlea, Mlechael d. Brennan, Held M. Van Dort, and Edith L Callagher \\ Bioremodiation Laboratory, Ceneral Eectric Corporate Research and Development, Enviromontal Research Centor. \\ Schenectady, New York 12301
}

The altered distribution of polychlorinated biphenyls (PCBs) observed in equatic sediments due to anserobic microbial activity displays a depletion of highty chlorinated PCB congeners with corresponding increases in the lower chlorinsted PCBs. Laboratory experiments demanstrated PCB dechlorination over a broad range of PCB concentrations (20-1500 ppm) and conditions. The observed rate of anaerobic PCB dechlorination in Hudson River, NY, cediments was most sizmificantly affected by PCB sediment concentrations in both laboratory experiments and in the enviromment. Therefore, these laboratory observations are consistent with the extent of PCB dechlorination oceurring naturally in Hudson River sediments and other aquatic sediments. Additions of various nutrients and surfactants resulted in inhibition or only minor (2fold) rate accelerations compared to unamended sediments. The addition of vitamin $B_{12}$ inhibited PCB dechlorionation rates 3-fold with an apparent $K_{i}$ of 100 m\&/L. Dechlorination of aged PCBs occurred at rates comparable $(80 \%)$ to that of freatly spiked material.

\section{Introduction}

Polychlorinated biphenyls (PCBs) are a family of compounds produced commencinlly by the direct chloriantion of biphenyl, with 209 different PCB congeners poesible (I). PCBa vere manufactured and sold as complex mirtures differing in thair average chlorination level under various trade names (Aroclor, Phenocior, Pyralene, Clophen, and Kanechlor). Because of excellent flame resistance, electrical properties, and chamical stability, PCBs found application in a wide veriety of industrial uses including beat-trannfer fluids, bydraulic fluids, solvent ertenders, planticizers, flame retardinets, organic diluents, and dielectric fluids (I).

In a 50-year period, approximately 1.4 billion pounds of PCBs were produced. Such extensive application of these chemically and thermally stable compounds has resuited in widespread contamination $(2,3)$. It is estimated that several humdred million pounds have been released to the environment (1). Most of the emvironmental contamination by PCBs is in the form of complex commercial mirtures (ef. Aroclar 1242) containing $>60$ different PCB congeners with varying defrees of chlorimation.

The aerobic bacterial biodequadation of PCBs is widely lmown and hn been well studied $(5-8)$. Several microorganisms have been isolated that can serobically degrade even herachiorobiphenyls; how ver, most PCB-dezrading aerobic bacterin are able to degrade only the lower chlorinated PCB congeners. Recently, microbial anaerobic dechlorination of even highly chlorinated PCBs has been demonstrated. These two naturally occurring processes

- Author to whor inquirea should be dinteted: telephone, (518)387-7072: far, (518)387-7611. are complementary, and sequential treatment of PCB mitcrea may result in mare complete destruction $(7,8)$. The altered congener distribution of residual PCB contumination observed in soveral aquatic sediments in cvidence of widespread microbial reductive PCB dechlo. rination in these environments (9-12). This process involves the saloctive removal of $m$ - and p-chlorines, resultiog in the deplotion of highly chlorinated PCB congevers with corresponding incresses in lower ehlori. nated, artho-substituted PCBs. This same activity has been observedin the laboratory $(13-16)$, where the selective removal of $m$ - and p-chlorines was also noted.

This paper will focus on recent findings involving factors that influence the rate of PCB dechlorination in laboratory coperiments with Hudson River sediments and how these reoults compere with documented environmental changes It is not clear what effect $\mathrm{PCB}$ concentration may have on PCB dehrlogenntion rates from previous stadies. This tady will directly compare dechlorination rates at various PCB concentrations in the laboratory with the ertent of altered PCB dintributions in the enviranment at the same PCB concentrotions.

\section{Materials and Methods}

Eodimant Colloction. The sadiments were collected ind stonsed unt we in soaled vessels at $4^{\circ} \mathrm{C}$. Aroclor 1242 couminated sediment ( 20 ppm) was taken from the upper Fndean River at river mile 193.5 (H7 aite) near Fort Ddward, NY (9). All experiments involving the use of PCB-couteminated Hudion River sediments were performed oxing anly H7 sodiments. The PCBs in this rediment had already been extensively dechlorinated by indigenous manobicmicroorganims in the environment. Arocior 1222 contaminated soil wes collected from the South Gl we Falla Dras Strip in Morean, NY. The original PCB micture in this soil eveporated over time and is now rimiln to Aroclor 1248. Clean (containing <1 ppm PCB) cediment obsened from the upper Fudson River at river mile 205, near Corinth, NY (Spier Falls site).

AnnemiseDechlorination Btudiex. All experimental procedures and sompling were performed in an oxygenfree atmoly $\left(95 \% \mathrm{~N}_{2}, 5 \% \mathrm{H}_{2}\right)$ within a glovebox. The wet sediment wa mired with liquid medium at a $2: 3$ ratio (vv) to prodece a sediment alury from which aliquots were rewond while mixing to obtain reproducible sam. pling. Unies otherwise stated, the medium consisted of a previoubls dnccibed revised anawobic minimal medium RAMMD, which cortains phosphate buffer, mineral salts, and trace methe modified with Zahnder and Wubrmann (17, 18) reduced with $0.1 \%$ L-y taina hydrochloride. The alury $\mathrm{mm}$ te. maforred into serum bottles $(2 \mathrm{~mL})$ into 10 mL serwm bottles or $30 \mathrm{~mL}$ into $50-\mathrm{mL}$ bottles) with a sterile, nitwogen-fluhed, wido-bore pipet. Samples were crimpsenled with Teflon-lined septa (Wheaton Scientific), vigurou is vertead for 1 min, and incubated statically in the dert $+23^{\circ} \mathrm{C}$. Identical samples autoclaved contin- 
uoualy for $3 \mathrm{~h}$ at $121^{\circ} \mathrm{C}$ served as controls. These artoclaved controls remained stable and inactive throughout the course of the experiments.

PCB addition to samples was performed from a concentrated PCB solution prepared in acetone. Aliquants of a compler PCB mirture of Aroclors 1242/1254/1260 (7: 2:1) or of a single PCB congener solution (2,3,4,3',4'pentachlorobiphenyl) were added to the sediment slurry to a final PCB concentration of 20-1500 ppm ( $\mu \mathrm{g} / \mathrm{mL}$ ) PCB. PCBs (Aroclor mirtures and single congeners) were purchased from AccuStandard (New Haven, CT).

RAMOM minus metals in the amendments study consisted of RAMMM lacking the trace metals component. Bacto fluid thioglycollate medium with beef ertract (Difoo Iaboratories, Detroit, MI) was added to an aqueous final concentration of $1.0 \mathrm{mg} / \mathrm{mI}$. Various nonionic detergents were investigated, such as Triton X-100, X-405, and X-750 (Rohn and Haas, Philadelphia, PA) at a concentration of 600 ppm, while sodium dodecyi benzene sulfonate (SDBS) was the anionic detergent used at the same concentration. Vitamin $B_{12}$ (Sigma Biochemical Co., St. Louis, MO) addition to the sediment slury was an aqueous solution.

PCB Ixtraction. Extraction of PCBs from 2-mL codiment alurry samples involved extraction of the entire cerum bottle and contents with $6 \mathrm{~mL}$ of diethyl ether (3:1 ratio, v.v). For the larger 30-mL slurry smples, serm bottles were returned to the glovebox, vortered for $30 \mathrm{~s}$, and immediately uncapped, and a 1-mL aliquot was withdrawn with a wido-bore pipet. These serum bottles were then resealed and asain stored stationary in the dart at $23^{\circ} \mathrm{C}$ for additional time points. This $1-\mathrm{mL}$ sample wes then extracted by addition of $3-5 \mathrm{~mL}$ of diethyl ether. Both extractions, 2-mL cediment vlury samples and 1-mL camples from 30-mL codiment slurries, yielded $>95 \%$ recovery of the PCB. Appromimately $0.5 \mathrm{~mL}$ of elemental mercury/mL of sediment slury was sdded to the ether/ codiment mixture to remove elemental sulfur and other culfur compounds present in sediment that can interfere with PCB analynis with an electron capture detector. Extraction vials were sealed, shnken vigorouly for 12-16 h on a horizontal ahaker, and centrifuged at $170 \mathrm{~g}$ for 30 min, and the ether phase of the supernatant was removed for subsequent gas chromstographic analyais.

Gas Chromatography. The ether phase was diluted with additional diethyl ether to a final PCB concentration of 1-10 ppm. This solution was analyzed by capillary gas chromatography with an electron capture detector (Varian Instruments, Walnut Creek, CA) on a fused silica capillary column ( $30 \mathrm{~m} \times 0.25 \mathrm{mmid}$ ) coated with $\mathrm{a} 0.25-\mu \mathrm{m}$ bonded liquid phase of DB-1 (polydimethylailorane, J\&W Scientific, Folsom, CA). The sample injector and detector were maintained at $300^{\circ} \mathrm{C}$; the column underwent a temperature profile of $160^{\circ} \mathrm{C}$ for $3 \mathrm{~min}$, ramp to $200^{\circ} \mathrm{C}$ at a rate of $2^{\circ} \mathrm{C} / m i n$, and a final ramp to $280^{\circ} \mathrm{C}$ at a rate of $8^{\circ} \mathrm{C} / \mathrm{min}$. Peak identities and individual response factors were determined for the 118-peat profile a previously described (11).

Chlorine Loss Determination. The average number of chlorines per biphenyl in the PCB mirtures was determined to compare the rate and extent of dechlorination. The dechlorination rate was defined as the micromoles of chlorine released per gram of sediment per unit of time. The dechlorination rates were quantified by determining the direct loss of chlorines, represented by the average number of $m$-chlorines plus p-chlorines per

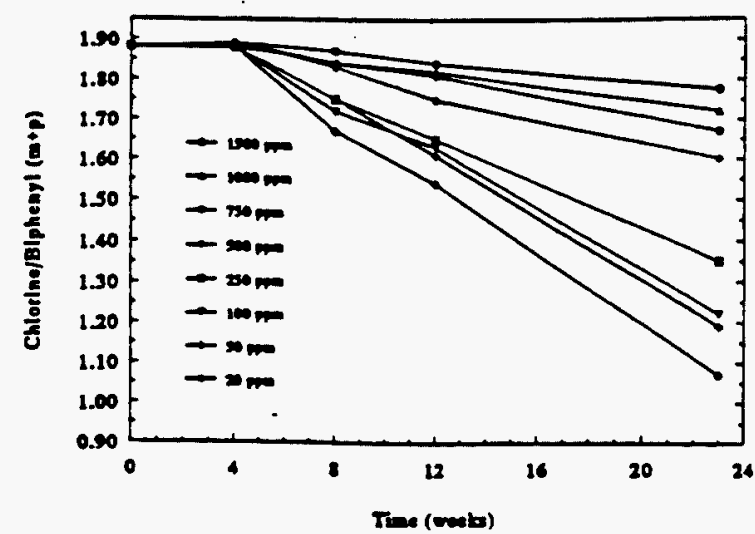

Fives 1. Effect of PCB concentration on the rate of PCB dectionthation in Huctson Pitwer sediment (20-1500 ppm PCB mbeture of Aroctor 1242/ 1254/1280). Dectionination was montioned by the changes in $m$ and pectiontine levels in the PCB mbetere.

biphenyl in the Aroclor mirture. The relative contribution of different PCB congeners in coeluting gas chromatocraphic peaks in the original Aroclor mirtures was determined by using the Hall electrode and mass spectrometry performed by R. J. May at the General Electric Research and Development Center $(11,14)$. No attempt was made to confirm these relative contributions upon annerobic dechlorination.

\section{Results}

Concentration Effect. PCB dechlorination was obeerved in laboratory experiments over a broad range of PCB concentrations, including 20-1500 ppm using the eddition of a PCB mixture comprising Aroclors 1242, 1254, and 1260 es ahown in Fipure 1. Significant decresses in the average chlorine level with time indicate that dechlorination occurs even at the lowest concentrations. Indeed the greateat changes in the average $m$-and p-chlorine level ware observed at the loweat PCB concentration investipated (20 ppm). The average number of o-chlorines per biphenyl remained unchanged under all conditions. This reoult differs from the earliest report of anaerobic PCB dechlorination, where no significant dechlorination was observed at lon concentrations of $14 \mathrm{ppm}$, wheress dechlorination wes observed at 140 and 700 ppm (13). PCB dechlorination in these experiments was observed after 4 weelo, and the rates remained constant for all PCB concentrations. Figure 1 appears to indicate that PCB dechlorination is alower at higher PCB concentrations; bowever, this is not the case. Actual dechlorination rates at various PCB concentrations can be determined by calculating total moles of chlorine removed over time per unit of sediment (Figure 2). The most rapid specific ectivity was observed at the highest concentrations (>750 ppm). Dechlorination rates are independent of PCB concentration at these higher concentrations, while a rearly linear relationship is noted between 0 and 250 ppm PCB.

Notrients. The addition of a minimal medium (RAMM) to the sediment resulted in a 2-fold increase in the rate of dechlorination and a 2 -fold decrease in the lag period as compared to the addition of only distilled water to the Hudson River sediment (Figure 3). This result angests that a nutrient present in RAMM may be limiting in upper Hudson River sediment. Sea salt completely inhibited dechlorination in the freshwater upper Hudson 


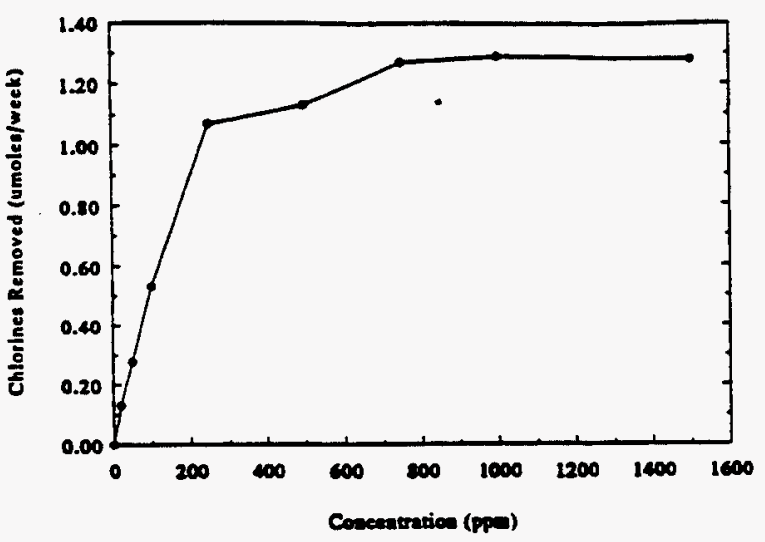

Froure 2. Relationship between PCB dechiorination rate and PCB concentration in thutson River sediment after 23 weeks, as measered by the total moles of chiorine removed per unt of sediment.

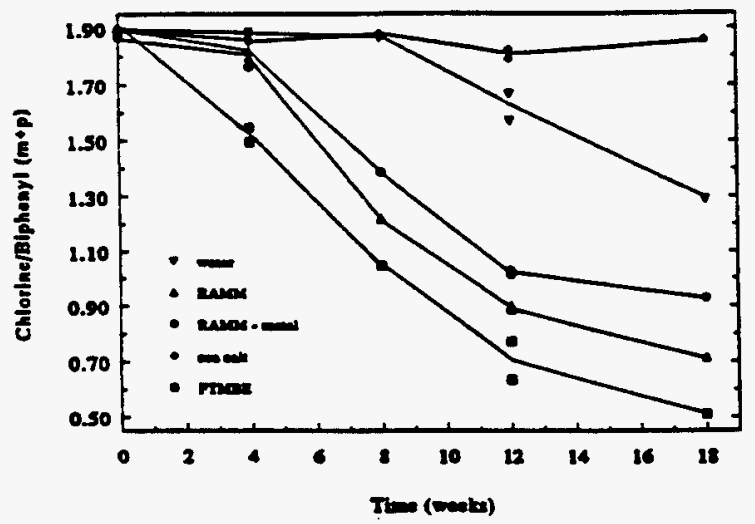

Pare 3. Eftect of amendments on PCB dectiontiation rates. $A$ eamples contein 500 pom PCB mbture (Aroctor 1242/1254/1260).

River sedimenta. With the addition of a complex carbon source to the RAMM, eg, fluid thioglycollate medium with beef erthact (FTMBE), the lag period was shortened, if not totally eliminated, and dechlorination rate increases were comparable to those observed with RAMM alone. Removing the motals from RAMM did not affect the lag, but did have a slight negative effect on the rate and extent of dechlorination. At later time points, more extensive dechlorination occurred in the water-only sample (data not shown).

Single congeners can be utilized to assess the effects of various sediment amendments, to determine the pathway of dechlorination, and to measure specific dechlorination rates. The stepwise dechlorination of the single congener $2,3,4,3^{\prime}, 4^{\prime}$-pentachlorobiphenyl $\left(2,3,4,3^{\prime}, 4^{\prime}-\mathrm{CB}^{\prime}\right)$ observed in Hudson River sediment with complete RAMM is shown in Figure 4. The dechlorination activity demonstrates a sequential and selective pathway. At the end of 12 weeks, the distribution of PCB congeners included $<1 \%$ of $2,4,3^{\prime}, 4^{\prime}-\mathrm{CB}, 5 \%$ of $2,4,3^{\prime}-\mathrm{CB}^{\prime}, 21 \%$ of $2,3^{\prime}-\mathrm{CB}$, and $29 \%$ of 2-CB with $44 \%$ of the starting penta-CB $\left(2,3,4,3^{\prime}, 4^{\prime}-\mathrm{CB}\right)$ remaining. This result demonstrates chlorine removal exclusively from the metal and para positions as was observed naturally in the river sediment (10). Strong selectivity was observed for each individual step; for example, 2,4,3',4'-CB is the only detectable tetrachlorinated product from $2,3,4,3^{\prime}, 4^{\prime}-\mathrm{CB}$ with Hudson River sediments, and it is produced in stoichiometric amounts. The end result of this process is the complete conversion
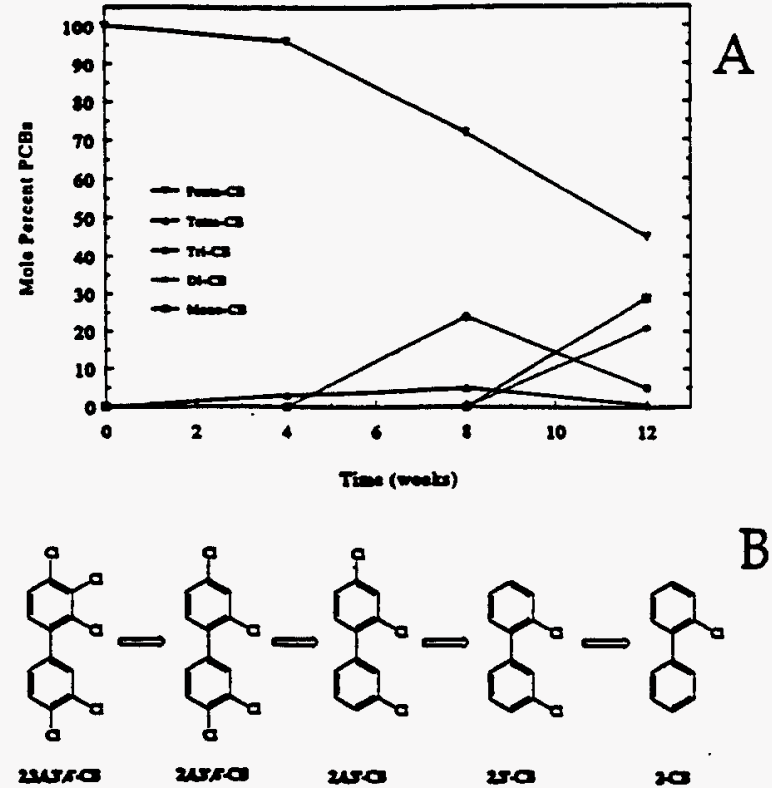

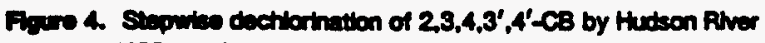
eciment (100 pin).

of a pentachlorobiphenyl via selective removal of all the $m$ - and p-chlorines into a monochlorobiphenyl that can be easily metabolized by aerobic bacteria.

Individual RAMM components were added in various combinations and concentrations to further investigate the stimulation of dechlorination of $2,3,4,3^{\prime}, 4^{\prime}$-CB observed with whole RAMM. The reductant cysteine hydrochloride was present in all cases. Note that the addition of the trace metale 2 (II), Cu(II), Ni(II), Se(II), and B(III) correlated with nearly a 2 fold increase in the rate of $2,3,4,3,4^{\prime}-\mathrm{CB}$ dechlorination. This rate acceleration is similar to that observed with whole RAMM (Figure 3) end is independent of the other components of RAMM. This accelention suggests that one or more of these trace motals mny represent a component that limits maximal PCB dechlo rimation rates in Hudson River sediment. Note that the selective pathway for $2,3,4,3^{\prime}, 4^{\prime}-\mathrm{CB}$ dechlorination was identicl under all conditions in these experiments. This unittened apecificity under a variety of conditions cuggests thes the same PCB dechlorinating microorganims are active Although the rate acceleration here closely recombles thin observed when RAMM itself was tested agninat Alucle mixtures, the effects may differ with different co aners or microbial populations.

The abitit of Hudson River sediment uncontaminated with PCBe (Spier Falls) to demonstrate PCB dechlorination activis was also investigated in this laboratory. Both Spier P.T, and Hudson River (H7) sediments were spiked with the single congener $2,3,4,3^{\prime}, 4^{\prime}-\mathrm{CB}$. Dechlorinstion wedetected in PCB-contaminated H7 sediment within 4 (Table I) and after 18 weeks in the uncontami ted Spier Falls sediment. Therefore, PCB dechlorint smicroorganiams are certainly present even in uncontm. inted sediments. The longer lag times before the activity observed is consistent with a lower initial cancentarat of these microorganisms in the uncontaminated emsorment.

Bnviro antally Transformed PCBs. It is possible that biodsolntion studies on soils spiked with PCBs may not pusi-lo sceurate linetic data for similar exper- 
Table I. Comparienn of PCB Dechlorination Bates Obearved with PCB-Contaminnted (B7) and

Uncontaminnted (Spior Falls) Hadeon Biver Sodiments (600 ppm 23,43',4'-CB Added)

\begin{tabular}{ccc} 
& \multicolumn{2}{c}{$\%$ dechlorination } \\
\cline { 2 - 3 } time (wk) & contramionted & uncontrminated \\
0 & 0.0 & 0.0 \\
4 & 5.0 & 0.0 \\
8 & 19.7 & 0.0 \\
12 & 23.6 & 0.0 \\
18 & $\mathrm{ND}$ & 9.0 \\
32 & 90.0 & 18.2
\end{tabular}

- ND = not detarmined.

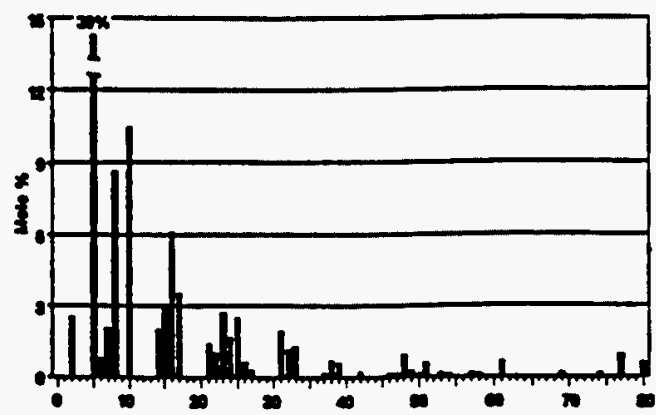

A
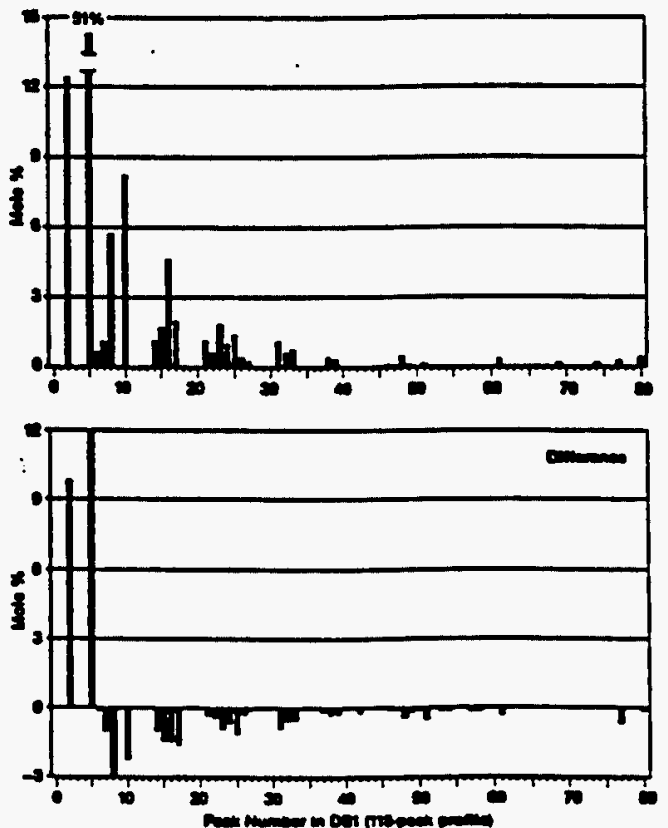

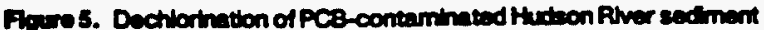
(24-weck timepolth, H7 stow). (Panel A) autocterved conterd (Panel B) Experimental. (Panel C) Difterenco tpakk $2=2-C B$, peak $5=2,2$ and 2,6-CB).

iments on aged PCB contamination. Howrever, it has been demonstrated in these experiments that anserobic microorganisms can dechlorinate such aged, environmental PCB contamination in several PCB-contaminated sediments, including PCBs from the Hudson River (Figure 5) and the South Glens Falls Drag Strip (Figure 6). These results are not surprising, since there erist several examples of natural, environmental dechlorination in PCB-contaminated sediments $(9-12,19)$. The observed dechlorination activity attacks nearly all of the more highly

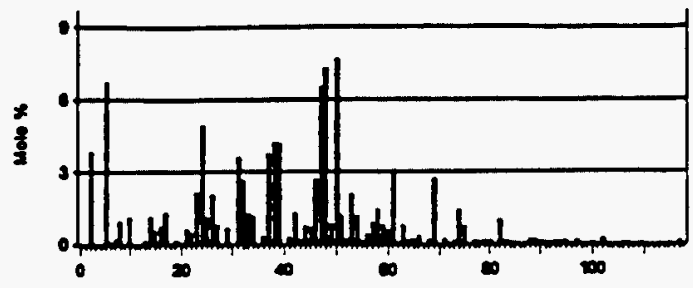

A

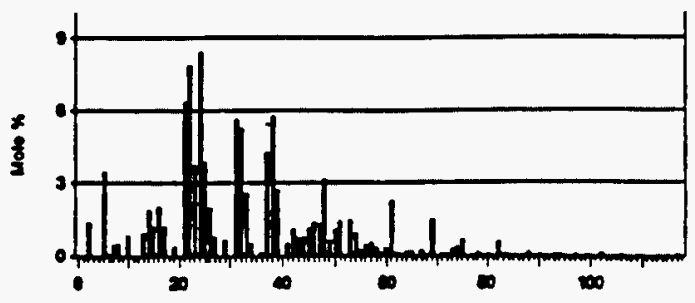

B

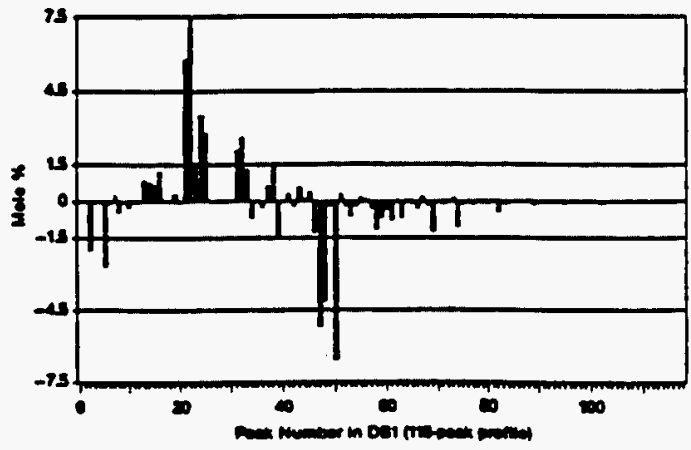

C

Fipere C. Ductiontration of PCB-contaminatud South Gens Fals soll

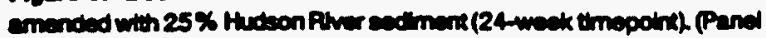

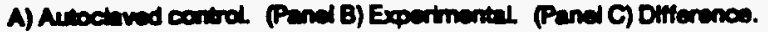

chlorinnted PCB congeners (difference plot in Figure 5 and 6 ) and is, therefore, quite broad in its specificity. By 24 weeks with Hudson River sodiments, the 2-CB bns increased from $<3$ to $>12$ mol \% and the 2,2'- ad 2,6-CB have inereanod from 39 to $51 \mathrm{~mol} \%$. Note that no ortho dechlorination wes detected and that lower chlorinated atho-enriched congeners eccumulated. With Hudson River sodiments, the exirting PCB contamination already dimplays evidence of aignificant PCB dechlorination (Figure 5A). The additional dechlorination detected in the Inboratory on this aged PCB material (Figure 5C) is similar in specificity to the extensive dechlorination pattern observed in upper Hudson River sediments, environmental pattern $\mathrm{C}$ (10).

The dechlorination rate with this aged contamination is comparable to that observed with Hudson River codiment apited with PCB mirtures. The aged anmple contained approximately 20 ppm of a dechlorinated PCB misture orijinlly contaminated over 15 years ago, which decreased from 255 to 2.23 total average chlorines per bipheayl within 24 weelos (0.0133 chlorine/week). The freably spilsed 20 ppm umplo decreased 0.80 chlorine par biphenyl in 23 meelo (Figure 1, 0.0348 chlorine/week, no ortho dochlocinntion). To directly compare these two results, one must consider that 52\% of the PCB congeners in the ased ample contain only o-chlorines (peairs 2,5 , and 10). No additional dechlorination of these PCBs is expected, ince ortho dechlorination has never been reported with Hudson River sodiments. Therefore, only 48\% of the PCBs in this aged sample can be further dechlocinnted. If all of the PCBs were available for 


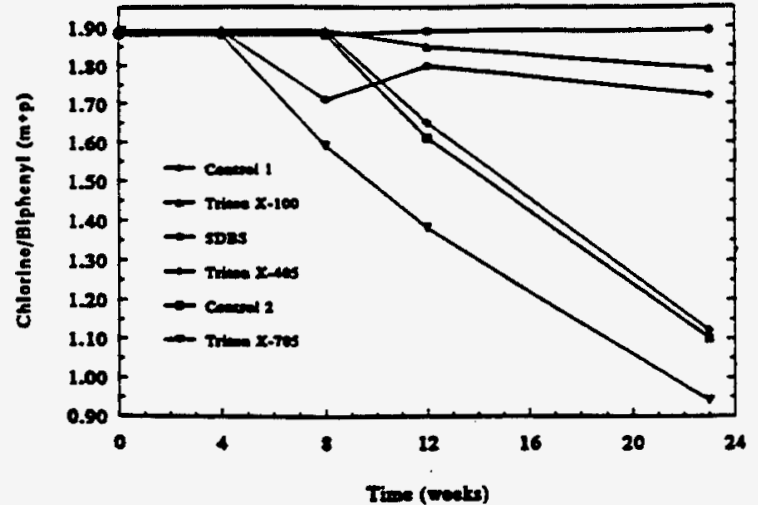

Fine 7. Effect of detergents on the rate of dectiorination in Huctson

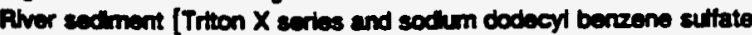
(EDBS) 600 pprm; 500 ppen FCB mbure of Aroctor 1242/1254/1260].

dechlorination, the expected rate would be 0.0277 chlorine/ week $[(0.0133 \mathrm{Cl} /$ wh divided by 0.48$) 80 \%$ of the rate with spiked PCBs].

The successful dechlorination of the aged Aroclor 1242 contamination in the drag strip soil demonstrates potential application to contaminated soils as well as sediments. The difference plot (Figure 6C) displays strong losses of the more highly chlorinated congeners (peak $39=2,3,6,4^{\prime}-$; penk $47=2,5,3^{\prime}, 4^{\prime}-;$ peak $48=2,3,6,2^{\prime}, 5^{\prime}-;$ and peak $50=$ $\left.2,3,3^{\prime}, 4^{\prime}-\mathrm{CB}\right)$ with the production of primarily tri- and dichlorinated products (peak $21=2,5,3^{\prime}-$; peak $22=2,4,3^{\prime}$-; peak $23=2,5,4^{\prime}-;$ peak $24=2,4,4^{\prime}-12,4,6,2^{\prime}-;$ peak $25=$ $3,4,2^{\prime}-12,3,3^{\prime}-12,3,4-;$ peak $31=2,5,2^{\prime}, 5^{\prime}-12,6,3^{\prime}, 5^{\prime}$-; and peak $\left.32=2,4,2,5^{\prime}-\mathrm{CB}\right)$.

Other Factors. Other agents investigated for their effect on PCB dechlorination ratea in Hudson River sediment include nonionic and ionichigh molecular weight surfactants (eg., Triton X saries, and sodium dodecyl benzenesulfonate (SDBS), respectively). SDBS (600 ppm) completely inhibited dechlorination, while Triton X-100 and both controls (without detargent) became active after 8 weelss (Figure 7). Live controls include complete RAMM with no other additions. Triton X-100 and X-405 dopressed the observed rate of dechlorinntion approrimately 8-fold. In contrast, high molecular weight Triton X-705 did not inhibit the dechlorination rate compared to the controls and reduced the lag period 2-fold. Dechlorination was more extensive at 12 weels with Triton X-705 than under any other conditions. Such conditions also atimulated dechlorination in Woods Pond (Lenox, MA) sediment (20). In general, as the molecular weight of the nonionic Triton $X$ surfactant increases, the lag times are decreased, and dechlorination is no longer inhibited.

It is known that corrinoids, including cobalamin vitamin $B_{12}$, can catalyze the reductive dechlorination of chlorinated organios in the presence of an electron donor (21, 22). It is possible that these cobalt-heme coenzymes may play an important role in anaerobic microbial PCB dehalogenation as well (23). Therefore, the effect of vitamin $B_{12}$ on the rate of $2,3,4,3^{\prime}, 4^{\prime}-C B$ dechlorination was investigated at several concentrations using Hudson River sediment (Figure 8). The addition of vitamin $B_{12}$ inhibited dechlorination of $2,3,4,3^{\prime}, 4^{\prime}-\mathrm{CB}$ with an apparent inhibitory concentration $\left(K_{i}\right)$ of approximately $100 \mu g / L$, although complete inhibition was not observed.

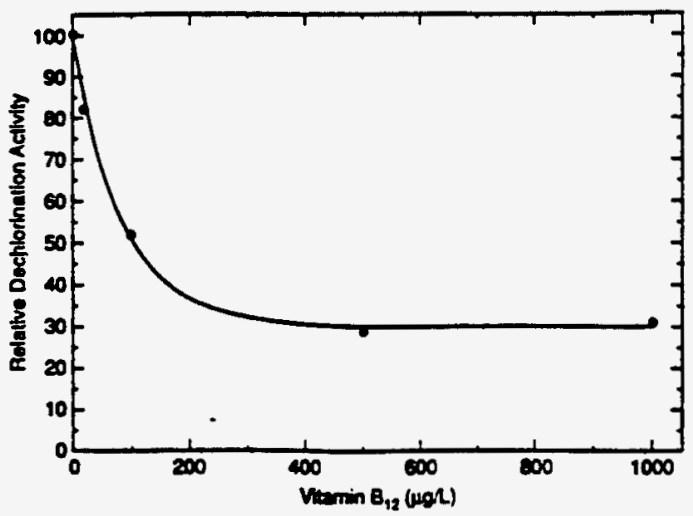

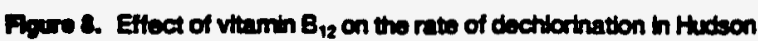
Prvor secimont (100 ppm 2,3,4,3',4'-C8).

\section{Discussion}

Annerobic microbial dechlorination of a variety of chlorinated aromatic compounds is well known; a review of the anaerobic dehalogenation of pesticides, chlorobensoates, chlorophenols, chloroanisoles, and herbicides has recently been published (24). Moreover, the microbial dechlorination of PCBs first discovered in the environment $(9-11)$ has now alwo been observed in the laboratory (13$16,25,26)$.

Dechlorination Rate Enhancement. The rate of PCB dechlorination in Hudson River sediments can be affected by various factors, with PCB concentrations being most aignificant. There is a aignificant increase in dechlorination rates as measured by the direct chlorine removal with increasing PCB concentrations (eee Figure 2). The obeerved rate of dechlorination is nearly linear until a threahold is reached (-250 ppm) where the rate is independent of PCB concentration. This laboratory result may be important to help understand the natural rates of dechlorination occurring in Hudson River sediments. In these sediments, PCB concentrations are generally below 250 and most are $\angle 50 \mathrm{ppm}$ (dry weight). Direct correlations between PCB concentrations and observed rates of dechlorinntion in the environment have been found, with mare extranive dechlorination noted at higher PCB concentration in the river. A greater percentage of codiment samples displayed extensive dechlorination with increasing PCB concentration, including $63 \%, 65 \%, 69 \%$, $86 \%$, and $93 \%$ of the 2000 samples containing 5-10, 10$20,20-50,50-100$, and $>100 \mathrm{ppm}$ PCB, respectively (27, 28). In addition, this demonstrates that PCB dechlorination occusent very low PCB concentrations (5-10 ppm), consistent with the result displayed in Figure 2

Tha curved ons.nstrating the relationship between PCB concentration and dechlorination rate (Figure 2) can be clocely fit to M.T. boelis-Menten hinetic parameters, yielding a $K_{m}$ value of approsimately 160 ppm PCB. However, it must be recoprized that the PCB mixture used in these experimentairsoluble in water to only extremely low levels (<1 ppm). Therefore, the added PCB level is not an sccurrate indicutor of soluble aubstrate concentrations. The relationhip diplayed in Figure 2 can more easily be explained bs simple physical partitioning of the substrate between the axwous phase and the solid organic phase of the sediment Uning typical partition coefficients for sediment orgu cmatter, concentrations of nearly $300 \mathrm{ppm}$ PCB would be required in the sediment to saturate PCB 
levels in the porewater (29). The nearly linear trend obeerved from 0 to $250 \mathrm{ppm}$ correlates well with expected substrate concentrations in the porewater. Rates are thus directly proportional to aqueous substrate concentrations, with saturated PCB levels in the equeous phase at sediment PCB concentrations greater than approrimately $300 \mathrm{ppm}$.

Dechlorination was observed in sediments which had received no amendments other than water, although with a longer lag period (see Figure 3). At later time points, the dechlorination continued in these sediments with imilar but leas ertensive changes than those observed in the nutrient-aupplement samples. These results are consistent with the observation that unamended upper Hudson River sediments undergo PCB dechlorination in the environment $(27,28)$.

The effect of vitamin $B_{12}$ on the dechlorination rate is shown in Figure 8. The decreased dechlorination activity in these experiments may be explained by the known inactivation of encymes with vitamin $B_{12}$ in the presence of amall molecular weight thiols (30-32). Harads and coworkers showed that micromolar (uM) concantrations of corrinoids like cyanocobinamide (factor B) and cobalamin (vitamin $B_{12}$ ) inactivate papain and yeast alcohol dehydrogenase via the formation of mired disulfides between amall molecular weight thiols and the encymes. The medium utilized in this experiment contained added cyuteine, so that the inhibition of PCB dechlorination may be explained by a cimilar ensyme inactivation. An alternate explanation could involve naturally produced thiols as the nucleophile responsible for the in vivo dechlorination (e-go, lipoic acid). Thiols are known to be involved in the direct nucleophilic displecement of chlorine from PCBs (33) and from chlorobeneses (33-35). Therefore, the added coenryme could inhibit dechlorination by inactivating the natural thiol nucleophile respomible for chloride displacement via disulfide formation.

Conclnsions. Support for ubiquitous anserobic PCB dechlorination includes the presence of dechlarinating microorganisms in PCB-free rediments (Table D), the observation of PCB dechlorination in unamended sodiments (Figure 3), the demomitration of dechlorination over a wide range of PCB concentrations (Figure 2), the documentation of wideapread enviranmental PCB dechlorination in Hudson River sediments $(27,28)$, snd similar environmental changes occurring at a number of other sites $(7,8,12,19)$. Although sea salt inhibited dechlorination in freshwater Hudson River sediments. PCB dechlorination also occurs in marine enviranments (19). Experiments on a variety of PCB-contaminated soils and cediments have demonstrated that this anserobic process will effectively attack even aged PCB-contaminated samples at rates comparable to that observed with spiked PCB anmples.

The effect of PCB concentration on dechlorination rates demonstrated in the Inboratory in comsistent with the ertent of dechlorination that his occured naturally in anaerobic sediments. Therefore, such haboratory results help to explain factors governing the rate of environmental tranaformations.

Widespread occurrence of anaerobic dechlorination in different sediments and in uncontaminated sediments indicates that it is a general phenomenon that oceurs in environments that differ grestly in their geography, seasonal temperature, microbial population, PCB concentration, PCB composition, and organic content. Such widespread dechlorination sugsests that either the dechlorinating organisens are ubiquitous or, more likely, that this process is part of a common biochemical pathway found in many different anserobic organisms.

\section{Acknowledgments}

The authors would like to thank Prof. Martin Stiles (University of Kentucly) for helpful discuscions regarding dechlorination mechanisms, Prof. Bruce Brownawell (SUNY, Stony Brook) for helpful discusaions on porewater substrate concentritions, and George M. Frame and Ralph J. May for invaluable asaistance in PCB analyses.

\section{Literature Cited}

(1) Hutringer, O.; Safe, S.; Zitko, V. The Chemistry of PCBs; CRC Pres: Cleveland, OH, 1974.

(2) Jensen, S. New Sci 1966, 32, 612

(3) Buctley, E. H. Science 1982, 216, 520-522.

(4) Hutringer, $0_{\text {; }}$ Veertamp, W. In Microbial degradation of xenobiatica and recalcitrant compounds; Leiainger, $T$. Hutter, R. Cook, A. M., Nuesch, J., Eds,; Academic Preas, Inc: Nen York, 1981; pp 3-45.

(5) Furuterm, K. In Biodegredation and detoxification of environmental pollutants; Chntraberty, A M., Ed.; CRC Preas, Ine: Bocn, Rntan, FL, 1982; pp 33-57.

(6) Funutown, K. In PCB, and the environment; Waid, J. S. Bd; CRC Preas, Inc: Boca Raton, FL, 1986; Vol 2, pp 89-99.

(D) Abramonica D. A In CRC Critical Reviews in Biotechnology, Steward, G. G. Ruseall, L, Eds.; CRC Press, Inc: Boca Raton, FL, 1990; Vol 10, pp 211-251.

(B) Bednrd, D. L In Biotechnology and biodegradation; Knmaly, D, Chritrabarty, A, Omenn, G. S., Edr.; Portfolio Publinhing Ca: The Woodlinds, TX, 1990; pp 369-388.

(9) Brown, J. F, Jr; Ferner, R. E; Bedard, D. L.; Brennan, M. J; Camahan, J. C. May, R. J. Northeast. Environ. Sci. 1984, 3 , 167-179.

(10) Brown, J.P. Jr.; Bedurd, D. L.; Brennan, M. J.; Carnaban. J. C. Fens. H. Wapner, R. E Science 1987, 236, 709-712

(11) Brown, J. F. Jr.; Wagner, R E. Feng, H; Boderd, D. L; Breman, M.J; Curnehne, J. C; Mny, R. J. Environ. Toricol Chem. 1587, 5, 579-593.

(12) Brown. J. P. Wagner, R E Enwiron. Toxicol. Chem. 1990, 9, 1215-1233.

(13) Queneen, J. F., III; Tiedje, J. M; Boyd, S. A Science 1988, 262, 752-754.

(14) Quenecen, J.F. III;Boyd, S. A.Tiedje, J. M. AppL Environ. Micrabiol 1990, 56, 2360-2369.

(15) Abramonicz, D. A.; Brenanen, M. J.; Van Dort, H. M. In Ixtended abetracts; 198th American Chemical Society National Moeting, Division of Environmental Chemistry: Wanhingtoon, DC, 1989, Vol. 29, pp 377-379 (ISSN 09333066).

(16) Abramonica, D. A.; Brennan, M J.; Van Dort, H. M. Galleter, B.L. In Chemical and biochemical det oxification of haserdous warte II; Glaver, J., Ed, Lowis Publishers: Cheber MI, 1990.

(17) Shelton,D.R.Tiedje, J.M. AppL Environ. Microbiol. 1984, 17, 850-857.

(18) Zahnder. A. J. B; Wuhrmann, K. Areh. Microbiol. 1977, 111, $199-205$.

(19) Lake, J. L; Pruall, R J; Osterman, F. A Mar. Environ. Res. $1922,33,1-17$.

(20) Bodard, D. L General Flectric Research and Development Center, Schenectedy, NY, personal communication, 1991.

(21) Krope, U. E: Thnuer, R. K. Hogentenmp, H. P. C. Biochescintry 1989, 28, $4908-4914$.

(22) Gantere, C. J.; Wectett, L. P. Environ. Sci. Technol. 1991, 25, 715-722

(23) Araf-A id, N.; Nies, Li Vogel, T. M. Appl. Environ. Yicrobiel 1992, 58, 1057-1060. 
(24) Kuhn, E. P; Suflita, J. M. In Reactions and movement of organic chemicals in soils; Sawhney, B. L., Brown, K., Eds.; SSSA Special Publication 22; Soil Science Society of America: Madison, WL, 1989, pp 111-180.

(25) Chen, M; Hong, C. S.; Bush, B.; Rhee, G.-Y. Ecotoxicol. Environ Saf. 1988, 16, 95-105.

(26) Nies, L; Vogel, T. M. Appl. Enviror. Microbiol. 1990, 56, 2612-2617.

(27) Abramowic, D. A.; Brown, J. F., Jr.; O'Donnell, M K In Research and Development Progrem for the Destruction of PCBs, Tenth Progress Report, General Electric Co. Schenectady, NY, 1991; pp 17-30.

(28) Abramowicz, D.A.;Brown,J.F.Harkeas, M.R; O'Donnell, M. K. In Proceedings of International Symposium on Implementation of Biotechnology in Industrial Waste ratment and Bioremediation; Lewis Publishers: Chelsen, MI, 1992.
(29) Brownawell, B. State Univeraity of New York at Stony Brook, NY, perconal communication, 1992.

(30) Harada, K.; Hitomi, H.; Utrumi, I Vitamins 1975, 19, 163170.

(31) Harads, K; Hitomi, H; Uttumi, I Vitamins 1975, 49, 201206.

(32) Harada, K; Hitomi, H; Utsumi, I Vitamins 1975, 49, 207210.

(33) Brunelle, D. J. Chemosphere 1983, 12, 167-181.

(34) Testaferri, L; Tieceo, M; Tingoli, M.; Chianelli, D.; Montanucei, M. Synthesis 1983, 751-755.

(35) Pastor, S. D.; Hearell, E. T. J. Org. Chem. 1985, 50, 48124815.

Received for review August 11, 1992. Revised monuseript received December 7, 1992. Accepted February 12, 1993. 
D. L. Bedard et al., "Activating Microbial Dechlorination of Aroclor 1260 in Woods Pond: A Field Study," pp.15-44 in Research and Development Program for the Destruction of PCBs, 12th Progress Report August 1, 1992-July 31, 1993, eds. D. A. Abramowicz and S. B. Hamilton, General Electric Company Corporate Research and Development, Schenectady, N.Y., September 1993

L. A. Smullen et al. "Development of a Customized Congener Specific PCB Standard for Qualification of Woods Pond Sediment PCBs," pp. 45-66 in Research and Development Program for the Destruction of PCBs, 12th Progress Report August 1, 1992-July 31, 1993, eds. D. A. Abramowicz and S. B. Hamilton, General Electric Company Corporate Research and Development, Schenectady, N.Y., September 1993

Reprinted with permission by the copyright owner. 


\title{
ACTIVATING MICROBIAL DECHLORINATION OF AROCLOR 1260 IN WOODS POND: A FIELD STUDY
}

\author{
Donna L. Bedard, Lynn A. Smullen, Kim A. DeWeerd, David K. Dietrich, \\ George M. Frame II, and Jan M. Principe \\ Environmental Laboratory \\ General Electric Corporate Research and Development \\ Schenectady, New York

\begin{abstract}
Thomas O. Rouse, William A. Fessler and Jeffrey S. Nicholson Pittsfield, Massachusetts
\end{abstract} \\ General Electric Pittsfield Environmental and Facilities Programs
}

\section{INTRODUCTION}

Woods Pond (Lenox, Massachusetts) is a shallow impoundment on the Housatonic River. For many years PCBs accumulated in the pond as a result of their release from now-discontinued GE transformer manufacturing operations in Pittsfield, 11 miles upstream. In 1981 GE signed a joint consent order with the US Environmental Protection Agency (EPA) and the Massachusetts Department of Environmental Protection (DEP), and in 1990 signed another consent order with DEP based on the Massachusetts Contingency Plan. GE has also received a RCRA (Resource Conservation and Recovery Act) corrective action permit from EPA Region I. Thus GE is under federal and state orders to conduct investigations of PCBs in the Housatonic River and to develop feasible alternatives for remediation, if such is ordered.

The stages of this process are: (1) identification and full description of the nature and extent of the contamination, (2) a full risk assessment to determine the impact, if any, of the contamination on human health and on the river ecosystem, (3) identification of alternatives for remediation, if required, and if so, (4) selection of the best remediation alternative, and (5) implementation of the selected remediation option.

Various options for remediation of PCBs in the Housatonic River and Woods Pond were evaluated between 1981 and 1985, including dredging, rechannelling, armoring, and sediment control. These options were unacceptable to the local 
public, and GE was asked to explore in situ bioremediation as a potential alternative. For the last four years our laboratory has focused on finding ways to accelerate the microbial dechlorination of PCBs in situ in Woods Pond sediments.

The PCB contaminant in Woods Pond sediments is Aroclor 1260 which is comprised of mainly hexa- and heptachlorobiphenyls and was used in transformer manufacturing operations from 1934 to 1972. Despite years in the sediments, the PCBs show evidence of only slight environmental dechlorination. For that reason Woods Pond offers a unique opportunity to investigate the parameters governing anaerobic microbial dechlorination of PCBs in sediments.

GE has been granted approval by the US Environmental Protection Agency under the Toxic Substances Control Act (TSCA) to conduct research and development on a biological method for the elimination of PCBs in Woods Pond. With this approval and the approval of the appropriate regulatory agencies of the Commonwealth of Massachusetts, a bioremediation evaluation and test station was installed in Woods Pond to examine the factors limiting in situ microbial decomposition of PCBs and to explore the degree to which these limitations can be overcome.

Our laboratory experiments have consistently shown that the indigenous microorganisms in Woods Pond sediment can dechlorinate the Aroclor 1260 contaminant when 2,6-dibromobiphenyl (2,6-BB), particularly in combination with disodium malate, is added to sediment slurries [Bedard et al., 1992]. The dibromobiphenyl itself is rapidly dehalogenated first to 2-bromobiphenyl (2-BB) and then to biphenyl. These results are consistent with the hypothesis that the dibromobiphenyl selectively enriches the microbial population that can dechlorinate PCBs, possibly by acting as a terminal electron acceptor. Alternatively, the dibromobiphenyl may act to induce the enzyme(s) responsible for PCB dechlorination, or it may act as both an inducer and an enrichment agent. The role of the malate is not understood. Both the 2,6-BB and the PCBs are dehalogenated more rapidly when malate is used in combination with $2,6-\mathrm{BB}$, but by itself malate has no effect on dehalogenation.

The PCB dechlorination that results from the addition of dibromobiphenyl is known as Pattern $\mathrm{N}$, and is characterized by the selective removal of meta chlorines that are adjacent to other chlorine substituents, particularly from 2345-, 245-, 234and 236-chlorophenyl rings. Because these are the most common ring constituents in Aroclor 1260, this Aroclor is particularly susceptible to Pattern N dechlorination. Pattern $N$ dechlorination is manifested by a large decrease in the hexa- through 
octachlorobiphenyls and an accumulation of tri- through pentachlorobiphenyls containing 24-, 25-, 26-, and 246- chlorophenyl groups. [Bedard et al., 1992]. The resulting PCB mixture exhibits a lower persistence in human tissues, indicating an overall reduction in its potential as a health hazard.

The discovery that 2,6-dibromobiphenyl activates microbial dechlorination of PCBs in Woods Pond sediments was a crucial finding. It was also the first demonstration of the favorable intervention of a chemical species in the anaerobic dechlorination of PCBs where the intervening chemical itself is rapidly degraded to innocuous products. The initial laboratory studies were done on a small scale $(30 \mathrm{ml})$ under carefully controlled conditions: constant temperature, periodic mixing, etc. As a first step in assessing the feasibility of in situ bioremediation, we felt that it was important to carry out in situ studies on a larger scale. These studies will help to determine the effectiveness of chemical intervention in activating PCB dechlorination under conditions where no attempt is made to control environmental factors such as temperature, $\mathrm{pH}$, microbial predation, aquatic biota, etc. In this chapter we report the results of the first year of an on-going field test performed at Woods Pond to determine if 2,6-dibromobiphenyl would activate the microbial dechlorination of sediment PCBs in situ under ambient conditions.

\section{Toxicity Assessment of 2,6-Dibromobiphenyl and its Products}

When a new use is proposed for a chemical, that chemical should be investigated for possible toxicity and adverse health effects. Because we proposed to use 2,6-BB for in situ experiments in Woods Pond, GE retained several consultants to provide an overview of available literature on 2,6-BB and to assess whether the proposed use of 2,6-dibromobiphenyl in a field test at Woods Pond would present a risk to human health. The consultants concluded, based on known structure-activity relationships, that 2,6-dibromobiphenyl and 2-bromobiphenyl are not acutely toxic, carcinogenic, promoters of two-stage hepatocarcinogenesis, mutagenic or comparable to Firemaster BP-6, and that the proposed use of 2,6-dibromobiphenyl for the in situ test of PCB dechlorination at Woods Pond posed no significant risk. The consultants' reports were presented to the New Chemicals Branch and the Chemical Regulation Branch of the EPA. They ruled that the proposed use $i$ : 2,6-dibromobiphenyl in the Woods Pond field test was acceptable. 


\section{METHODS AND MATERIALS}

\section{Description of Caissons}

The bioremediation and evaluation test station consists of six steel caissons driven seven feet into the clay subsoil of the pond. Each six foot diameter caisson encloses a depth of 18 to 24 inches of PCB-contaminated sediment and 24 to 30 inches of water overlying the sediment. The caissons are arranged in a rectangular configuration $(3 \times 2)$ with the long side of the rectangle paralleling the northwest shore of the pond. A work surface above the pond surface is provided by a railed platform of steel grating surrounding the upper portions of the caissons. A forty foot floating walkway with controlled access connects the platform to the shore. The subsoil and a welded cover on each caisson provide a hydraulic seal and isolate the contents of each cell from the pond. There are ports through each cover for a thermocouple tree to measure water and sediment temperatures, a water level monitor, a stirring motor, and for tubing and valves to introduce nitrogen and vent methane and other gases. Each caisson was fitted with a pressure release valve set at 0.3 psi to prevent excessive buildup of methane.

The inside of each caisson was painted to reduce corrosion. The depth of the sediment in the caissons used in the test was estimated to average 20 inches prior to mixing. The water and sediment temperatures in the caissons were monitored using thermocouples fixed to a support rod extending through a port in the caisson cover and positioned in the water and near the top, middle, and bottom of the sediment. A thermocouple tree with probes in the same positions was also installed in the pond at the south side of the platform to monitor temperatures of the pond water and sediments. The gas phase of each caisson was kept anoxic by purging the headspace with nitrogen gas prior to and during sampling of the caissons.

\section{Beginning of the Field Test}

Only two caissons, one control and one experimental, were used in this phase of the field test. These were located on the southeast side of the platform. Each caisson contained approximately $400 \mathrm{Kg}$ sediment (dry weight) and a total volume of 3500 liters (water and sediment). One month before the field test, a variable speed rotary mixer (Lightnin, Rochester, NY), fitted with a 17 inch impeller positioned in the water column, was used to briefly suspend and mix the sediment in a controlled 
manner to make it as homogeneous as possible without disturbing the more compact clay subsoil. The sediments were then allowed to settle. Initial sediment cores were taken from the experimental and control caissons four days prior to the addition of malate, acetone, and 2,6-BB.

A solution of disodium malate $(1.99 \mathrm{M})$ was prepared by titrating $\mathrm{L}(-)$ malic acid (97\% purity, United States Biochemical Corp.) with $\mathrm{NaOH}$ to a pH of 6.55. Both caissons received $17.5 \mathrm{~L}$ of the malate solution to yield a final concentration of $10 \mathrm{mM}$. In addition, the experimental caisson received $365 \mathrm{~g}$ of 2,6-BB dissolved in $17 \mathrm{~L}$ of acetone (Nanograde, Mallinckrodt Specialty Chemicals Co., Paris, KY), and the control caisson received $17 \mathrm{~L}$ of acetone but no bromobiphenyl. The 2,6-dibromobiphenyl was synthesized at the General Electric Corporate Research and Development Center and purified to a level of $99.93 \%$ as determined by GC/FID.

The additions were made to the caissons on June 8,1992 , which was designated $t_{0}$. The sediments were suspended to form a slurry and a 5 gallon stainless steel pressurized dispensing canister was used to add first the malate, and then the acetone or 2,6-BB dissolved in acetone to the caissons. The canister was pressurized under nitrogen and the chemicals were individually added to the slowly stirred caissons over a period of 20 to 30 minutes via a dip tube 18" under the surface of the water in order to ensure an even distribution. Positive nitrogen flow was maintained throughout the procedure to eliminate the possibility of introducing oxygen to the system.

\section{Sampling}

Gas samples were taken periodically from the headspace of the caissons prior to opening the caissons for sediment samples. Hydrogen sulfide and carbon monoxide were measured on site using a Gastech GX-91 four gas portable monitor (Gastech Inc., Newark, CA). Methane, carbon monoxide, carbon dioxide, and hydrogen sulfide were also monitored on site using Dräger gas sampling tubes (National Dräger, Inc., Pittsburgh, PA). Acetone in the headspace was monitored using Sensidyne gas sampling tubes (Sensidyne, Inc., Clearwater, FL). During the first several months gas samples were also collected using a gastight syringe and were transferred to evacuated crimp sealed culture tubes for quantitative analysis of carbon dioxide and methane in the laboratory.

Core samples were collected through four separate six inch diameter sampling 
ports located on each caisson in a square array. A sampling pattern was designed to permit access to samples in three concentric circles of 7,11 , and 15 inch radii about each port center at the bottom of the sediment. In the outermost circle, samples could be taken every $20^{\circ}$, and in the middle and innermost circles every $30^{\circ}$ or $45^{\circ}$, respectively. This sampling pattern enabled us to take 38 core samples from every port while allowing 2 inches of space between adjacent samples in all directions, thus ensuring representative samples. To access these positions, a system was adopted using a $360^{\circ}$ referenced guide that was placed over the port and a bracket which could be set at a defined vertical angle to accurately guide the core sampler. At each sampling one core was taken from each of the four ports of the caisson using a 2 inch diameter lexan tube. Samples were taken from the outermost circles first and the sample locations were selected from all available positions not previously sampled. The tubes were driven several inches into the bottom clay to provide a plug to retain the loose sediment. The lexan tubes were cut 2 inches above the sediment level for each core sample, sealed with a plastic cap, transported to the laboratory, and frozen in an upright position. Later, the subsoil plug was cut from the darker sediment layer in each tube, and the sediment was separated into three sections, typically six to seven inches each, (depending on the total depth of the sediment core) and designated as the top, middle, and bottom sections, respectively. Compression of the sediments did occur with time and this was taken into account when the cores were sectioned. All sediment samples were kept frozen. Portions of each core section were removed for analysis and the remainder were kept archived in frozen storage for additional analysis as needed. Water samples were collected for bromide and malate analysis and were kept frozen.

\section{Analytical}

Quantitative carbon dioxide and methane analysis. Carbon dioxide and methane were measured using a Shimadzu GC-3BT gas chromatograph (GC), (Shimadzu, Columbia, MD) equipped with a thermal conductivity detector. The gas components were separated on a CTR- 1 column ( $6 \mathrm{ft} \times 0.25$ inch OD, Alltech, Deerfield, IL) using helium as the carrier gas. Samples were quantified by comparison with standard mixtures of $3.83 \%$ methane, $3.77 \%$ hydrogen, and $4.82 \%$ carbon dioxide by volume in helium (Scott Specialty Gases, Plumsteadville, PA), and additional standard mixtures (Scott Specialty Gases) containing $99.8 \%$ carbon dioxide or $99.6 \%$ methane. A Hewlett-Packard 3393A integrator/recorder (Hewlett- 
Packard, Avondale, PA) was used for integration and quantification.

$\mathrm{pH}$ Analysis. The $\mathrm{pH}$ of the sediment and the water was monitored manually using an Orion 250A pH meter (Orion Research, Inc., Boston, MA) fitted with a Sensorex $4500 \mathrm{pH}$ probe (Sensorex, Stanton, CA).

Bromide analysis. Bromide ion concentrations were determined using a Waters 840 high pressure liquid chromatography system (HPLC) (Millipore, Waters Chromatography, Marlborough, MA) equipped with an IC-PAK A anion column (Waters) and a Waters 431 conductivity detector. Anions were eluted from the column with a mobile phase of nanopure water containing $25 \%(\mathrm{v} / \mathrm{v})$ glycerin, $2.5 \%$ $(w / v)$ sodium tetraborate decahydrate, $1.8 \%(w / v)$ boric acid, and $1.6 \%(w / v)$ sodium gluconate. Quantification was done using a four point external calibration.

Malate analysis. L-Malate was analyzed using a Shimadzu LC-4 HPLC system equipped with an Aminex HPX-87H ion exclusion column (BioRad, Hercules, CA) and a Shimadzu multiple wavelength spectrophotometric detector. Organic acids were eluted with a mobile phase of $0.01 \mathrm{~N} \mathrm{H}_{2} \mathrm{SO}_{4}$ and their absorbance at $214 \mathrm{~nm}$ was measured. Quantification was done using a four point external calibration.

Extraction and Analysis of PCBs and Bromobiphenyls

We used two methods of extraction for our samples. Duplicate samples from each level of sediment at each time point were extracted using a Soxhlet extractor and a rigorous cleanup. These samples were extracted and analyzed in Pittsfield for determination of $\mathrm{PCB}$ concentration and for monitoring the dehalogenation of 2,6-BB. Additional samples extracted by this method were concentrated 40-fold and used for congener-specific GC-MS analysis at GE CRD. Congener specific GC-ECD analysis of samples was done at GE CRD using samples extracted by a one-step ether procedure.

Soxhlet Extraction. Wet sediment samples were extracted for 20 to $24 \mathrm{~h}$ with 2,2,4-trimethylpentane (isooctane, pesticide grade, EM Science, Gibbstown, NJ) in a Soxhlet apparatus fitted with a Dean Stark trap to collect the water removed during extraction. Octachloronaphthalene was added to the isooctane as a surrogate to track recovery. The extracts were treated with triple distilled mercury to remove elemental sulfur and then with concentrated sulfuric acid to remove polar hydrocarbons. 
Ether Extraction. Wet sediment samples were extracted by vigorous shaking for 16 to $40 \mathrm{~h}$ on a horizontal platform shaker with 5 volumes of anhydrous ether and $1 / 5$ volume acid-cleaned copper filings (to remove sulfur). See Chapter 3 of this report for a comparison of results obtained with the two extraction methods.

Determination of PCB Concentration in the Sediment. Total PCB concentration in the sediment was initially determined by packed column chromatography based on EPA method 8080. A Varian GC (Varian Instrument Group, Sugarland, TX) equipped with an ECD, a $3 \%$ SP2100 1/8" X 6' stainless steel packed column (Supelco Inc., Bellefonte, PA) and a Varian 8000 autosampler was used. An external standard composed of Aroclors 1242 and 1260, 1:2, w/w was used, and quantification was based on the analysis of Aroclors by Webb and McCall [1973]. When considerable dechlorination had occurred in the experimental caisson, this method could not be used because the congeners produced by dechlorination do not correspond to those in Aroclor 1242 (see Smullen et al., Chapter 3, this report). Therefore, determination of $P C B$ concentration in later samples was done by capillary chromatography based on EPA method 8081. A Varian 3500 GC equipped with an ECD, a fused silica capillary column ( $30 \mathrm{~m}$ by $0.25 \mathrm{~mm}, \mathrm{ID}$ ) coated with a $0.25 \mu \mathrm{m}$ bonded liquid phase of SPB-1 (polydimethylsiloxane, Supelco Inc.), a Varian 8025 autosampler, and a Varian Maxima 820 data system was used. The customized quantitative Woods Pond standard described in Chapter 3 [Smullen et al.] was used. (Extracts of twelve samples taken from the experimental caisson between days 21 and 52 were analyzed using both procedures. The results of the packed column analyses averaged $1.9 \mathrm{ppm}$ higher than those of the capillary column analyses.)

Bromobiphenyl / Biphenyl Analysis. The dehalogenation of 2,6-BB to 2-BB and biphenyl was monitored by GC-MS in the selected ion mode. Splitless injections were done using a Hewlett-Packard 5890 GC equipped with a HewlettPackard 5971 mass selective detector, a Hewlett-Packard 7673 autosampler, a Hewlett-Packard Vectra data system, and a fused silica capillary column ( $30 \mathrm{~m}$ by $0.25 \mathrm{~mm}$, inner diameter) coated with a $0.25 \mu \mathrm{m}$ bonded liquid phase of SPB-1 (Supelco Inc.). The ions monitored were $m / z 312$ and 310 for 2,6-BB, $m / z 234$ and 232 for 2-BB, and $m / z 154$ for biphenyl. Quantitation was done using a three point calibration with 2-fluorobiphenyl $(\mathrm{m} / \mathrm{z} 172)$ as an internal standard. 
Congener-specific GC Analysis of PCBs. The GC-ECD and GC-MS congenerspecific analyses for PCBs are described in detail by Smullen et al. and Frame, respectively, in Chapters 3 and 4 of this report.

\section{RESULTS AND DISCUSSION}

\section{Concentration Measurements: PCBs, Bromobiphenyls, and Biphenyl}

The sediment in Woods Pond is a fine silt with high organic content including $5 \mathrm{~g} / \mathrm{Kg}$ dry sediment of an unidentified hydrocarbon oil. Previous sampling studies in the pond have shown considerable heterogeneity in both $\mathrm{PCB}$ concentration and PCB congener distribution (unpublished results). However, the two brief mixing operations done before and at the time additions were made to the caissons were sufficient to achieve a very homogeneous sediment $\mathrm{PCB}$ concentration, $\mathrm{PCB}$ congener distribution, and, in the experimental caisson, 2,6-BB concentration in the sediment. In the control caisson the average PCB concentration (calculated from 22 samples collected over the first 18 days) was $30.6 \mathrm{ppm}$ on a dry weight basis, and values for the top, middle, and bottom sections of the sediment were $33.4 \pm 2.1$, $31.4 \pm 1.0$, and $27.5 \pm 3.2 \mathrm{ppm}$, respectively. In the experimental caisson the average PCB concentration was $26.0 \mathrm{ppm}$, with values of $27.0 \pm 2.0,25.9 \pm 0.5$, and $25.0 \pm 1.7 \mathrm{ppm}$ for the top, middle, and bottom sections, respectively. The average 2,6-BB concentration in the experimental caisson as determined at the start of the field test, was 880 ppm on a dry sediment basis, with values of $969 \pm 77,884 \pm 93$, and $809 \pm 106 \mathrm{ppm}$ for the top, middle, and bottom sections, respectively. In all instances there was a small concentration gradient from top to bottom. This probably reflects both a higher $\mathrm{PCB} / \mathrm{BB}$ affinity for the fines, which would tend to settle at the top, and some mixing of the clay subsoil in the bottom samples.

Throughout the field test the total PCB concentration in the experimental caisson did not change even though congener specific analysis by GC-ECD indicated extensive PCB dechlorination had occurred. Averages calculated from eight samples for each sediment level taken from the experimental caisson between mid-October and April showed PCB concentrations of $28.7 \pm 2.1,25.1 \pm 2.4$, and $10.9 \pm 5.8 \mathrm{ppm}$, for the top, middle, and bottom sections, respectively. The low value and the large standard deviation in the bottom sample most likely reflect substantial contamination of the bottom sediments with clay and sand from the subsoil. A comparison of the PCB concentrations in the top two levels at the 
beginning of the experiment and in the later samples shows that there was no significant change.

Headspace Gases, pH, and Malate Consumption

Headspace gases were essentially the same for both the experimental and the control caisson. Methane was detected in both caissons at the first sampling on dav 2. Periodically, methane and carbon dioxide were analyzed quantitatively in the laboratory. Methane was measured in both caissons at levels of 3 to $10 \%$, during July and early August. In mid-August through mid-September readings increased to $41 \%$. Carbon dioxide levels ranged from 0.6 to $2.5 \%$ in July and early August, and then increased to 18 to $19 \%$ by mid-September. After this point, sampling was less frequent and quantitative gas measurements of methane and carbon dioxide were discontinued. Carbon monoxide was detected at levels of 5 to $20 \mathrm{ppm}$ at all times measured from late June to late October of 1992, but was not detectable in November or January. No subsequent readings were taken. Hydrogen sulfide was detectable only three times: September 9, 1992, at levels of 0.5 to $1.5 \mathrm{ppm}$, and July 7 and 28, 1993, at levels of 4 to $6 \mathrm{ppm}$.

The $\mathrm{pH}$ of the water and the sediment was checked periodically in the pond and in both caissons. Although some $\mathrm{pH}$ fluctuations were seen, there was no consistent trend. The $\mathrm{pH}$ of the water in the pond ranged from 7.14 to 7.50 , with an average value of 7.32 . This was slightly higher than the $\mathrm{pH}$ of the water in the caissons which averaged 7.16 for each caisson and spanned a range of 7.00 to 7.47 in the control caisson and 7.00 to 7.57 in the experimental caisson. There was no significant difference between the $\mathrm{pH}$ of the sediment in the pond and that in the caissons. The average $\mathrm{pH}$ of the sediment was 7.05, and the range was 6.86 to 7.36 .

L-Malate was added to both caissons in amounts calculated to yield a final concentration of $10 \mathrm{mM}$. Unfortunately, no measurements were made to determine the actual concentration. The only data available at this time are measurements taken during the period of June 23 to July 6,1992 ( 2 to 5 weeks after the addition). During this time the malate concentration ranged from 0.87 to $0.72 \mathrm{mM}$ in the control caisson and from 1.14 to $1.01 \mathrm{mM}$ in the experimental caisson. These data suggest that roughly $90 \%$ of the malate had been consumed in the first two weeks and are consistent with laboratory experiments in which most of the malate was consumed within 48 hours. 
Temperatures

The temperatures of the water and sediments within the caissons closely tracked those in Woods Pond throughout the experiment. The temperatures were lower than expected because the summer of 1992 was the coldest in this region since 1946. The average air temperature for June, July, and August averaged $17.6^{\circ} \mathrm{C}$ $\left(63.7^{\circ} \mathrm{F}\right)$. The temperature trends at the various depths of the sediment closely followed the pond water, but the sediment temperatures did not reach the extremes of the water (Figure 2-1). The temperature near the top of the sediment hovered near $18^{\circ} \mathrm{C}\left(65^{\circ} \mathrm{F}\right)$ and the bottom ranged from 15 to $17^{\circ} \mathrm{C}$ during the summer months. In the last two weeks of September the air temperature plummetted and the water temperature dropped $11^{\circ} \mathrm{C}$. A similar precipitous temperature drop was observed in the sediments $0 \%$ er the next three weeks, followed by a slow continued temperature drop until February. In general, the layers of the sediment in closest contact with the water were also the closest in temperature to the water. Hence, during the cold months the top of the sediment was coldest, and during the summer months it was the warmest. In January the top 6 inches of the water froze, and in February and March the temperature of the uppermost sediments dropped as low as $1^{\circ} \mathrm{C}$, whereas the bottom sediments did not drop below $3^{\circ} \mathrm{C}$. In mid-April, as soon as the ice thawed, the sediments rapidly warmed and the top sediments again became warmer.

\section{Dehalogenation of 2,6-Dibromobiphenyl}

We first detected dehalogenation of 2,6-BB to 2-BB at 15 days, and biphenyl was first detected at all levels of the sediment at 21 to 24 days (Figure 2-2). Dehalogenation progressed more rapidly in the top layer of sediment, presumably due to the warmer temperatures there. The small concentration gradient of 2,6-BB from the top to the bottom of the caisson may have been a factor as well. There was a $99 \%$ conversion of $2,6-\mathrm{BB}$ to biphenyl in 78 days in the top layer of sediment and a 98\% conversion to biphenyl by day 115 in the bottom layer. Trace amounts $(<20 \mathrm{ppm})$ of 2,6-BB were still detected at 170 days. Bromide ion was first detected as a dehalogenation product in the water column at 32 days and continued to increase slowly with time.

We have not completed our analyses of the total concentration of biphenyl remaining at later timepoints and therefore will not address the fate of biphenyl now. 

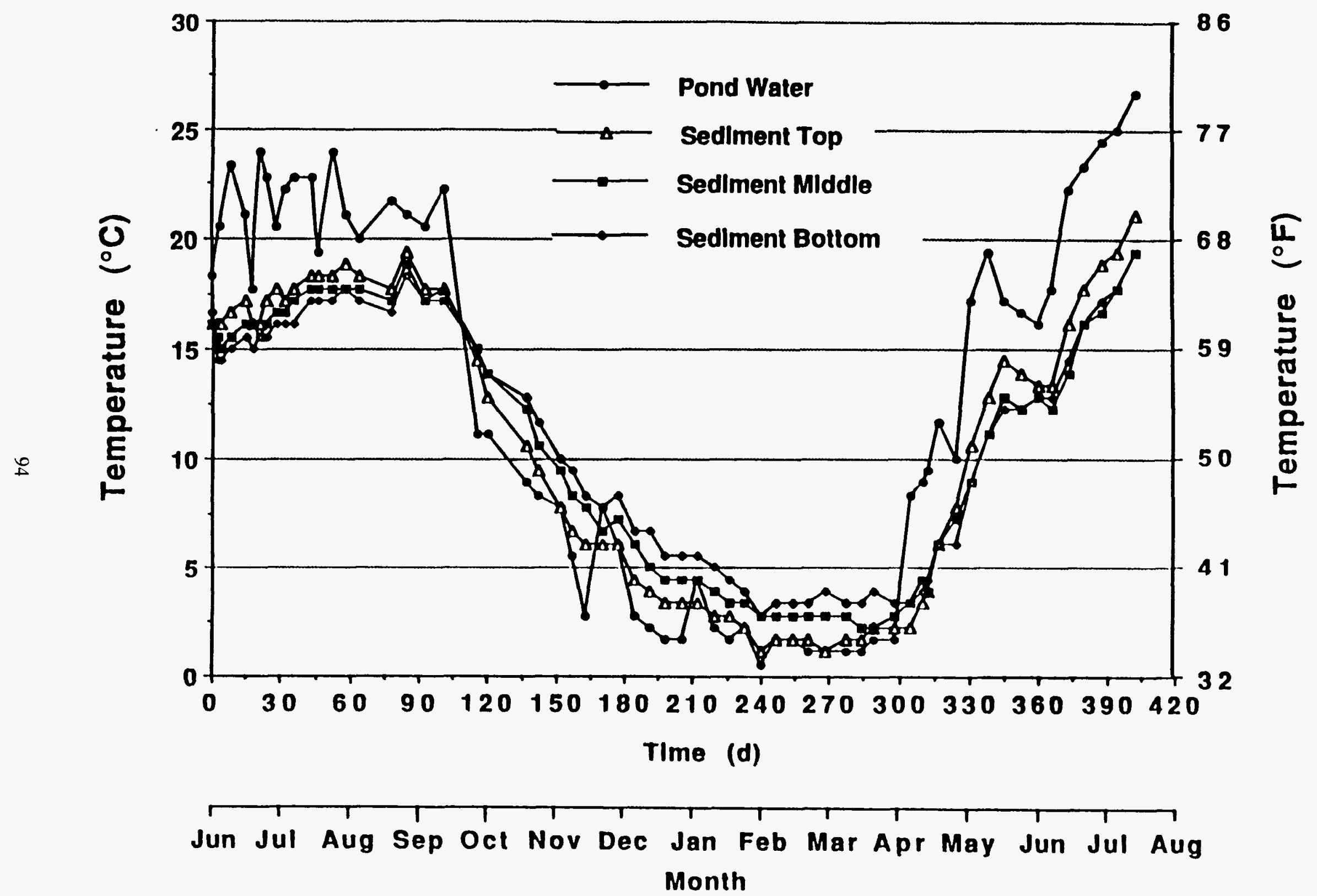

Figure 2-1. Plot of water and sediment temperatures vs time for the pond water outside the caisson and for the top, middle and bottom of the sediment in the experimental caisson. 

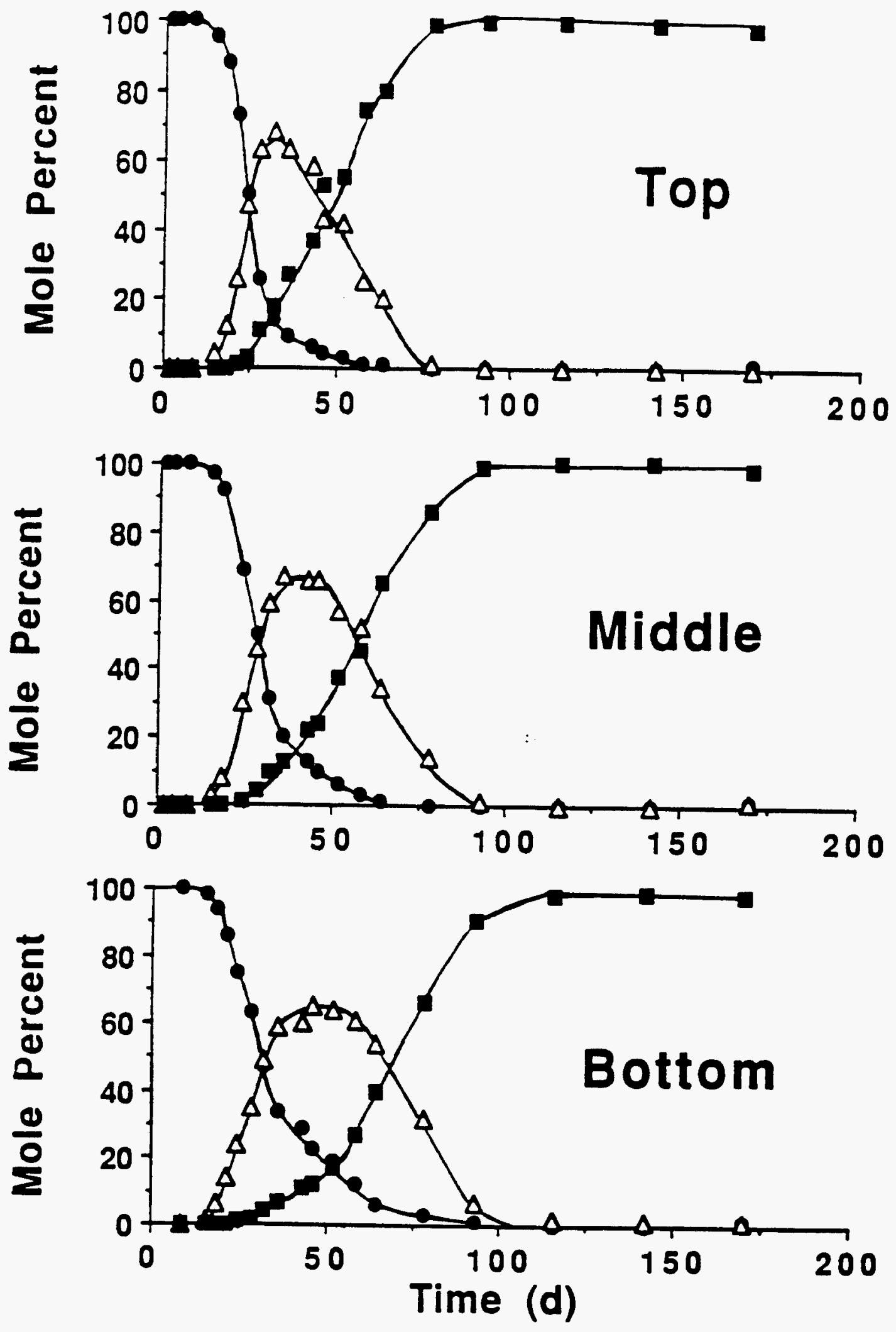

Figure 2-2. Time course of dehalogenation of 2,6-dibromobiphenyl at the top, middle, and bottom of the sediment. Symbols: $\bullet, 2,6-B B ; \triangle, 2-B B ;$ and $\triangle$, biphenyl. 


\section{Dechlorination of PCBs}

The PCB contaminant in Woods Pond was unaltered in the control caisson after 373 days (Figure 2-3A). Methanogenesis was observed in both caissons during the summer months indicating that the anaerobic conditions required for $P C B$ dechlorination were evident, but the presence of a low reduction potential was not sufficient in itself to promote $\mathrm{PCB}$ dechlorination in the control caisson.

In contrast, the experimental caisson showed a substantial change in the $\mathrm{PCB}$ homolog distribution, resulting in decreases of 70,57 and $27 \%$ in the hexa-, hepta-, and octachlorobiphenyls, respectively, in the top layer after 93 days (Figure 2-3B). The top sediment section showed a $61 \%$ decrease in the combined amounts of hexathrough nonachlorobiphenyls; the bottom section was somewhat slower and showed a $57 \%$ decrease in these homologs. The dechlorination of hexa-, hepta-, and octachlorobiphenyls continued, yielding total decreases of 77, 75 and 50\%, respectively, in the top of the sediment after 373 days. At this point the combined hexa- through nonachlorobiphenyls showed total decreases in the top and bottom sections of 74 and $69 \%$, respectively. The dechlorination of the more highly chlorinated PCB congeners resulted in an accumulation of the tri-, tetra- and pentachlorobiphenyls which accounted for approximately $75 \%$ of the total PCBs at 373 days.

Despite dechlorination of most of the pentachlorobiphenyls that were originally present, the total amount of pentachlorobiphenyls increased slightly. This is because specific pentachlorobiphenyl congeners were formed from the dechlorination of the hexa- through octachlorobiphenyls, as shown by GC-MS analysis (See Chapter 3, Figure 3-1).

The kinetics of $\mathrm{PCB}$ dechlorination in the experimental caisson show that the combined mole percents of the hexa- through nonachlorobiphenyls decreased very rapidly during the first hundred days of the field test (Figure 2-4). After this, the dechlorination continued, but at a slower pace, probably reflecting both the drop in temperature and depletion of the PCB congeners most susceptible to dechlorination. During the winter months the dechlorination of PCBs in the top and middle sections of the sediment nearly ceased. In contrast, PCB dechlorination continued at a very slow rate throughout the winter in the warmer bottom section. Because of this, the extent of PCB dechlorination in the bottom section was very close to that of the other sections in April when the sediment temperatures began to increase again. 


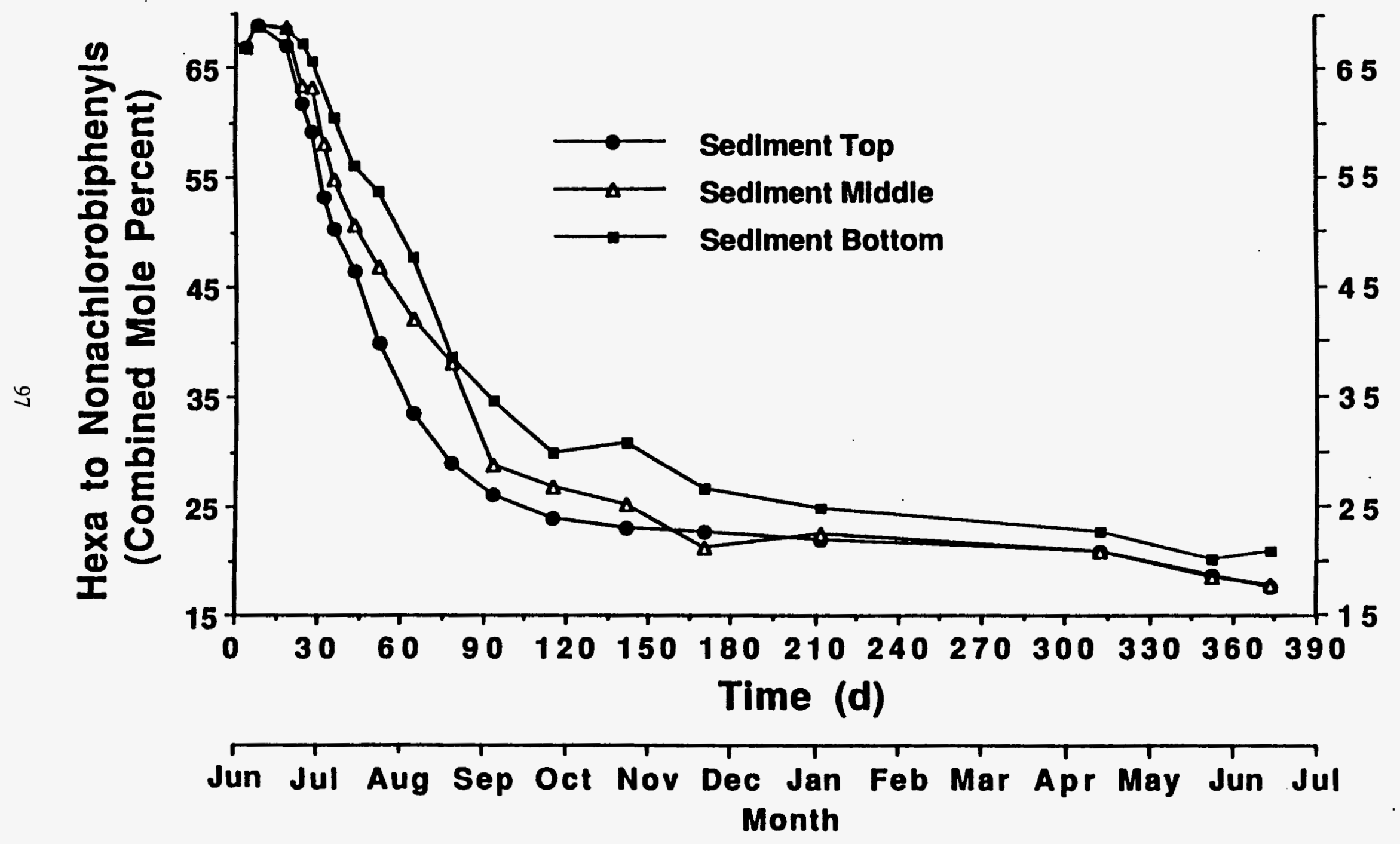

Figure 2-4. Decrease in hexa- through nonachlorobiphenyls vs time. 

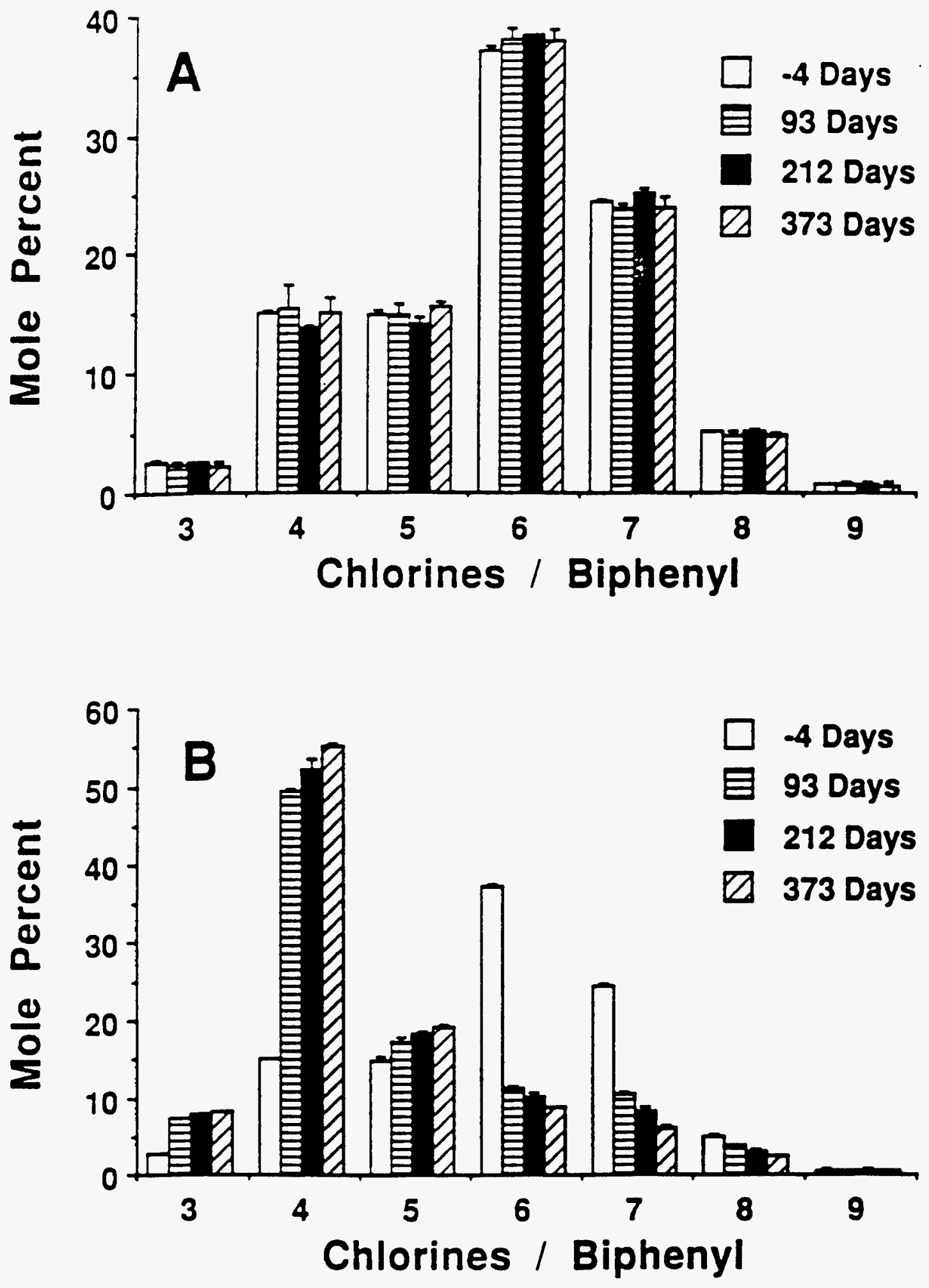

Figure 2-3. PCB homolog distribution in the control (Panel A) and experimental (Panel B) caissons at various times. 
Comparisons of the PCBs prior to and 373 days after the addition of 2,6-BB show that the average number of chlorines per biphenyl dropped 21\%, from 5.83 to 4.61 , and the number of meta chlorines per biphenyl dropped 54\%, from 2.14 to 0.99 . The number of para chlorines per biphenyl dropped only $6 \%$, from 1.31 to 1.23 , and the number of ortho chlorines per biphenyl was constant at 2.39 .

\section{Congener Specific Analysis of PCB Dechlorination}

Congener specific analysis of the Aroclor 1260 contaminant in Woods Pond showed that the PCB congener distribution of the sediment PCBs prior to the addition of 2,6-BB differed from that of unaltered Aroclor 1260. The tri- and tetrachlorobiphenyls represented by peaks 17 through 33 , and the pentachlorobiphenyls in peaks 37A, 41, 44, 46A, 49, 54, and 55 (Figure 2-5, top) are not present in Aroclor 1260. Their presence in Woods Pond sediment is evidence of environmental dechlorination of more highly chlorinated $\mathrm{PCB}$ congeners prior to the start of the field test [Bedard et al., 1990]. The average number of chlorines per biphenyl is 6.35 for Arocior 1260, but only 5.83 for the sediment PCBs. Thus, the environmental dechlorination over the years has resulted in an $8 \%$ decrease in the number of chlorines. Comparison of the number of ortho, meta, and para chlorines per biphenyl in Aroclor 1260 and sediment PCBs indicates that a $14 \%$ decrease in the meta chlorines ( 2.50 vs 2.14 ), and an $8 \%$ loss in para chlorines (1.42 vs 1.31 ) can be attributed to environmental dechlorination. The number of ortho chlorines per biphenyl is 2.43 for Aroclor 1260 and 2.39 for sediment PCBs.

The congener distribution of the sediment PCBs changed significantly during the year after the addition of 2,6-BB, and at 373 days showed extensive decreases of the highly chlorinated PCB congeners, as well as further increases in the same tri-, tetra-, and pentachlorobiphenyl congeners that had previously been produced by environmental dechlorination (Figure 2-5). This indicates that the Pattern N dechlorination stimulated by the addition of $2,6-\mathrm{BB}$ is a major component of the environmental dechlorination that has occurred in Woods Pond sediment over the years.

Four of the largest components of Aroclor 1260 are 245-245-CB (pk 75), 234-245-CB (pk 82), 2345-245-CB (pk 102), and 2345-234-CB (pk 106) (Figure 2-5 and Table 2-1). Each of these major congeners was decreased by 76 to $91 \%$ and was 
TABLE 2-1. Mass balance of the predominant PCB congeners which were dechlorinated or formed by dechlorination.

\begin{tabular}{|c|c|c|c|c|c|c|c|c|}
\hline \multicolumn{5}{|c|}{$\begin{array}{c}\text { PCB Congeners Decreased } \\
\text { by Dechlorination }\end{array}$} & \multicolumn{3}{|c|}{$\begin{array}{l}\text { PCB Congenars Formed } \\
\text { by Dechlorination }\end{array}$} & \multirow{2}{*}{$\begin{array}{l}\text { Mass } \\
\text { Balance }\end{array}$} \\
\hline $\begin{array}{c}\text { DB1 } \\
\text { Peak } \\
\text { Number }\end{array}$ & $\begin{array}{c}\text { PCB } \\
\text { Congener }\end{array}$ & $\begin{array}{l}\text { Initial } \\
\text { Amount } \\
\text { Mol\% }\end{array}$ & $\begin{array}{l}\text { Day } 373 \\
\text { Amount } \\
\text { Mol\% }\end{array}$ & $\begin{array}{c}\text { Obeerved } \\
\text { Decrease } \\
\text { Mol } \% \\
\end{array}$ & $\begin{array}{l}\text { Expected } \\
\text { Final } \\
\text { Product } \\
\end{array}$ & $\begin{array}{c}\text { OB1 } \\
\text { Peak } \\
\text { Number } \\
\end{array}$ & $\begin{array}{l}\text { Obeerved } \\
\text { Incresese } \\
\text { Mol \% }\end{array}$ & \\
\hline $\begin{array}{r}61 \\
103\end{array}$ & $\begin{array}{l}236 \cdot 34 \\
2356 \cdot 345 \\
\text { Sum }\end{array}$ & $\begin{array}{l}2.76 \\
0.31\end{array}$ & $\begin{array}{l}0.51 \\
0.14\end{array}$ & $\begin{array}{l}2.25 \\
0.16 \\
2.41\end{array}$ & $26-4$ & 17 & 2.50 & $102 \%$ \\
\hline $\begin{array}{l}60 \\
78\end{array}$ & $\begin{array}{l}236 \cdot 236 \\
2356 \cdot 236 \\
\text { Sum }\end{array}$ & $\begin{array}{l}1.03 \\
1.11\end{array}$ & $\begin{array}{l}0.28 \\
0.61\end{array}$ & $\begin{array}{l}0.76 \\
0.49 \\
1.25\end{array}$ & $26-26$ & 19 & 1.49 & $119 \%$ \\
\hline $\begin{array}{r}48 A \\
69 \\
74 \\
95\end{array}$ & $\begin{array}{l}24 \cdot 34 \\
245 \cdot 34 \\
234 \cdot 34 \\
2345 \cdot 34 \\
\text { Sum }\end{array}$ & $\begin{array}{l}0.94 \\
1.46 \\
0.14 \\
0.48\end{array}$ & $\begin{array}{l}0.49 \\
0.11 \\
0.01 \\
0.10\end{array}$ & $\begin{array}{l}0.45 \\
1.35 \\
0.13 \\
0.35 \\
2.28\end{array}$ & $24-4$ & 24 & 2.25 & $99 \%$ \\
\hline $\begin{array}{r}488 \\
64\end{array}$ & $\begin{array}{l}236-25 \\
2356-25 \\
\text { Sum }\end{array}$ & $\begin{array}{l}2.00 \\
2.05\end{array}$ & $\begin{array}{l}0.00 \\
0.59\end{array}$ & $\begin{array}{l}2.00 \\
1.46 \\
3.46\end{array}$ & $25-26$ & 25 & 4.06 & $117 \%$ \\
\hline $\begin{array}{c}488 \\
69 \\
71 \\
74 \\
93\end{array}$ & $\begin{array}{l}245 \cdot 26 \\
236 \cdot 245 \\
2345 \cdot 26 \\
234 \cdot 236 \\
2345 \cdot 236 \\
\text { Sum }\end{array}$ & $\begin{array}{l}0.22 \\
6.68 \\
0.27 \\
2.15 \\
2.61\end{array}$ & $\begin{array}{l}0.00 \\
0.50 \\
0.08 \\
0.10 \\
0.39\end{array}$ & $\begin{array}{l}0.22 \\
6.18 \\
0.19 \\
2.05 \\
2.22 \\
10.86\end{array}$ & $\begin{array}{c}24-26 \\
+ \\
235.26\end{array}$ & $\begin{array}{c}26 \\
464 !\end{array}$ & $\begin{array}{c}11.14 \\
0.80 \\
12.03\end{array}$ & $111 \%$ \\
\hline $\begin{array}{l}53^{3} \\
77\end{array}$ & $\begin{array}{l}245-25 \\
2345-25 \\
\text { Sum }\end{array}$ & $\begin{array}{l}3.20 \\
1.28\end{array}$ & $\begin{array}{l}0.00 \\
0.00\end{array}$ & $\begin{array}{l}3.20 \\
1.28 \\
4.48\end{array}$ & $\begin{array}{c}24-25 \\
235-25\end{array}$ & 32 & $\begin{array}{l}4.71 \\
0.44 \\
5.15\end{array}$ & $115 \%$ \\
\hline $\begin{array}{r}54 \\
75 \\
82 \\
89 \\
102 \\
106 \\
115\end{array}$ & $\begin{array}{l}245 \cdot 24 \\
245 \cdot 245 \\
234 \cdot 245 \\
234 \cdot 234 \\
2345 \cdot 245 \\
2345 \cdot 234 \\
2345 \cdot 2345 \\
\text { Sum }\end{array}$ & $\begin{array}{l}1.85 \\
8.51 \\
5.73 \\
0.71 \\
7.40 \\
2.70 \\
1.27\end{array}$ & $\begin{array}{l}0.34 \\
0.78 \\
1.14 \\
0.00 \\
1.77 \\
0.57 \\
0.68\end{array}$ & $\begin{array}{r}1.52 \\
7.73 \\
4.59 \\
0.71 \\
5.62 \\
2.13 \\
0.59 \\
22.89\end{array}$ & $\begin{array}{c}24-24 \\
+ \\
236-24\end{array}$ & 53 & $\begin{array}{r}18.71 \\
3.00 \\
21.71\end{array}$ & $95 \%$ \\
\hline $\begin{array}{c}90 \\
95 \\
110 \\
110 \\
112\end{array}$ & $\begin{array}{l}2346-245 \\
2346-234 \\
2345-2346 \\
23456-245 \\
23456-234 \\
\text { Sum }\end{array}$ & $\begin{array}{l}1.66 \\
0.73 \\
0.47 \\
0.96 \\
0.61\end{array}$ & $\begin{array}{l}0.37 \\
0.15 \\
0.22 \\
0.46 \\
0.26\end{array}$ & $\begin{array}{l}1.29 \\
0.58 \\
0.25 \\
0.50 \\
0.35 \\
2.97\end{array}$ & 246.24 & 4 & 3.12 & $105 \%$ \\
\hline $\begin{array}{r}88 \\
94 \\
109\end{array}$ & $\begin{array}{l}2356.245 \\
2356.234 \\
2345.2356 \\
\text { Sum }\end{array}$ & $\begin{array}{l}3.44 \\
1.61 \\
1.18\end{array}$ & $\begin{array}{l}0.89 \\
0.26 \\
0.52\end{array}$ & $\begin{array}{l}2.55 \\
1.35 \\
0.66 \\
4.56\end{array}$ & $\begin{array}{c}238.24 \\
+ \\
2358.24\end{array}$ & $\begin{array}{l}19 \\
67 .\end{array}$ & $\begin{array}{l}2.25 \\
\frac{2.61}{4.86}\end{array}$ & $107 \%$ \\
\hline
\end{tabular}


TABLE 2-1 Footnotes:

1 Denotes one component of a peak containing more than one congener.

2 The calculated yield of $235-26-C B$, based on $40 \%$ para dechlorination of $2345-26-C B$ and $2345-236-C B$, is 0.96 mole percent. Another 0.31 mole percent of $235-26-\mathrm{CB}$ would be generated by the meta dechlorination of 2356-235-CB (pk 85) (see text). Thus the calculated yield is 1.27 mole percent, which agrees reasonably well with the observed increase of 0.89 mole percent.

3 This peak contains $245-25-C B$ and $235-24-C B$. Based on chlorine substitution pattern, we have assumed that essentially all 245-25-CB has been dechlorinated to 24-25-CB, and that 235-24-CB has been formed by dechlorination, thus leading to a change in the composition of the peak. See text for further discussion.

4 This peak is composed of $234-25-C B$ and $235-35-C B$. Based on chlorine substitution pattern, we have assumed that the increase in this peak is due to formation of 235-35-CB. The calculated yield of 235-35$C B$, based on $40 \%$ para dechlorination of $2345-25-C B$, is 0.51 mole percent, which agrees well with the observed increase of 0.44 mole percent. We have not included calculations for other congeners carrying 2345-chlorophenyl groups because the portion of each attributed to para dechlorination is less than 0.3 mole percent and would not significantly change the calculated mass balance.

5 GC-MS analysis indicated that $71 \%$ of this peak was $2356-24-\mathrm{CB}$ (and the remainder pentachlorobiphenyl) before the addition of 2,6-BB. At 93 days and later the peak contained only 2356-24-CB.

TABLE 2-2. Proposed route of dechlorination of chlorophenyl rings.

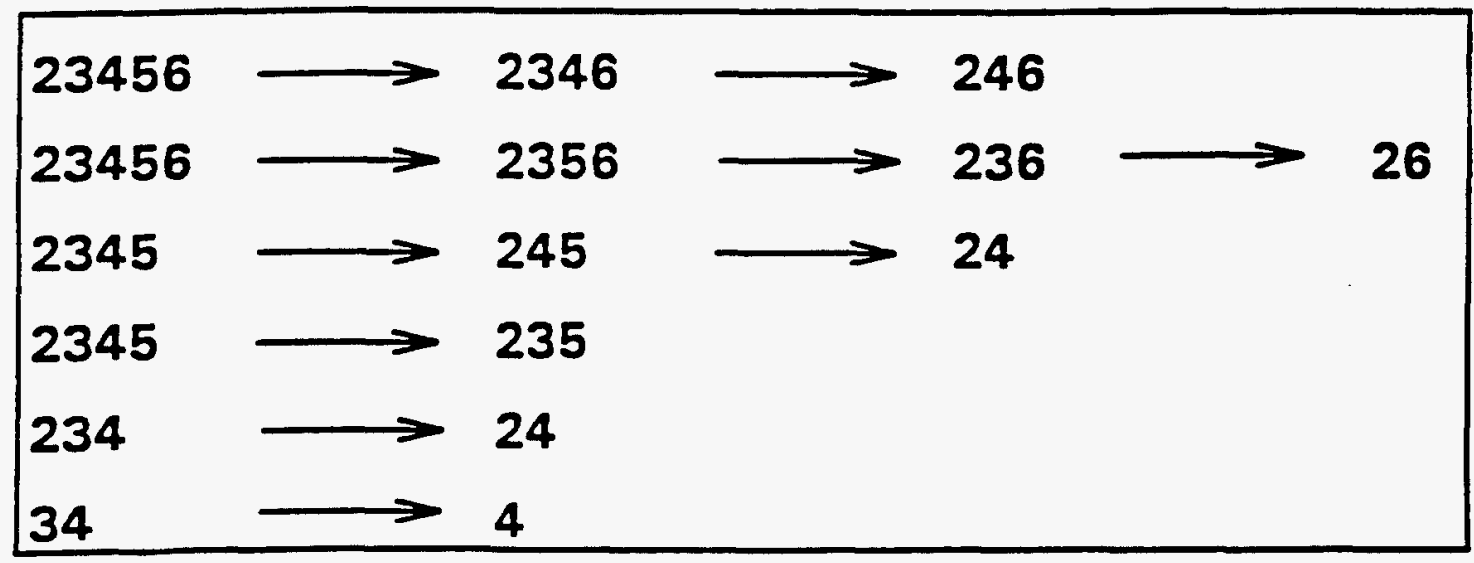




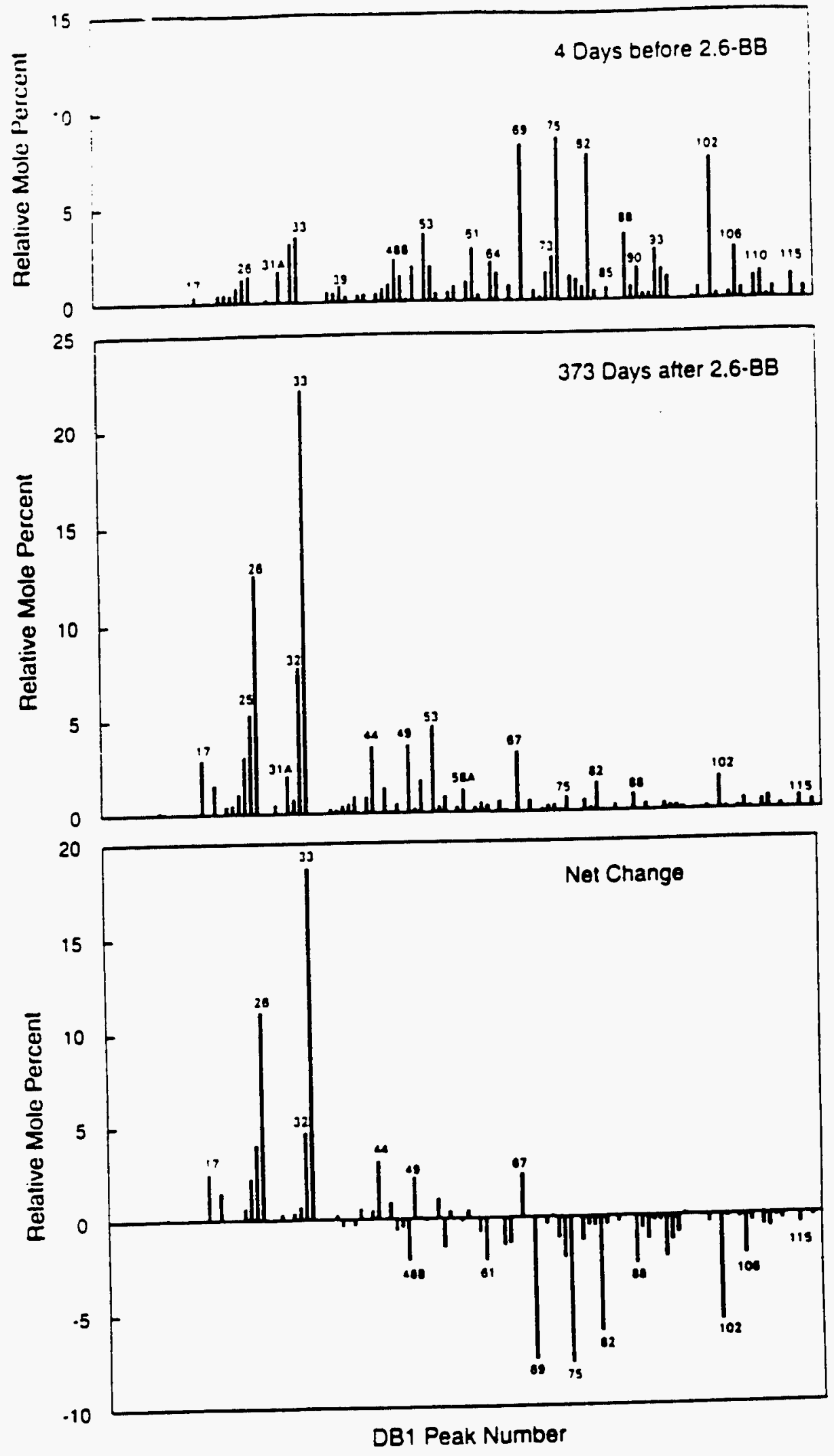

Figure 2-5. PCB congener distribution in the experimental caisson before and 373 days after the addition of 2,6-BB. Peak identifications are given in Chapter 3. 
dechlorinated primarily by the loss of all meta chlorines to 24-24-CB (pk 33), thus accounting for the large increase in that tetrachlorobiphenyl. Several other congeners were also dechlorinated to 24-24-CB, namely 245-24-CB (pk 54), 234-234-CB (pk 89), and 2345-2345-CB (pk 115). Table 2-2 shows the proposed route of dechlorination for various chlorophenyl substituents of these and other congeners.

Other prominent $P C B$ congeners include $236-245-C B$, the primary component of peak 69, 234-236-CB (pk 74), and 2345-236-CB (pk 93). These were primarily dechlorinated to 24-26-CB (pk 26), which accounted for 12.6 mole percent of the PCBs 373 days after the addition of $2,6-\mathrm{BB}$. A third group of prominent $\mathrm{PCB}$ congeners consists of 2356-245-CB (pk 88), 2356-234-CB (pk 94), and 2345-2356-CB (pk 109). Each of these congeners was dechlorinated to $2356-24-\mathrm{CB}$ (pk 67) and 236-24-CB (pk 49) (Table 2-1).

\section{Mass Balance: Dechlorination Substrates and Products}

Mass Balance: Meta Dechlorination. The mass balance of the predominant PCB congeners that were dechlorinated or formed by dechlorination was calculated (Table 2-1). The PCBs formed by dechlorination are composed largely of 24-, 26-, 25-, and 246-chlorophenyl groups which were produced by meta dechlorination. In fact after dechlorination, more than 55 mole percent of the PCB congeners contained at least one 24-chlorophenyl group, and 24-24-CB alone accounted for 22.2 mole percent of the PCBs. However, although meta dechlorination accounts for about 93\% of the observed dechlorination, it cannot fully explain all of the losses and products seen.

Para Dechlorination Attributed to Pattern N. Our data indicate that $6 \%$ of the total chlorine loss was from the para position. To better explain our data, we propose that the 2345-chlorophenyl group was dechlorinated by either of two distinct routes: (1) Meta dechlorination of the 2345-chlorophenyl group generated 24-chlorophenyl groups, and (2) para dechlorination generated 235-chlorophenyl groups (Table 2-2). This proposal is consistent with our previous observations that $2345-C B$ can be simultaneously dechlorinated to both 235-CB and 245-CB by microorganisms in Woods Pond sediment [Van Dort and Bedard, unpublished data]. In addition, because the para chlorine in the 2345-chlorophenyl group is flanked by two chlorines, it is a particularly good candidate for dechlorination. 
Supporting evidence for our proposal is presented below.

The assumption that only meta dechlorination occurred presents three immediate problems. (1) The observed increase in 24-24-CB (18.71 mole percent) accounts for only $82 \%$ of the observed decrease (22.89 mole percent) in those congeners expected to be dechlorinated to 24-24-CB, leaving a discrepancy of 4.18 mole percent (Table 2-1). (2) Peak 53, which was initially composed of $90 \%$ 245-25-CB and 10\% 235-24-CB [Schulz et al., 1989], increased from 3.55 to 4.63 mole percent (Figure 2-5). It is unlikely that this increase was due to accumulation of 245-25-CB, because this congener should be readily dechlorinated to 24-25-CB. Therefore, we would be unable to account for the increase. (3) In addition, the observed increase (4.71 mole percent) in 24-25-CB (pk 32) cannot be accounted for unless we assume that all of the $245-25-C B$ in peak 53 was dechlorinated.

All of these problems can be resolved if we assume that some para dechlorination of 2345-chlorophenyl groups occurred. We shall address the problems stated above in reverse order. In order to account for the amount of 24-25-CB formed, we have made the assumption that the composition of peak 53 changed during dechlorination. We propose that the 245-25-CB component of peak 53 ( 3.20 mole percent) was removed by dechlorination and was in turn replaced by 235-24-CB (4.28 mole percent) formed by dechlorination. This allows us to obtain a mass balance for 24-25-CB (Table 2-1).

We must still account for the formation of 235-24-CB. This congener could be formed by meta dechlorination of 235-245-CB (pk 73), 2345-24-CB (pk 79), and 234-235-CB (pk 80), but the total losses in these congeners add up to only 1.28 mole percent, leaving 3.0 mole percent of $235-24-C B$ unaccounted for. We propose that the remainder of the 235-24-CB was formed from 2345-245-CB (pk 102) and 2345-234-CB (pk 106) by para dechlorination of the 2345-chlorophenyl group and meta dechlorination of the trichlorophenyl group. Since 2345-245-CB and 2345-234-CB together showed a net decrease of 7.75 mole percent, conversion of 3.0 mole percent to $235-24-C B$ would indicate that approximately $40 \%$ of the 2345 -chlorophenyl group was dechlorinated by para dechlorination and $60 \%$ by meta dechlorination. This is consistent with our previous observations that both meta and para dechlorination of these congeners does occur in Woods Pond sediment [Bedard et al., 1990].

We expect that other congeners bearing a 2345-chlorophenyl group would also undergo some para dechlorination. Calculations for several of these congeners appear in Table 2-1. 
We also propose that 23456-chlorophenyl rings were dechlorinated from the para position $40 \%$ of the time. This is consistent with our previous observations of concurrent meta and para chlorine losses from 23456-pentachlorobiphenyl incubated in Woods Pond sediment slurries [Bedard et al., 1990]. These same slurries manifested Pattern N dechlorination of the sediment PCBs.

Mass Balance: Para Dechlorination. We assessed whether the proposed para dechlorination of 2345- and 23456-chlorophenyl groups was consistent with our data, by comparing the overall loss of para chlorines per biphenyl with the amount that would be expected based on the observed decreases in congeners that have 2345- or 23456-chlorophenyl groups. ${ }^{1}$ The total mole percent decreases in the congeners with 2345- and 23456-chlorophenyl groups were 14.63, and 1.80, respectively. Therefore, if the para chlorine were removed $40 \%$ of the time, we would expect a $6.57 \%$ decrease in the number of para chlorines per biphenyl. The actual measured loss of para chlorines/biphenyl was $5.88 \%$. Thus all of our observations are consistent with the proposed para dechlorination of 2345- and 23456-chlorophenyl groups, although the actual proportion of para dechlorination of these chlorophenyl groups may be closer to $36 \%$.

Effect of the Unattacked Ring on Dechlorination of 236- and 2356-Chlorophenyl Rings. The dechlorination of 2356-chlorophenyl groups to 236- and then 26-chlorophenyl also merits discussion. Although these chlorophenyl groups are substrates for Pattern $\mathrm{N}$ dechlorination, it appears that the reactivity of these groups can be negatively influenced by the chlorine substitution pattern on the opposite ring, especially 24- and 26-chlorophenyl groups. The accumulation of 2356-24-CB (pk 67) initially led us to believe that the 2356-chlorophenyl group was not a substrate for Pattern N dechlorination. However, it is apparent from Table 2-1 that the increase in $2356-24-\mathrm{CB}$ accounts for less than $60 \%$ of the loss in peaks 88,94 , and 109. Apparently $2356-24-C B$ was further dechlorinated to $236-24-C B$ (pk 49), which increased by 2.25 mole percent and accounts for the remainder of the loss of peaks 88,94 , and 109.

The accumulation of $236-24-C B$ was unexpected, because most congeners

1 We have assumed that the 2345- and 23456-chlorophenyl rings in all of these congeners were dechlorinated. This assumption appears to be valid because there was no accumulation of any congener containing either of these chlorophenyl groups. 
containing 236-chlorophenyl groups were readily dechlorinated by dechlorination of the 236-ring, e.g. 236-236-CB (pk 60), 236-25-CB (pk 48B), and 236-34-CB (pk 61). In addition, other congeners containing 2356-chlorophenyl groups apparently lost both meta chlorines from this group with no accumulation of the intermediate containing the 236-chlorophenyl group. For example, 2356-25-CB (pk 64) was dechlorinated to 26-25-CB (pk 25) with no accumulation of the 236-25-CB (pk 48B) intermediate, and 2356-235- $\mathrm{CB}$ (pk 85) was dechlorinated to 235-26-CB (pk 46A) without accumulation of the 235-236-CB (pk 65) intermediate. These data indicate that 25-, 34-, 235-, and 236-chlorophenyl groups do not hinder the reactivity of the 236- and 2356-chlorophenyl groups. In contrast, the accumulation of 2356-24-CB and 236-24-CB indicates that the juxtaposition of the 24-chlorophenyl group decreased the reactivity of the 236- and 2356-chlorophenyl groups.

There is also evidence that the 26-chlorophenyl group has a negative impact on the reactivity of an adjoining 236- or 2356-chlorophenyl group. Peak 78, 2356-236-CB, was apparently dechlorinated by initial attack on the 236-ring according to the following pathway: 2356-236-CB --> 2356-26-CB (pk 57A) --> 236-26-CB (pk 40/41) --> 26-26-CB (pk 19). ${ }^{2}$ Both intermediates, which contain 26-chlorophenyl rings, increased, suggesting that they were dechlorinated more slowly than the parent congener, 2356-236-CB. ${ }^{3}$ The 236-26-CB was apparently formed both as an intermediate in the dechlorination of $2356-236-\mathrm{CB}$ and as the first dechlorination product of 236-236-CB (pk 60). Since 236-236-CB decreased by 0.76 mole percent (Table 2-1), but 236-26-CB increased by only 0.32 mole percent [Chapter 3, Tables 3-4 \& 3-5], at least some of the 236-26-CB intermediate must have been dechlorinated to $26-26-C B$ (pk 19). These data suggest that the 26-chlorophenyl group may also adversely affect the reactivity of 236- and 2356-chlorophenyl rings.

It is clear that the 2356-chlorophenyl group is dechlorinated first to a 236- and then to a 26-chlorophenyl group. However, it would appear that the juxtaposition of a 24-chlorophenyl group, and to a lesser extent a 26-chlorophenyl group, with

2 A second possible dechlorination pathway is $2356-236-\mathrm{CB} \rightarrow 236-236-\mathrm{CB} \rightarrow 236-26-\mathrm{CB} \rightarrow 26-26-\mathrm{CB}$. However, the more rapid decrease of $236-236-C B$ (pk 60) relative to 2356-236-CB suggests that the 236-chlorophenyl group is more reactive than the 2356-chlorophenyl group, which in turn suggests that the 236-ring of 2356-236-CB was probably dechlorinated first. This interpretation is further supported by the partial accumulation of $2356-26-C B$, and $236-26-C B$, which are intermediates of the pathway proposed.

3 Peak $57 \mathrm{~A}$ is composed of $245-23-\mathrm{CB}$ and $2356-26-\mathrm{CB}$ which can be separated by GC/MS. Overall, the peak decreases, but the amount of 2356-26-CB increases [Smullen et al., Chapter 3, Tables 3-4 \& 3-5, this report]. 
either a 2356- or a 236-chlorophenyl group hinders meta dechlorination in this system and results in partial accumulation of these intermediates.

Effect of Pattern N on 235-Chlorophenyl Rings. We are unable to accurately determine from our data whether any dechlorination of 235-chlorophenyl groups occurred because nearly all congeners containing this group coelute with other congeners. Our laboratory experiments have shown that the dechlorination of 235-CB to 25-CB in Woods Pond sediment is possible, but that this dechlorination requires a much longer acclimation period than the dechlorination of other chlorophenyl groups and may reflect the activity of a distinctly different microbial population than the one responsible for Pattern $\mathrm{N}$ dechlorination [Van Dort and Bedard, 1991a].

Overall Mass Balance. The mass balances calculated for dechlorinated PCB congeners and their proposed products ranged from 95\% to $119 \%$ and showed discrepancies of no more than 0.67 mole percent for all except the two groups of congeners that generate 24-24-CB and 235-24-CB, and 24-26-CB and 235-26-CB (Table 2-1). The discrepancy for the latter congeners was higher, but was within $11 \%$ of the expected value. These results demonstrate that both the quantities and the chlorination substitution pattern of the $\mathrm{PCB}$ congeners formed in the field test are completely consistent with Pattern N microbial dechlorination of the Woods Pond sediment PCBs. The results also attest to the accuracy of congener assignments and quantitation in our analytical method (See also Smullen et al., Chapter 3, this report).

\section{Effect of Dechlorination on Biodegradability}

Aroclor 1260 is virtually nondegradable by aerobic bacteria because the high degree of chlorine substitution precludes or greatly hinders the initial ring oxidation by biphenyl dioxygenase [Bedard, 1990; Abramowicz, 1990; Furukawa, 1982]. In contrast, many of the PCB congeners produced by Pattern $N$ dechlorination, including the major product, 24-24-CB, can be at least partially degraded by aerobic bacteria [Bedard et al., 1986; 1987; Focht, 1988; Bedard, 1990; Furukawa et al., 1978; 1979]. 
There is concern that the PCBs which may pose the greatest potential health risk, at least for some endpoints, are those which are not easily metabolized and therefore persist and accumulate in human and animal tissues [Safe, 1984; Brown, 1992]. The susceptibility of PCBs to metabolism is a function of the number and position of chlorines on the biphenyl ring. John F. Brown, Jr., has analyzed the clinical data and literature reports of the metabolism of PCBs in human and animal tissues and has assigned each of the congeners to a category based on its persistence in humans, animals, and bioassays [Brown, 1992]. Table 2-3 compares the persistence of the components of Aroclor 1260, the slightly dechlorinated Aroclor 1260 in Woods Pond sediment, and the extensively dechlorinated Aroclor 1260 that resulted from the addition of 2,6-BB. In unaltered Aroclor 1260, 45 mole percent of the PCB constituents have a half-life of 10 years or more and are considered highly persistent. An additional 16 mole percent have a half-life of at least one year and are considered moderately persistent. The data in the column labelled Day -4 reflect the composition of the sediment PCBs 4 days before the addition of 2,6-BB and demonstrate the effect of environmental dechlorination. The environmental dechlorination has decreased the most highly persistent PCBs by $26 \%$, but nearly $50 \%$ of the PCBs in Woods Pond are still classified as moderately or highly persistent. 4 As a result of the dechlorination stimulated by 2,6-BB in the field test, the highly persistent PCBs decreased by an additional $73 \%$ and the moderately persistent PCBs by $56 \%$, with the net result that 84.6 mole percent of the PCBs remaining are only slightly persistent, i.e. are metabolized with a half-life of less than one year in the human. Therefore, the $\mathrm{PCB}$ dechlorination stimulated by the addition of 2,6-BB significantly reduced the mammalian bioaccumulation potential of the sediment $\mathrm{PCBs}$ and any potential health risk associated with bioaccumulation of PCBs.

4 These values are different than those reported last year largely because we are now using the more accurate customized standard [Smullen et al., Chapter 3, this report] for quantification. 
TABLE 2-3. Effect of dechlorination on the persistence of PCBs in the human.

\begin{tabular}{|c|c|c|c|c|}
\hline \multirow{3}{*}{$\begin{array}{c}\text { Metabolic } \\
\text { Susceptibility }\end{array}$} & \multicolumn{4}{|c|}{ Mole \% in Specimen } \\
\hline & \multirow{2}{*}{$\begin{array}{c}\mathrm{T}_{1 / 2} \text { in } \\
\text { human } \\
(\mathrm{yr})\end{array}$} & \multirow[t]{2}{*}{ Aroclor 1260} & \multicolumn{2}{|c|}{$\begin{array}{l}\text { Dechlorinated Aroclor } \\
1260 \text { in Woods Pond } \\
\text { Sediment }\end{array}$} \\
\hline & & & Day -4 & $\begin{array}{l}+2,6-\mathrm{BB} \\
\text { Day } 373 \\
\end{array}$ \\
\hline $\begin{array}{l}\text { Very rapidly cleared. } \\
\text { Not seen in tissues. }\end{array}$ & $<0.01$ & 0.0 & 0.0 & 0.2 \\
\hline $\begin{array}{l}\text { Soon cleared. } \\
\text { Rarely seen in tissues. }\end{array}$ & $0.01-0.10$ & 1.2 & 4.7 & 23.7 \\
\hline $\begin{array}{l}\text { Slightly persistent. } \\
\text { Barely detectable in } \\
\text { tissues. }\end{array}$ & $0.1-1.0$ & 37.8 & 47.5 & 60.7 \\
\hline $\begin{array}{l}\text { Moderately persistent. } \\
\text { Usually detected in } \\
\text { tissues. }\end{array}$ & $1.0-10.0$ & 16.0 & 14.6 & 6.4 \\
\hline $\begin{array}{l}\text { Highly persistent. } \\
\text { Always detectable } \\
\text { after exposure. }\end{array}$ & $>10.0$ & 45.0 & 33.2 & 9.0 \\
\hline
\end{tabular}




\section{SUMMARY AND CONCLUSIONS}

We have conducted the first in situ test of anaerobic dechlorination of PCBs in contaminated sediment. We have successfully used a single addition of 2,6-BB to stimulate microbial dechlorination of the Aroclor 1260 contaminant in caissons installed in Woods Pond. The field test was conducted at ambient temperatures and with no stirring after the initial additions. Dehalogenation of the 2,6-BB began within two weeks, and by 78 to 115 days, 98 to $99 \%$ of the 2,6-BB had been dehalogenated to biphenyl at all levels of the sediment. $P C B$ dechlorination was first observed at three weeks. The hexa- through nonachlorobiphenyls in the top 6 inches of the sediment decreased from an initial value of 68 mole percent of the total PCBs to 26 mole percent at day 93,22 mole percent at day 212, and 17.6 mole percent at day 373. Corresponding increases were seen in tri- and tetrachlorobiphenyls. The dechlorination progressed somewhat more slowly in the colder lower sediments, but continued longer into the cold months, probably because the lower sediments were not as cold as those at the top. The dechlorination was highly specific for meta-chlorines positioned adjacent to other chlorines. By 312 days, the PCBs in the lower sediments had been dechlorinated almost as extensively as those in the upper sediments. Our data indicate that $\mathrm{PCB}$ dechlorination continued throughout the winter, at least in the bottom of the sediment.

No dechlorination was observed in the control caisson, indicating that the 2,6- $\mathrm{BB}$ was responsible for stimulating the extensive $\mathrm{PCB}$ dechlorination observed in the experimental caisson. These results also suggest either that environmental PCB dechlorination in this sediment has ceased, or that it occurs at such a slow rate that no significant changes could be detected in a year.

The PCB congeners generated by dechlorination in this field test are more susceptible to biodegradation by aerobic bacteria and metabolism by higher organisms, and are therefore less persistent in the environment and have a lower potential for bioaccumulation.

The results of the first year of the field test are very encouraging. We have demonstrated that it is possible to stimulate substantial microbial dechlorination of highly chlorinated PCBs in situ with a single addition of a chemical that is degraded to innocuous products and without temperature control. Our results also imply that a single chemical intervention can have a long-term beneficial effect on PCB dechlorination by indigenous microorganisms, even in a cold New England climate. 


\section{ACKNOWLEDGEMENTS}

We thank Dr. James Cella and Elliott Shanklin for synthesizing and purifying the 2,6-BB, Blasland \& Bouck Engineers, P.C. (Syracuse, NY) for designing the test station and assisting in collecting samples, and Angelo Bracco, Dr. Kenneth Fish, Dr. Mark Stephens, and Bill Sweeney for expert technical assistance. We also thank Qingzhong Wu, and Dr. Juergen Wiegel of the University of Georgia for their important temperature studies of $\mathrm{PCB}$ dechlorination in Woods Pond sediment slurries prior to the field test. 
The following references were qouted in the previous section:

Abramowicz, D.A. 1990. Aerobic and anaerobic biodegradation of PCBs: A Review. In CRC Critical Review's in Biotechnologv. G.G. Steward and I. Russell (eds.). CRC Press, Inc. 10:241-251.

Bedard, D.L., R. Unterman, L.H. Bopp. M.J. Brennan. M.L. Haberl, and C. Johnson 1986. Rapid assay for screening and characterizing microorganisms for the ability to degrade polychlorinated biphenyls. Appl. Environ. Microbiol. 51:761-768.

Bedard D.L., R.E. Wagner, M. L. Brennan, M. L. Haberl, and J. F. Brown, Jr. 1987a. Extensive degradation of Aroclors and environmentally transformed polychlorinated biphenyls by Alcaligences eutrophus H850. Appl. Environ. Microbiol. 53:1094:1102.

Bedard, D.L. 1990. Bacterial transformations of polychlorinated biphenyls. In Biotechnologv and Biodegradation, D. Kamely, A. Chakrabarty and G.S. Omenn (eds.), Adv. Appl. Biotechnol. Series. Portfolio Publishing Co., The Woodlands, TX Vol. 4, 369-388.

Bedard, D.L., S.C. Bunnell. and H.M. Van Dort 1990. Anaerobic dechlorination of endogenous PCBs in Woods Pond Sediment. In General Electric Company Research and Development Program for the Destruction of PCBS, Ninth Progress Report. General Electric Company Research and Development. Schenectady, NY. Ch. 5:43-54.

Bedard, D.L., H.M. Van Dort, R.J. May. K.A. DeWeerd, J.M. Principe, and L.A. Smullen 1992. Stimulation of dechlorination of Aroclor 1260 in Woods Pond sediment. In General Electric Company Research and Development Program for the Destruction of PCBs, Eleventh Progress Report. General Electric Corporatc Research and Development. Schenectady, NY Ch. 10:269-280.

Brown, J.F., Jr. 1992. Quantitation and implications of PCB accumulability' in higher animals. In General Electric Company Research and Development Program for the Destruction of PCBs, Eleventh Progress Report. General Electric Corporate Research and Development, Schenectady, NY. Ch. 3:177-188.

Furukawa, K. 1982. Microbial degradation of polychlorinated biphenyls, (PCBs). In Biodegradation and Detoxification of Environmental Pollutants, A.M. Chakrabarty (ed.). CRC Press, Inc., Boca Raton, FL., p. 33-57.

Furukawa, K., K. Tonomura, and A. Kamibayashi 1978. Effect of chlorine substitution on the biodegradability of polychlorinated biphenyls. Appl. Environ. Microbiol. 35:223-227.

Furukawa, K., F. Matsumure, and K. Tonomura 1978. Alcaligenses and Acinetobacter strains capable of degrading polychlorinated biphenyls. Agric. Biol. Chem. 42:543-548.

Furukawa, K., K. Tonomura. and A. Kamibayashi 1979. Effect of chlorine substitution pattern on the bacterial metabolism of various polychlorinated biphenyls. Appl. Environ. Microbiol. 38:301-310.

Schulz, D.E., G. Petrick, and J.C. Duinker 1989. Complete characterization of polychlorinated biphenyl congeners in commercial Aroclor and Clophen mixtures by multidimensional gas chromatography-electron capture detection. Environ. Sci Technol. 23:852-859.

Safe, S. 1984. Polychlorinated biphenyls (PCBs) and polybrominated biphenyls (PBBs): Biochemistry, Toxicology, and Mechanism of Action. Crit. Rev. Toxicol. 13:319-395.

Van Dort, H.M. and D.L. Bedard 1991a. Reductive ortho and meta dechlorination of a polychlorinated biphenyl congener by anaerobic microorganisms in sediment slurries. In General Electric Company Rescarch and Development Program for the Destruction of PCBs, Tenth Progress Report. General Electric Corporatc Research and Development, Schenectady, NY. Ch. 5:55-63. 


\title{
DEVELOPMENT OF A CUSTOMIZED CONGENER SPECIFIC PCB STANDARD FOR QUANTIFICATION OF WOODS POND SEDIMENT PCBS
}

\author{
Lynn A. Smullen, Kim A. DeWeerd, and Donna L. Bedard \\ Environmental Laboratory \\ General Electric Corporate Research and Development \\ Schenectady, New York \\ William A. Fessler \\ General Electric Pittsfield Environmental and Facilities Program \\ Pittsfield, Massachusetts \\ James C. Carnahan and Robert E. Wagner* \\ Materials Characterization Laboratory \\ General Electric Research and Development \\ Schenectadv, New York
}

\section{INTRODUCTION}

The microbial dechlorination that we have stimulated with 2,6-dibromobiphenyl (26-BB) in Woods Pond sediments removes primarily meta chlorines, but only from positions that have adjacent chlorines [Bedard et al., Chapter 2, this report]. Meta chlorines that have no adjacent chlorines, such as the chlorine on a 2,5-dichloro-biphenyl (25-CB) ring, are not removed, nor are ortho chlorines. Para chlorines are removed, but only from congeners with a 2,3,4,5-chlorophenyl ring. This pattern of dechlorination is known as Pattern N [Quensen et al., 1990; Bedard et al., 1990; 1992]. Woods Pond samples that exhibit limited environmental dechlorination of Arocior 1260 via the loss of meta and para chlorines will be referred to in this study as environmentally dechlorinated sediment PCBs. Woods Pond samples that have undergone further meta dechlorination by the addition of 2,6-BB, will be referred to as Pattern $\mathrm{N}$ dechlorinated sediment PCBs.

*R.E.Wagner is now located at Northeast Analytical Laboratory, Schenectady, NY 
Aroclors are complex mixtures of PCBs usually composed of 60-70 different congeners. Congener specific analysis by capillary gas chromatography using an electron capture detector (GC-ECD) and a mass selective detector (GC-MS) has demonstrated that many of the $P C B$ congeners produced by Pattern $N$ dechlorination are either not present in any of the Aroclors or present only in minor quantities. These include, 26-26-CB (pk 19), 25-26-CB (pk 25), 24-26-CB (pk 26), 24-24-CB (pk 33), 246-26-CB (pk 37A), 246-25-CB (pk 43), 246-24-CB (pk 44), 246-34-CB (pk 55), and 2356-24-CB (pk 67). In addition, some of these congeners coelute with less chlorinated $\mathrm{PCB}$ congeners that are more prominent in the commercial Aroclors. For example, two prominent products of Pattern $\mathrm{N}$ dechlorination, 25-26-CB (pk 25) and 24-26-CB (pk 26) coelute with trichlorobiphenyls in Aroclor 1260.

It was apparent that we could not accurately quantify dechlorinated sediment PCBs in the field test using any single Aroclor or mixture of Aroclors as a standard. We therefore developed a quantitative PCB standard that included Aroclor 1260, plus all of the congeners formed in Woods Pond sediment by environmental and Pattern $N$ dechlorination.

\section{MATERIALS AND METHODS}

\section{PCB Extraction and Qualitative GC-MS Analysis}

Wet sediment samples ( 30 grams) were mixed with anhydrous sodium sulfate ( $\sim 30$ grams) and extracted three times by vigorous shaking for 1 hour on a horizontal platform shaker with $50 \mathrm{mls}$ of a 50:50 (v/v) mixture of acetone/2,2,4-trimethylpentane (isooctane) (EM Science, Gibbstown, NJ). The combined extracts were then brought to a $250 \mathrm{ml}$ volume with isooctane. A portion of the combined extract ( $25 \mathrm{mis}$ ) was solvent exchanged with $100 \%$ isooctane. The extract was treated with triple distilled mercury to remove elemental sulfur and then with concentrated sulfuric acid to remove polar hydrocarbons. The clean extracts were analyzed on a Hewlett-Packard 5890 gas chromatograph (Hewlett-Packard Co., Palo Alto, CA) equipped with a Hewlett-Packard 5971A mass selective detector. The column used was a $30 \mathrm{~m} \mathrm{SPB-1}$ fused silica (polydimethylsiloxane) capillary column $(0.25 \mathrm{~mm}$ ID and film thickness of $0.25 \mu \mathrm{m}$ ) (Supelco Inc., Bellefonte, PA). The samples were compared to a standard mixture of $70 \%$ Aroclor 1242, 20\% Aroclor 1254, and $10 \%$ Aroclor 1260 (70/20/10). Qualitative GC-MS selective ion monitoring (SIM) 
analyses were performed to determine the $\mathrm{PCB}$ homolog composition for each peak. $M / z$ ratios monitored for the various homologs were: 188.0, 221.9, 255.9, 291.9, 325.8, $359.8,395.8,429.7$, and 463.7 for mono- through nonachlorobiphenyls, respectively.

\section{Original PCB Congener Peak Assignments}

Brown et al. [1987b] found that the PCB components of all Aroclors could be resolved into 118 peaks on a $30 \mathrm{~m} \mathrm{DB-1}$ fused silica (polydimethylsiloxane) capillary column $(0.25 \mathrm{~mm}$ ID and film thickness of $0.25 \mu \mathrm{m}$ ) (J\&W Scientific, Folsom, CA) and have published peak assignments for all Aroclors. Seventy of their 160 congener assignments were based on co-injection of those congeners that were commercially available at that time with the Aroclors. The remaining assignments were based on the relative retention times published for all 209 PCB congeners on a slightly different column phase (SE-54, 95\% dimethylsiloxane, 5\% diphenylsiloxane copolymer) [Mullin et al., 1984; Safe et al., 1985], and on assignments published by Ballschmiter and Zell [1980], but with further refinements as follows. (1) Brown et al. [1987] used GC-MS analysis to discriminate between non-isomeric coeluting congeners in each Aroclor. (2) They also considered the relative proportions of the individual chlorophenyl groups in each Aroclor, and concluded that several coeluting isomers would be present at levels too low to be included as significant peak components.

\section{Verification of PCB Congener Assignments}

Based on the congener assignments of Brown et al. [1987b], we identified 150 individual congeners as possible components of Woods Pond sediment PCBs. These were purchased either in neat form (99\% pure) or as $35 \mu \mathrm{g} / \mathrm{ml}$ solutions in isooctane from either AccuStandard Inc., (New Haven, CT) or from Ultra Scientific, (North Kingstown, RI). For determination and verification of retention times, hexane solutions of the individual congeners were injected on a Hewlett-Packard 5890 gas chromatc graph equipped with an electron capture detector and a $30 \mathrm{~m}$ DB-1 fused silica capulary column $(0.25 \mathrm{~mm} \mathrm{ID}$ and film thickness of $0.25 \mu \mathrm{m})$ and a HewlettPackard 7673 autosampler. The retention time of each individual congener was compared to that of the assigned peak in the 70/20/10 Aroclor standard. Each congener was chromatographed 2 or 3 times and the average retention times were calculated. Original congener assignments [Brown et al., 1987b] were considered to be correct if the retention times of the pure congener and the assigned peak agreed within 0.05 minutes. Congeners that coeluted, per Brown et al. [1987b], were verified 
both individually and together in hexane solutions to determine if the combination of congeners affected their elution time.

\section{Quantification of Aroclor 1260}

The weight percent contributions of the $\mathrm{PCB}$ components of each peak in Aroclor 1260 were previously calculated [R.E. Wagner, J.C. Carnahan, R.J. May, unpublished data] by a modification of the method of Webb and McCall [1973]. The weight of chlorine per unit peak area was determined by using a Hall (instead of a Coulson) electrolytic conductivity detector (Tracor Instruments, Austin TX) and mass spectrograms of the isomer classes present in each peak.

Fifteen minor peaks representing 17 congeners of Aroclor 1260 had not been previously quantified (Table 3-1). We prepared a quantitative standard of these 17 congeners in isooctane. This was used to generate a 3-point calibration curve using GC-MS in the SIM mode. A known concentration of Aroclor 1260 was analyzed, and the 15 minor peaks were quantified by reference to the standard curve of the 17 congeners. The weight fractions of these 17 congeners in Aroclor 1260 were calculated and are reported in Table 3-1. Together, they represent 4.99 weight percent of the PCBs in Aroclor 1260. These data were combined with our previous data [Wagner et al., unpublished data] to calculate the weight composition of Aroclor 1260.

\section{RESULTS AND DISCUSSION}

\section{Verification and Reassignment of PCB Congeners}

GC-ECD and GC-MS were used to verify $\mathrm{PCB}$ congener assignments in Aroclor 1260 and to determine which additional PCB congeners were present in environmentally and Pattern $N$ dechlorinated samples. A total of 160 congeners were reported in the 118 peak method [Brown et al., 1987b]. We verified every congener assignment in Arocior 1260 and every expected Pattern $N$ dechlorination product of Aroclor 1260. Our results indicated that 15 of the 150 congeners that we checked had been misassigned by one peak. In addition, seventeen congeners previously believed to coelute are in fact separately resolved. For example, 25-25-CB and 26-35-CB which were originally assigned to DB-1 peak 31, are resolved and have been reassigned to peaks $31 \mathrm{~A}$ and $31 \mathrm{~B}$, respectively. Nine congeners previously believed to separate actually coelute. For example, 24-35-CB and 
TABLE 3-1. Weight percent values for minor PCB congeners in Aroclor 1260.

\begin{tabular}{|c|l|l|l|}
\hline DB1 & \multicolumn{1}{|c|}{$\begin{array}{c}\text { PCB } \\
\text { Peak }\end{array}$} & $\begin{array}{c}\text { IUPAC } \\
\text { Congener }\end{array}$ & $\begin{array}{c}\text { Weight } \\
\text { Number }\end{array}$ \\
\hline $72 / 6$ & $2346-23$ & 131 & 0.066 \\
$72 / 6$ & $235-235$ & 133 & 0.066 \\
$74 / 5$ & $234-34$ & 105 & 0.169 \\
$79 / 6$ & $2345-24$ & 137 & 0.108 \\
$80 / 6$ & $234-235$ & 130 & 0.108 \\
$81 / 7$ & $2346-236$ & 176 & 0.550 \\
$83 / 6$ & $2346-34$ & 158 & 0.768 \\
$89 / 6$ & $234-234$ & 128 & 0.474 \\
$92 / 7$ & $23456-25$ & 185 & 0.500 \\
$96 / 6$ & $234-345$ & 157 & 0.106 \\
$96 / 8$ & $2356-2356$ & 202 & 0.323 \\
$99 / 8$ & $2346-2356$ & 201 & 0.269 \\
$101 / 8$ & $2346-2346$ & 197 & 0.089 \\
$103 / 7$ & $2356-345$ & 193 & 0.419 \\
$104 / 7$ & $2346-345$ & 191 & 0.150 \\
$105 / 8$ & $23456-236$ & 200 & 0.634 \\
$111 / 7$ & $2345-345$ & 189 & 0.189 \\
& & & \\
& & total & 4.988 \\
\hline
\end{tabular}


(a) Aroclor mixture

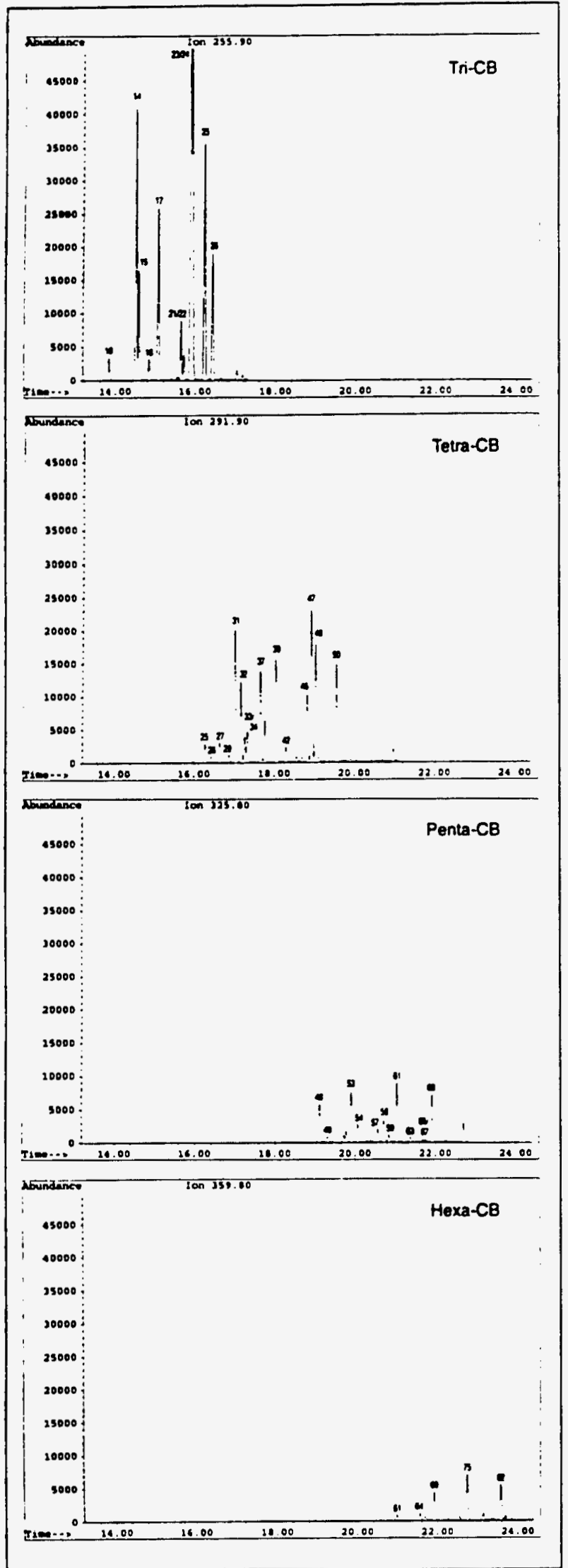

(b) Environmentally dechlorinated PCBs

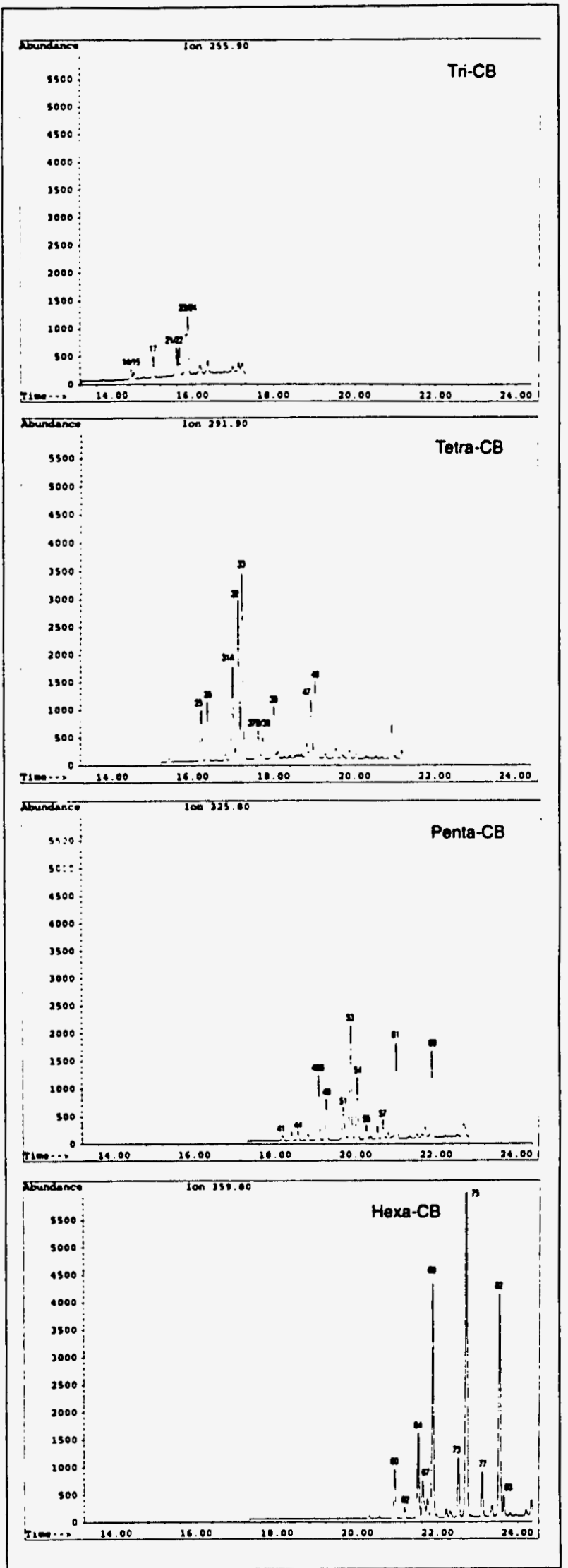

Figure 3-1. GC-MS SIM analysis of: (a) Aroclor standard 70/20/10; (b) Environmentally dechlorinated PCBs from Woods Pond sediment; (c) Pattem N dechlorinated PCBs from Woods Pond sediment; (d) Customized, quantitative, congener specific PCB standard for Woods Pond field test. 
(c) Pattern $\mathrm{N}$ dechlorinated PCBs

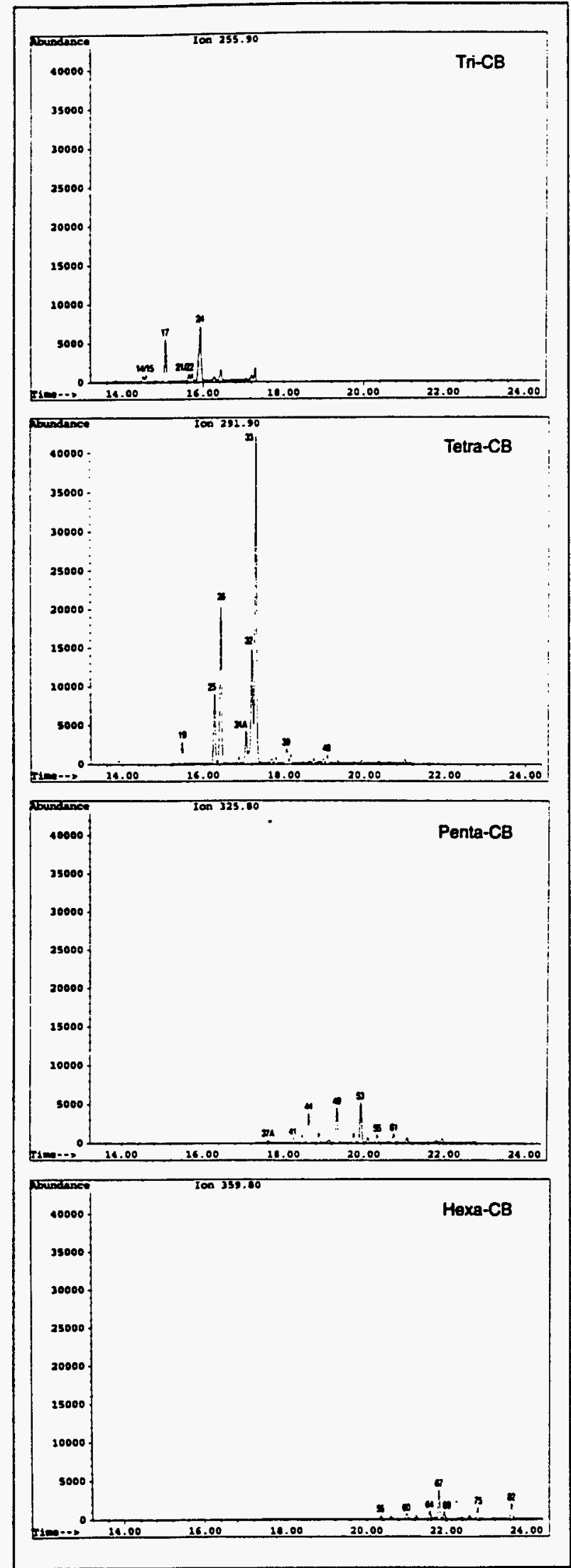

(d) Customized PCB standard

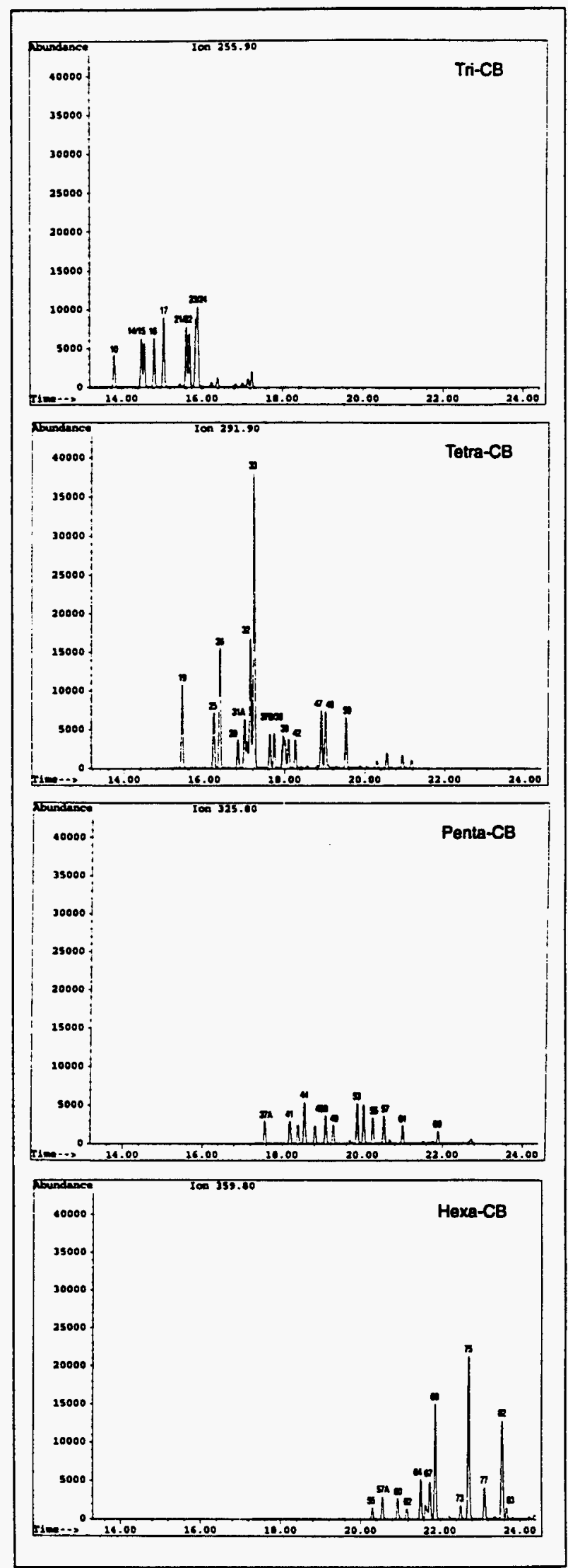

Figure 3-1 continued 
TABLE 3-2. Revised PCB congener assignments for DB-1 fused silica capillary column.

\begin{tabular}{|c|l|c|c|}
\hline $\begin{array}{c}\text { IUPAC } \\
\text { No. }\end{array}$ & $\begin{array}{c}\text { PCB } \\
\text { Congener }\end{array}$ & $\begin{array}{c}\text { Original DB1 } \\
\text { Assignment }\end{array}$ & $\begin{array}{c}\text { Correct DB1 } \\
\text { Assignment }\end{array}$ \\
\hline 43 & $235-2$ & none & 32 \\
52 & $25-25$ & 31 & $31 \mathrm{~A}$ \\
73 & $26-35$ & 31 & $31 \mathrm{~B}$ \\
104 & $246-26$ & 37 & $37 \mathrm{~A}$ \\
44 & $23-25$ & 37 & $37 \mathrm{~B}$ \\
68 & $24-35$ & 40 & $40 / 41$ \\
96 & $236-26$ & 41 & $40 / 41$ \\
58 & $23-35$ & 45 & 44 \\
94 & $235-26$ & 46 & $46 \mathrm{~A}$ \\
61 & 2345 & 47 & $46 \mathrm{~B}$ \\
98 & $246-23$ & 49 & $48 \mathrm{~A}$ \\
76 & $345-2$ & 47 & $48 \mathrm{~A}$ \\
66 & $24-34$ & 48 & $48 \mathrm{~A}$ \\
102 & $245-26$ & $n 0 n e$ & $48 \mathrm{~B}$ \\
93 & $2356-2$ & 48 & $48 \mathrm{~B}$ \\
95 & $236-25$ & 48 & $48 \mathrm{~B}$ \\
112 & $2356-3$ & 55 & $56 \mathrm{~A}$ \\
83 & $235-23$ & 56 & $56 \mathrm{~A}$ \\
109 & $2346-3$ & 56 & $56 \mathrm{~B}$ \\
97 & $245-23$ & 57 & $57 \mathrm{~A}$ \\
152 & $2356-26$ & 57 & $57 \mathrm{~A}$ \\
86 & $2345-2$ & 57 & $57 \mathrm{~B}$ \\
87 & $234-25$ & 58 & $58 \mathrm{~A}$ \\
111 & $235-35$ & 58 & $58 \mathrm{~A}$ \\
115 & $2346-4$ & 58 & $58 \mathrm{~B}$ \\
139 & $2346-24$ & 70 & 69 \\
161 & $2346-35$ & 73 & 74 \\
137 & $2345-24$ & 80 & 79 \\
130 & $234-235$ & 79 & 80 \\
160 & $23456-3$ & 82 & 83 \\
157 & $234-345$ & 97 & 96 \\
204 & $23456-246$ & 99 & 100 \\
192 & $23456-35$ & 100 & 101 \\
\hline & & &
\end{tabular}


236-26-CB originally assigned to DB-1 peaks 40 and 41 , respectively, coelute. The peak has been renamed 40/41. All changes from the original assignments are reported in Table 3-2. The original numbering system for the 118 peak assignments was not changed, but in cases where additional peaks were positively identified, the letters $A$ and $B$ were added to the previously assigned peak number.

The ability to resolve some closely eluting peaks appears to be a function of the relative concentrations of the congeners in question and of the column resolution. This is the case for DB-1 peaks 23 and $24,(25-4-C B$ and $24-4-C B)$, peaks $48 \mathrm{~A}$ and $48 \mathrm{~B},(24-34-\mathrm{CB}$ and $236-25-\mathrm{CB} / 245-26-C B)$, peaks 77 and $78,(2345-25-\mathrm{CB}$ and 2356-236-CB), and peaks 81 and 82, (2346-236-CB and 234-245-CB/2356-34-CB/ 236-345-CB). Peaks $48 A$ and $48 B, 77$ and 78 , and 81 and 82 are each composed of congeners with differing homologs; tetra- $C B$ and penta- $C B$, hexa-CB and hepta- $C B$, and hepta-CB and hexa-CB, respectively. Although their resolution may be difficult by GC-ECD it is easily achieved via GC-MS.

\section{Identification of PCB Dechlorination Products in Sediment PCBs}

We used GC-MS-SIM analysis to compare the PCB congener composition of environmentally and Pattern N dechlorinated PCBs from Woods Pond sediment with that of Aroclor 1260 (not shown) and the 70/20/10 Aroclor standard (Figure 3-1A and 3-1B). For each sample all homologs are shown on the same scale in order to show their relative proportions. We identified 34 PCB congeners in Woods Pond sediment that were not present in Aroclor 1260 and four more that were not present in Aroclor 1260 in sufficient amounts to accurately quantify the sediment PCBs.

Many of these 38 congeners were present in Aroclor 1242 or 1254, but the homolog composition was often radically different from that of the dechlorinated sediment PCBs (Figure 3-1). For example: (1) Peak 19 (26-26-CB), a significant Pattern N dechlorination product, was not present in the Aroclor mixture, making its quantification impossible. (2) Peaks 25 and 26 in the sediment PCBs are tetrachlorobiphenyls, $25-26-C B$ and $24-26-C B$, respectively, which contain 3 ortho chlorines each and accumulate to high levels. In contrast, peaks 25 and 26 in the Aroclor mixture are each composed of trichlorobiphenyls, which contain only a single or tho chlorine, 234-CB/23-3-CB/34-2-CB and 23-4-CB, respectively. Thus, using an Aroclor based standard to quantify the dechlorinated PCBs would result in 
misreporting these tetrachlorobiphenyls as trichlorobiphenyls and would yield an artificially low number of ortho chlorines suggesting that ortho dechlorination had occurred. (3) Peak 33 (24-24-CB), is the major product of Pattern N dechlorination of Aroclor 1260 (final expected value of 25.5 mole\%). In the Aroclor mixture, this congener is not present in a sufficient amount to accurately quantify the amounts generated by dechlorination. (4) The pentachlorobiphenyl peaks 37A (246-26-CB), 41 (236-26-CB), 43 (246-25-CB), $44(246-24-C B)$ and 55 (246-34-CB), are not present in the Aroclor mixture making their quantification with an Aroclor standard impossible. (5) Peak 67, 2356-24-CB is the major hexachlorobiphenyl formed (3.4 mole\%) by Pattern $\mathrm{N}$ dechlorination and contains no pentachlorobiphenyl. In contrast, peak 67 is an extremely small peak in the Aroclor mixture, composed of only pentachlorobiphenyls, 235-34-CB/234-35-CB. Therefore, quantification of this peak in Woods Pond sediments using an Aroclor standard is not possible. (6) In the environmentally dechlorinated sediment $\mathrm{PCBs}$, peak 69, 245-34-CB/236-245-CB, contains $82 \%$ hexachlorobiphenyl and only $18 \%$ pentachlorobiphenyl. In the Aroclor mixture, peak 69 contains more pentachlorobiphenyl than hexachlorobiphenyl (exact percentages unavailable).

The differences in the congeners found in the dechlorinated sediment PCBs versus the pure Aroclors can be attributed to the highly specific nature of microbial dechlorination. Aroclors were prepared by a ferric chloride catalyzed chlorination reaction. Consequently, congener distribution in the Aroclors is determined by the general rules for electrophilic substitution. Certain chlorophenyl groups such as 25-, 245-, 2345-, 234- and 236-, are abundant, whereas others such as 24-, 246-, 26-, and 235are rare. Pattern $N$ dechlorination is a highly specific type of meta-dechlorination which generates primarily tetra- and pentachlorobiphenyls containing 24-, 246-, and 26-chlorophenyl groups. It is likely that other types of microbial dechlorination of PCBs also generate $\mathrm{PCB}$ congeners that cannot be accurately quantified with Aroclor standards. We expect this to be especially true for partial dechlorination of Aroclors 1254 and 1260 because these Aroclors contain primarily penta-, hexa- and heptachlorobiphenyls and can therefore be dechlorinated to tetra- and pentachlorobiphenyls composed of atypical di- and trichlorophenyl rings.

\section{Preparation of the Customized Standard}

To prepare the customized standard, we combined Aroclor 1260, the 38 congeners identified as products of Pattern $\mathrm{N}$ dechlorination, and 7 congeners that are frequently observed $\mathrm{PCB}$ dechlorination products in other locations, e.g., the 
Hudson River. The 7 congeners were added because if additional dechlorination occurs (not Pattern $\mathrm{N}$ ) these congeners may become important and may need to be quantified. The 45 individual congeners were weighed on an analytical balance and dissolved in isooctane. The relative amounts of the 45 congeners used in the customized standard were based on estimates of the amounts present in the Pattern $\mathrm{N}$ dechlorinated PCBs. Table 3-3 identifies all PCB congeners present in the Woods Pond customized standard and gives the weight percent compositions of Aroclor 1260, the supplemental congener mix, and the final customized standard. The original weight percent values for Aroclor 1260 [Wagner et al., unpublished data] without the 15 minor peaks are also given. Two nonachlorobiphenyls 23456-2356-CB (pk 113) and 23456-2346-CB (pk 114), were not quantified in the final customized standard because they are present in Aroclor 1260 at $<0.1$ mole\%. Aroclor 1260 and the additional congener mixes were combined in the final customized standard in a ratio that would permit quantification of all peaks ranging from Aroclor 1260 to Pattern $N$ dechlorinated Aroclor 1260 (Figure 3-1d). It should be noted that 236-246-CB (pk 55) and 245-246-CB (pk 62) were added in a separate solution. A visual comparison of the homolog distribution between our customized standard and the sediment PCBs in panels (b) and (c) shows that this standard can accurately quantify the entire range of $P C B$ congeners in Woods Pond sediment including Aroclor 1260 and the intermediate and end products of Pattern N dechlorination.

\section{Data Reduction}

Congener specific analysis of Woods Pond sediment PCBs is done by GCECD as previously described. The data are collected using Dionex AI-450 Chromatography software (Dionex Corp., Sunnyvale, CA). The method uses a four point external calibration (219 ppb - $3509 \mathrm{ppb}$ range) with a quadratic fit forced through zero. A four point calibration curve is needed to accurately quantify the PCBs before and after dechlorination due to the large changes that occur in the amounts of many congeners as a result of Pattern $\mathrm{N}$ dechlorination. This is clearly illustrated by comparing the relative amounts of peaks 69, 75 and 82, the major hexachlorobiphenyl peaks in Aroclor 1260, before and after 26-BB addition (Figure 3-1b and $1 \mathrm{c}$ ). These hexachlorobiphenyls are almost completely removed by Pattern $\mathrm{N}$ dechlorination. Also note the relative amounts of peaks 26 and 33 . Before the addition of 26-BB these peaks were present, but in fairly low proportions. Following Pattern $N$ dechlorination (Figure 3-1c), they are the two largest components of the dechlorinated PCBs. 
TABLE 3-3. Congener identification and weight percent composition of Aroclor 1260 and the customized Woods Pond standard.

\begin{tabular}{|c|c|c|c|c|c|c|}
\hline DBI PK & $\begin{array}{c}\text { PCB } \\
\text { Congener }\end{array}$ & $\begin{array}{c}\text { IUPAC } \\
\text { No. }\end{array}$ & $\begin{array}{c}\text { Onginal } \\
W \% \\
\text { in } 1260\end{array}$ & $\begin{array}{l}\text { Revised } \\
1260 \\
W n \% \\
\end{array}$ & $\begin{array}{l}\text { Wh in the } \\
43 \text { added } \\
\text { congeners }\end{array}$ & $\begin{array}{l}\text { W\% in } \\
\text { Custom } \\
\text { Standard } \\
\end{array}$ \\
\hline 2 & 2 & 1 & & & 3.26 & 2.29 \\
\hline 4 & 4 & 3 & & & 3.32 & 2.34 \\
\hline 5 & $2-2$ & 4 & & & 3.18 & 2.24 \\
\hline 7 & $2-3$ & 6 & & & 1.91 & 1.35 \\
\hline 8 & 24 & 8 & & & 2.16 & 1.52 \\
\hline 10 & $26-2$ & 19 & & & 1.54 & 1.09 \\
\hline $14 \sqrt{2}$ & 4 & 15 & & & 2.14 & 1.50 \\
\hline $14 / 3$ & $25-2$ & 18 & & & 2.16 & 1.52 \\
\hline $15 / 3$ & $24-2$ & 17 & & & 1.91 & 1.35 \\
\hline $16 / 3$ & $26-3$ & 27 & & & 1.69 & 1.19 \\
\hline $17 / 3$ & $26-4$ & 32 & & & 1.97 & 1.39 \\
\hline $19 / 4$ & $26-26$ & 51 & & & 3.25 & 2.29 \\
\hline $21 / 3$ & $25-3$ & 26 & & & 1.62 & 1.14 \\
\hline $22 \sqrt{3}$ & $24-3$ & 25 & & & 1.44 & 1.02 \\
\hline $23 / 3$ & 254 & 31 & & & 1.62 & 1.14 \\
\hline $24 / 3$ & 244 & 28 & & & 1.94 & 1.37 \\
\hline $25 / 4$ & 25.26 & 53 & & & 2.61 & 1.84 \\
\hline $26 / 4$ & $24-26$ & 51 & & & 5.59 & 3.94 \\
\hline $29 / 4$ & $23-26$ & 46 & & & 1.56 & 1.10 \\
\hline 3iAN4 & $25-25$ & 52 & & & 2.04 & 1.44 \\
\hline $318 / 4$ & $26-35$ & 73 & & & 1.08 & 0.76 \\
\hline $32 / 4$ & 2425 & 49 & & & 5.41 & 3.82 \\
\hline $33 / 4$ & $24-24$ & 47 & & & 10.67 & 7.52 \\
\hline $37 A 55$ & $246-26$ & $1 C \perp$ & & & 1.56 & 1.10 \\
\hline $378 / 4$ & $23-25$ & Aد & & & 1.61 & 1.13 \\
\hline $38 / 4$ & $23-24$ & 42 & & & 1.53 & 1.08 \\
\hline $39 / 4$ & $26-34$ & 71 & & & 0.85 & 0.60 \\
\hline $39 / 4$ & $25-35$ & 72 & & & 0.87 & 0.62 \\
\hline $40-1 / 4$ & $24-35$ & 68 & & & 0.87 & 0.62 \\
\hline $40-41 / 5$ & $236-26$ & 98 & & & 1.63 & 1.15 \\
\hline $42 / 4$ & $23-23$ & 40 & & & 1.61 & 1.13 \\
\hline $43 / 5$ & $246-25$ & 103 & & & 1.49 & 1.05 \\
\hline $4 / 15$ & $246-24$ & 100 & & & 3.33 & 2.35 \\
\hline 46A15 & $235-26$ & 94 & & & 1.63 & 1.15 \\
\hline 47 & $25-34$ & 70 & & & 1.61 & 1.13 \\
\hline 48A/4 & $24-34$ & 66 & & & 1.62 & 1.14 \\
\hline $488 / 5$ & $236-25$ & 95 & 2.35 & 2.24 & & 0.68 \\
\hline $48 B / 5$ & $245-26$ & 102 & & & & \\
\hline $49 / 5$ & $236-24$ & 91 & & & 1.56 & 1.10 \\
\hline $50 / 4$ & $23-34$ & 56 & & & 1.48 & 1.04 \\
\hline $50 / 4$ & $234-4$ & 60 & & & & \\
\hline $51 / 5$ & $235-25$ & 92 & 0.63 & 0.60 & & 0.18 \\
\hline $51 / 5$ & $236-23$ & 84 & & & & \\
\hline $53 / 5$ & $235-24$ & 90 & & & & \\
\hline $53 / 5$ & $245-25$ & 101 & 3.09 & 2.94 & & 0.87 \\
\hline 5N/5 & $245-24$ & 99 & & & 2.69 & 1.89 \\
\hline $55 / 5$ & $246-34$ & 119 & & & 1.44 & 1.02 \\
\hline $55 / 6$ & $236-246$ & 150 & & & & 0.58 \\
\hline 57AN5 & $245-23$ & 97 & & & 2.15 & 1.51 \\
\hline 57AV6 & $2356-26$ & 152 & & & 1.54 & 1.09 \\
\hline 58AN5 & $234-25$ & 87 & 0.66 & 0.63 & & 0.18 \\
\hline 58AN5 & $235-35$ & 111 & & & & \\
\hline $60 / 6$ & $236-236$ & 136 & 1.53 & 1.46 & & 0.43 \\
\hline $61 / 5$ & $236-34$ & 110 & 1.47 & 1.40 & & 0.41 \\
\hline $62 / 6$ & $245-246$ & 154 & & & & 0.61 \\
\hline
\end{tabular}

- these congeners were added in a separate solution 
Hudson River. The 7 congeners were added because if additional dechlorination occurs (not Pattern N) these congeners may become important and may need to be quantified. The 45 individual congeners were weighed on an analytical balance and dissolved in isooctane. The relative amounts of the 45 congeners used in the customized standard were based on estimates of the amounts present in the Pattern $\mathrm{N}$ dechlorinated PCBs. Table 3-3 identifies all PCB congeners present in the Woods Pond customized standard and gives the weight percent compositions of Aroclor 1260, the supplemental congener mix, and the final customized standard. The original weight percent values for Aroclor 1260 [Wagner et al., unpublished data] without the 15 minor peaks are also given. Two nonachlorobiphenyls 23456-2356-CB (pk 113) and 23456-2346-CB (pk 114), were not quantified in the final customized standard because they are present in Aroclor 1260 at $<0.1$ mole\%. Aroclor 1260 and the additional congener mixes were combined in the final customized standard in a ratio that would permit quantification of all peaks ranging from Aroclor 1260 to Pattern $N$ dechlorinated Aroclor 1260 (Figure 3-1d). It should be noted that 236-246-CB (pk 55) and 245-246-CB (pk 62) were added in a separate solution. A visual comparison of the homolog distribution between our customized standard and the sediment PCBs in panels (b) and (c) shows that this standard can accurately quantify the entire range of $\mathrm{PCB}$ congeners in Woods Pond sediment including Aroclor 1260 and the intermediate and end products of Pattern N dechlorination.

\section{Data Reduction}

Congener specific analysis of Woods Pond sediment PCBs is done by GCECD as previously described. The data are collected using Dionex AI-450 Chromatography software (Dionex Corp., Sunnyvale, CA). The method uses a four point external calibration ( $219 \mathrm{ppb}-3509 \mathrm{ppb}$ range) with a quadratic fit forced through zero. A four point calibration curve is needed to accurately quantify the PCBs before and after dechlorination due to the large changes that occur in the amounts of many congeners as a result of Pattern $\mathrm{N}$ dechlorination. This is clearly illustrated by comparing the relative amounts of peaks 69, 75 and 82, the major hexachlorobiphenyl peaks in Aroclor 1260, before and after 26-BB addition (Figure 3-1b and Ic). These hexachlorobiphenyls are almost completely removed by Pattern $\mathrm{N}$ dechlorination. Also note the relative amounts of peaks 26 and 33 . Before the addition of $26-\mathrm{BB}$ these peaks were present, but in fairly low proportions. Following Pattern $N$ dechlorination (Figure 3-1c), they are the two largest components of the dechlorinated PCBs. 
TABLE 3-3. Congener identification and weight percent composition of Aroclor 1260 and the customized Woods Pond standard.

\begin{tabular}{|c|c|c|c|c|c|c|}
\hline DB1 PK & $\begin{array}{c}\text { PCB } \\
\text { Congener }\end{array}$ & $\begin{array}{c}\text { IUPAC } \\
\text { No. }\end{array}$ & $\begin{array}{c}\text { Onginal } \\
\text { Wi\% } \\
\text { in } 1260\end{array}$ & $\begin{array}{c}\text { Revised } \\
1260 \\
\text { W\% }\end{array}$ & $\begin{array}{l}\text { Wh\% in the } \\
43 \text { added } \\
\text { congeners }\end{array}$ & $\begin{array}{l}\text { W\% in } \\
\text { Custom } \\
\text { Standard }\end{array}$ \\
\hline 2 & 2 & 1 & & & 3.26 & 2.29 \\
\hline 4 & 4 & 3 & & & 3.32 & 2.34 \\
\hline 5 & $2-2$ & 4 & & & 3.18 & 2.24 \\
\hline 7 & $2-3$ & 6 & & & 1.91 & 1.35 \\
\hline 8 & $2-4$ & 8 & & & 2.16 & 1.52 \\
\hline 10 & $26-2$ & 19 & & & 1.54 & 1.09 \\
\hline $14 / 2$ & 4 & 15 & & & 2.94 & 1.50 \\
\hline $14 / 3$ & $25-2$ & 18 & & & 2.16 & 1.52 \\
\hline $15 / 3$ & $24-2$ & 17 & & & 1.91 & 1.35 \\
\hline $16 / 3$ & $26-3$ & 27 & & & 1.69 & 1.19 \\
\hline $17 / 3$ & $26-4$ & 32 & & & 1.97 & 1.39 \\
\hline $19 / 4$ & $26-26$ & 51 & & & 3.25 & 2.29 \\
\hline $21 / 3$ & $25-3$ & 26 & & & 1.62 & 1.14 \\
\hline $22 / 3$ & $24-3$ & 25 & & & 1.44 & 1.02 \\
\hline $23 / 3$ & $25-4$ & 31 & & & 1.62 & 1.14 \\
\hline $24 / 3$ & 244 & 28 & & & 1.94 & 1.37 \\
\hline $25 / 4$ & $25-26$ & 53 & & & 2.61 & 1.84 \\
\hline $26 / 4$ & $24-26$ & 51 & & & 5.59 & 3.94 \\
\hline $29 / 4$ & $23-26$ & 46 & & & 1.56 & 1.10 \\
\hline $31 A / 4$ & $25-25$ & 52 & & & 2.04 & 1.44 \\
\hline $318 / 4$ & $26-35$ & 73 & & & 1.08 & 0.76 \\
\hline $32 / 4$ & 2425 & 49 & & & 5.41 & 3.82 \\
\hline $33 / 4$ & $24-24$ & 47 & & & 10.67 & 7.52 \\
\hline 37AV5 & $246-26$ & $i c d$ & & & 1.56 & 1.10 \\
\hline $378 / 4$ & $23-25$ & هـ & & & 1.61 & 1.13 \\
\hline $38 / 4$ & $23-24$ & 42 & & & 1.53 & 1.08 \\
\hline $39 / 4$ & $26-34$ & 71 & & & 0.85 & 0.60 \\
\hline $39 / 4$ & $25-35$ & 72 & & & 0.87 & 0.62 \\
\hline $40-41 / 4$ & 2435 & 68 & & & 0.87 & 0.62 \\
\hline $40-41 / 5$ & $236-26$ & 96 & & & 1.63 & 1.15 \\
\hline $42 / 4$ & $23-23$ & 40 & & & 1.61 & 1.13 \\
\hline $43 / 5$ & $246-25$ & 103 & & & 1.49 & 1.05 \\
\hline $4 / 5$ & $246-24$ & 100 & & & 3.33 & 2.35 \\
\hline 46AV5 & $235-26$ & 24 & & & 1.63 & 1.15 \\
\hline 47 & $25-34$ & 70 & & & 1.61 & 1.13 \\
\hline ABNA & 2434 & 66 & & & 1.62 & 1.14 \\
\hline $488 / 5$ & $236-25$ & 95 & 2.35 & 2.24 & & 0.66 \\
\hline $488 / 5$ & $245-26$ & 102 & & & & \\
\hline $49 / 5$ & $236-24$ & 91 & & & 1.56 & 1.10 \\
\hline $50 / 4$ & $23-34$ & 56 & & & 1.48 & 1.04 \\
\hline $50 / 4$ & $234-4$ & 60 & & & & \\
\hline $51 / 5$ & $235-25$ & 92 & 0.63 & 0.60 & & 0.18 \\
\hline $51 / 5$ & $236-23$ & 84 & & & & \\
\hline $53 / 5$ & $235-24$ & 90 & & & & \\
\hline $53 / 5$ & 245-25 & 101 & 3.09 & 2.94 & & 0.87 \\
\hline $5 / 15$ & $245-24$ & 99 & & & 2.69 & 1.89 \\
\hline $55 / 5$ & $246-34$ & 119 & & & 1.44 & 1.02 \\
\hline $55 / 6$ & $236-246$ & 150 & & & & 0.58 \\
\hline 57A 5 & $245-23$ & 97 & & & 2.15 & 1.51 \\
\hline 57A 6 & $2356-26$ & 152 & & & 1.54 & 1.09 \\
\hline 58Av5 & $234-25$ & 87 & 0.66 & 0.63 & & 0.19 \\
\hline $58 \times 15$ & $235-35$ & 111 & & & & \\
\hline $60 / 6$ & $236-236$ & 136 & 1.53 & 1.46 & & 0.43 \\
\hline $61 / 5$ & $236-34$ & 110 & 1.47 & 1.40 & & 0.41 \\
\hline $62 / 6$ & $245-246$ & 154 & & & & 0.61 \\
\hline
\end{tabular}

"these congeners were added in a separate solution 
TABLE 3-3 continued

\begin{tabular}{|c|c|c|c|c|c|c|}
\hline DB1 PK & $\begin{array}{c}P C B \\
\text { Congener }\end{array}$ & $\begin{array}{c}\text { IUPAC } \\
\text { No. }\end{array}$ & $\begin{array}{c}\text { Onginal } \\
1260 \\
\text { W } \%\end{array}$ & $\begin{array}{c}\text { Revised } \\
\text { Wi\% } \\
\text { in } 1260\end{array}$ & $\begin{array}{l}\text { Wh\% in the } \\
43 \text { added } \\
\text { congeners }\end{array}$ & $\begin{array}{l}\text { Wi\% in } \\
\text { Custom } \\
\text { Slandard }\end{array}$ \\
\hline $64 / 6$ & $2356-25$ & 151 & 3.10 & 2.96 & \multirow{54}{*}{3.19} & 0.87 \\
\hline $65 / 5$ & $345-25$ & 124 & & & & \\
\hline $65 / 6$ & $235-236$ & 135 & 1.18 & 1.12 & & 0.33 \\
\hline $66 / 6$ & $2346-25$ & 144 & 1.18 & 4.12 & & 0.33 \\
\hline $67 / 5$ & $235-34$ & 107 & & . & & \\
\hline $67 / 5$ & $234-35$ & 108 & & & & \\
\hline $67 / 6$ & $2356-24$ & 147 & & & & 2.25 \\
\hline $69 / 5$ & $245-34$ & 198 & 0.95 & 0.90 & & 0.27 \\
\hline $69 / 6$ & $236-245$ & 149 & 9.35 & 8.91 & & 2.63 \\
\hline $71 / 6$ & $2356-23$ & 134 & 0.64 & 0.61 & & 0.18 \\
\hline $71 / 6$ & $2345-26$ & 143 & & & & \\
\hline 7216 & $2346-23$ & 131 & & 0.07 & & 0.02 \\
\hline $72 / 6$ & $235-235$ & 133 & & 0.07 & & 0.02 \\
\hline $73 / 6$ & $235-245$ & 146 & 1.16 & 1.10 & & 0.32 \\
\hline $74 / 5$ & 23434 & 105 & & 0.17 & & 0.05 \\
\hline $74 / 6$ & $234-236$ & 132 & 2.76 & 2.63 & & 0.78 \\
\hline $75 / 6$ & $245-245$ & 153 & 12.16 & 11.59 & & 3.42 \\
\hline $77 / 6$ & $2345-25$ & 141 & 2.49 & 2.37 & & 0.70 \\
\hline $78 \pi 7$ & $2356-236$ & $i 79$ & 2.09 & 1.99 & & 0.59 \\
\hline $79 / 6$ & $2345-24$ & 137 & & 0.11 & & 0.03 \\
\hline $80 / 6$ & $234-235$ & 130 & & 0.11 & & 0.03 \\
\hline $81 / 7$ & $2346-236$ & 176 & & 0.55 & & 0.16 \\
\hline $82 / 6$ & $234-245$ & 138 & 10.70 & $\cdot 2.19$ & & 3.01 \\
\hline $82 / 6$ & $236-345$ & 164 & & & & \\
\hline $82 / 6$ & $2356-34$ & 163 & & & & \\
\hline $83 / 6$ & $2346-34$ & 158 & & 0.77 & & 0.23 \\
\hline $85 / 7$ & $2356-235$ & 178 & 0.90 & 0.86 & & 0.25 \\
\hline $88 / 7$ & $2356-245$ & 187 & 5.22 & 4.97 & & 1.47 \\
\hline $89 / 6$ & $234-234$ & 128 & & 0.47 & & 0.14 \\
\hline $90 \pi$ & $2346-245$ & 183 & 3.10 & 2.95 & & 0.87 \\
\hline $91 / 6$ & $245-345$ & 167 & & 0.22 & & 0.07 \\
\hline $92 \pi$ & $23456-25$ & 185 & 0.72 & 0.68 & & 0.20 \\
\hline $93 \pi$ & $2345-236$ & 174 & 4.63 & 4.41 & & 1.30 \\
\hline $94 \pi$ & $2356-234$ & 177 & 2.51 & 2.39 & & 0.71 \\
\hline $95 / 6$ & $2345-34$ & $i 56$ & 0.68 & 0.65 & & 0.19 \\
\hline $95 \pi$ & $2346-234$ & 171 & 1.04 & 0.99 & & 0.29 \\
\hline $96 / 6$ & $234-345$ & 157 & & 0.11 & & 0.03 \\
\hline $96 / 8$ & $2356-2356$ & 202 & & 0.32 & & 0.10 \\
\hline $99 / 8$ & $2346-2356$ & 201 & & 0.27 & & 0.08 \\
\hline $100 \pi$ & $2345-235$ & 172 & 0.93 & 0.88 & & 0.26 \\
\hline 101/8 & $2346-2346$ & 197 & & 0.09 & & 0.03 \\
\hline $102 \pi$ & $2345-245$ & 180 & 11.09 & 10.57 & & 3.12 \\
\hline $103 \pi$ & $2356-345$ & 193 & & 0.42 & & 0.12 \\
\hline $104 / 7$ & $2346-345$ & 191 & & 0.15 & & 0.04 \\
\hline $105 / 8$ & $23456-236$ & 200 & & 0.63 & & 0.19 \\
\hline $106 / 7$ & $2345-234$ & 170 & 3.76 & 3.58 & & 1.06 \\
\hline $907 \pi$ & $23456-34$ & 190 & 0.94 & 0.89 & & 0.26 \\
\hline $109 / 8$ & $2345-2356$ & 199 & 1.66 & 1.58 & & 0.47 \\
\hline $110 / 8$ & $2345-2346$ & 196 & 2.09 & 1.99 & & 0.59 \\
\hline $110 / 8$ & $23456-245$ & 203 & & & & \\
\hline 1117 & $2345-345$ & 489 & & 0.19 & & 0.06 \\
\hline $112 / 8$ & $23456-234$ & 195 & 0.88 & 0.84 & & 0.25 \\
\hline $115 / 8$ & $2345-2345$ & 194 & 1.65 & 1.57 & & 0.46 \\
\hline \multirow[t]{2}{*}{$117 / 9$} & $23456-2345$ & 206 & 0.71 & 0.68 & & 0.20 \\
\hline & & & 100.00 & 100.00 & & 100.00 \\
\hline
\end{tabular}


The raw data from the Dionex is transferred to an Excel (Microsoft Excel version 4.0, Frontline Systems Inc., Incline Village, NV) spreadsheet where the mole percents of each individual congener, the ortho, meta, para and total chlorines per biphenyl, and the homolog distribution are calculated for each sample. Statistical analyses for each set of samples including average, standard deviations, $\mathrm{T}$-test, and confidence intervals are also calculated.

\section{Comparison of Data Analysis by GC-ECD vs. GC-MS}

Due to the large number of samples collected from the field and concurrent laboratory studies (several thousand to date), a rigorous Soxhlet extraction and cleanup was not practicable for all samples. Instead, one step ether extractions of wet sediments with copper cleanup were done routinely on samples to be analyzed by GC-ECD [Bedard et al., Chapter 2, this report]. In order to ensure that the ether extraction procedure was adequate, entire sets of samples at various time points were also extracted by the Soxhlet procedure [Bedard et al., Chapter 2, this report] and then analyzed by GC-MS in the SIM mode [Frame, Chapter 4, this report]. This serves as a dual check for both the extraction procedure and the GC-ECD analysis. Table 3-4 compares the GC-ECD and GC-MS results for each individual PCB congener, the $\mathrm{PCB}$ homolog distribution, the ortho, meta, para chlorine distribution, and the total number of chlorines per biphenyl for sediment samples before 26-BB addition. Table 3-5 shows the same comparison for samples 212 days after 26-BB addition. The values are averages and standard deviations of four different samples from the same core sections.

Overall, there is very close agreement between the two analytical methods. All of the homologs agree within $10 \%$ except for the pentachlorobiphenyls in Table 3-4, which agree within 15\%; and the hepta- and nonachlorobiphenyls in Table 3-5, which agree within $20 \%$. The ortho, meta, para, and total chlorines agree within 6\% for both Table 3-4 and Table 3-5. Except for the discrepancies listed below, in Table 3-4 and Table 3-5, 93\% and 63\%, respectively, of the congeners present in quantities $>1.0$ mole\% agree within $15 \%$; and $96 \%$ and $89 \%$, respectively, agree within $20 \%$.

There are some discrepancies in the data; peaks $2,4,5,7$ and 8 were not quantified in samples analyzed by ECD. Contaminants in both the ether and in the sediment extract elute in the region of peaks 1-8 and make detection and accurate quantitation of these peaks by ECD impossible. This is a shortcoming of the extraction procedure. However, GC-MS analysis confirmed that these peaks are not 
major components of the dechlorinated PCBs ( $<0.5$ mole\%). In addition, 26-BB coelutes with peaks 14,15 , and 16 and its high response factor precludes accurate quantitation of these peaks in the ECD. However, deletion of these peaks had little effect on the overall homolog distribution of each sample. Although all of these peaks can be detected and quantified using the MS, the MS detector is much less sensitive than the ECD and requires a 40-fold concentration of extracts for accurate detection and quantitation. We therefore analyzed the samples using GC-ECD and cross checked periodically using GC-MS analyses.

The ECD cannot distinguish the difference between two homologs in a single peak, i.e., peak 55, 246-34-CB and 236-246-CB, therefore, the mole percent is reported as a single amount. For these peaks, multiplication factors are used in the Excel spreadsheet based on the proportions of the congeners present in the standard. This assigns a proportion of the overall mole percent value of the peak to each of the homologs present and helps to reduce biasing on the overall homolog distribution. Multiplication factors are also used to calculate the ortho, meta, and para chlorines in peaks with multiple components.

Several discrepancies between the GC-ECD and GC-MS analyses were apparently caused by differences in the chromatography conditions. We were able to resolve peaks 23 and 24 and peaks 74 and 75 by GC-ECD analysis using a 50minute run. These peaks were not resolved by GC-MS using a shorter 34-minute run.

A few discrepancies between the GC-ECD and the GC-MS analyses such as those for peaks 64 and 69 (Table 3-4) are not fully understood. One possible explanation is the flexibility of the integration software. The Dionex AI-450 software is much more flexible with respect to baseline integration than the MS software. The MS software does not allow any change in integration of individual peaks, all changes must be made over the entire spectrum. The Dionex allows for manipulation of individual peaks and, therefore, noise and other interferences can be taken into account. 
TABLE 3-4. Comparison of GC-ECD and GC-MS analyses of sediment PCBs 4 days prior to the addition of 26-BB.

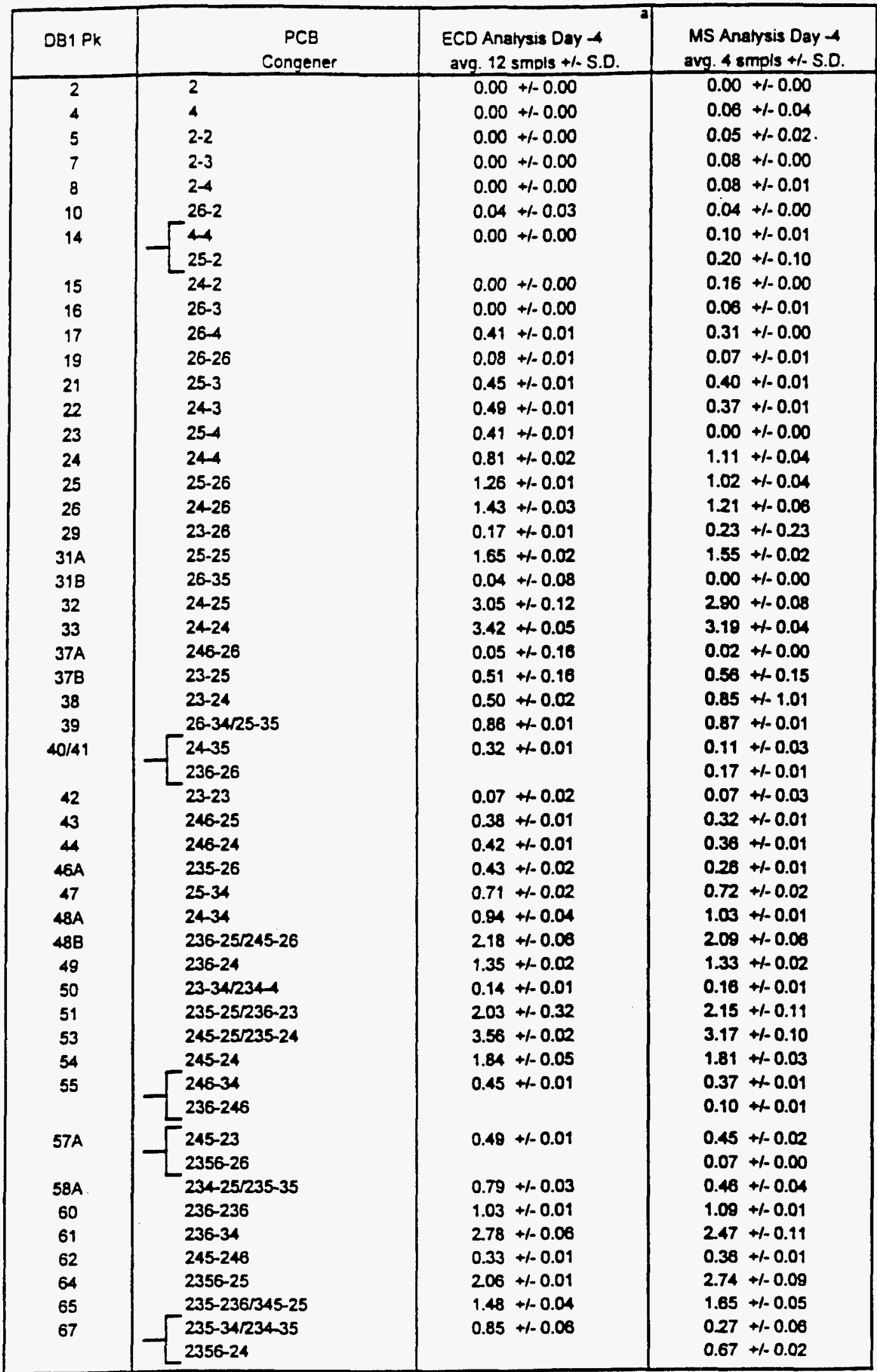

a- for Deaks contauning oifferent congener homologs unresomed by

GC-ECD analysis, value snown is the sum of the offterent homologs 
TABLE 3-4 continued

\begin{tabular}{|c|c|c|c|c|}
\hline \multirow{3}{*}{$\frac{\text { DB1 Pk }}{69}$} & $\begin{array}{c}\text { PCB } \\
\text { Congener } \\
\end{array}$ & $\begin{array}{l}\text { ECD Analysis Day } 4 \\
\text { avg. } 12 \text { smpis +1. S.D. }\end{array}$ & \multicolumn{2}{|c|}{$\begin{array}{l}\text { MS Anatyzis Day } 4 \\
\text { avg. } 4 \text { smpis +1- S.D. }\end{array}$} \\
\hline & $245-34$ & $8.14+1-0.17$ & 1.31 & $+1 \cdot 0.11$ \\
\hline & $236-245$ & & 6.01 & +1.0 .07 \\
\hline 71 & $2356-23 / 2345-26$ & $0.55+1-0.02$ & 0.57 & +1.0 .02 \\
\hline 72 & $2346-23 / 235-235$ & $0.22+1.0 .02$ & 0.16 & +1.0 .02 \\
\hline 73 & $235-245$ & $1.51+1-0.03$ & 1.44 & $+1-0.03$ \\
\hline 74 & $234-34 / 234-236$ & $227+1-0.04$ & 0.00 & $+1-0.00$ \\
\hline 75 & $245-245$ & $8.53+1-0.09$ & 10.15 & $+1-0.14$ \\
\hline$\pi$ & $2345-25$ & $1.28+1-0.04$ & 1.17 & $+1-0.02$ \\
\hline 78 & $2356-236$ & $1.11+1-0.06$ & 1.36 & +1.0 .03 \\
\hline $79 / 80 / 81$ & $2345-24 / 234-235$ & $0.73+1-0.02$ & 0.36 & $+1-0.04$ \\
\hline & $2346-236$ & & 0.35 & $+/-0.01$ \\
\hline 82 & $234-245 / 2356-34 / 236-345$ & $7.57+1-0.10$ & 7.52 & $+1-0.19$ \\
\hline 83 & $2346-34$ & $0.50+1-0.01$ & 0.47 & $+1-0.01$ \\
\hline 85 & $2356-235$ & $0.65+1-0.02$ & 0.66 & $+1-0.01$ \\
\hline 88 & $2356-245$ & $3.48+1-0.05$ & 3.45 & $+1-0.07$ \\
\hline 89 & $234-234$ & $0.66+1-0.09$ & 0.58 & +1.0 .01 \\
\hline 90 & $2346-245$ & $1.67+1-0.02$ & 1.84 & $+/-0.05$ \\
\hline 91 & $245-345$ & $0.33+1-0.02$ & 0.34 & $+/ .0 .01$ \\
\hline 92 & $23456-25$ & $0.36+1-0.01$ & 0.39 & $+/-0.01$ \\
\hline 93 & $2345-236$ & $2.60+1-0.03$ & 2.67 & $+1-0.04$ \\
\hline 94 & $2356-234$ & $1.61+1-0.02$ & 1.64 & $+1-0.03$ \\
\hline 95 & $2345-34$ & $1.20+1-0.03$ & 0.58 & $+/-0.01$ \\
\hline & $2346-234$ & & 0.63 & $+1-0.01$ \\
\hline 96 & $2356-2356 / 234-345$ & $0.00+-0.00$ & 0.27 & $+1-0.01$ \\
\hline 99 & $2346-2356$ & $0.17+-0.01$ & 0.19 & $+/-0.01$ \\
\hline 100 & $2345-235$ & $0.64+/-0.01$ & 0.51 & $+1-0.03$ \\
\hline 101 & $2346-2346$ & $0.05+1-0.00$ & 0.06 & +1.0 .01 \\
\hline 102 & $2345-245$ & $7.37+-0.10$ & 6.50 & $+1-0.09$ \\
\hline 103 & $2356-345$ & $0.33+1-0.03$ & 0.31 & $+1-0.01$ \\
\hline 104 & $2346-345$ & $0.08+1.0 .00$ & 0.10 & $+1-0.00$ \\
\hline 105 & $23456-236$ & $0.38+1-0.01$ & 0.50 & $+1-0.05$ \\
\hline 106 & $2345-234$ & $2.69+1-0.06$ & 2.38 & $+1-0.04$ \\
\hline 107 & $23456-34$ & $0.56+-0.01$ & 0.57 & $+/-0.01$ \\
\hline 109 & $2345-2356$ & $1.18++0.02$ & 1.12 & $+1-0.03$ \\
\hline 110 & $2345-2346 / 23456-245$ & $1.44+1-0.02$ & 1.32 & $+1-0.03$ \\
\hline 111 & $2345-345$ & $0.19+\infty 0.01$ & 0.18 & $+1-0.02$ \\
\hline 112 & $23456-234$ & $0.63++0.04$ & 0.62 & $+1-0.04$ \\
\hline 115 & $2345-2345$ & $1.27+\infty 0.03$ & 1.17 & $+1-0.03$ \\
\hline 117 & $23456-2345$ & $0.68+0.04$ & 0.62 & +1.0 .03 \\
\hline Ortho CIBP & & $2.38+0.00$ & 2.32 & $+1-0.01$ \\
\hline Meta CVBP & & $2.15+1-0.00$ & 2.20 & $+1-0.02$ \\
\hline Para CVBP & & $1.31+0.01$ & 125 & $+1-0.01$ \\
\hline Total CVBP & & $5.84+1-0.01$ & 5.78 & $+1-0.03$ \\
\hline mol\% mono & & $0.00+1-0.00$ & 0.06 & $+1-0.04$ \\
\hline mol\% di & & $0.00+-0.00$ & 0.31 & $+1-0.04$ \\
\hline mol\% tri & & $2.62+1-0.05$ & 2.65 & $+1-0.11$ \\
\hline mol\% tetra & & $14.85+1-0.25$ & 14.52 & $+1-1.10$ \\
\hline mol\% penta & & $14.87++0.34$ & 16.97 & $+1-0.43$ \\
\hline mol\% hexa & & $37.30+1-0.26$ & 36.00 & $+1-0.48$ \\
\hline mol\% hepta & & $24.52+1-0.20$ & 23.52 & $+1-0.35$ \\
\hline mol\% octa & & $5.06+1-0.09$ & 5.26 & $+1-0.15$ \\
\hline mol\% nona & & $0.68+/-0.04$ & 0.62 & $+1-0.03$ \\
\hline mol\% deca & & $0.00+1-0.00$ & & $+1-0.00$ \\
\hline
\end{tabular}


TABLE 3-5. Comparison of GC-ECD and GC-MS analyses 212 days after the addition of 26-BB.

\begin{tabular}{|c|c|c|c|c|}
\hline \multirow{2}{*}{$\frac{\text { DB1 PK }}{2}$} & \multirow{2}{*}{$\begin{array}{c}\text { PCB } \\
\text { Congener } \\
\end{array}$} & $\begin{array}{c}\text { ECD Anatysis Day } 212 \text { Top } \\
\text { avg. } 4 \text { smols }+1-5 . D \text {. }\end{array}$ & \multicolumn{2}{|c|}{$\begin{array}{c}\text { MS Analysis Day } 212 \text { Top } \\
\text { avg. } 5 \mathrm{smpls}+1-5.0 .\end{array}$} \\
\hline & & $0.00+1.0 .00$ & 0.00 & $+1-0.00$ \\
\hline 4 & 4 & $0.00+1-0.00$ & 0.07 & $+1-0.02$ \\
\hline 5 & 2.2 & $0.00+1.0 .00$ & 0.13 & $+1-0.04$ \\
\hline 7 & $2-3$ & $0.00+1-0.00$ & 0.09 & $+1-0.01$ \\
\hline 8 & 24 & $0.00+1-0.00$ & 0.18 & $+1-0.01$ \\
\hline 10 & $26-2$ & $0.19+1.0 .00$ & 0.15 & $+1-0.02$ \\
\hline \multirow[t]{2}{*}{14} & 4 & $0.00+1-0.00$ & 0.35 & $+1-0.01$ \\
\hline & $25-2$ & & 0.54 & $+1-0.03$ \\
\hline 15 & 242 & $0.00+1-0.00$ & 0.63 & $+1-0.03$ \\
\hline 16 & $26-3$ & $0.00+1-0.00$ & 0.07 & $+1-0.01$ \\
\hline 17 & $26-4$ & $2.71+1-0.07$ & 2.39 & $+1-0.11$ \\
\hline 19 & $26-26$ & $1.41+1.0 .09$ & 1.22 & $+1-0.08$ \\
\hline 21 & $25-3$ & $0.46+1-0.02$ & 0.43 & $+1-0.02$ \\
\hline 22 & 243 & $0.52+1-0.02$ & 0.42 & $+1-0.02$ \\
\hline 23 & $25-4$ & $0.84+1-0.04$ & 0.00 & +1.0 .00 \\
\hline 24 & 244 & $3.10+1-0.06$ & 3.82 & $+1-0.11$ \\
\hline 25 & $25-26$ & $4.86+1.0 .07$ & 4.73 & $+1-0.07$ \\
\hline 26 & $24-26$ & $11.11+1-0.29$ & 10.84 & $+1-0.38$ \\
\hline 29 & $23-26$ & $0.54+1-0.04$ & 1.61 & $+1-1.96$ \\
\hline $31 A$ & $25-25$ & $1.91+1-0.09$ & 1.92 & $+1-0.02$ \\
\hline $31 B$ & $26-35$ & $0.79+1-0.05$ & 0.20 & $+1-0.28$ \\
\hline 32 & $24-25$ & $7.97+1.0 .02$ & 7.70 & $+1-0.22$ \\
\hline 33 & $24-24$ & $21.32+1.1 .58$ & 17.97 & $+1-0.60$ \\
\hline $37 A$ & $246-26$ & $0.25+1-0.02$ & 0.28 & $+1-0.01$ \\
\hline $37 \mathrm{~B}$ & $23-25$ & $0.28+1-0.03$ & 0.35 & $+1-0.02$ \\
\hline 38 & 23.24 & $0.52+1-0.03$ & 0.42 & $+1-0.02$ \\
\hline 39 & $26-34 / 25-35$ & $0.82+1-0.06$ & 0.00 & $+1-0.00$ \\
\hline \multirow[t]{2}{*}{$40 / 41$} & 2435 & $0.99+1-0.10$ & 0.41 & $+1-0.01$ \\
\hline & $236-26$ & & $0.48+$ & $+1-0.02$ \\
\hline 42 & $23-23$ & $0.00+1-0.00$ & 0.04 & $+1-0.03$ \\
\hline 43 & $246-25$ & $0.90+1-0.05$ & $0.89+$ & $+1-0.02$ \\
\hline 4 & $246-24$ & $3.12+1-0.10$ & $3.31+$ & $+1-0.11$ \\
\hline $46 A$ & $235-28$ & $1.13+1-0.04$ & $1.17+$ & $+1-0.04$ \\
\hline 47 & $25-34$ & $0.14+1.0 .02$ & $0.22+$ & $+1-0.04$ \\
\hline $48 A$ & $24-34$ & $0.78+1-0.09$ & 0.38 & +1.0 .02 \\
\hline $48 B$ & $236-25 / 245-26$ & $0.00+1-0.00$ & 0.58 & $+1-0.20$ \\
\hline 49 & $236-24$ & $3.39+1-0.13$ & 3.76 & $+1-0.24$ \\
\hline 50 & $23-34 \sqrt{234-4}$ & $0.03+1-0.00$ & $0.06+$ & $+1-0.01$ \\
\hline 51 & $235-25 / 236-23$ & $1.56+1.0 .09$ & $207+$ & $+1-0.06$ \\
\hline 53 & $245-25 / 235-24$ & $4.50+6.96$ & $3.63+$ & +1.0 .08 \\
\hline 54 & $245-24$ & $0.48+1.0 .05$ & $0.52+$ & $+1-0.05$ \\
\hline \multirow[t]{2}{*}{55} & $246-34$ & $0.84+1-0.04$ & $0.65+$ & $+1-0.02$ \\
\hline & $236-246$ & & $0.35+$ & $+1-0.01$ \\
\hline \multirow[t]{2}{*}{$57 A$} & $245-23$ & $0.32+1-0.03$ & $0.12+$ & $+1-0.02$ \\
\hline & $2356-26$ & & $0.30+$ & $+1-0.01$ \\
\hline $58 A$ & $234-25 / 235-35$ & $1.00+1-0.08$ & $1.89+$ & $+1-0.08$ \\
\hline 60 & $236-236$ & $0.32+1-0.04$ & $0.46+$ & $+1-0.01$ \\
\hline 61 & $236-34$ & $0.51+1-0.06$ & $0.51+$ & $+1-0.09$ \\
\hline 62 & $245-246$ & $0.39+1-0.04$ & $0.41+$ & $+1-0.01$ \\
\hline 84 & $2356-25$ & $0.71+1-0.07$ & $0.69+$ & +1.0 .03 \\
\hline 65 & $235-236 / 345-25$ & $0.17+0.03$ & $0.20+$ & $+1-0.01$ \\
\hline \multirow[t]{2}{*}{67} & $235-341234-35$ & $3.38+1-0.14$ & $0.00+$ & $+1-0.00$ \\
\hline & $2356-24$ & & $3.39+$ & $+1-0.1$ \\
\hline
\end{tabular}


TABLE 3-5 continued

\begin{tabular}{|c|c|c|c|c|}
\hline \multirow{3}{*}{$\frac{\text { DB1 PK }}{69}$} & $\begin{array}{c}\text { PCB } \\
\text { Congener } \\
\end{array}$ & $\begin{array}{c}\text { ECD Anatysis Day } 212 \text { Top } \\
\text { avg. } 4 \text { smpls +1-S.D. }\end{array}$ & \multicolumn{2}{|c|}{$\begin{array}{c}\text { MS Analysis Day } 212 \text { Top } \\
\text { avg. } 5 \text { smpls +1-S.D. }\end{array}$} \\
\hline & $245-34$ & $0.83+1-0.16$ & 0.32 & $+1-0.04$ \\
\hline & $236-245$ & & 0.77 & $+1-0.05$ \\
\hline 71 & $2356-23 / 2345-26$ & $0.17+1-0.02$ & 0.20 & $+1-0.01$ \\
\hline 72 & $2346-23 / 235-235$ & $0.24+1-0.02$ & 0.22 & $+1-0.02$ \\
\hline 73 & $235-245$ & $0.39+1-0.03$ & 0.35 & $+1-0.01$ \\
\hline 74 & $234-34 / 234-236$ & $0.16+1-0.06$ & 0.06 & $+1-0.01$ \\
\hline 75 & $245-245$ & $1.08+1-0.25$ & 1.30 & $+1-0.07$ \\
\hline$\pi$ & $2345-25$ & $0.00+1-0.00$ & 0.11 & $+1-0.01$ \\
\hline 78 & $2356-236$ & $0.61+1-0.09$ & 0.43 & $+1-0.02$ \\
\hline $79 / 80 / 81$ & $2345-24 / 234-235$ & $0.18+1-0.02$ & 0.05 & $+1-0.04$ \\
\hline & $2346-236$ & 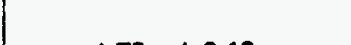 & 0.06 & $+1-0.00$ \\
\hline 82 & $234-245 / 2356-34 / 236-345$ & $1.78+1.0 .18$ & 1.93 & $+1-0.08$ \\
\hline 83 & $2346-34$ & $0.09+1-0.02$ & 0.06 & $+1-0.01$ \\
\hline 85 & $2356-235$ & $0.42+1.0 .02$ & 0.35 & $+1-0.01$ \\
\hline 88 & $2356-245$ & $1.17+1-0.09$ & 1.11 & $+1-0.04$ \\
\hline 89 & $234-234$ & $0.05+1-0.01$ & 0.08 & $+1-0.01$ \\
\hline 90 & $2346-245$ & $0.49+1-0.04$ & 0.48 & $+1-0.02$ \\
\hline 91 & $245-345$ & $0.07+1-0.01$ & 0.05 & $+1-0.00$ \\
\hline 92 & $23456-25$ & $0.08+1-0.01$ & 0.07 & $+1-0.00$ \\
\hline 93 & $2345-236$ & $0.56+1-0.08$ & 0.52 & $+1-0.03$ \\
\hline 94 & $2356-234$ & $0.38+1-0.04$ & 0.34 & $+1-0.03$ \\
\hline 95 & $2345-34$ & $0.39+1.0 .01$ & 0.09 & $+1-0.01$ \\
\hline & $2346-234$ & & 0.15 & $+1-0.01$ \\
\hline 96 & $2356-2356 / 234-345$ & $0.00+1-0.00$ & 0.16 & $+1-0.00$ \\
\hline 99 & $2346-2356$ & $0.10+1-0.01$ & 0.10 & $+1-0.00$ \\
\hline 100 & $2345-235$ & $0.25+1-0.01$ & 0.20 & $+1-0.01$ \\
\hline 101 & $2346-2346$ & $0.02+1-0.00$ & 0.04 & +1.0 .00 \\
\hline 102 & $2345-245$ & $2.48+1-0.14$ & 2.08 & $+1-0.08$ \\
\hline 103 & $2356-345$ & $0.18+1-0.00$ & 0.15 & $+1-0.00$ \\
\hline 104 & $2346-345$ & $0.03+1-0.00$ & 0.03 & +1.0 .00 \\
\hline 105 & $23456-236$ & $0.21+1-0.01$ & 0.23 & $+1-0.01$ \\
\hline 106 & $2345-234$ & $0.92+1-0.05$ & 0.70 & $+1-0.03$ \\
\hline 107 & $23456-34$ & $0.20+1-0.01$ & 0.17 & $+1-0.01$ \\
\hline 109 & $2345-2356$ & $0.68+1-0.01$ & 0.66 & $+1-0.03$ \\
\hline 110 & $2345-2346 / 23456-245$ & $0.90+1-0.01$ & 0.81 & $+1-0.02$ \\
\hline 111 & $2345-345$ & $0.09+1-0.00$ & 0.08 & $+1-0.01$ \\
\hline 112 & $23456-234$ & $0.38+1-0.01$ & 0.38 & $+1-0.02$ \\
\hline 115 & $2345-2345$ & $0.88+1-0.03$ & 0.79 & $+1-0.02$ \\
\hline 197 & $23456-2345$ & $0.59+1-0.10$ & 0.49 & $+1-0.01$ \\
\hline Ortho CVBP & & $2.38+\not 0.01$ & 2.38 & $+1-0.01$ \\
\hline Meta CVBP & & $1.09+1-0.03$ & 1.11 & $+1-0.02$ \\
\hline Para CVBP & & $1.26+1-0.02$ & 1.18 & $+1-0.02$ \\
\hline Total CVBP & & $4.73+1-0.02$ & 4.67 & $+1-0.02$ \\
\hline mot\% mono & & $0.00+1-0.00$ & 0.07 & $+1-0.02$ \\
\hline mol\% di & & $0.00+1-0.00$ & 0.75 & $+1-0.06$ \\
\hline mol\% tri & & $7.82+1-0.22$ & 8.45 & $+1-0.32$ \\
\hline mol\% tetra & & $51.98+1-1.39$ & 48.96 & +1.1 .23 \\
\hline mol\% penta & & $18.23+1-0.39$ & 20.24 & $+1-0.60$ \\
\hline mol\% hexa & & $10.02+1-0.77$ & 11.02 & $+1-0.31$ \\
\hline mol\% hepta & & $8.20+1.0 .54$ & 6.90 & $+1-0.30$ \\
\hline mol\% octa & & $3.15+1-0.05$ & 3.14 & $+1-0.08$ \\
\hline mol\% nona & & $0.59+1-0.10$ & 0.49 & $+1-0.01$ \\
\hline mol\% deca & & $0.00+1-0.00$ & 0.00 & $+1-0.00$ \\
\hline
\end{tabular}




\section{SUMMARY AND CONCLUSIONS}

Congener specific GC-ECD and GC-MS analyses have demonstrated that many of the congeners resulting from Pattern $N$ dechlorination of Aroclor 1260 are either not present in any Aroclor or are present only in minor quantities. It was necessary to develop a $P C B$ standard that could accurately quantify Aroclor 1260 and all of the congeners resulting from Pattern $N$ dechlorination of Aroclor 1260.

Based on published Aroclor peak assignments [Brown et al., 1987b] we identified 150 individual congeners as possible components of Woods Pond sediment PCBs. Each of these individual congeners was coinjected with an Aroclor standard to verify the original peak assignments. Our results indicated that 15 of these 150 congeners had been misassigned by one peak. Results also indicated 17 congeners previously believed to coelute could be separated, and 9 congeners previously believed to separate actually coelute. The original 118 peak assignments have been revised accordingly.

We identified $38 \mathrm{PCB}$ congeners that were present in the environmentally or Pattern N dechlorinated sediment PCBs, but were either absent or present in very small amounts in Aroclor 1260. We combined these and 7 additional congeners that are potential products of further dechlorination (not Pattern N) with Aroclor 1260 to prepare a customized standard which enabled us to quantify all of the PCB congeners present in Aroclor 1260 and in the environmentally and Pattern N dechlorinated sediment PCBs. Of the possible 118 peaks representing 209 PCB congeners, we have observed 83 peaks representing 106 PCB congeners in Woods Pond sediment PCBs.

Our method allows calculation of mole percent values of the individual PCB congeners, number of ortho, meta, para and total chlorines per biphenyl, homolog distribution, and statistical analysis for each sample set.

Analysis of field test samples using the customized standard demonstrated that the expected Pattern $\mathrm{N}$ dechlorination products of the major components in Aroclor 1260 were indeed being formed. The observed decreases in the PCB congeners attacked by the Pattern $N$ dechlorination agree with the observed increases in the amounts of the predicted dechlorination products [Bedard et al., Chapter 2, Table 2-1, this report].

The mass balance and the GC-MS analyses both confirm that this method is highly effective for accurate quantification of environmentally and Pattern $\mathrm{N}$ dechlorinated Woods Pond sediment PCBs. 
Caution should be used whenever an Aroclor-based standard is used to quantify dechlorinated $\mathrm{PCB}$ samples. As already pointed out, microbial dechlorination of PCBs is often highly selective and can generate PCB congener profiles that are quite distinct from the Aroclors. The work done for the development of this standard and method is specific for quantifying the dechlorination of PCBs in Woods Pond sediment, but the principle can be applied to other sediments and microbial populations.

\section{ACKNOWLEDGMENTS}

We would like to acknowledge the technical assistance of Dr. John F. Brown, Jr., Ralph May, and Nancy Marotta of GE CRD, Jeff Nicholson of GE, Pittsfield, and Scott O'Neill of Northeast Analytical; without their help the development of this standard would not have been possible. 
The following references were qouted in the previous section:

Bedard, D.L., S.C. Bunnell, and H.M. Van Dort 1990. Anaerobic dechlorination of endogenous PCBs in Woods Pond Sediment. In General Electric Company Research and Development Program for the Destruction of PCBs, Ninth Progress Report. General Electric Corporate Research and Development, Schenectady, NY. Ch. 5:43-54.

Bedard, D.L., H.M. Van Dort, R.J. May, K.A. De Weerd, J.M. Principe, and L.A. Smullen 1992. Stimulation of dechlorination of Aroclor 1260 in Woods Pond sediment. In General Electric Company Research and Development Program for the Destruction of PCBs, Eleventh Progress Report. General Electric Corporate Research and Development, Schenectady, NY Ch. 10:269-280.

Brown, J.F., Jr., R.E. Wagner, H. Feng. D.L. Bedard, M.J. Brennan, J.C. Carnahan, and R.J. May. $1987 b$. Environmental Dechlorination of PCBs. Environ. Toxicol. Chem. 6:579-593.

Brown, J.F., Jr., R.E. Wagner, D.L. Bedard. M.J. Brennan, and J. C. Carnahan 1987a. Environmental transformations of PCBs. In General Electric Company Research and Development Program for the Destruction of PCBs, Sixth Progress Report. General Electric Corporate Research and Development, Schenectady, NY. Ch. 6:35-41.

Mullin, M.D., C.M. Pochini, S. McCrindle, M. Romkes, S.H. Safe, and L.M. Safe 1984. High-resolution PCB analysis: synthesis and chromatographic properties of all 209 PCB congeners. Environ. Sci. Technol. 18:468-476.

Quensen, J.F., III, S.A. Boyd, and J.M. Tiedje 1990. Dechlorination of four commercial polychlorinated biphenyl mixtures (Aroclors) by anaerobic microorganisms from sediments. Appl. Environ. Microbiol. 56:2360-2369.

Safe, S., S. Bandiera, T. Sawyer, L. Robertson, L. Safe, A. Parkinson, P.E. Thomas, D.E. Ryan, L.M. Reik, W. Levin, M.A. Denomme, and T. Fujita. 1985. PCBs: structure-function relationships and mechanism of action. Environ. Health Perspect. 60:47-56.

Webb, R. G. and A. C. McCall. 1973. Quantitative PCB standards for election capture gas chromatography. J. Chromatogr. Sci. 11:366-373. 
ORNL/TM-13242

\title{
Distribution List
}

\section{INTERNAL DISTRIBUTION}

\author{
1. J. W. Barton \\ 2. A. G. Croff \\ 3. N. H. Cutshall \\ 4. C. W. Gehrs \\ 5-9. K. T. Klasson \\ 10. A. P. Malinauskas \\ 11. L. E. McNeese \\ 12. M. E. Reeves \\ 13. S. M. Robinson \\ 14. Office of Technology Transfer, B. B. Bovee \\ 15. ORNL Office of Science and Technology Partnerships, W. P. Painter \\ 16. Y-12 Office of Science and Technology Partnerships, E. L. Epple \\ 17. K-25 Office of Science and Technology Partnerships, J. B. Clendenen \\ 18. DOE ORNL Site Office, P. L. Gorman \\ 19. DOE Office of Patent Council, R. M. Poteat \\ 20. Central Research Library \\ 21. Laboratory Records \\ 22. Laboratory Records, RC \\ 23. ORNL Patent Section \\ 24. Y-12 Technical Library, Document Reference Section
}

\section{EXTERNAL DISTRIBUTION}

25-26. Office of Scientific and Technical Information, P.O. Box 62, Oak Ridge, TN 37831

27. Office of Assistant Manager for Energy Research and Development, DOE-OR, P.O. Box 2001, Oak Ridge, TN 37831

28. D. A. Abramowicz, Bioremediation Laboratory, General Electric Corporate Research and Development, Environmental Research Center, Schenectady, NY 12301

29. J. S. Walker, EM-53, Cloverleaf Bldg., 19901 Germantown Rd., Germantown, MD 20874-1290

30. J. O. Moore, DOE-OR, P.O. Box 2001, Oak Ridge, TN 37831

31. J. E. Conner, MWFA Program Office, P.O. Box 1625, MS-3875, Idaho Falls, ID 38415

32. J. Wright, DOE-Savannah River, Bldg. 70346-A, rm. 256, rd. 1, Aiken, SC 29802

33. P. Hart, DOE-METC, P.O. Box 880, MS-E06, Morgantown, WV 26507-0880 
M98054605

Report Number (14) ORNL/TM--13242

Publ. Date (11) 199606

Sponsor Code (18) DOEIEM , XF

UC Category (19) UC-2000, DOE/ER

19980720109

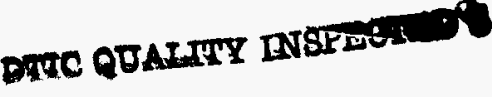

DOE 